\title{
Effects of Package Holiday Information Presentation on Destination Choice
}

by

\section{Walaiporn Rewtrakunphaiboon}

Submitted for the degree of Doctor of Philosophy

School of Management

University of Surrey

2004

(C) Walaiporn Rewtrakunphaiboon 2004 
To my mother with love \&o

In memory of my father 


\section{Abstract}

Holiday packaging has become an increasingly important tool for destination marketing. To date, little is known about the influence of package information on tourist decisions. This study aims to test whether and how the presentation of information about package holidays can influence consideration and choice of holiday destinations. The study focuses on two key issues. First, it is argued that the information of other package attributes or the format of package information can draw consumers' attention away from the name of destination and thus reduce its importance. Second, it is asserted that a certain timing of exposures could provide an advantage for less-preferred destinations. If confirmed, this explains that lesspreferred destinations can benefit from the presentation format and the exposure.

To test these two notions, an experiment is employed. The respondents are asked to choose beach holiday destinations from the designed sets of available destinations. Destinations with high and low market shares are included in the study. The experiment is conducted with two convenience samples. One sample consists of 200 undergraduate students and the other consists of 200 adults in Guildford. To examine the effects of presentation format, a condition where only the name of destination is presented is compared with that where the name of destination is presented with other package attributes. Within the latter condition, the name of destination is either presented as a package heading or embedded in the package description, using price as a package heading. To investigate the effects of exposure, the conditions where the destinations are presented in early or last stages of the decision-making process are compared.

There are two main conclusions drawn from the study. First, it appears that in the experimental setting of this study, the name of the destination itself is the major determinant of tourist destination choice. Other factors have only a limited influence. Presentation format does not appear to help less-preferred destinations to become a final choice. Second, the results suggest that for less-preferred destinations, there is no general advantage to be gained either by early exposure or late exposure. It is further observed that for students, presenting price as a package heading increases their intention to visit all beach holiday destinations. For adults, late exposure to less-preferred destinations increases their intention to visit such destinations when price is used as a package heading. This thesis provides theoretical contribution for tourist decision-making, methodological contribution for studies on the effects of travel stimuli on tourist decision making, implications for destination marketing and recommendations for future research on holiday packaging, bundling and information presentation. 


\section{List of Contents}

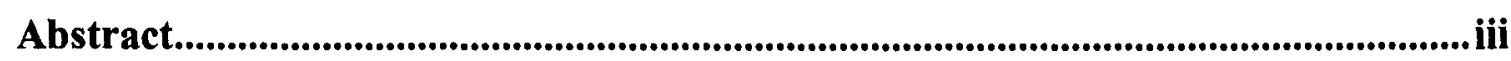

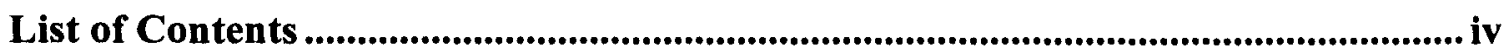

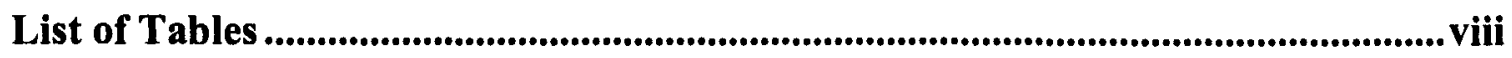

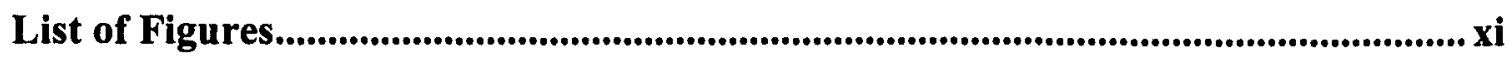

Acknowledgements ................................................................................................................... xiii

Chapter One: Introduction ........................................................................................ 1

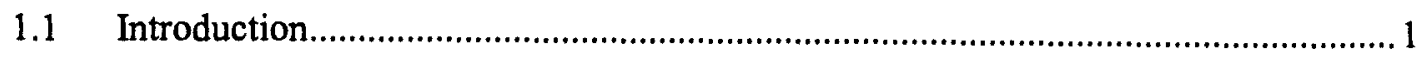

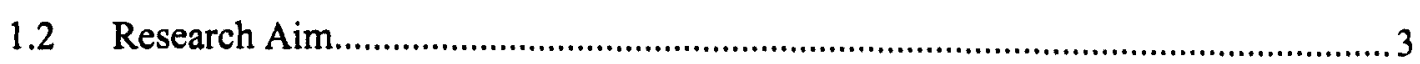

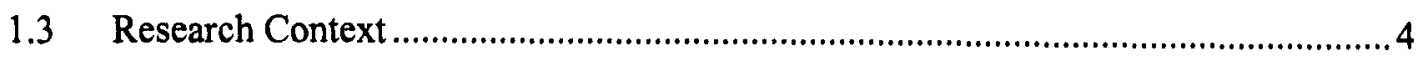

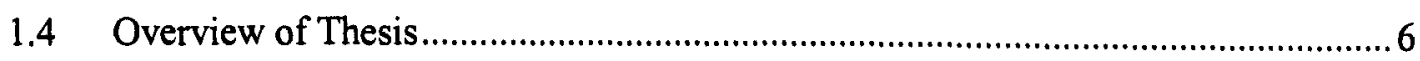

Chapter Two: Tourist Decision-making .................................................................................. 8

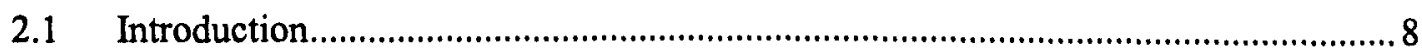

2.2 Tourist Decision-making Process ......................................................................

2.2.1 Package Holiday Decision Process................................................................ 19

2.3 Destination Choice Process .............................................................................21

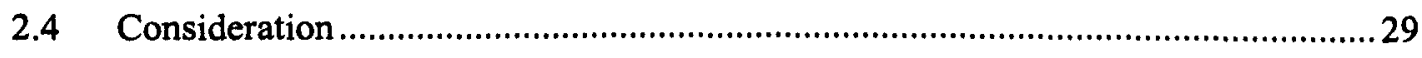

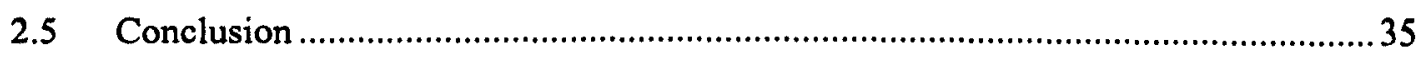

Chapter Three: Package Information Presentation ............................................................ 37

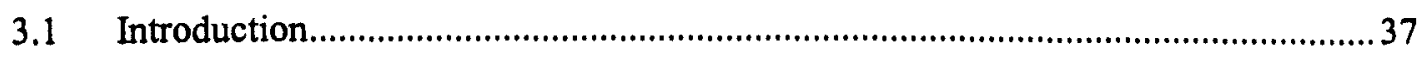

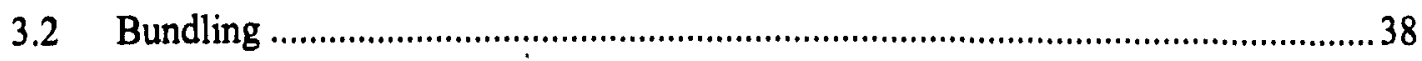

3.2.1 Definition of Bundling............................................................................... 39

3.2.2 Consumer Research on Bundling ................................................................. 41 


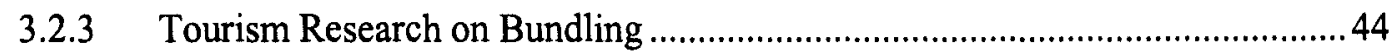

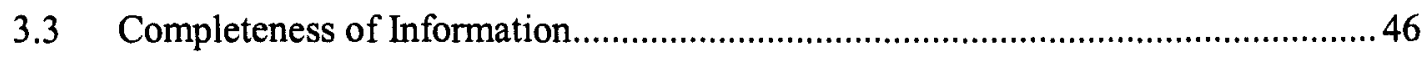

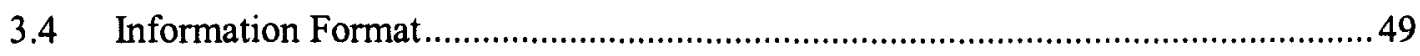

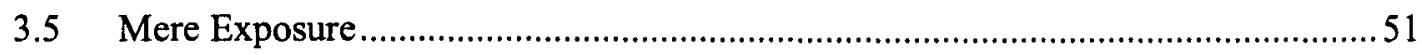

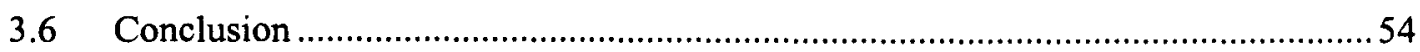

Chapter Four: Theoretical Framework and Hypotheses................................................. 57

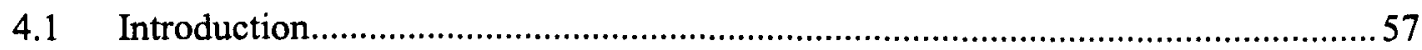

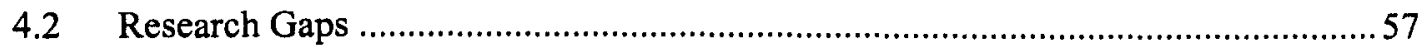

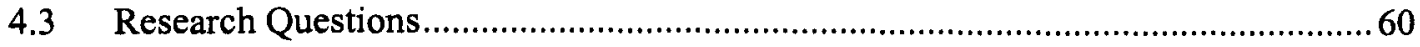

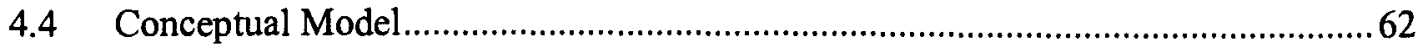

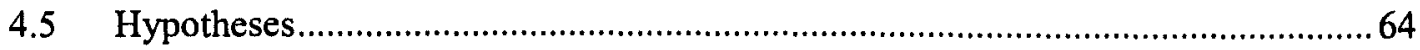

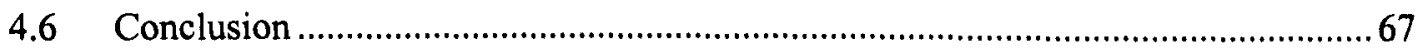

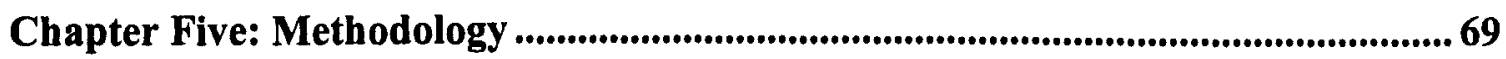

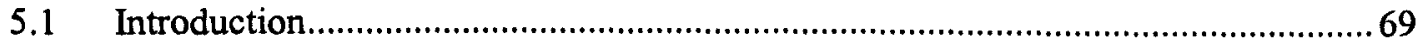

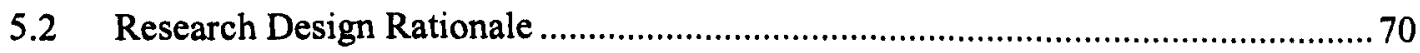

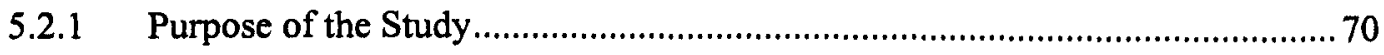

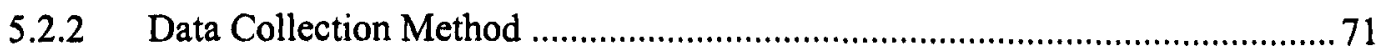

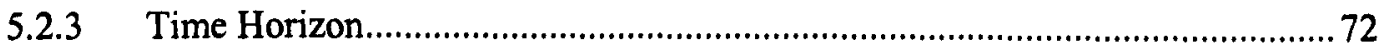

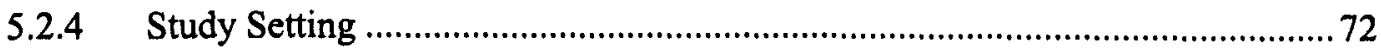

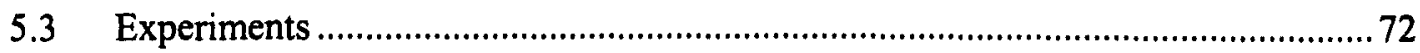

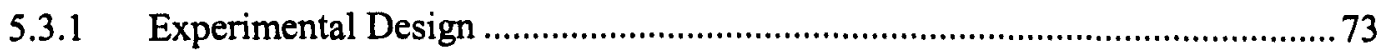

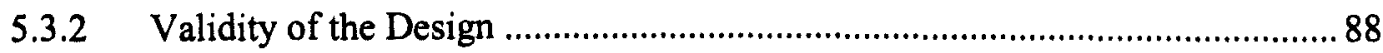

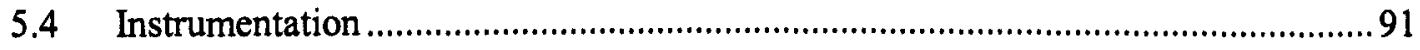

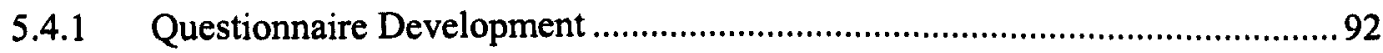

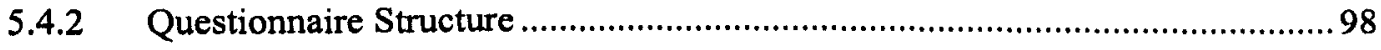

5.4.3 Reliability of the Measurement Scales ........................................................ 103

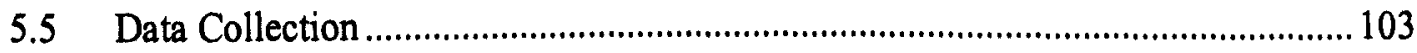

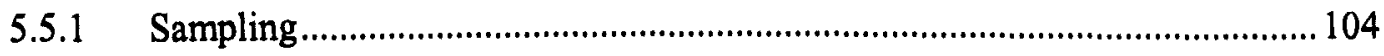

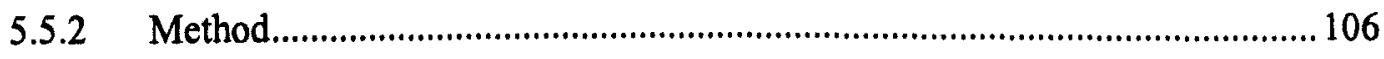

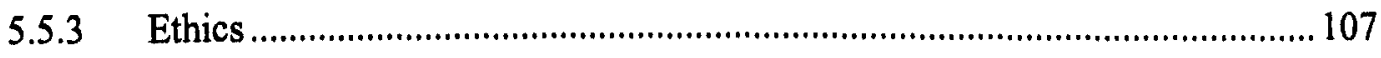

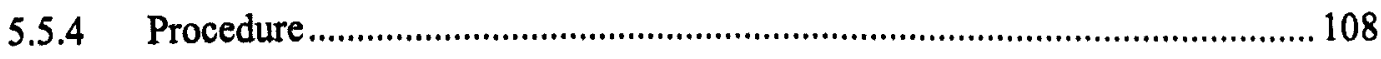

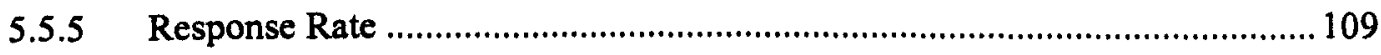

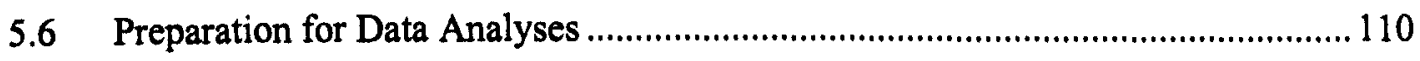




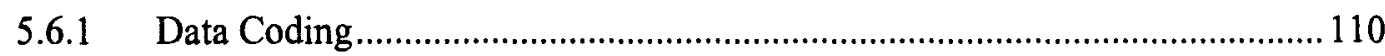

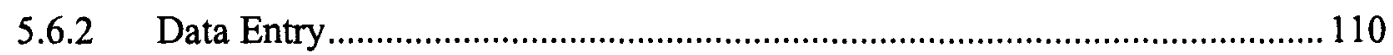

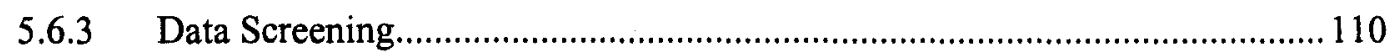

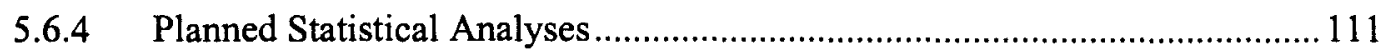

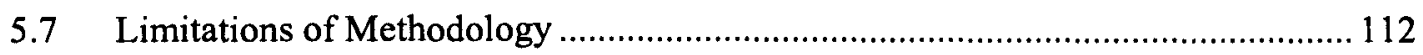

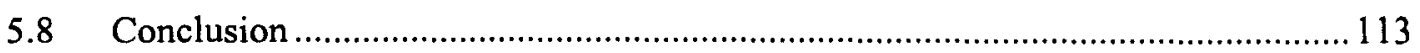

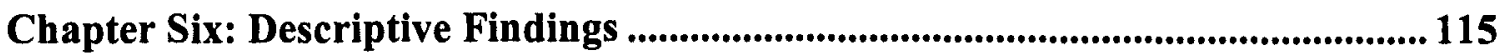

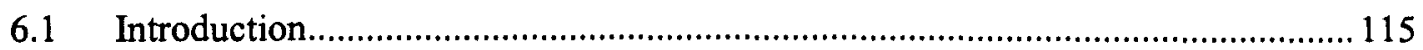

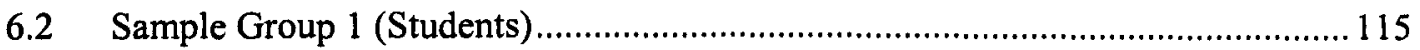

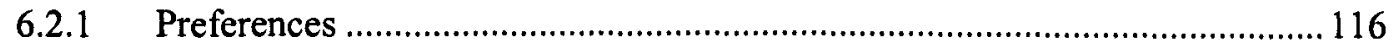

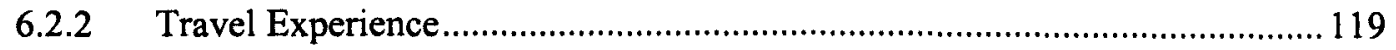

6.2.3 Past Visits and Destination Knowledge...................................................... 120

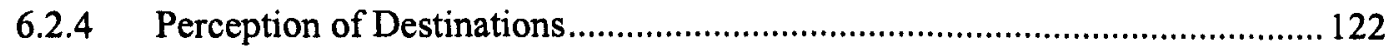

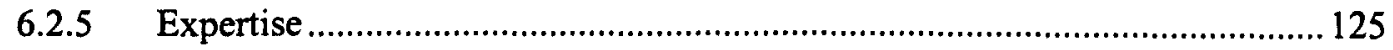

6.2.6 Experiment Manipulation Check on Destination Preference ......................... 125

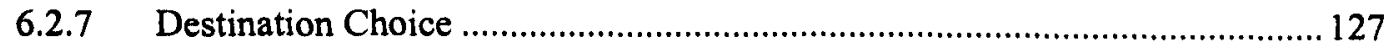

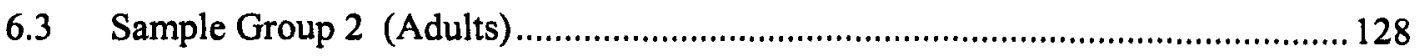

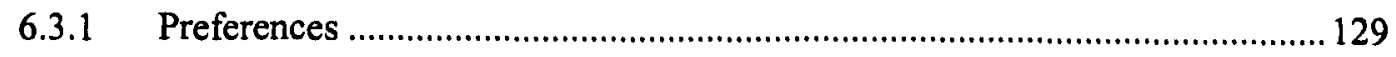

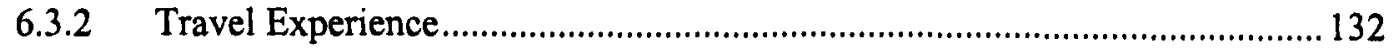

6.3.3 Past Visits and Destination Knowledge.................................................... 133

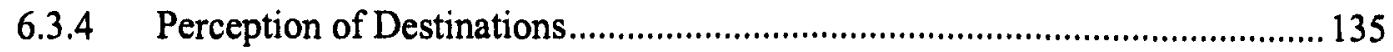

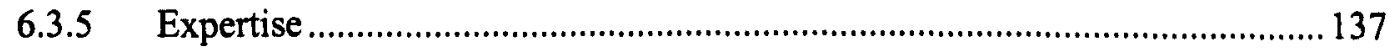

6.3.6 Experiment Manipulation Check on Destination Preference ......................... 138

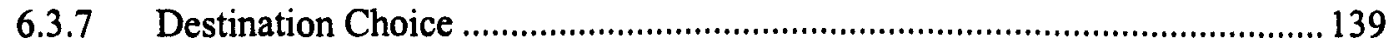

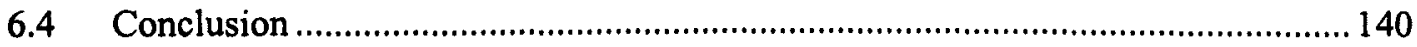

\section{Chapter Seven: Hypothesis Testing ................................................................................ 141}

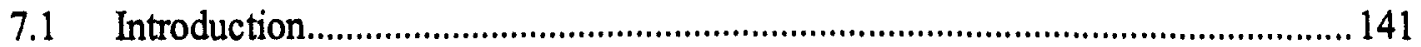

7.2 Effects of Presentation Format on Destination Choice Process............................ 142

7.2.1 Effects of Presentation Format on Intention to Visit .................................... 143

7.2.2 Effects of Presentation Format on Late Consideration................................. 147

7.2.3 Effects of Presentation Format on Choice .................................................. 150

7.3 Effects of Presentation Format on Destination Importance ................................... 154

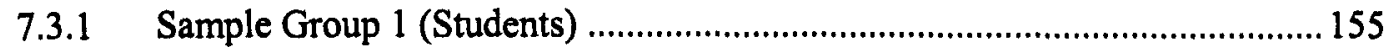




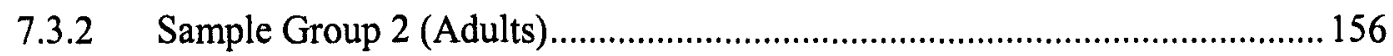

7.4 Effects of Exposure on Destination Choice Process ........................................... 158

7.4.1 Effects of Exposure on Intention to Visit ..................................................... 160

7.4.2 Effects of Exposure on Late Consideration................................................... 167

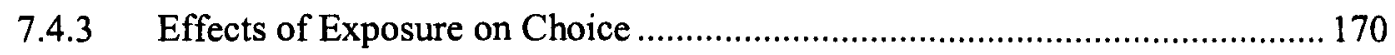

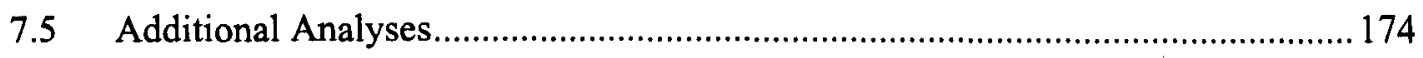

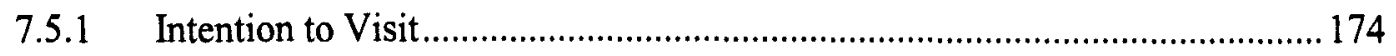

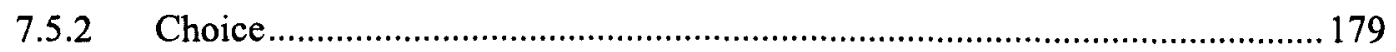

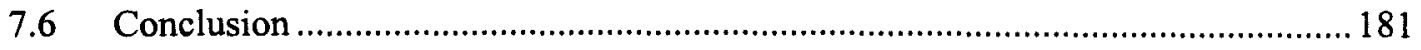

Chapter Eight: Discussion and Conclusions .................................................... 183

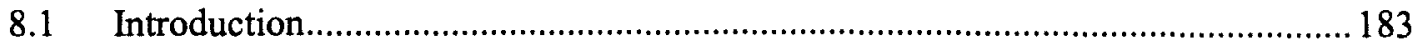

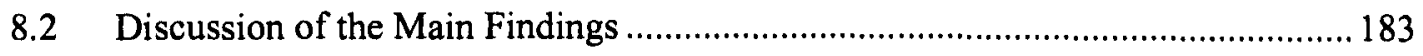

8.2.1 Effects of Presentation Format on Destination Choice Process ..................... 184

8.2.2 Effects of Presentation Format on Destination Importance ........................... 186

8.2.3 Effects of Exposure on Destination Choice Process.................................... 188

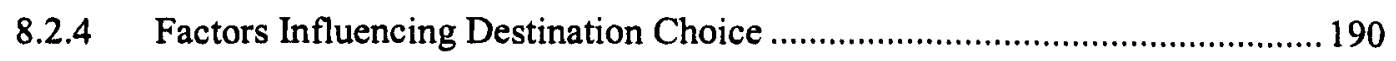

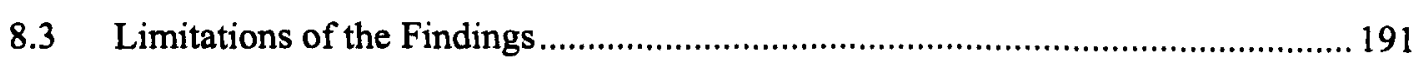

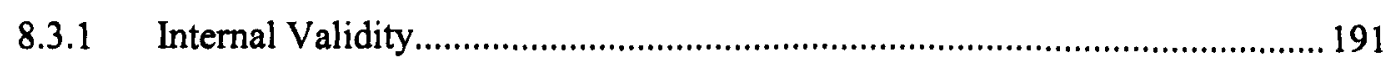

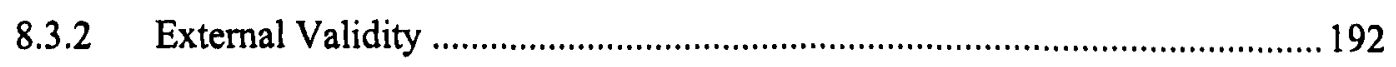

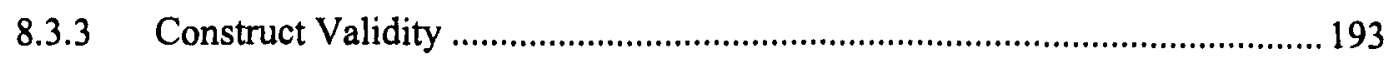

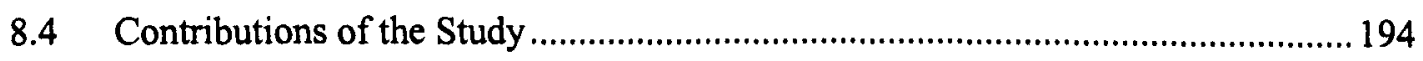

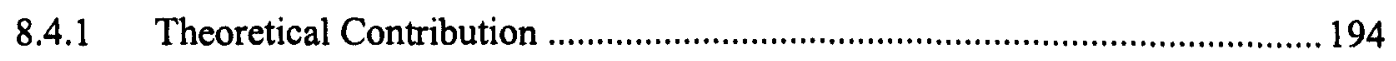

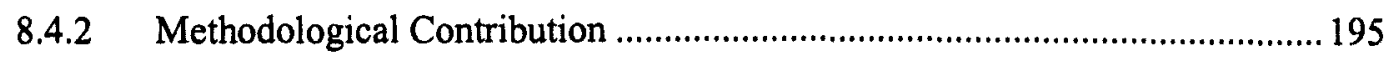

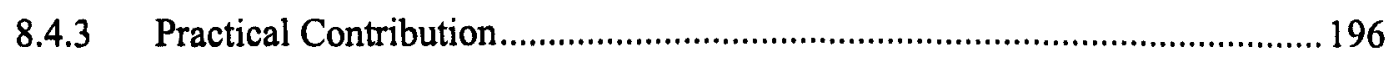

8.5 Conclusions and Recommendations for Future Research .................................. 197

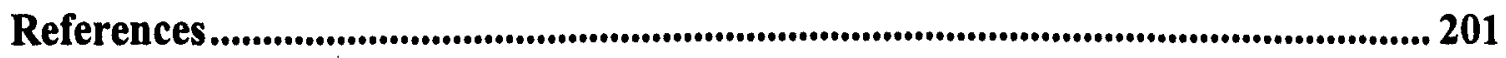

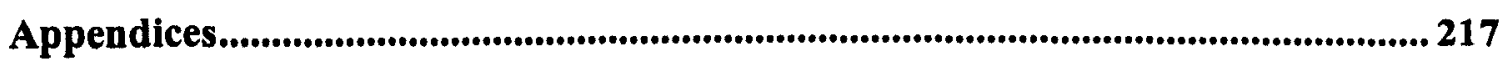




\section{List of Tables}

Table 1.1: UK Residents' Overseas Holiday Visits by Package Holidays.............................. 4

Table 1.2: World's Top Three Tourism Spenders................................................................ 5

Table 1.3: UK Residents' Overseas Holiday Visits by Area.................................................5

Table 2.1: List of Variables Influencing Tourist Decision-making Process .......................... 18

Table 2.2: Terms Used in Destination Choice Process ..........................................................2

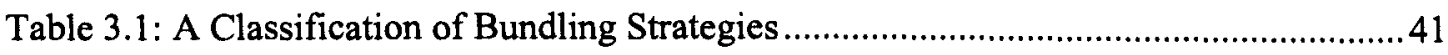

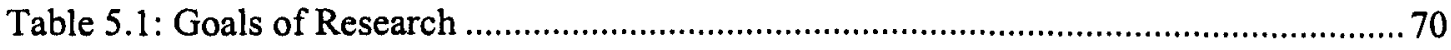

Table 5.2: Number of UK Residents' Visits by Destination ...............................................80

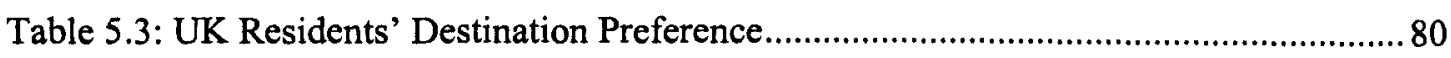

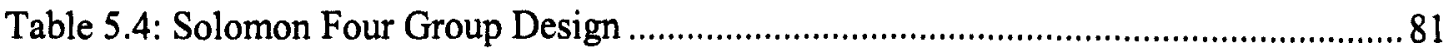

Table 5.5: Steps of Fitting Eight Destinations into Latin Square Design............................... 82

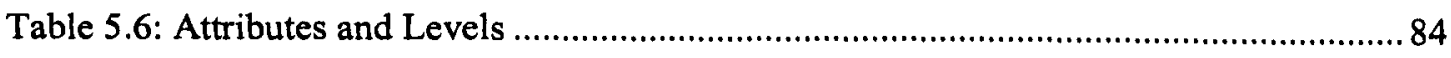

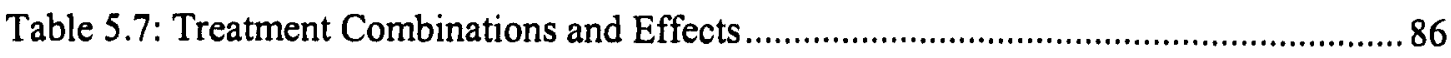

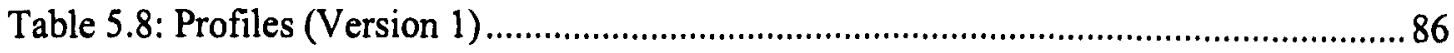

Table 5.9: Levels of Destinations in Each Block of Profiles ..............................................87

Table 5.10: Questionnaire Distribution for Experimental Group....................................... 106

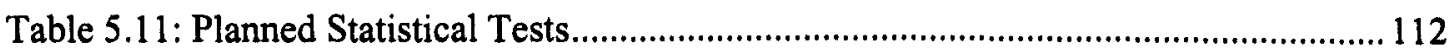

Table 6.1: Number of Respondents between Group by Gender (Students) .......................116

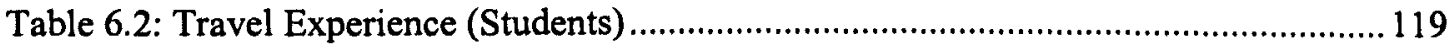

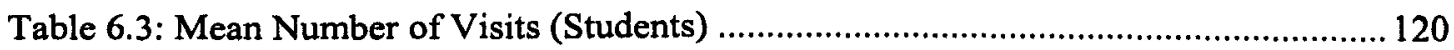

Table 6.4: Number of Respondents Visiting Destination at Least Once (Students) ........... 121

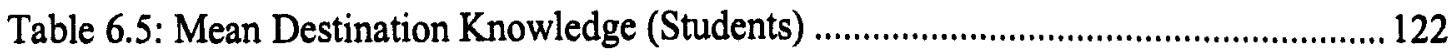

Table 6.6: Perception of Destination Attributes by Destination (Students) ........................ 123

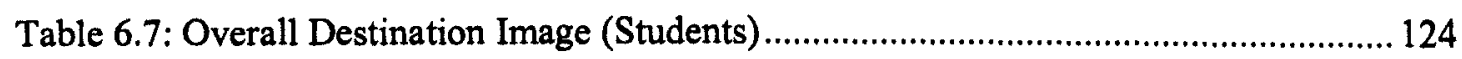

Table 6.8: Frequency of the Most Expensive and the Cheapest Destinations (Students) .... 124

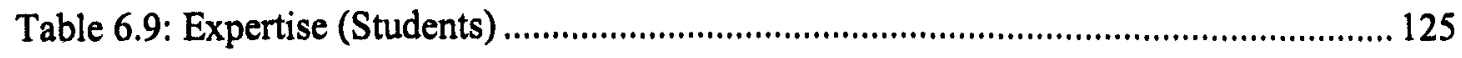

Table 6.10: Mean Intention to Visit by Preference (Students) ........................................... 126

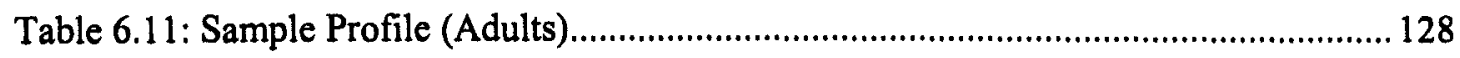


Table 6.12: Number of Respondents between Group by Gender (Adults) . 129

Table 6.13: Travel Experience (Adults) 132

Table 6.14: Mean Number of Visits to Destinations (Adults). 133

Table 6.15: Number of Respondents Visiting Destination at Least Once (Adults) ... 134

Table 6.16: Mean Destination Knowledge (Adults) ... 134

Table 6.17: Perception of Destination Attributes by Destination (Adults) 136

Table 6.18: Overall Destination Image (Adults). 136

Table 6.19: Frequency of the Most Expensive and the Cheapest Destinations (Adults) ..... 137

Table 6.20: Expertise (Adults) 138

Table 6.21: Mean Intention to Visit by Preference (Adults) 138

Table 7.1: Mean Intention to Visit between Group by Preference (Students) ..... 144

Table 7.2: Two-way ANOVA (Students). 145

Table 7.3: Mean Intention to Visit between Group by Preference (Adults). 146

Table 7.4: Two-way ANOVA (Adults) 146

Table 7.5: Probability of Entering Late Consideration between Group by Preference (Students) 148

Table 7.6: Parameter Estimates for Probability of Entering Late Consideration (Students) 149 Table 7.7: Probability of Entering Late Consideration between Group by Preference (Adults) 149

Table 7.8: Parameter Estimates for Probability of Entering Late Consideration (Adults) ... 150 Table 7.9: Probability of Becoming a Choice between Group by Preference (Students) .... 151

Table 7.10: Parameter Estimates for Probability of Becoming a Choice (Students) ............ 152

Table 7.11: Probability of Becoming a Choice between Group by Preference (Adults) ..... 153

Table 7.12: Parameter Estimates for Probability of Becoming a Choice (Adults)............... 153

Table 7.13: Mean Attribute Importance between Group (Students) ................................... 155

Table 7.14: MANOVA for Attribute Importance (Students) ............................................. 156

Table 7.15: Mean Attribute Importance between Group (Adults) ..................................... 157

Table 7.16: MANOVA for Attribute Importance (Adults) ................................................ 157

Table 7.17: Mean Intention to Visit between Exposure by Preference (Students)................ 161

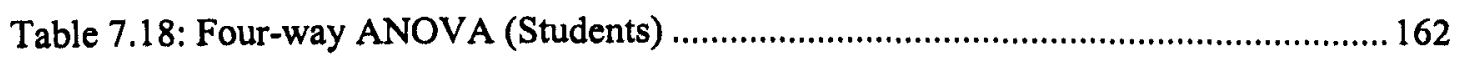

Table 7.19: Mean Intention to Visit between Exposure by Preference (Adults)................... 164

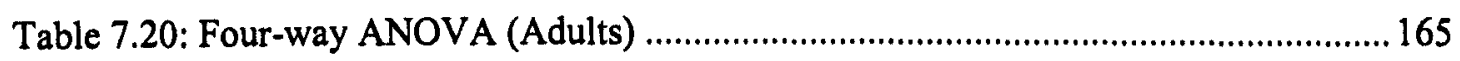


Table 7.21: Probability of Entering Late Consideration between Exposure by Preference (Students) 168

Table 7.22: Parameter Estimates for Probability of Entering Late Consideration (Students)

Table 7.23: Probability of Entering Late Consideration between Exposure by Preference

(Adults)

Table 7.24: Parameter Estimates for Probability of Entering Late Consideration (Adults) 170

Table 7.25: Probability of Becoming a Choice between Exposure by Preference (Students)

Table 7.26: Parameter Estimates for Probability of Becoming a Choice (Students)

Table 7.27: Probability of Becoming a Choice for Late Exposure by Preference (Students)

Table 7.28: Probability of Becoming a Choice between Exposure by Preference (Adults). 173

Table 7.29: Parameter Estimates for Probability of Becoming a Choice (Adults) 174

Table 7.30: Intercorrelations between Intention to Visit and Control Variables for Sample

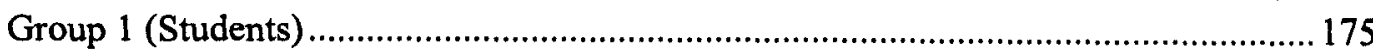

Table 7.31: Two-way ANCOVA for Intention to Visit for Sample Group 1 (Students) ..... 176

Table 7.32: Four-way ANCOVA for Intention to Visit for Sample Groupl (Students) ...... 177

Table 7.33: Intercorrelations between Intention to Visit and Control Variables for Sample

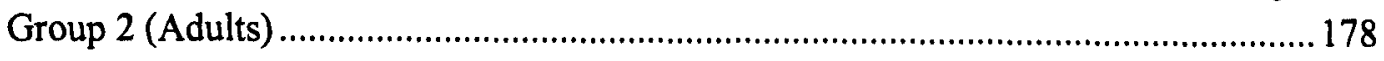

Table 7.34: Two-way ANCOVA for Intention to Visit for Sample Group 2 (Adults) ........ 178

Table 7.35: Four-way ANCOVA for Intention to Visit for Sample Group2 (Adults) ......... 179

Table 7.36: Parameter Estimates for Probability of Becoming a Choice for Sample Group 1

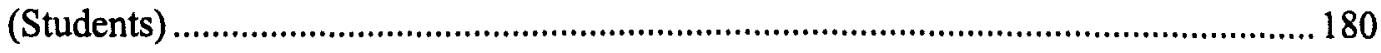

Table 7.37: Parameter Estimates for Probability of Becoming a Choice for Sample Group 2

(Adults) 


\section{List of Figures}

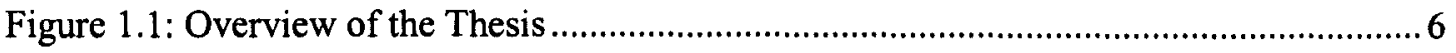

Figure 2.1: Travel Decision Process Model .............................................................................. 11

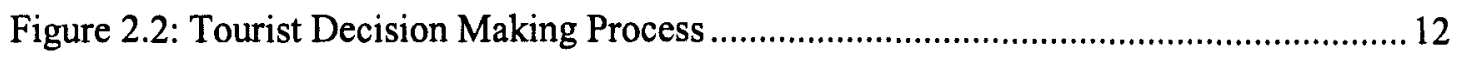

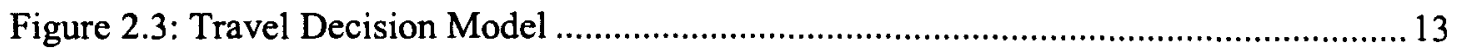

Figure 2.4: Tourist's Holiday Decision Model ................................................................... 14

Figure 2.5: Tourists' Cognitive Decision Making............................................................. 15

Figure 2.6: Stimulus-response Model of Buyer Behaviour................................................. 16

Figure 2.7: Basic Components of Pre-purchase Alternative Evaluation Process for a Tourism

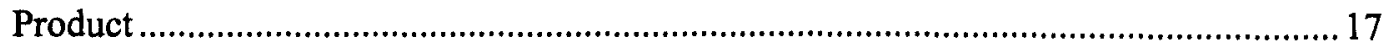

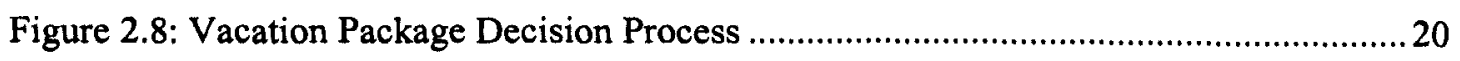

Figure 2.9: General Model of Traveler Leisure Destination Awareness and Choice............. 23

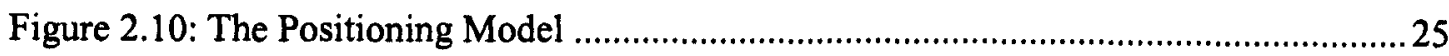

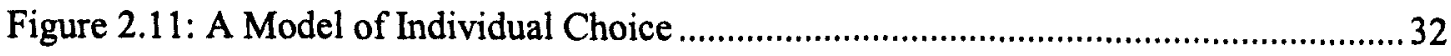

Figure 3.1: Anchoring and Adjustment Model of Bundle Evaluation ..................................42

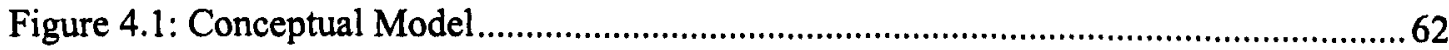

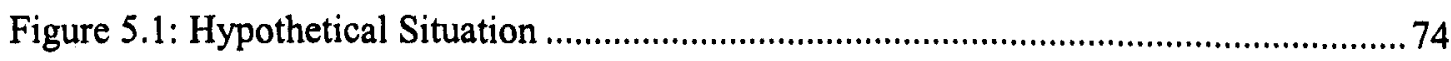

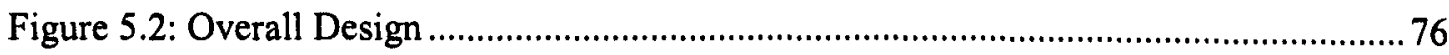

Figure 5.3: Package Heading of Two Experimental Groups................................................ 77

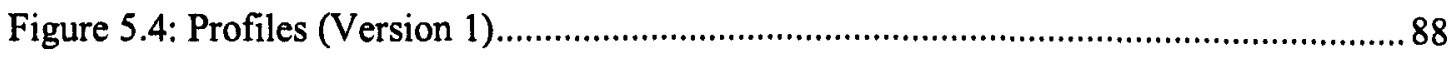

Figure 6.1: Preferred Type of Overseas Holiday (Students) ............................................. 117

Figure 6.2: Preferred Month of Next Overseas Holiday (Students) ................................... 118

Figure 6.3: Preferred Destination (Students) ....................................................................119

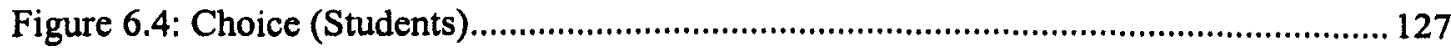

Figure 6.5: Preferred Type of Overseas Holiday (Adults) ................................................ 130

Figure 6.6: Preferred Month for Next Overseas Holiday (Adults)....................................131

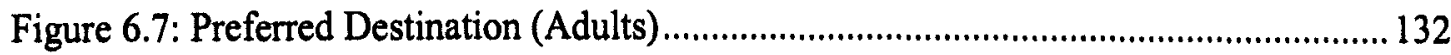

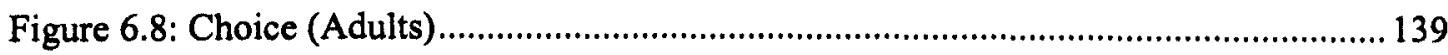


Figure 7.1: Mean Intention to Visit of Late Exposure by Preference (Students)- 8

Destinations. 163

Figure 7.2: Mean Intention to Visit of Late Exposure by Preference (Adults)- 4 Destinations 166 


\section{Acknowledgements}

Doing a $\mathrm{PhD}$ involves a degree of uncertainty, isolation and frustration. To overcome such feelings is a challenge that one learns during the path of a doctoral process. A thesis such as this cannot be completed without considerable support and encouragement from various people who are fully worth to be acknowledged here.

First, I would like to thank my sponsor, Bangkok University, for giving me a chance to pursue my study. Next, I would like to thank Professor Harmen Oppewal for sharing his research inspiration, challenging comments and expertise on the experimental design. Thank you for foreseeing my potentials to grow as a fellow researcher. My thanks extend to Professor David Airey for his endless support and encouragement. I am grateful for his advice and understanding when I was very much in the clouds. Many thanks go to Dr. Abbas Haydari, Dr. Outi Niininen, Dr. Panos Louvieris, Mr. Rajat Tandon, Mrs. Anneke Oppewal, Jeab, Goy and Tong for their kind support with the data collection.

Special thanks also go to my wonderful family who continuously provide me their love and support. Thank you for always believing in me in which this has given me so much power to overcome many obstacles in life. This work is specially dedicated to my mother who has devoted all her life for her proud children. A very big thank you to Auntie Lek and my sister (Kay) who have lifted the responsibilities from my shoulders while I was trying to complete the study. I would also like to thank Noom for his everlasting love, faith and patience from my MSc. to this $\mathrm{PhD}$. Thank you so much for his understanding and everything he has done for me through these years. My thanks extend to Abbas for sharing my laughs and tears during these rollercoaster years. Thank you all for caring so much for me and putting up with my emotions when I was in such a stressful time to complete this thesis.

Last but not least, I thank 'the Hunts' and all my friends either in the UK or in my home country who have consistently cheered me up in whatever ways they possibly could. Many thanks for providing the unconditional support whenever it is needed. Without these special people, not only a complete thesis but also an enjoyable $\mathrm{PhD}$ experience was possible. 


\section{Chapter One}

\section{Introduction}

\subsection{Introduction}

Tourism is the world's largest industry and it is one of the fastest growing economic sectors (WTO, 1999a). For many destinations, tourism is an important part of the economy (WTO, 2001a). Tourism receipts are a significant contributor to income, investment and employment (Middleton and Clarke, 2001). The growth of tourism in South East Asia and Eastern Europe, for example, gives an impression of a readymade answer in the economic needs for those regions (Seaton, 1996).

Due to its significance for the economy of the destinations, the tourism industry has become highly competitive with the development of an increasing number of available holiday destinations. Effective marketing strategies to influence the choice of destination are of the utmost interest to marketers. Further insights into such strategies will enable them better to design and promote their destinations to increase market share and associated tourism revenues.

In 2000, international tourism receipts amounted to US\$ 475 billion (WTO, 2001b). Over half of this amount (US\$ 258 billion) was shared among the world's top ten destinations; namely USA, Spain, France, Italy, UK, Germany, China, Austria, Canada and Greece (WTO, 2001b). These ten destinations accounted for $54 \%$ of the total market share. Since tourism is also significant for the rest of the world, the research problem of this study concerns marketing strategies to assist those 
destinations with a small market share which are referred here as 'less-preferred destinations' to increase their number of tourist arrivals and their tourism revenues.

This study is concerned with holiday packaging particularly on how the presentation of information for package holidays can benefit less-preferred destinations. In today's market, packaging is used not only to convey the information but also to influence the consumer choice (Fill, 1995). Package holidays are prevalent and constitute a significant part of the tourism industry (Sheldon and Mak, 1987; Swarbrooke and Horner, 1999). In such a context, destination and other components e.g. accommodation and flights are combined as package holidays. When purchasing package holidays, destination is considered as part of the total holiday decision.

Based on the notion that destination is combined with other components as package holidays, several researchers (Woodside and Carr, 1988; Mill, 1990) suggest that the name of destination is not a strong factor for choice and consumers are willing to substitute one destination for the other. This study further argues that the holiday packaging strategy will be more effective when particularly applied in the context of beach holidays. Since beach holidays offer similar products, those tourists who look for sun, sea and sand will find similar holidays in Spain, Turkey and Greece. In such a context, a choice of beach holiday destinations can be substituted one for another.

Travel stimuli are regarded as the important factors affecting the choice of holiday destinations (Woodside and Lysonski, 1989; Um and Crompton, 1990). Information about package holidays appears in various forms of travel stimuli such as advertising, promotion and travel literature (Schmoll, 1977; Moutinho, 1987). Despite the prevalence of the information about package holidays that the consumers are exposed to, the present understanding about the effects of information presentation relating to package holidays on a choice of holiday destinations is very limited.

This study focuses on the two key issues regarding the presentation of information relating to package holidays so as to help less-preferred destinations. The first is 
related to the way the information of package holidays is presented such that it can draw consumers' attention from the destination to other package components. This would reduce the importance of destination and be extremely useful for marketing less-preferred destinations. Previous research suggests that the amount of information given can affect consumer choice (Johnson and Levin, 1985; Kivetz and Simonson, 2000) and the display of information with a specific attribute increases the importance of that attribute and facilitates the choice processing by that attribute (Areni et al., 1999). The present study aims at two ways of reducing the destination importance; namely the amount of information given and the package heading.

The second is concerned with the timing of exposure to less-preferred destinations. To date, there are three contrasting views regarding the exposure in determining the consideration sets. First, the consideration sets are viewed as stable and the exposure to alternatives should be presented as early as possible (Crompton and Ankomah, 1993). Second, the consideration sets are viewed as unstable and the exposure to alternatives can add them to the consideration sets at any point in time until the consumers decide to make a final choice (Shocker et al., 1991; Roberts and Nedungadi, 1995). Third, the consideration sets are also viewed as unstable but the exposure to alternatives should be as close to a time of choice as possible (Hulland, 1992). Due to these contradicting views, the present study aims to examine the effective timing of exposure to less-preferred destinations such that it can help them to become a final choice.

\subsection{Research Aim}

The aim of this study is to examine whether the presentation of information about package holidays can influence consideration and choice of beach holiday destinations. By examining this issue, this study will contribute to the design of more effective marketing strategies for less-preferred destinations. The study focuses on two aspects of presenting the information about package holidays to the consumers. The first concerns the presentation format including the amount of 
information provided and the package heading. The second concerns the timing of the exposure to destinations.

Although there is a widespread practice of holiday packaging, there are surprisingly a limited number of studies on the effective ways of presenting the information of package holidays in such a way as to help less-preferred destinations become a final choice. It is intended that the findings of this study will be beneficial to both the theoretical developments of tourist decision-making and practical implications for the tourism industry.

\subsection{Research Context}

The study focuses on the UK holiday market for three reasons. First, beach holidays constitute an important part of the UK holiday market, with a $46 \%$ market share (WTO, 1999b). For British holidaymakers, beach holidays are primarily to relax and to get away from the British climate (WTO, 1999b).

Second, the UK holiday market is regarded as one of the most developed outbound package holiday markets in the world (Keynote, 1999). Table 1.1 illustrates overseas travel by package holidays in the UK market from 1996 to 2000.

Table 1.1: UK Residents' Overseas Holiday Visits by Package Holidays (in thousands)

\begin{tabular}{|c|c|c|c|c|c|}
\cline { 2 - 6 } \multicolumn{1}{c|}{} & 1996 & 1997 & 1998 & 1999 & 2000 \\
\hline Total overseas holiday visits & 26,765 & 29,138 & 32,306 & 35,023 & 36,685 \\
\hline Of which by package holidays & 13,901 & 15,393 & 17,437 & 19,077 & 20,055 \\
\hline (package as percentage of total) & $\mathbf{( 5 1 . 9 )}$ & $\mathbf{( 5 2 . 8 )}$ & $\mathbf{( 5 4 . 0 )}$ & $(\mathbf{5 4 . 5 )}$ & $\mathbf{( 5 4 . 7 )}$ \\
\hline
\end{tabular}

From 1996 to 2000 , Table 1.1 shows that the use of package holidays increases from 13.9 million to 20.1 million overseas holiday visits. Each year, over $50 \%$ of overseas holiday visits are in the form of package holidays. The popularity of package holidays in this market is due to their convenience and price competitiveness (Laws, 1997; Taylor, 1998). 
Third, the UK has been one of the world's top three tourism spenders. Table 1.2 shows the world leading tourism spenders.

Table 1.2: World's Top Three Tourism Spenders

\begin{tabular}{|c|c|c|}
\hline Country & $\begin{array}{c}\text { International Tourism } \\
\text { Expenditure (US\$ billion) } \\
\mathbf{2 0 0 0}\end{array}$ & $\begin{array}{c}\text { Market share } \\
\text { (\%) 2000 }\end{array}$ \\
\hline USA & 65.0 & 13.7 \\
\hline Germany & 47.6 & 10.0 \\
\hline UK & 36.6 & 7.7 \\
\hline World & $\mathbf{4 7 5 . 8}$ & $\mathbf{1 0 0}$ \\
\hline
\end{tabular}

Table 1.2 shows that the UK alone contributes $7.7 \%$ of the total international tourism expenditure in 2000. Despite the September 11 terrorist attack in 2001, UK is the country among the world's top three tourism spenders which has shown the highest increase in tourism expenditure (10.8\%) from 2001 to 2002 (WTO, 2003).

When relating the research problem of this study to the UK holiday market, it is necessary to take into account the travel pattern of UK residents. Table 1.3 shows the number of UK residents' holiday visits by area from 1996 to 2000.

Table 1.3: UK Residents' Overseas Holiday Visits by Area (in thousands)

\begin{tabular}{|c|c|c|c|c|c|}
\hline Main Area & $\mathbf{1 9 9 6}$ & $\mathbf{1 9 9 7}$ & $\mathbf{1 9 9 8}$ & $\mathbf{1 9 9 9}$ & $\mathbf{2 0 0 0}$ \\
\hline North America & $\mathbf{2 , 2 6 7}$ & 2,244 & 2,591 & 2,964 & 3,052 \\
\hline EU Europe & 19,428 & 21,594 & 23,510 & $\mathbf{2 5 , 9 7 8}$ & 26,768 \\
\hline Non-EU Europe & 2,593 & 2,684 & 3,058 & 2,769 & 3,193 \\
\hline Other countries & $\mathbf{2 , 4 7 7}$ & 2,616 & 3,147 & 3,312 & 3,671 \\
\hline Total holiday visits & $\mathbf{2 6 , 7 6 5}$ & $\mathbf{2 9 , 1 3 8}$ & $\mathbf{3 2 , 3 0 6}$ & $\mathbf{3 5 , 0 2 3}$ & $\mathbf{3 6 , 6 8 5}$ \\
\hline
\end{tabular}

Table 1.3 shows that EU Europe has been the most popular area for overseas holiday visits by UK residents. This region accounts for over $70 \%$ of all holiday visits each year. In 2000, the top ten visited countries for UK residents were France, Spain, USA, Irish Republic, Greece, Italy, Germany, the Netherlands, Belgium and Portugal (National Statistics, 2001). These ten destinations are clearly the dominant players or the high-preferred destinations of the UK holiday market. Nine out of those ten 
destinations are in EU Europe while six of those ten destinations are among the world's top ten tourism earners as discussed in section 1.1 .

\subsection{Overview of Thesis}

The thesis is organised into five major parts as follows: literature review, theoretical framework and hypotheses, methodology, results, discussion and conclusions. Figure 1.1 shows the overview of thesis.

Figure 1.1: Overview of the Thesis

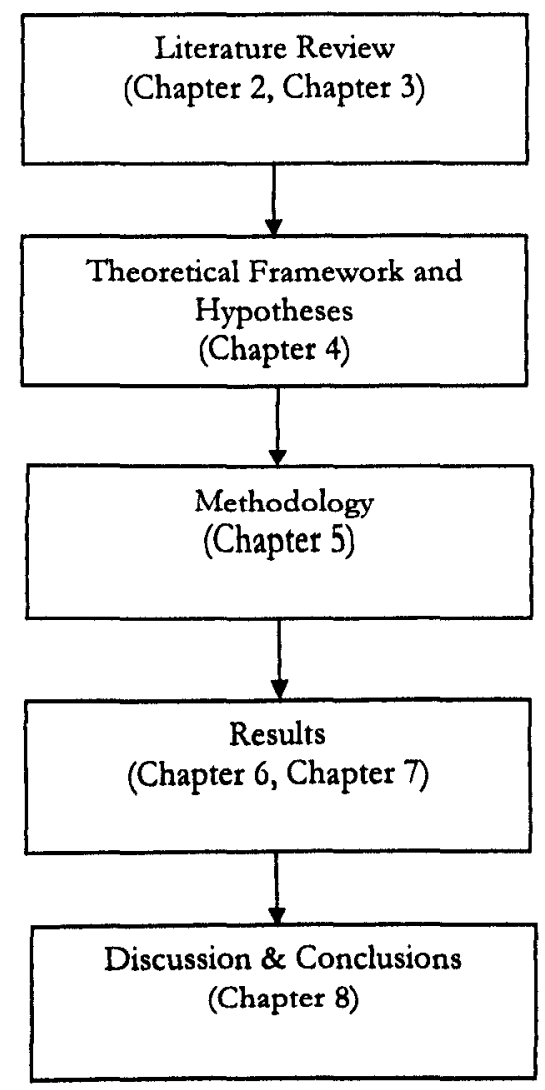

The literature review consists of two chapters. Chapter 2 reviews the literature on the tourist decision-making process and the destination choice process to outline how the decisions are made and what factors can influence such decisions. It highlights the potential effects of travel stimuli which have received very little attention in tourism research. It also reveals that there is limited understanding on the tourist decisions in the context of package holiday purchase. The chapter further reviews 
the literature relating to the nature of consideration sets from which a final choice is selected. Chapter 3 reviews the previous studies on bundling to highlight the importance of tourism research on bundling. It also proposes the information presentation strategies to enhance the bundling practice. It suggests that tourism research on the presentation of information relating to package holidays, a form of bundling in tourism industry, is still lacking. The chapter focuses on three key issues of information presentation strategies including completeness of information, information format and mere exposure.

Chapter 4 illustrates the theoretical framework of the study developed from the literature review. This chapter outlines the gaps existing in the theories of tourist decision-making and presents the research questions of the study. It illustrates a conceptual model of the study and discusses the formulation of hypotheses.

Chapter 5 outlines the methodology of the study. The chapter first provides a justification for selecting the experiments. It then describes the experimental research design, the development of the instrument, the data collection methods, the preparation for data analyses and the limitations of the methodology.

The results of the study are divided into two chapters. Chapter 6 first presents the descriptive findings. Chapter 7 illustrates the results of hypothesis testing and summarises the findings.

Chapter 8 discusses the main findings of the study. It defines the limitations of the findings and provides the contributions of the study. It serves as a conclusion to the study and suggests directions for further research. 


\section{Chapter Two}

\section{Tourist Decision-making}

\subsection{Introduction}

To influence the choice of destinations, an understanding of how decisions are made and which factors can influence them are regarded as the important pieces of information (Woodside and Carr, 1988; Middelkoop et al., 2001). A clear understanding of such factors will help formulate better destination marketing strategies (Goodall, 1991; Chen, 1998) which are of great interest to travel-related companies and national tourism organisations. To date, there appears to be a limited number of tourism research examining the influence of marketing factors on the tourist decisions.

The term 'tourist decision-making' refers to all choice decisions related to the process of taking pleasure trips such as destination choice, accommodation choice and travel mode choice (Um, 1993). Moutinho (1987) calls these choice decisions as 'sub-decisions'. Among these sub-decisions, destination choice appears to be the most important and has received much attention from tourism researchers. Others (Dellaert et al., 1998; Fesenmaier and Jeng, 2000) argue that studies focusing on destination choice alone have ignored the fact that a holiday choice is actually a complex and multifaceted decision process in which a destination is related to other elements comprising a holiday. In the context of package holiday purchase, the present study argues that the destination choice should be considered as part of the sub-decisions. 
This chapter reviews literature related to the tourist decision-making process and destination choice process, to outline the important variables influencing both processes. It also reviews the literature regarding the nature of consideration sets from which the final choice is selected. The chapter is divided into three sections as follows: tourist decision-making process, destination choice process and consideration. The chapter ends with a conclusion section.

\subsection{Tourist Decision-making Process}

Purchase decisions for tourism products are described as 'unique' (Wahab et al., 1976; Moutinho,1987) and 'unusual' (Mathieson and Wall, 1982). Tourism products are mainly services (Swarbrooke and Horner, 1999). Like other services, tourism products have a number of distinctive features which differentiate them from goods. Palmer (2001) describes these unique characteristics of services which are relevant to purchase decisions for tourism products as intangibility, inseparability and inability to own. Their intangible nature means that tourism products cannot be examined before they are purchased. Tourism products are inseparable in the sense that the production and consumption is simultaneous, that is, consumers need to visit destinations rather than the destinations being transported to the consumers (Mathieson and Wall, 1982; Middleton and Clarke, 2001). The lack of ownership is due to the characteristics of intangibility. Thus, the purchase of tourism products is for experience rather than ownership.

It has been generally agreed that buying a tourism product is a high-risk and high involvement purchase due to its intangibility and the considerable expenditure involved (Goodall, 1988; Maser and Weiermair, 1998; Cooper et al., 1998; Swarbrooke and Horner, 1999). Purchasing a tourism product is often an event of emotional significance partly due to the fact that a holiday is an escape from the usual environment. To reduce the lack of intangibility and the level of uncertainty, an important marketing implication is to add physical evidence to the products such as hotel quality and airline name (Palmer, 2001). 
Most models explaining tourist purchase behaviour are extended problem-solving models. Extensive problem solving is 'a situation where consumers have no established criteria for evaluating a product category or have not narrowed down the number of alternatives they will consider to a small manageable subset' (Schiffman and Kanuk, 1994, p.565). These extended problem-solving models apply to purchases with high levels of perceived risk and involvement and where the information search and evaluation of alternatives play an important part in the purchasing decision (Cooper et al., 1998). The final choice which involves the effort of information search and evaluation of available alternatives is seen as emerging from a 'funnelling process' (Moutinho, 1987).

It was in the 1970s that the tourist decision-making models began to develop. One of the earliest attempts was by Wahab et al. (1976). Their model is based on the belief that any potential tourist goes through a logical and linear decision-making process: initial stimulus, conceptual framework, fact gathering, definition of assumptions, design of alternatives, forecast of consequences, cost-benefit analysis, ranking alternatives, decision and outcome. The authors provide a useful suggestion that tourism marketers can adapt the marketing effort to influence the tourist decisionmaking process. However, this model seems to ignore variables which are internal and external to the tourists. In fact, these variables can affect the tourist decisionmaking process.

Schmoll (1977) introduces a travel decision process model involving four stages: travel desires, information search, assessment of travel alternatives, and decision. The model explains that purchase decisions are the result of interaction of four fields of influence, which are external and internal to the tourists. This model proposes all possible factors affecting tourist decision-making in detail. It clearly suggests that travel stimuli such as advertising, promotion and travel literature can affect tourist decision-making. Figure 2.1 illustrates Schmoll's (1977) Travel Decision Process Model. 
Figure 2.1: Travel Decision Process Model

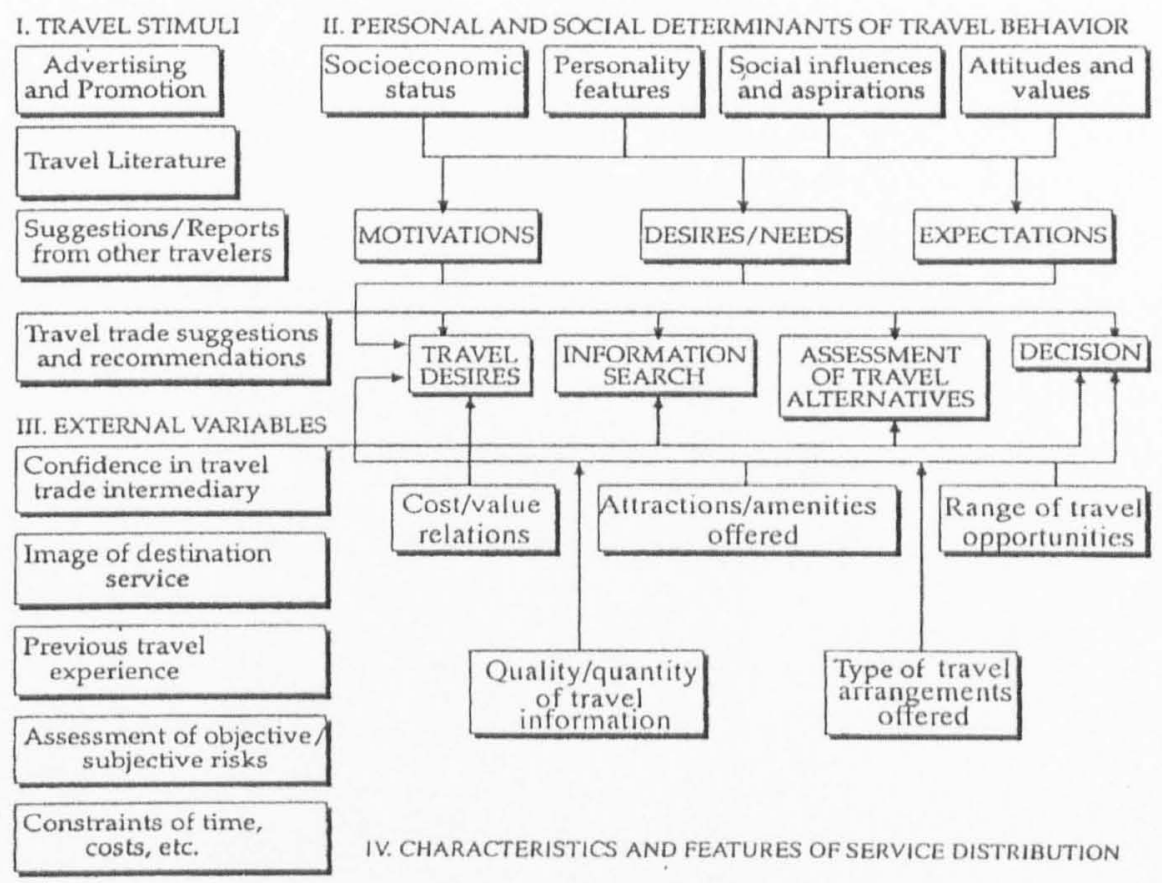

Source: Schmoll (1977)

Cooper et al. (1998) comment on Schmoll's model that it ignores the post purchase stage which may influence future holiday purchases. Although this model is not a proper tool for prediction, it is the only model that pays attention to constraints and their impacts on the tourist decision-making process and provides many important variables influencing tourists' decision-making (Hudson, 1999). Schmoll's model has in fact raised further attention to the factors affecting the tourist decision-making.

Mathieson and Wall (1982) offer a five stage process of travel buying behaviour which includes travel desire, information collection and evaluation, travel decision, travel preparations as well as travel experiences and travel satisfaction evaluation. Figure 2.2 illustrates the Tourist Decision Making Process by Mathieson and Wall (1982). 
Figure 2.2: Tourist Decision Making Process

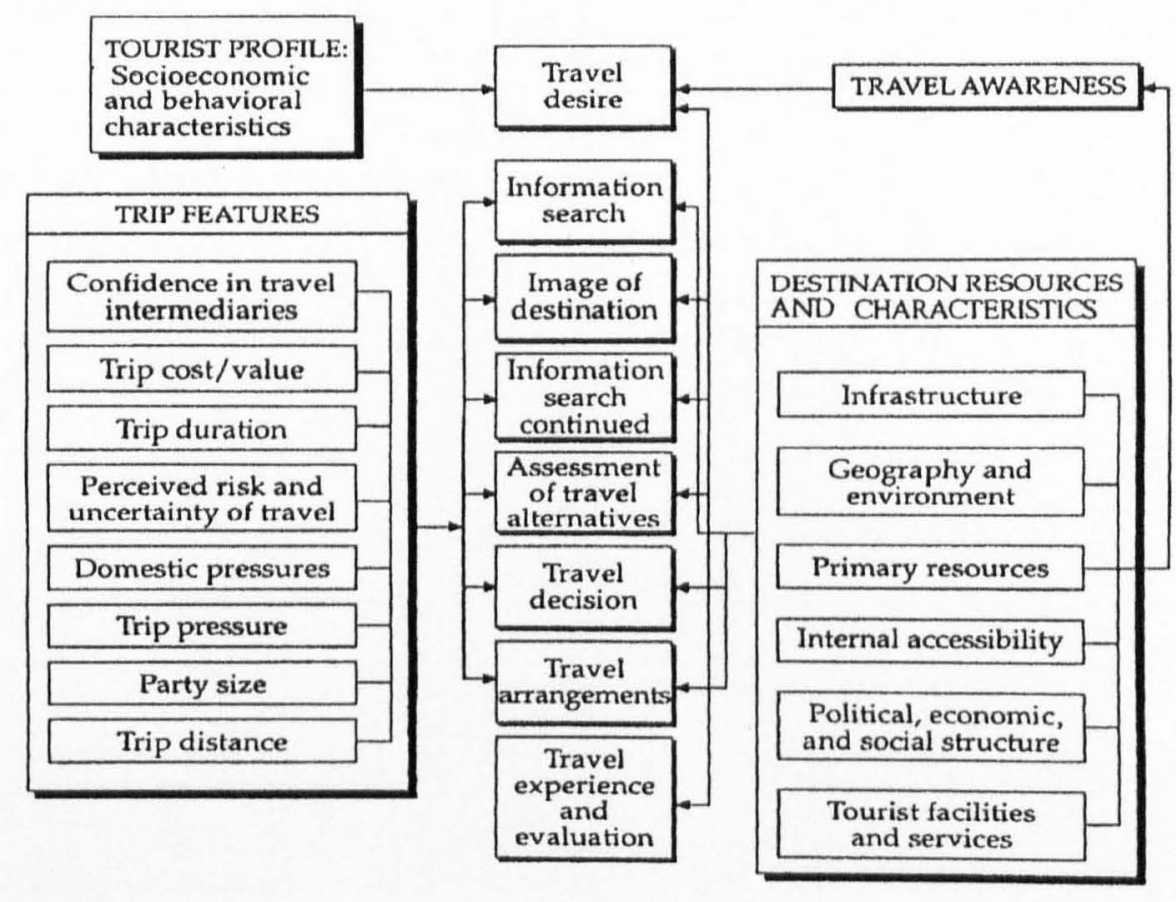

Source: Mathieson and Wall (1982)

The model shown in Figure 2.2 highlights trip features and destination attributes as the major influences on the tourist decision-making process. Socio-economic aspects of tourists (age, education, income, previous experience), behavioural characteristics of tourists (motivations, attitudes, needs and values) and awareness of destinations are also included in the model.

To place the destinations in consideration, the potential tourists must be aware of information about such destinations (Mathieson and Wall, 1982). Through marketing efforts, tourist decision-making may be directed towards particular destinations. By manipulating the marketing factors influencing tourist decisionmaking, tourists' destination preferences can be changed (Mathieson and Wall, 1982). In other words, potential tourists may have their own destination preferences. Providing them with attractive travel stimuli may affect their destination preferences.

Van Raaij and Francken (1984) introduce a 'vacation sequence' as a framework to describe the five main stages of tourists' behaviour. These are generic decision, information acquisition, joint decision-making, vacation activities as well as 
satisfaction and complaints. This formulation resembles the consumption decision process of Engel and Blackwell (1982). Socio-demographic, household and individual factors (attitudes, expectations, aspirations, values, needs and experience) are considered as important factors influencing the vacation sequences.

Moutinho (1987) proposes a Travel Decision Model. Similar to Schmoll (1977), this model refers to the same four groups of factors influencing the travel decision process. Figure 2.3 illustrates Moutinho's (1987) Travel Decision Model.

Figure 2.3: Travel Decision Model

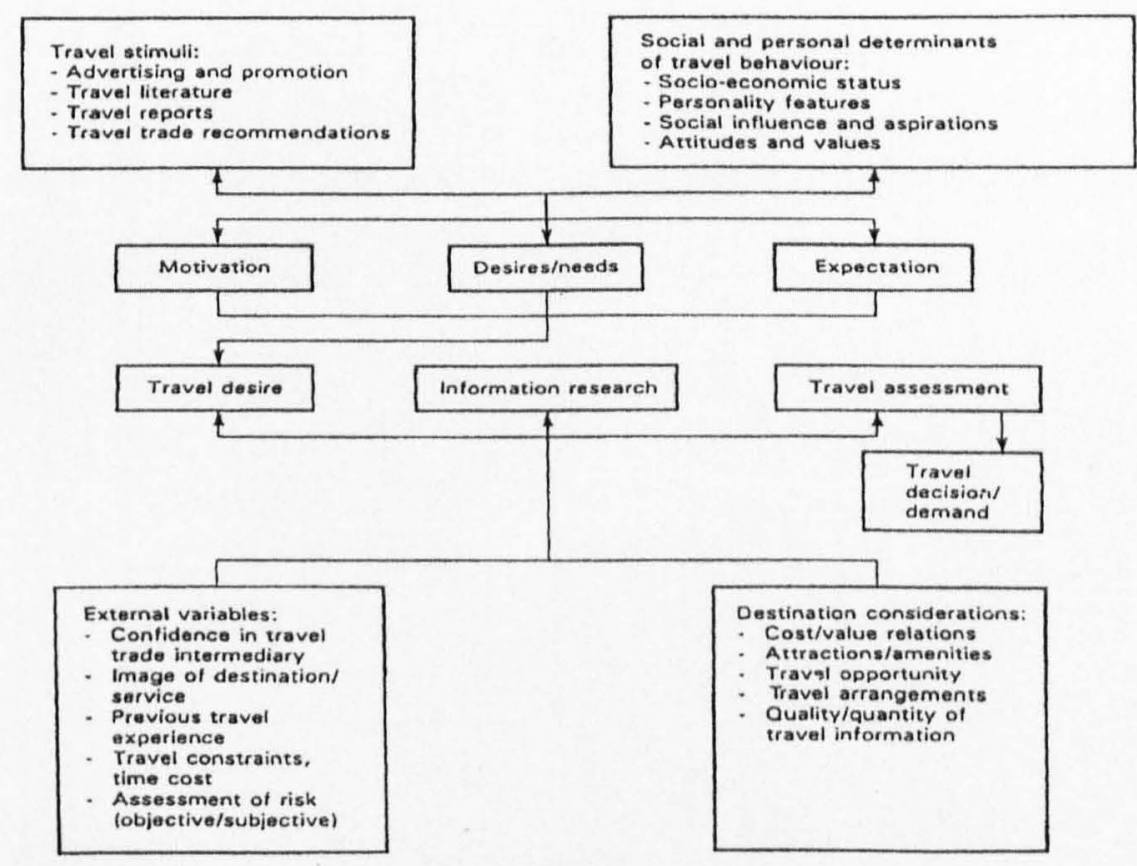

Source: Moutinho (1987)

Moutinho's model focuses on how travel stimuli and social and personal determinants create travel desire. During the later stages, potential tourists need to search for information and make travel decisions. External variables such as confidence in travel agents, the overall image of the alternative destinations, previous travel experience, travel constraints (time, cost) and the degree of perceived risks are considered as important determinants in the travel decision. 
Goodall (1988) proposes a Tourist's Holiday Decision Model consisting of five stages: need recognition, information search, evaluation of alternatives, purchase decision and post purchase evaluation. Figure 2.4 shows Goodall's (1988) Tourist's Holiday Decision Model.

Figure 2.4: Tourist's Holiday Decision Model

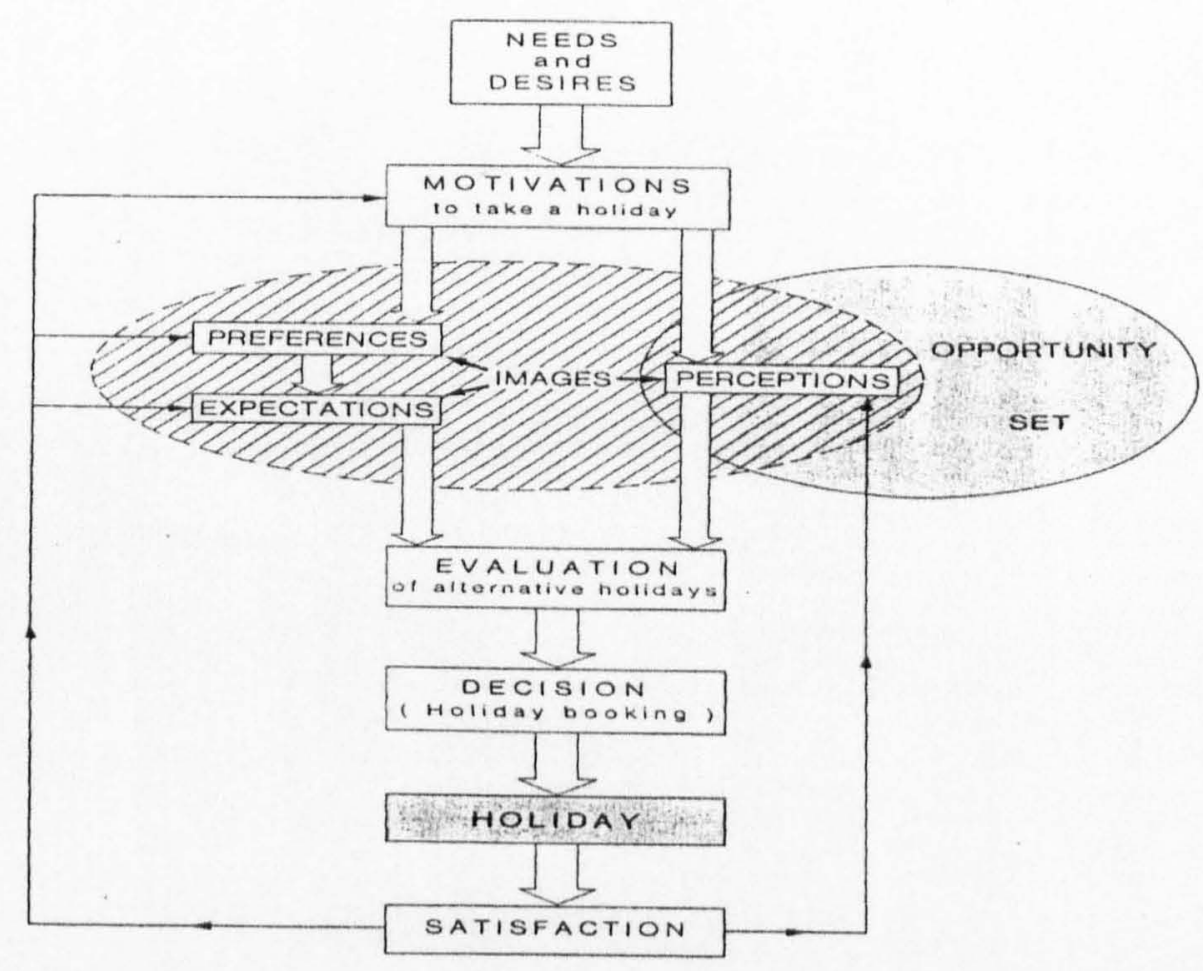

Source: Goodall (1988)

Goodall (1988) introduces the concept of an opportunity set to the model and explains that converting motivations into a holiday purchase requires tourist's preferences, experience and knowledge of holiday destinations. One's perception of holiday destinations is conditioned by available information. The perceived opportunity set will include destinations appearing to meet one's expectation and these must be further evaluated according to several factors such as value for money and destination attractions.

Chen (1998) proposes a framework for the tourist decision-making process called the Tourists' Cognitive Decision Making (TCDM) which embodies five decision- 
making components: problem formulation, information search, evaluation, implementation and latent influence. Figure 2.5 shows Chen's (1998) Tourists' Cognitive Decision Making.

Figure 2.5: 'Tourists' Cognitive Decision Making

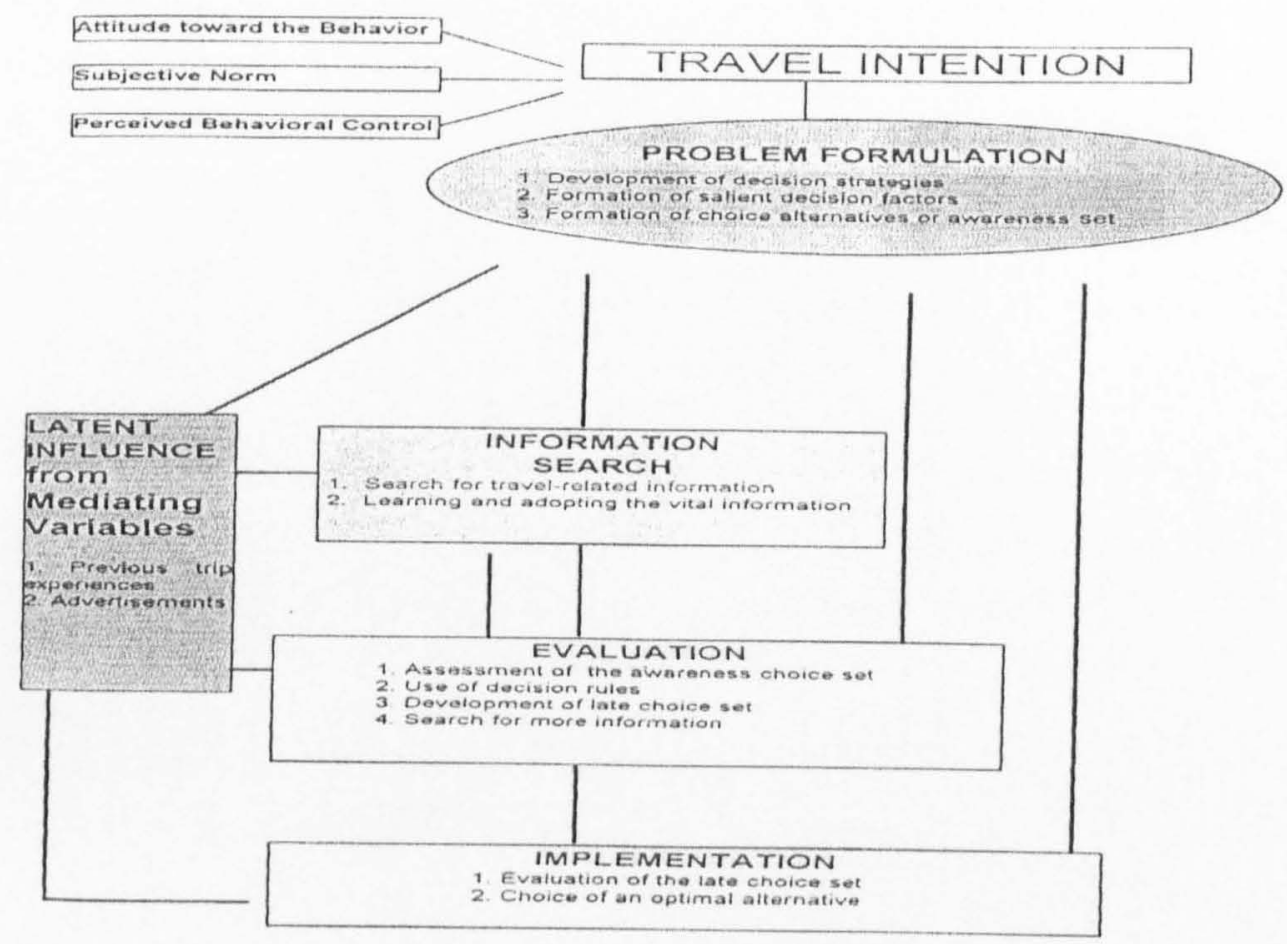

Source: Chen (1998)

In Chen's (1998) model, the consideration set formation from the awareness set to a final choice is included in the tourist decision-making process. There are latent variables affecting tourist choice behaviour in each stage of the decision-making. These are previous travel experience and advertisements.

Middleton (1994) proposes a model explaining the buyer behaviour for the tourism industry. Figure 2.6 shows Middleton's (1994) Stimulus-response Model of Buyer Behaviour. 
Figure 2.6: Stimulus-response Model of Buyer Behaviour

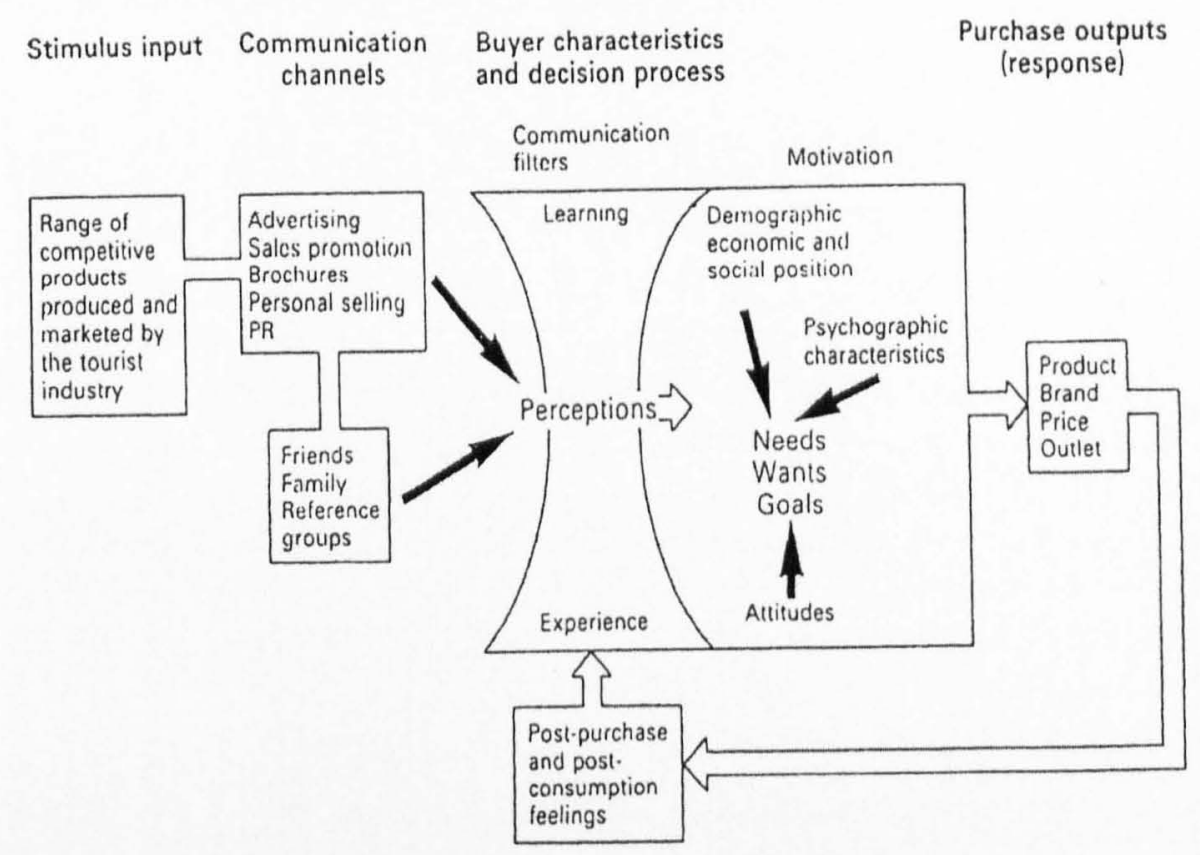

Source: Middleton (1994)

In Middleton's (1994) model, motivation links interest in the product to the purchase of the product. The model also shows that the tourist decision process can be influenced by travel stimuli such as advertising, promotion and travel brochures before any potential tourists reach their decisions. Previous experience of visiting the destinations is also seen as another important factor influencing the decision process.

Dellaert et al. (1998) recommend a conceptual framework for tourists' sequential choices of travel components, focusing on the choices the travellers make in booking and planning their travel facilities. The results of their findings indicate that the choice of different facets of travel (e.g. destination, accommodation or travel duration) represent interrelated decisions that jointly make up the total travel decision process. They further suggest three types of constraints: authority constraints (work or school hours), constraints concerning household members, friends and colleagues, and capacity constraints concerning the availability of travel mode and financial resources. 
In the tourist decision-making process, tourists use two kinds of information to evaluate alternatives: evoked set and destination attributes (Moutinho, 1987). To frame a choice strategy, one will first determine which attributes are important for evaluation in the decision-making process. Intuition and past experience will be used to select these important attributes (Chen, 1998). The model shown in Figure 2.7 is adapted from Engel et al. (1995) to explain the basic components of the pre-purchase alternative evaluation process for a tourism product.

Figure 2.7: Basic Components of Pre-purchase Alternative Evaluation Process for a Tourism Product

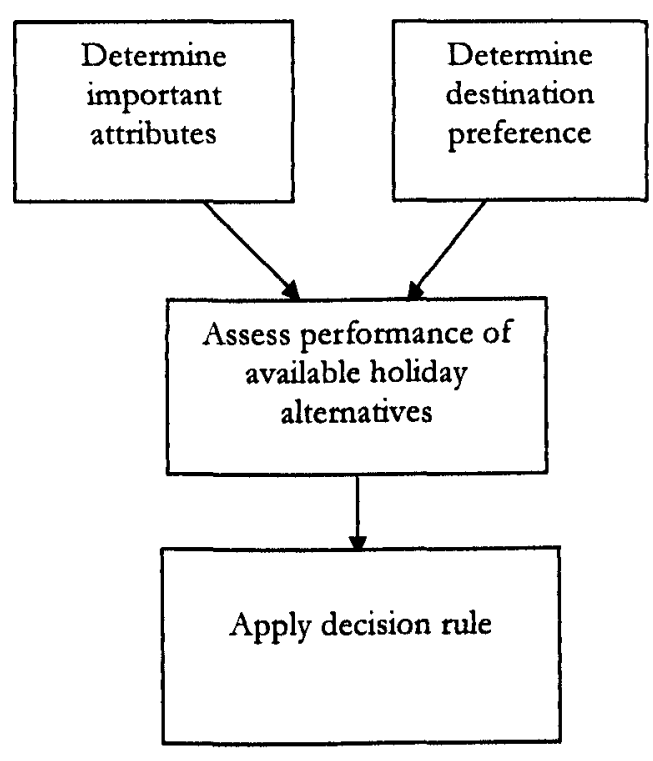

Figure 2.7 includes two major factors in consumer evaluation of the tourism products. These two factors are destination preference and the important attributes in judging the available alternatives. The term 'important attributes' can refer to the features that are significant to consumers when evaluating the alternatives. For example, package holidays would include several attributes such as accommodation, airline company, etc. When an attribute is considered as important to an individual, it presumably has some consequence or significance when he or she forms overall evaluation and makes a choice among alternatives (Myers and Alpert, 1977). Decision rules are then applied to select a particular choice of holiday alternatives. 
Tourist decision-making is assumed to incur extensive problem solving since it involves a fair degree of high risk and is an expensive and infrequent purchase. Tourists try to choose the best alternative to fulfil their psychological values. Variables considered by various authors as important to the tourist decision-making process are summarised in Table 2.1

Table 2.1: List of Variables Influencing Tourist Decision-making Process

\begin{tabular}{|c|c|}
\hline Variables & Authors \\
\hline Travel stimuli & Schmoll (1977), Moutinho (1987), Middleton (1994), Chen (1998) \\
\hline $\begin{array}{c}\text { Confidence in travel } \\
\text { intermediary }\end{array}$ & Schmoll (1977), Mathieson and Wall (1982), Moutinho (1987) \\
\hline Destination image & Schmoll (1977), Mathieson and Wall (1982), Moutinho (1987) \\
\hline $\begin{array}{c}\text { Previous travel experience } \\
\text { Schmoll (1977), Mathieson and Wall (1982), Moutinho (1987), } \\
\text { Middleton (1994), Goodall (1988), Van Raaij and Francken (1984), } \\
\text { Chen (1998) }\end{array}$ \\
\hline Perceived risks & Schmoll (1977), Mathieson and Wall (1982), Moutinho (1987) \\
\hline Travel constraints & Schmoll (1977), Moutinho (1987), Dellaert et al. (1998) \\
\hline Destination attributes & Schmoll (1977), Mathieson and Wall (1982), Moutinho (1987) \\
\hline $\begin{array}{c}\text { Social and personal } \\
\text { determinants }\end{array}$ & $\begin{array}{c}\text { Schmoll (1977), Mathieson and Wall (1982), Moutinho (1987), } \\
\text { Middleton (1994), Van Raaij and Francken (1984) }\end{array}$ \\
\hline Destination knowledge & Mathieson and Wall (1982), Goodall (1988) \\
\hline
\end{tabular}

Variables influencing the tourist decision-making can be categorised into two main groups as follows:

(a) personal determinant variables

- personal factors, e.g., age, gender, education, income, life cycle stage, occupation, lifestyle

- psychological factors, e.g., motivation, perception, learning, personality and attitudes

- role and family, reference groups, social class, culture and subculture

- destination knowledge and previous experience

(b) external determinant variables

- travel stimuli

- destination attributes, destination images

- political, economic and social factors 
Much of the tourism research concerning the influence of the external variables on the tourist decision-making focus on destination image (e.g. Baloglu and McCleary, 1999; Chen and Hsu, 2000; Bigne et al., 2001) and destination attributes (e.g. Goodrich, 1978; Haider and Ewing, 1990; Yau and Chan, 1990; Hu and Ritchie, 1993). When wars and terrorist attacks significantly affect the tourism industry and travel patterns, there is an increasing attention of research on political factors (e.g. Seddighi and Theocharous, 2002) and terrorism (e.g. Sonmez and Graefe, 1998). However, studies on the influence of travel stimuli on tourist decision-making are still lacking.

Swarbrooke and Horner (1999) comment that the existing models of tourist decisionmaking are generally based on few or no empirical findings. Pu (2000) also addresses the fact that the lack of empirical evidence of such models casts a doubt on the actual tourist choice. Furthermore, $\mathrm{Pu}(2000)$ argues that the purchase of package holidays may require a different model of tourist decision making.

Having provided an overview of tourist decision-making and having outlined the important variables affecting tourist decision-making, the next section proceeds to review the literature on a specific type of tourist decision-making, the package holiday decision process.

\subsubsection{Package Holiday Decision Process}

Although there is a widespread use of package holidays, it is surprising to note that almost no researchers have paid attention to the tourist decision-making relating to package holidays. To date, Moutinho (1987) seems to be the only author discussing package holiday decision process. Figure 2.8 illustrates Moutinho's Vacation Package Decision Process. 
Figure 2.8: Vacation Package Decision Process

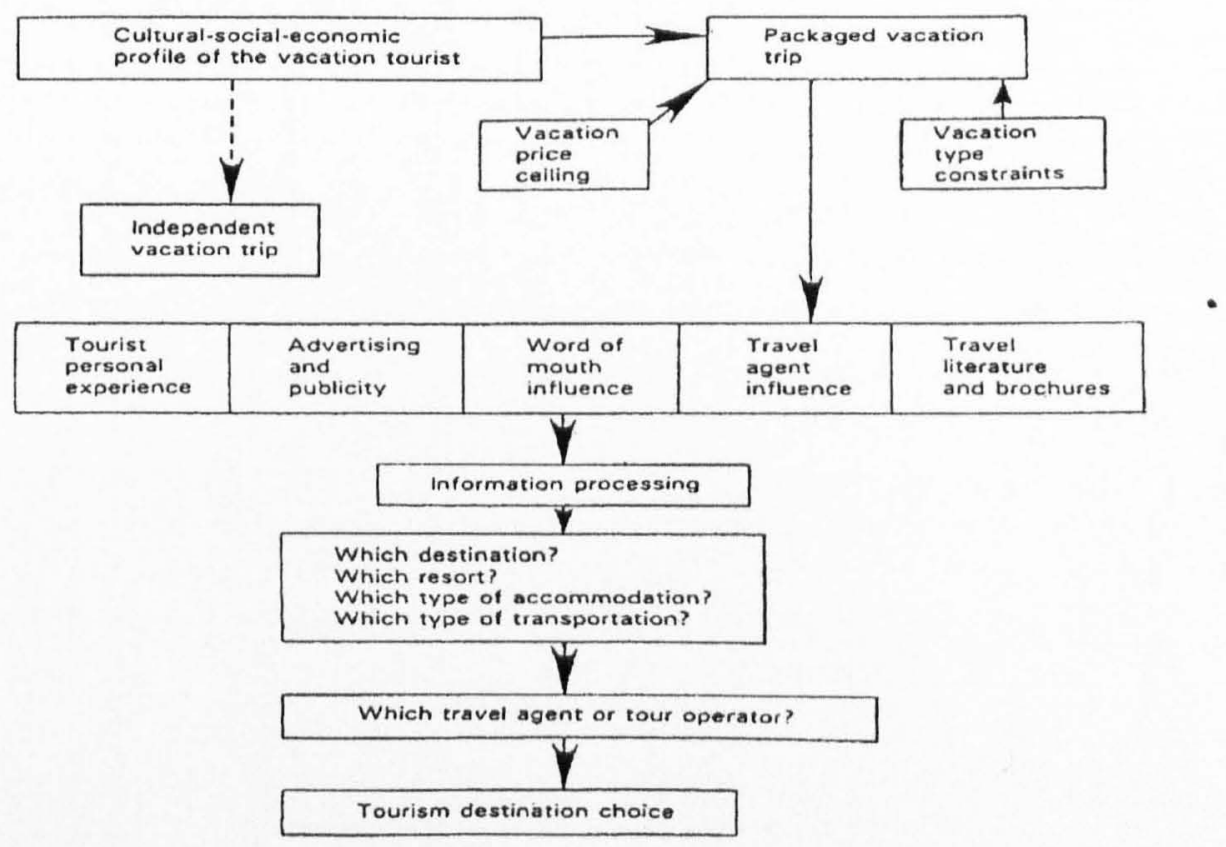

Source: Moutinho (1987)

Moutinho's model describes an information search process that contains five main sources: previous experience, advertising and publicity, word of mouth, travel agent and travel literature. Moutinho suggests that vacation type and price ceiling in relation to a particular tourist are the most important elements in reaching a final decision. It is argued that there are also other attributes in package holidays such as accommodation, airline, travel agents and length of stay that are important to the holiday decision. As pointed out by Dellaert et al. (1998), these attributes are interrelated choice aspects. The study by Money and Crotts (2003) reveals that the reason that the tourists purchase package holidays is to simply avoid the uncertainty arising from the number of these sub-decisions that they may otherwise face.

Purchasing package holidays is also viewed as less dependent on the destination (Burkart, 1984). In such a context, the name of destination is not a strong factor for choice and consumers are willing to substitute one destination for the other (Woodside and Carr, 1988; Mill, 1990). To date, there seems to be no studies examining these issues. Such findings can provide useful marketing implications for less-preferred destinations to influence the consumers' choice of destinations. 
It has been acknowledged that travel stimuli can affect the tourist decision-making process and can cause an individual to favour one destination over another. Information about package holidays appears in all sorts of travel stimuli. Despite its prevalence, the effects of information presentation relating to package holidays on the tourist decisions have hardly been examined. The next section reviews the previous work on the destination choice process further to highlight the significance of the effects of travel stimuli.

\subsection{Destination Choice Process}

The term 'destination' refers to 'the geographic location to which a person is traveling' (Metalka, 1986, p.31). Medlik (1997, p.251) specifically defines the term 'destinations' as 'countries, regions, towns and other areas, which attract tourists and are the main locations of tourist activity'. In the context of this study, the term 'destination' is confined to countries.

Among all decisions in the tourist decision-making process, destination choice has been regarded as the most important factor (Um, 1993). Much research effort has been directed towards how individuals form a set of destinations from which they make a final choice. Although destination is considered as an important choice for a holiday decision, this study argues that tourism is in fact a complementary product in which a holiday decision comprises a destination decision as well as other related sub-decisions. When one thinks of taking a holiday, one would think of several elements such as where to go, how to get there and where to stay, etc. As a result, destination choice is mostly bundled with other choices such as accommodation choice and travel mode choice. These choices are inter-related and thus it seems rather unrealistic to study destination choice separately from other choices.

The notion of consideration sets has been widely accepted in studies on destination choice as a useful structural framework for conceptualising how tourists sift through a large number of vacation destinations available to them (Crompton, 1992; Crompton and Ankomah, 1993). Consideration sets are most likely to be applicable 
when the purchase task is a new or modified one in which individuals typically seek information and evaluate alternatives, and when the purchase entails some degree of high risk (Spiggle and Sewall, 1987). Many choice decisions for vacation destinations are likely to meet these two criteria (Crompton, 1992). The concept postulates that there is a funnelling process involving a relatively large initial set of destinations being reduced to a smaller late set from which a final destination is selected (Ankomah et al., 1996).

Consumers are likely to consider rather a limited number of travel destinations in planning their holiday. Woodside and Sherrell (1977) developed this rationale and proposed a model of travel destination set in leisure behaviour based on Howard's (1963) concept of 'evoked set'. An evoked set is defined as 'the subset of brands that a consumer considers buying out of the sets of brands that he or she is aware of in a given product class' (Howard, 1963, p.84). The evoked set is part of the awareness set and it is a set before potential tourists reach the final destination choice. The final destination choice is a subset of the evoked set (Woodside and Sherrell, 1977). The terms 'inept set' and 'inert set' have been borrowed from Narayana and Markin (1975). Narayana and Markin (1975, p.2) define an inept set as 'those brands the consumer has rejected from his purchase consideration, either because he has had an unpleasant experience or because he has received negative feedback from other sources'. Narayana and Markins (1975, p.2) define an inert set as 'those brands the consumer has neither a positive nor a negative evaluation'.

Woodside and Sherrell (1977) apply the terms mentioned above to the tourism industry and suggest the following operational definitions for leisure travel:

- Evoked set refers to the travel destinations of which the consumer is aware and has some likelihood greater than zero of visiting within some time period.

- Inert set refers to the travel destinations of which the consumer is aware and is undecided on visiting within some time period.

- Inept set refers to the travel destinations of which the consumer is aware and has zero likelihood of visiting within some time period. 
Woodside and Lysonski (1989) propose a model explaining the destination awareness and choice. In this model, they refer to the evoked set (Woodside and Sherrell, 1977) as a consideration set. Figure 2.9 shows the General Model of Traveler Leisure Destination Awareness and Choice by Woodside and Lysonski (1989).

Figure 2.9: General Model of Traveler Leisure Destination Awareness and Choice

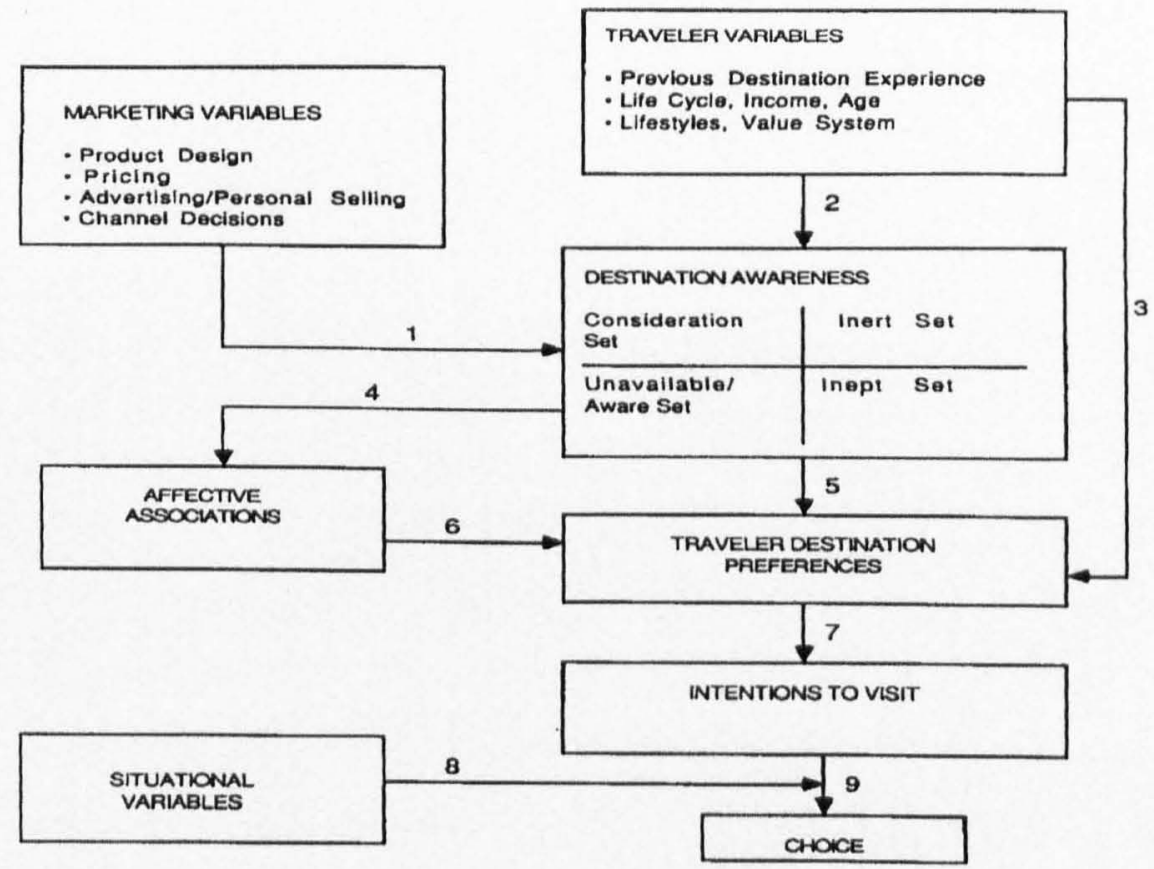

Source: Woodside and Lysonski (1989)

Figure 2.9 shows that marketing variables and previous experience can affect destination awareness which can further develop to preference and intention to visit. The term 'intention to visit' is defined as 'the traveller's perceived likelihood of visiting a specific destination within a specific time period' (Woodside and Lysonski, 1989, p.8). The study by Woodside and Lysonski (1989) partially confirmed that intention to visit is influenced by destination preference since this relationship appears to be strong for some destinations.

Um and Crompton (1990) propose a Model of the Pleasure Travel Destination Choice Process. The model shows the progression from awareness set to evoked set and a final destination choice. It identifies and integrates five processes as follows: 
(a) the formation of subjective beliefs about destination attributes in the awareness set (b) the decision to undertake a pleasure trip (c) evolution of an evoked set from an awareness set (d) the formation of subjective beliefs about the destination attributes of each alternative in the evoked set of destinations and (e) selection of a specific travel destination. The model suggests that the external input such as social interactions and travel stimuli to which one may be exposed can affect the evolution from the awareness set to the evoked set.

Goodall (1991) applies the concept of opportunity sets to the holiday destination choice. An opportunity set represents 'holidays available at a particular time' (Goodall, 1991, p.68). Information on holiday product range and holidaymaker's preferences and goals will reduce a total opportunity set to a realizable opportunity set, and with further reduction to consideration, choice and decision sets until a holiday is finally selected.

Crompton (1992) integrates the work by several authors (Nicosia, 1966; Howard and Sheth, 1969; Narayana and Markins, 1975; Brisoux and Laroche, 1980; Spiggle and Sewall, 1987) and formulates a structure of destination choice sets to tourism. These sets are shaped by both internal and external forces such as motives, previous experience, knowledge and obtained information. Crompton (1992) defines the terms as follows:

- Awareness set refers to all the destinations of which an individual may be aware at any given time.

- Early or initial consideration set refers to the destinations which a traveller is considering as possible vacation destinations within some period of time.

- Late consideration set refers to the destinations which a traveller is considering as probable destinations within some period of time.

A key conceptual differentiating element between early and late consideration sets is a period of time elapses between them that is sufficiently long to enable individuals to evaluate and reduce their list of destinations from a broad set of possible destinations to a narrower set of probable destinations (Crompton, 1992). The terms 
'awareness set', 'early or initial consideration set' and 'late consideration set' have also been used in the later studies by Crompton and Ankomah (1993) as well as Botha et al. (1999).

Botha et al. (1999) propose the positioning elements for a destination. These include personal motivations, destination attributes and situational inhibitors. Figure 2.10 illustrates The Positioning Model by Botha et al. (1999).

Figure 2.10: The Positioning Model

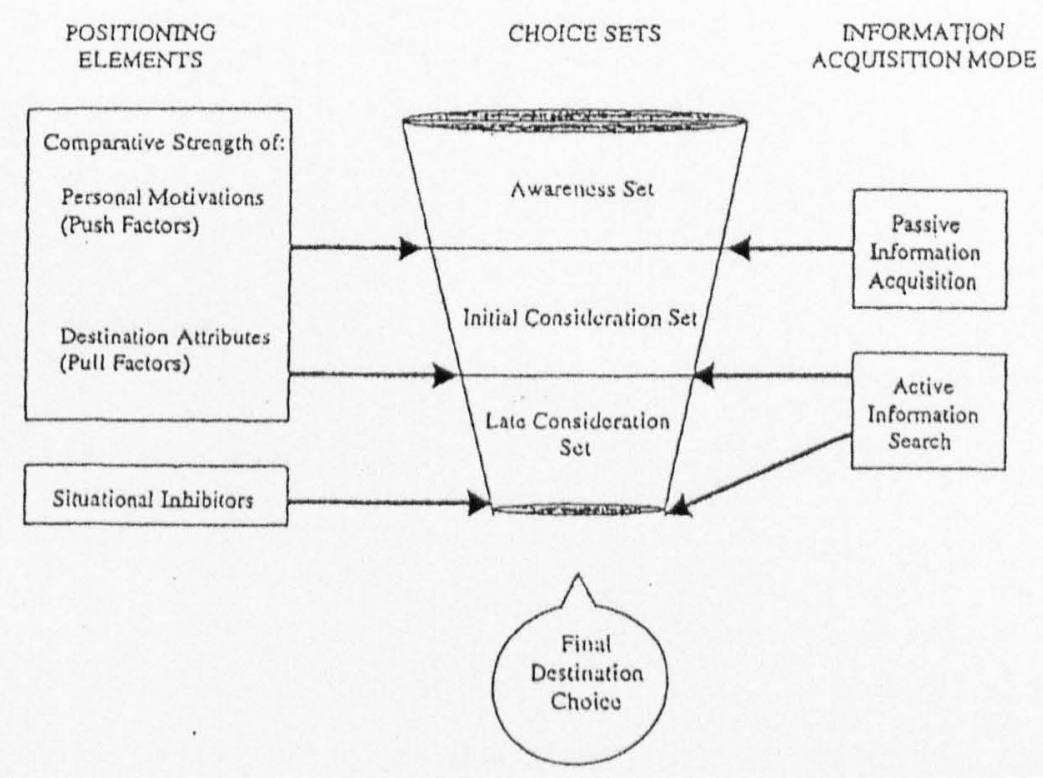

Source: Botha et al. (1999)

It can be seen from Figure 2.10 that potential visitors evaluate the destinations in the consideration sets against personal motivation (push factors), destination attributes (pull factors) and the situational inhibitors or constraints of visiting destinations. The active information search effort is directed at seeking information about important destination attributes, the ability of destination attributes to meet psychological needs of travel desire and perceived barriers to visit a destination (time, money, destination image) which lead to it being eliminated from further consideration. 
A destination possesses multiple attributes that distinguish it from other destinations such as climate, natural beauty and accessibility (Sirakaya et al., 1996). It has long been recognised in tourism literature that the perception of destination attributes or the pull factors is very crucial for the destination choice (Dann, 1977; Crompton, 1979; Gartner, 1989; Uysal and Jurowski, 1994; Mok and Armstrong, 1995). To date, there are plenty of studies on the perception of destination attributes to evaluate the attractiveness of particular destinations (Kim, 1998). Besides, the destination image is also regarded as such a critical element for destination choice that the more favourable the images of a destination, the greater the likelihood of being selected (Chon, 1990; Um, 1993). Pike (2002) reviews the previous studies on the destination image since the 1970s and reveals that there is also a wealth of studies on the destination image. Most of the destination image studies focus on the perception of a particular destination and target visitors at the destination (Pike, 2002). There is very limited attention paid to the effects of destination image or destination attributes on the actual destination choice process (Oppermann, 2000). In fact, destination choice should be studied at the pre-purchase stage rather than at the destinations themselves. Moreover, the linkage between previous visits and destination choice has hardly been investigated (Oppermann, 2000).

Having reviewed the literature on the destination choice process, it is observed that there seems to be no agreement on terms, operational definitions and consideration set size. This study summarises the inconsistency of the three aspects in this area. The first inconsistency is the terms used in the destination choice process. Table 2.2 summarises the terms used by various researchers on the destination choice. 
Table 2.2: Terms Used in Destination Choice Process

\begin{tabular}{|c|c|}
\hline Destination choice process & Authors \\
\hline Awareness set - evoked set - choice & $\begin{array}{c}\text { Woodside and Sherrell (1977), } \\
\text { Woodside and Ronkainen (1980), } \\
\text { Um and Crompton (1990) }\end{array}$ \\
\hline Awareness set - consideration set -choice & Woodside and Lysonski (1989) \\
\hline $\begin{array}{c}\text { Opportunity set - consideration set - } \\
\text { choice set - decision set - choice }\end{array}$ & Goodall (1991) \\
\hline $\begin{array}{c}\text { Awareness set - initial consideration set - } \\
\text { late consideration set - action set - } \\
\text { interaction set - choice }\end{array}$ & Crompton (1992) \\
\hline $\begin{array}{c}\text { Awareness set - early consideration set - } \\
\text { late consideration set - action set - } \\
\text { choice }\end{array}$ & Crompton and Ankomah (1993) \\
\hline $\begin{array}{c}\text { Awareness set - initial consideration set - } \\
\text { late consideration set-choice }\end{array}$ & Botha et al. (1999) \\
\hline
\end{tabular}

Although there are various terms referring to the development of destination choice as shown in Table 2.2, central to all of these models is the concept of consideration sets, which offers a conceptualisation of how potential tourists narrow down the number of destinations considered to reach a final choice (Botha et al., 1999). There appears to be an agreement among tourism researchers that destination selection goes through three major stages: (a) an early consideration set or an awareness set (b) a late consideration set or an evoked set and (c) a final destination choice (Crompton and Ankomah, 1993).

The second inconsistency is the operational definitions of consideration sets. This inconsistency makes the comparison of results difficult (Crompton, 1992). Concerning this issue, Crompton (1992) suggests that consideration sets can be operationalised by using an open-ended question format since the number of alternatives individuals consider are relatively small. Closed list format alternatives are appropriate in situations where a particular destination has a clearly defined set of known destinations in competition with it. A destination can be assessed on how it is positioned relative to competitors in potential tourists' mind, by presenting respondents with the defined list of alternatives and asking them to assign the alternatives to consideration sets on the basis of the operational definitions offered. 
The third inconsistency is the empirical findings of the evoked set or late consideration set size of holiday destinations. There are several consideration set sizes: 2.3 (Pu, 2000), 2.7 (Thompson and Cooper, 1979), 3.4 (Woodside and Sherrell, 1977), 3.52 (Woodside and Ronkainen, 1980), 3.54 (Botha et al., 1999), 4.2 (Woodside and Lysonski, 1989), 5.2 (Gilbert, 1992). Due to these inconsistent findings, Crompton et al. (1998) conclude that the average number of destinations that an individual will seriously consider will not exceed four.

It is clearly shown that the influence of travel stimuli has been widely recognised not only among tourism researchers whose interests are in the tourist decision-making process (Schmoll, 1977; Mathieson and Wall, 1982; Moutinho, 1987; Middleton, 1994; Chen, 1998) but also among those whose interests are particularly in the destination choice process (Woodside and Sherrell, 1977; Woodside and Lysonski, 1989; Um and Crompton, 1990). Despite the potential effects of the travel stimuli addressed by several tourism researchers, Crompton and Ankomah (1993) claim that if a destination is not in an individual's early consideration set, then it has no chance of being selected. To date, there seems to be no empirical studies to verify this claim.

Many studies have traditionally focused on destination choice alone and have ignored the possible effects of other choices. An obvious example is package holidays which comprise destination and other package attributes. Others, however, have explained that many travel decisions are not single independent choices of separate elements such as destination, accommodation or transportation but rather are a complex set of multi-faceted decisions in which the choices for different elements are interrelated (Dellaert et al., 1998). Burkart (1984) further supports the view that package holidays are a product that is destination indifferent and that destination is no longer a prime factor in the choice of a holiday. Studies on destination choice alone are, therefore, considered as limited and may be misleading if destination choice is related to the choice of other components of the package (Dellaert et al., 1997). In fact, a destination choice is a compromise decision of related elements (Swarbrooke and Horner, 1999). 
Leisure travellers are likely to have a positive evaluation of destinations in their evoked sets (Woodside and Sherrell, 1977; Woodside and Ronkainen, 1980). The use of package holidays may move destinations in one's inert set to the evoked set (Woodside and Sherrell, 1977). Although they associate each destination with a particular set of benefits, they may be willing to substitute one benefit-destination combination with a competing benefit-destination package (Woodside and Carr, 1988). For example, a traveller may think of going to Malaysia when asked directly and may not consider Thailand at all. However, when they are presented with the information about available package holidays to Thailand, the same person may end up choosing Thailand after all.

In most destination choice models, the linearity of progression from awareness set to final destination choice assumes that situational factors remain reasonably constant during the decision-making process although the external environment is dynamic. In reality, there will be occasions when linear progression is disrupted, such as in an example given above, causing previous choice set decisions to be reviewed and perhaps revised in response to a new situational variable (Crompton, 1992).

This section has reviewed the literature on the destination choice process and has revealed that tourism researchers neglected the fact that purchasing a holiday is actually a complex decision comprising destination and other sub-decisions. Although it has been widely acknowledged that travel stimuli can influence the destination choice process, there seems to be a lack of empirical evidence on such effects. Studies relating to the effects of travel stimuli are therefore very crucial in advancing the theories of destination choice. The next section reviews the previous work on the consideration sets.

\subsection{Consideration}

Consideration is a key element in consumer choice and has attracted increasing attention from both academics and managers. In many product categories, leading brands derive large market share by entering the consideration sets of more 
consumers than do their competitors (Roberts and Lattin, 1991). Tourism products are no exception to this. Some popular holiday destinations are receiving large market share while other less-preferred destinations are making efforts to reduce the market share of these popular destinations.

A consideration set is sometimes referred to as an evoked set (Roberts and Lattin, 1991). Howard (1963) first introduces the concept of an evoked set and this concept is further elaborated by Howard and Sheth $(1969$, p.98) who define the concept of the evoked set as 'brands that the buyer considers acceptable for his next purchase'. Since then, the term 'evoked set' has been used with several different meanings from 'brands the consumer would consider' to 'brands acceptable to the consumer'.

Brown and Wildt (1992) review the previous work on evoked set and reveal that there is no consistently used or commonly accepted conceptual definition for operational method. They summarise various conceptual definitions of evoked set as follows:

- brands which are acceptable for purchase (Belonax, 1979)

- brands which the subject considers buying (Narayana and Markin, 1975)

- brands which the subject would consider if faced with an immediate purchase decision (Klenosky and Rethans, 1988)

- brands which the subject would consider for a specified consumption situation (Brisoux and Laroche, 1980)

- brands which the subject would buy if buying today, and other brands the subject is willing to buy if the first choice is not available (Church et al., 1985)

Wright and Barbour (1977), on the other hand, introduce the term 'consideration set' to refer to the evoked set. Consideration set is defined as 'the set of brands brought to mind on a particular choice occasion' (Nedungadi, 1990, p.264). Roberts and Lattin (1991, p.430) define a consideration set as the brands that a consumer would consider buying in the near future. A consideration set is purposely introduced as consisting of goal-satisfying alternatives, which are accessible at a particular situation. Although there are many alternatives that one may be aware of, there are 
only a few alternatives that come to mind (Shocker et al., 1991). Consideration is therefore related to the retrieval process from the memory (Nedungadi, 1990). Previous research focusing on choice modelling (e.g. Roberts, 1989; Hauser and Wernerfelt, 1990) usually labels the 'consideration set' as specifying the relevant pool of brands from which the eventual choice is made. These applications often assume a multi-stage process, where the final stage consists of selecting the chosen brand from the consideration set (Brown and Wildt, 1992).

Roberts and Nedungadi (1995) reviewed studies on consideration and classified them into three perspectives. The first is the cost-benefit approach (e.g. Hauser and Wernerfelt, 1990) which is based on the notion that consumers weigh the cost of evaluating alternatives in the consideration set against the benefits of adding other alternatives. Although there is a chance that the consideration set will evolve, the cost involved will keep the consideration set unchanged. The second is the learning theory approach (e.g. Howard and Sheth, 1969) where consumers learn to include alternatives in the consideration set through repeated exposure and purchase. The third is the information processing theory approach (e.g. Nedungadi, 1990). This approach focuses on the processes by which the consideration is formed and used by the consumer for subsequent purchase operation. The emphasis is on the factors that determine the inclusion in consideration set and choice. In this approach, consumers are not viewed as having a stable consideration set to carry on from one purchase to the next, but rather the context facilitates access and leads to the consideration. Factors that can influence the consideration formation are therefore of great importance.

In line with the information processing theory approach, Shocker et al. (1991) propose a model to explain an individual choice and comment that consideration formation is actually a dynamic process. Their model suggests that the alternatives may be recalled and additional alternatives may be encountered during the process itself. Figure 2.11 shows A Model of Individual Choice. 
Figure 2.11: A Model of Individual Choice

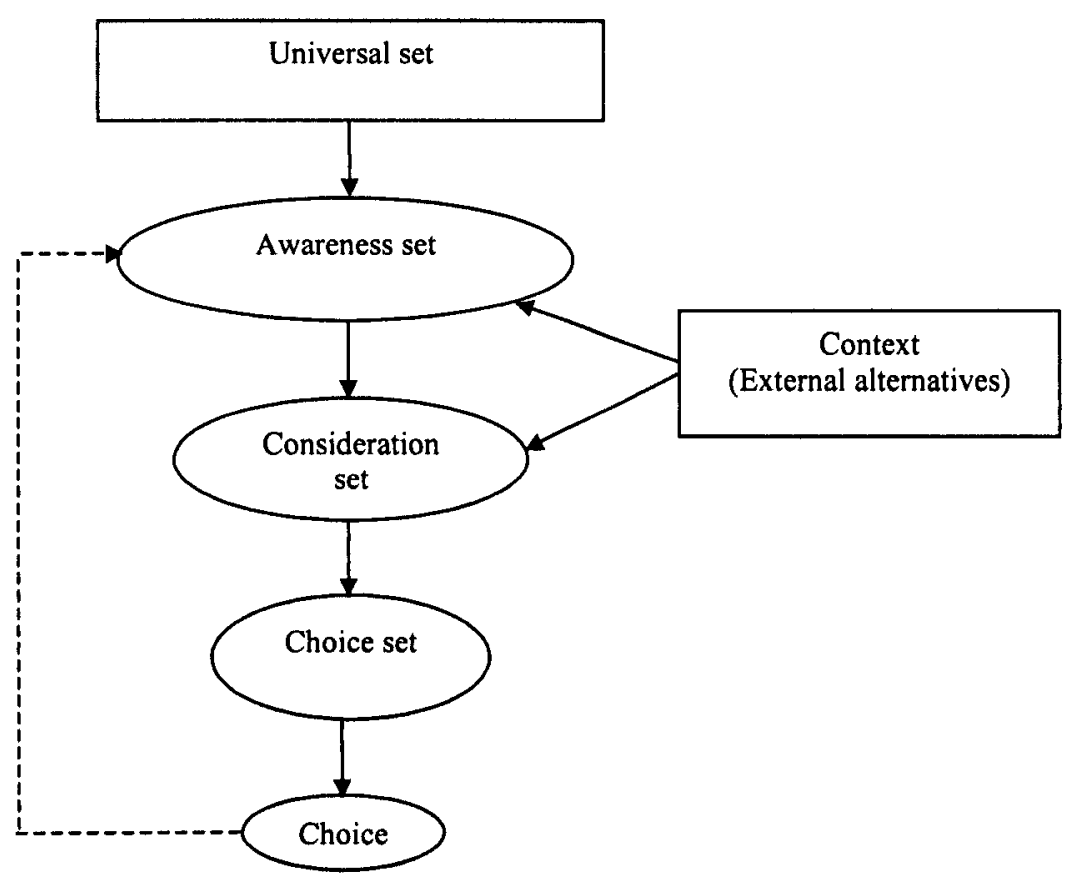

Source: Shocker et al. (1991)

The universal set in the model shown in Figure 2.11 is defined as the totality of alternatives that could be obtained or purchased (Shocker et al., 1991). Due to the dynamic nature of consideration set formation, Shocker and colleagues (1991) refer to the term 'choice set' as the final consideration set, that is, the set of alternatives considered immediately prior to choice. They suggest that the meaning of evoked set is the closest to that of the choice set. However, some authors do not distinguish between consideration set and choice set but use the term 'consideration set' for both constructs. The process of reducing from a big set to a small set does not imply sequencing since it can occur simultaneously (Shocker et al., 1991). The consumers process their options by adding and deleting as necessary. The feedback (dotted line) suggests that experience can also affect those alternatives considered and those chosen at a later time.

Consideration has been traditionally thought of as being a relatively static construct (Alba et al., 1991). Consumers are assumed to store a set of acceptable alternatives on each shopping occasion (Mitra, 1995). Roberts and Nedungadi (1995) comment that the present understanding of consideration sets is still imperfect. Most choice 
decisions are dynamic and consideration set formation is a dynamic process that may evolve until consumers decide to make a final choice (Roberts, 1989; Shocker et al., 1991; Mitra, 1995; Roberts and Nedungadi, 1995).

There is a stream of research on consumer decisions using stimulus-based task environments where all relevant choice alternatives are available and there is an emphasis on the role of memory-based choice (Lynch and Srull, 1982). Nedungadi (1990) suggests that the influence of memory should not be confined to the given information but should extend to the retrieval of the alternatives. He emphasises that retrieval plays an important role in many situations such as when alternatives are not present or when consumers know what they are looking for. When consumers retrieve alternatives from their memory, comparison sets are also determined. Whenever the consideration set alternatives are no longer attractive, external available alternatives will have chances of receiving serious attention. At any point in time, the consumers can consider a number of alternatives which may enter and leave the set until the consumer decides to make a final choice (Shocker et al., 1991; Roberts and Nedungadi, 1995).

Consideration sets are not fixed and can change across choice occasions (Nedungadi, 1990). Previous research has provided evidence to support this statement. Klenosky and Rethans (1988) conducted a longitudinal study of consideration set formation in a gift giving context. The results reveal that the consideration set formation is a dynamic process. Some alternatives remain in the consideration over time while other alternatives can be dropped from or added to the consideration as it develops. A study by Hulland (1992) suggests that variability of accessibility of prior information and number of previous choices affect the composition of consideration. There are two implications from this study. First, early entrant alternatives can be successful if they can be sustained in consumers' consideration. Second, consumers are unwilling to consider rejected alternatives and therefore there is only one chance of an alternative being included in a consideration set. This suggests that once the brand is rejected, it is difficult to gain entry again. Mitra (1995) studied the effects of advertising on the stability of consideration sets over multiple purchase occasions 
and the results also provide evidence that consideration sets are dynamic. The findings reveal that consumers do not consider the same alternatives on all choice occasions. Mitra suggests that factors that would increase the chances of being included in the consideration set are extremely important. In other words, these factors can be powerful in disrupting the decision-making process and they may add new alternatives to the consideration. The findings of Sivakumaran and Kannan (2002) further suggest that variety seekers tend to have dynamic consideration sets. In the tourism arena, choosing a holiday destination can be viewed under variety seeking conditions where tourists may want to visit different places. Although these studies have provided a further understanding of consideration, Roberts and Nedungadi (1995) assert that there is still very little work on the nature of consideration sets.

In unfamiliar choice situations, consideration sets are more likely to be unstable over time. The composition of the consideration set is likely to change as the consumers learn more about alternatives that might be relevant to the particular situations. Even in highly familiar choice situations, the contents of the consideration set will vary between different purchase situations (Klenosky and Rethans, 1988). These unstable conditions of the consideration sets across occasions would depend upon the external factors that are present at the time of decision-making and individual factors (Klenosky and Rethans, 1988; Shocker et al., 1991; Brown and Wildt, 1992; Mitra, 1995). The extent to which the different elements are put together including available alternatives, package information and information format can activate the retrieval process and affect the consideration formation (Bettman and Park, 1980; Nedungadi, 1990).

Tourism marketing is a new area and most theories applied to it have been directly borrowed from the marketing of goods. Having reviewed the previous studies regarding the consideration, this provides the evidence that the present understanding of the destination choice process needs to be further developed. Although previous research suggests that the consideration sets are dynamic, there is very little work in 
marketing to examine such an issue (Roberts and Nedungadi, 1995). This lack of research seems to be relatively obvious in tourism.

Roberts and Lattin (1997) reviewed the previous studies on consideration and recommended that there are still many aspects that should be researched in order to gain insight into the consideration sets. Such insights into this area would be very useful for theoretical development related to tourist decision-making and implications for the tourism industry.

\subsection{Conclusion}

This chapter has reviewed the previous work on the tourist decision-making process, destination choice process and consideration. It has provided four main implications for the conceptual underpinning of the present study. First, many tourism researchers acknowledge the fact that travel stimuli can affect the tourist decision and destination choice but the there is a lack of empirical evidence to support such effects.

Second, previous studies focus mainly on how tourists select a destination choice from a set of alternatives. Although such studies are very useful, the present study argues that studies focusing on destination choice alone do not explain the real tourist decisions. Destination should not be studied separately from other elements since tourism is in fact a complementary product where destination is often bundled with accommodation and transportation. An example of such bundles is package holidays.

Third, there appears to be a limited understanding on the tourist decisions relating to the purchase of package holidays. In such a context, destination is assumed to be a less powerful factor since a tourist decision may be a compromise of other related elements in the package holidays (Burkart, 1984; Swarbrooke and Horner 1999). To date, there seems to be very little attention paid to whether and how the packaging 
can reduce the importance of destination. Such a decrease is very useful to market less-preferred destinations.

Fourth, there are three contrasting views on the timing of exposure to alternatives in determining the consideration sets. First, the consideration sets are viewed as stable and the exposure to alternatives should be as early as possible (Crompton and Ankomah, 1993). Second, the consideration sets are viewed as unstable and the exposure to alternatives can add them to the consideration sets at any point in time (Shocker et al., 1991; Roberts and Nedungadi, 1995). Third, the consideration sets are unstable but the exposure to alternatives should be as close to a time of choice as possible (Hulland, 1992). To date, there seems to be no studies testing a widely held assumption in tourism by Crompton and Ankomah (1993). Moreover, little is known on the effective timing of exposure to less-preferred destinations to help them become a final choice. Such findings will provide an empirical evidence for the theoretical advancement of tourist decision making.

The next chapter reviews the previous work regarding the package information presentation, the stimuli of the study. The chapter reviews the previous studies on bundling and highlights the significance of tourism research on bundling. It further suggests the factors relating to the information presentation. 


\section{Chapter Three \\ Package Information Presentation}

\subsection{Introduction}

Bundling has become a very common phenomenon in the market place. Manufacturers and retailers routinely offer a single unit of multiple products or multiple units of the same product for one bundled price (Soman and Gourville, 2001). An example of bundling in the tourism industry is package holidays, which include airfares and hotels in a single price tag. Package holidays have been a significant component of the travel business (Sheldon and Mak, 1987) and have played a major part in the growth of the tourism industry (Burkart, 1984).

A number of previous studies have focused on how bundling affects consumer evaluation (e.g. Yadav and Monroe, 1993; Yadav, 1994; Simonin and Ruth, 1995; Harris, 1997; Naylor and Frank, 2001) or consumption behaviour (e.g. Soman and Gourville, 2001) or shopping behaviour (e.g. Oppewal and Holyoake, in press). In view of the extent to which bundling strategies have been employed in today's market, there is surprisingly little research on information presentation strategies for bundles (e.g. Harlam et al., 1995; Johnson et al., 1999; Munger and Grewal, 2001). Consumer responses to the information presentation issues indeed add a potentially important dimension to bundling research (Johnson et al., 1999). 
This chapter reviews the previous work on bundling and information presentation strategies with two purposes. The first purpose is to pinpoint the importance of consumer research on bundling, particularly, in the tourism industry. The second purpose is to propose how information presentation can enhance bundling strategies. Therefore, this chapter is divided into four main sections; namely bundling, completeness of information, information format and mere exposure. The chapter ends with a conclusion section.

\subsection{Bundling}

The practice of bundling is prevalent in the market in one form or another. The variety of bundling strategies appears to be endless (Strahilevitz, 1995). Examples are package holidays (transportation and hotels sold as a bundle), value meals in fast food restaurants (burger, fries and soft drink sold as a bundle) and sport or theatre season tickets (tickets to various events sold as a bundle). Within the tourism industry, bundling is a common strategy whereby transportation and lodging are combined. Considering the nature of tourism products which tends to be perishable and under-utilised, bundling as a marketing strategy can benefit the tourism suppliers involved (Middleton and Clarke, 2001; Naylor and Frank, 2001). From the consumers' perspective, bundling also benefits them through the reduction of transaction costs, information search and the convenience of buying complementary products in a single package (Paroush and Peles, 1981; Johnson et al., 1999; Middleton and Clarke, 2001).

The concept of consideration sets as discussed in Chapter 2 can be expanded through marketing strategies such as bundling. One item in the bundle may be one already in an individual's consideration set, but other items in the bundle often are not. Consumers may evaluate the worth of a product differently when it is in a bundle from when it is not. Linking two or more items together is likely to influence the context in which consumers evaluate those items because it will literally force the consumer to evaluate them in the context of one another (Harris, 1997). In line with this argument, this study argues that bundling may assist less-preferred destinations 
to enter the consideration sets if presented in such a way as to influence the consumer evaluation.

Previous studies of bundling originate from an economics perspective (see Adams and Yellen, 1976; Paroush and Peles, 1981; Schmalensee, 1984; Hanson and Martin, 1990; Mulhern and Leone, 1991). Economic research focuses on when and why price bundling is a revenue maximising or profit-maximising strategy (Soman and Gourville, 2001). Consumer research pays attention to how bundling affects consumer perception and evaluation (Yadav and Monroe, 1993; Yadav, 1994). Considering the widespread use of bundling in the market, consumer research on bundling has appeared only recently (Yadav and Monroe, 1993). Since this study examines bundling as a marketing strategy to promote less-preferred destinations to the consumers, the focus is particularly on consumer evaluation perspective rather than economics perspective.

This section on bundling is divided into three parts. The first part provides a definition of bundling. The second part reviews previous consumer research on bundling. The final part examines the tourism research on bundling.

\subsubsection{Definition of Bundling}

The term 'bundling' has evolved over the years. A tie-in sale (Burstein, 1960) is the oldest concept of bundling. In a tie-in sale, a durable product (tying good) is combined with different complementary products (tied goods) and the buyer must accept the whole offer. Block booking (Stigler, 1968) is also a classic example of bundling. The concept was used in connection with a selling arrangement where a film producer only sell its films together with other films so that it can use the popular films to increase the sales of the unsuccessful ones.

Several authors have attempted to define the term 'bundling'. Adams and Yellen (1976, p.475) define bundling as 'the practice of package selling'. Guiltinan (1987, p.74) defines bundling as 'the marketing strategy of two or more products and/or services in a single package for a special price'. Yadav and Monroe (1993, p.350) 
refer to bundling as 'the selling of two or more products and/or services at a single price'. Recently, Stremersch and Tellis (2002, p.56) define the term as 'the sale of two or more separate products in one package'. With this new definition, they clarify that in some bundling circumstances, buyers are able to buy the products separately.

Stremersch and Tellis (2002) criticise the fact that the terms price bundling and product bundling have been used interchangeably. They believe that the two terms are different. Stremersch and Tellis (2002, p.56) define price bundling as 'the sale of two or more separate products in a package at a discount without any integration of the products'. In this case, bundling does not create added value. Instead, the discount is the factor that motivates consumers to buy a bundle. Stremersch and Tellis (2002, p.57) define product bundling as 'the integration and sale of two or more separate products or services at any price'. Whereas price bundling is a pricing and promotional tool, product bundling is more strategic in the sense that it creates added value. Another difference is that price bundling can be done easily while product bundling requires a long-term plan. This study observes particularly price bundling as a promotional tool.

There are three main forms of bundling. Pure bundling refers to the products or services available only in package form' (Adams and Yellen, 1976). An example of pure bundling is a computer and software. Mixed bundling refers to the products or services available individually as well as a package (Adams and Yellen, 1976). An example of mixed bundling is value meals offered in fast food restaurants. Besides bundling, there is another situation, which is called 'pure components' (Schmalensee, 1984). This situation is called 'unbundling' and is defined as 'a strategy in which a firm sells only the products separately, but not the bundle' (Stremersch and Tellis, 2002, p.57). The focus of this study is on the mixed bundling context.

Stremersch and Tellis (2002) identify two key dimensions of bundling: (a) the focus of bundling, whether on price or product and (b) the form of bundling, whether pure or mixed. Figure 3.1 shows the classification of bundling strategies. 
Table 3.1: A Classification of Bundling Strategies

\begin{tabular}{|c|c|c|}
\hline Form/Focus & Price & Product \\
\hline Unbundling & \multicolumn{2}{|c|}{$\mathrm{X}$} \\
& & $\mathrm{Y}$ \\
\hline Pure bundling & $(\mathrm{X}, \mathrm{Y})$ & $(\mathrm{X} \oplus \mathrm{Y})$ \\
\hline & $(\mathrm{X}, \mathrm{Y})$ & $(\mathrm{X} \oplus \mathrm{Y})$ \\
Mixed & $\mathrm{X}$ & $\mathrm{X}$ \\
bundling & $\mathrm{Y}$ & $\mathrm{Y}$ \\
\hline
\end{tabular}

Source: Stremersch and Tellis (2002)

The focus of bundling is along the horizontal axis, that is, on either price or product. The form of bundling is along the vertical axis, that is unbundling, pure or mixed. Two products namely, $X$ and $Y$ are included in Figure 3.1. Combinations of $X$ and $\mathrm{Y}$ represent the terms of the sale. Thus $(\mathrm{X}, \mathrm{Y})$ represents the sale of the price bundle, $(\mathrm{X} \oplus \mathrm{Y})$ represents the sale of a product bundle, $\mathrm{X}$ and $\mathrm{Y}$ without parentheses represent the sale of separate products.

\subsubsection{Consumer Research on Bundling}

Studies on consumer evaluation of bundling have recently attracted attention (Yadav and Monroe, 1993; Harlam et al., 1995; Suri and Monroe, 1995). Yadav and Monroe (1993) comment that this research stream is limited for two main reasons. First, there is an inadequate attention to individual buyer behaviour. Second, the analytical framework has been subjected to little empirical verification. The aim of this part is to review the previous work on consumer evaluation of bundling and to illustrate how the present study aims to fill the gap in this particular area.

To date, there are several studies examining the potential effects of bundling on consumers' evaluations and perceptions. An early work in this area is a study by Yadav and Monroe (1993) on mixed bundling scenarios to examine the perceptions of overall savings when evaluating the bundle versus individual items in a situation when price reductions are offered to both conditions. The results of their study indicate that additional savings offered on the bundle have a greater impact on a buyer's evaluation than savings offered on individual items. This study shows that consumers are willing to buy more if they perceive additional savings. 
The study by Herrmann et al. (1997) reveals that bundles composed of complementary products result in greater purchase intention than bundles of moderately related or unrelated products. Their study suggests that bundling works best in complementary goods. Harris (1997) studied the effects of promotional bundling on consumers' evaluations of product quality and risk purchase. The results suggest for a new product that the bundling of that product with an established product will increase perceived product quality and decrease perceived risks relating to that new product among buyers of the established product. Mixed bundling is a strategy which can increase the demand for the bundle when the prices of individual items are high. The study by Schwartz and Cohen (1999), for example, shows that mixed bundling used in fast food restaurants in a form of value meals induces higher willingness to pay for the bundles.

Yadav (1994) focuses on the mechanism that consumers use for bundle evaluation and proposes three stages for the anchoring and adjusting model of bundle evaluation: scanning, anchor selection, and anchoring and adjusting. Figure 3.1 illustrates Yadav's (1994) model.

Figure 3.1: Anchoring and Adjustment Model of Bundle Evaluation

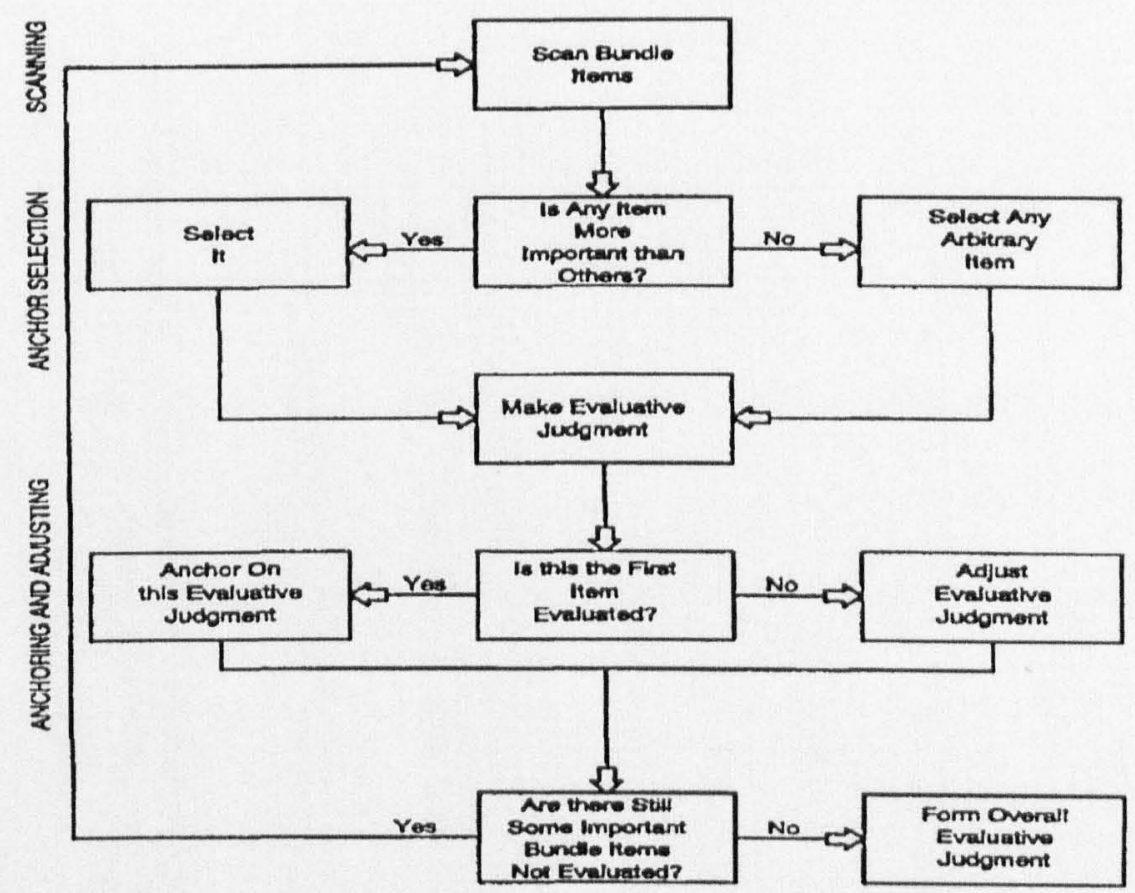

Source: Yadav (1994) 
Yadav's (1994) findings reveal that the consumers anchor on the most important item in a bundle and adjust their evaluations of the remaining bundle items in decreasing order of their perceived importance. Based on the concept of anchoring and adjustment process, the consumer judgement of bundles may be biased towards the evaluation of the first bundle item presented to them and may deflect them from making a rational decision (Estelami, 1999). This indicates that consumer evaluation can be influenced by the way the information of the bundle is presented.

Previous studies of bundling have given guidelines on how bundling can influence consumer evaluation and how consumers evaluate bundles. However, there is very little attention focusing on how to efficiently present the bundle information to influence choice. Information presentation variables are regarded as important factors for decision-making. To reflect the consumer choice accurately, such variables should be taken into account (Allenby and Ginter, 1995). A lack of research into this dimension in fact limits the optimum use of bundling strategies (Johnson et al., 1999).

One of the studies on the information presentation of bundles is by Harlam et al. (1995). Their findings suggest that different presentation formats for describing the price of bundles influence purchase intention. Johnson et al. (1999) examine presentation of price information of bundles based on mental accounting principles. Thaler (1985) describes mental accounting by which gains will have their maximum effect when accounted for separately, but perceived losses may be minimised by lumping them together. The findings of Johnson et al. (1999) show that bundling of price information and unbundling price discount information increases positive consumer evaluation. Munger and Grewal (2001) study the promotional discount format (rebate, conventional discount, free options) of bundling. Their results suggest that different formats for promoting bundling affect consumer evaluation.

Recent research efforts have highlighted the need for a more comprehensive understanding of consumer evaluation of bundle offers. What is currently known about the evaluation of bundle offers is very limited (Yadav, 1994). Studies focusing 
on the consumer perceptions of bundles are so rich with phenomena that further research promises to be fruitful (Stremersch and Tellis, 2002). As highlighted in this study, there is still a lack of research on the effects of information presentation relating to bundle. This area of research is extremely significant for the advancement in bundling literature and a much more powerful bundling strategy.

\subsubsection{Tourism Research on Bundling}

The tourism industry employs a mixed bundling strategy. There are two levels of tourism products: package holidays and stand-alone products (Swarbrooke and Horner, 1999). Examples of stand-alone products are air ticket, hotel rooms or a theme park visit. Package holidays constitute a form of bundling and are an important component of the travel business. A package holiday is 'a combination of many components of a vacation such as transportation, accommodation, sightseeing and meals which are sold to consumers at a single price' (Sheldon and Mak, 1987, p.13). Airlines and hotels often combine several services into a package as a reduced price vacation to a destination (Bojanic and Calantone, 1990). Burkart (1984) views package holidays as a new kind of tourism product in which the destination is combined with other components.

Package holidays covered by UK regulations are defined as 'the pre-arranged combination of at least two of the followings: transport, accommodation and other tourist services, when sold or offered for sale at an inclusive price and when the service covers a period of more than twenty-four hours or includes overnight accommodation' (Grant and Mason, 1994, p.3). Package holidays vary according to their inclusiveness. Of all the different types of package holidays, the simplest is the basic package holiday, which typically includes transportation and accommodation only. Inclusive package holidays also offer some sightseeing and entertainment at the destination. All-inclusive package holidays include meals and sometimes are escorted (Sheldon and Mak, 1987).

Package holidays deliver price advantage to the consumers since the price of a package is usually lower than it would be if the items were purchased separately 
(Schwartz and Cohen, 1999; Middleton and Clarke, 2001). In most cases, consumers do not know the prices of the individual components because they purchase the entire package either from a travel agent who is a retailer of vacation products or from a tour operator who creates the package holidays and publishes them in the brochure. The key advantages of purchasing package holidays as opposed to purchasing separate elements are price, ease of purchase and availability through the high street or shopping centres (Sheldon and Mak, 1987; Laws, 1997). Package holidays are a means to minimise holiday decision-making efforts. Buying bundles reduces nonprice costs such as time and waiting and this results in a higher perception of value (Naylor and Frank, 2001).

Previous tourism studies on bundling have focused on the economic perspective (e.g. Kinberg and Sudit, 1979; Taylor, 1998). Very few tourism studies have given attention to the effects of bundling on consumer evaluation. Bojanic and Calantone (1990) studied the use of price bundling in recreation services with a conjoint analysis method to determine the importance of various service attributes. The results show that price is the most important attribute in the service bundles. Josiam and Hobson (1995) focus on the effect of decoy package holidays, high price and low value products. Their results suggest that decoy effects can shift some consumer preferences to higher priced package holidays. Naylor and Frank (2001) examined how an all-inclusive price bundle (airport transfer, meals, lodging and beauty, exercise and pampering service) at an upscale spa resort affected consumer perception of value. The findings suggest that price bundle, even if actual monetary outlay is higher, increases perception of value for first-time holidaymakers. Although these studies have brought the effects of bundling to the attention of tourism researchers, tourism studies relating to this stream is still very limited, especially with regard to the presentation of bundle information.

This section has provided the definition of bundling and has highlighted the significance of consumer research on bundling particularly in the tourism industry. It has raised an issue that the studies relating to the presentation of bundle information is lacking. Given that the practice of bundling in the form of package holidays is 
widespread, the way these package holidays are presented is very crucial for successful destination marketing. This study aims particularly at the presentation of package holiday information which incorporates three factors: the completeness of information, the information format and the mere exposure. The next section will first describe the potential effects that the amount of information presented has on the consumer decisions.

\subsection{Completeness of Information}

The first factor involved in the presentation of information for package holidays is the amount of information provided. With the rise of new distribution channels such as the Internet, marketers have great control over the provision of information and can decide how much information to provide for consumers. Consumers, on the other hand, increasingly face the situation of information overload and they are unlikely to process all available information (Kivetz and Simonson, 2000). The effects that the amount of information presented have on consumers' decisions are very crucial for the product's success and it is necessary to investigate this issue in order to make an accurate prediction of consumer choice (Johnson and Levin, 1985).

In today's market, products presented in store or on the Internet are seldom fully described and this situation is referred to as 'missing information'. Missing information is defined as 'values for one or more attributes considered relevant for the decision task that are not available for one or more alternatives in the choice set' (Burke, 1995, p.224). Missing value is a source of uncertainty since the actual value may be unattractive (Meyer, 1981). A study by Johnson and Levin (1985) suggests that the greater the amount of missing information, the less favourable the evaluation. The findings of Kivetz and Simonson (2000) further show that missing information can affect preference, especially for inferior products, in such a way that missing information is used as a reason to reject these options. Missing information however does not show an effect on superior products. 
Another line of argument is that it is not often the case that consumers may wish to have a complete set of information (Bettman et al., 1998). Several studies focus on the processing strategies that consumers use in forming inferences about missing information (e.g. Ford and Smith, 1987; Burke, 1990; Dick et al., 1990; Chernev and Carpenter, 2001). Some researchers (Johnson and Levin, 1985; Huber and McCann, 1982) confirm that consumers infer values for missing information and then use those inferences in the evaluation process. Other researchers find little evidence of such inference (e.g. Simmons and Lynch, 1991; Sirdeshmukh and Unnava, 1992). The findings of Burke (1995) show that choice processing in the situations where there is missing information is different from those where full information is given. However, consumers do not always form inferences when faced with missing attributes. When they do, their results show that the choice processing is similar to that where the full information is given.

Some studies of missing information focus on the role of consumer expertise on inference. For example, Kardes et al. (1990) focus on the ability of consumers to detect the absence of information about product attributes. Their results indicate that novices and moderately knowledgeable individuals tend to overlook important missing information. Experts, on the other hand, can detect the absence of the important information. As argued by Alba and Hutchinson (1987), consumers with high product knowledge are able to fill gaps in presented products by recalling product information from memory. These results show that the ability to detect the missing information increases as the expertise increases.

The study by Ford and Smith (1987) raises a methodological concern for the previous studies on inference processing strategies. The method of asking the subjects to indicate the value for the missing attribute and then ask them to evaluate the product is questioned in that it may place a great emphasis on the inference making. Such a method would force subjects to make inferences that they may not make otherwise (Sirdeshmukh and Unnava, 1992). This is supported by their findings that missing information does not affect evaluation when consumers are not explicitly informed that the information is missing. 
Although previous studies provide important insights into how consumers treat and process missing information, a key question which has not yet been answered is whether providing detail of package information (e.g. accommodation or number of nights) can reduce the importance of destination and thus influence a choice of destinations. Such an outcome could be very helpful for less-preferred destinations. To date, there is still very limited understanding of the effects of the amount of information presented on the consumer choice (Kivetz and Simonson, 2000).

This study aims to extend the existing work of the potential effects that the amount of presented information has on consumer evaluation, with an awareness of a debate on a methodological issue. It therefore attempts to examine such effects without explicitly making the subjects aware of the situations. The focus is on the extent to which the amount of information presented has an effect on consumer responses to less-preferred destinations. This study aims to test two ways of presenting the information of package holidays. The first situation is where the detailed information about package holidays is provided by means of presenting the destination name along with other attributes such as quality of accommodation and number of nights. The second situation is where the information is missing by means of presenting the name of destination only. Based on the previous studies (Johnson and Levin, 1985; Kivetz and Simonson, 2000), it is expected that the situation with missing information will harm less-preferred destinations. Presenting detailed package information, on the other hand, can turn consumers' attention to other package attributes. Such attributes may help reducing the destination importance and as a result influence the choice of destinations.

This section has explained the potential effects of the amount of information presented. The next section outlines the second factor relating to the presentation of information for package holidays, the information format. 


\subsection{Information Format}

A second factor relating to the presentation of information for package holidays is the information format. The term 'information format' refers to 'the presentation and organisation of information about the available alternatives and their attributes' (Cooper-Martin, 1993, p.240). The information format affects the way consumers acquire and process information and the consumers will process information in ways which are congruent with the format in which it is presented (Bettman and Kakkar, 1977; Bettman and Zins, 1979; Stoddard and Fern, 1996).

Consumers construct their preferences when faced with a purchase decision and they tend to depend upon the ways the alternatives are presented to them (Simonson, 1999). Although consumer memory about product information may be brand organised, previous research shows that the structure of the external stimuli can affect information processing (Biehal and Chakravarti, 1982). Furthermore, the way the information is organised can have a major impact on consumer evaluation (Simonson and Tversky, 1992) and choice (Bettman et al., 1998). Products of equivalent value can be evaluated differently depending on the way in which the bundle information is presented (Harlam et al., 1995).

Previous research further suggests that the way a product is presented influences the importance consumers assign to various attributes when making a purchase decision. There are two possible ways in which information format can affect consumer perception. First, the importance of an attribute increases when products are displayed according to a specific attribute e.g. by brand or by price (Tversky, 1969; Glass and Holyoak, 1986; Simonson, 1999). The importance that the attribute receives influences the way the consumers evaluate products and/or make purchase decisions (MacKenzie, 1986; Hutchinson and Alba, 1991). Secondly, presenting product information according to a given attribute makes it easier for consumers to compare alternatives using that particular attribute (Russo, 1977; Bettman, 1979; Simonson, 1999). 
There are several studies on the effects of information format on consumer evaluation. A study by Bettman and Kakkar (1977) finds that information format encourages a particular type of information processing and the information can be organised in such a way to enhance the effect. Della Bitta et al. (1981) studied consumer perception of comparative price advertisements and found that presenting information as different combinations of sale price, regular price, percentage off and dollar amount off resulted in different perceptions of the offer. In line with the study of Della Bitta et al. (1981), Chen et al. (1998) studied the effects of framing a price reduction in percentage versus dollars. Their results suggest that different price reduction frames affect consumer evaluation. The findings of Simonson and Winer (1992) further confirm that changing the information format can influence consumer purchases. When all things are kept equal, these studies show that information format affects consumer perception and evaluation.

Sanfey and Hastie (1998) examined the information format of data for judgement. Their results demonstrate that the format used has an impact on how information is utilised when making judgements. Different formats for displaying information yield different patterns of information utilisation. Stoddard and Fern (1996) conducted a study of the effects information format has on individual buying decisions. The results show that information format has an effect on choice. The subjects used the information as presented and did little information transformation to simplify choice alternatives. Since attempts to restructure information need extra processing efforts, consumers will process information in an easy fashion by using the displayed format (Biehal and Chakravarti, 1982).

Recent research on information format which is of most relevance to this study is that conducted by Areni et al. (1999) who reveals that displaying products according to distinct levels or values of a specific attribute affects purchase likelihood. Displaying a specific attribute increases the importance of that particular attribute and makes it easier for consumers to compare the alternatives with that attribute. In other words, displaying a particular attribute facilitates choice processing by that attribute. An implication of this study is that products from less-known regions 
should highlight attributes on which they are likely to compare favourably rather than focusing solely on the region. In addition, a study by Miyazaki et al. (2000) illustrates that the prominence of unit price information affects consumer evaluation. These findings provide a practical indication to marketers of how to manipulate the format so as to influence ways in which consumers process the information. Also, they suggest that consumers tend to use the information in the format presented to them and process the presented information accordingly.

The findings from previous studies have provided an implication for the presentation of information for package holidays. One of the aims of this study is to extend the previous work by testing the package holiday heading. Package holidays are often presented with destination and sometimes with price as an overall heading. Based on the work of Areni et al. (1999), it is expected that the less-preferred destinations would benefit from presenting price as an overall package heading rather than destination as an overall package heading. Presenting price as an overall package heading may increase the importance of price and may also reduce the importance of destination. It appears that the effects of information format relating to package holidays have not yet been tested in tourism research. Such findings would provide very important implications on the formatting of the package holidays.

This section has described the effects of information format as one of the information presentation strategies for package holidays. The next section outlines the potential effects of the third factor, the mere exposure.

\subsection{Mere Exposure}

The third factor relating to the presentation of information for package holidays is mere exposure. The term 'mere exposure' has been introduced recently to consumer behaviour and advertising as a way in which low-involvement exposures to marketing stimuli can generate more positive effects for those stimuli (Vanhuele, 1994). The term 'mere exposure' refers to 'a positive repetition-affect relationship 
that results from exposure alone' (Obermiller, 1985, p.18). Increased exposure to a given stimulus generally increases preference for that stimulus (Zajonc, 1968).

Given the advertising strategies used in the holiday market in attempts to create consumer awareness of destinations, the potential effects of exposure to the alternatives on consumer evaluation are very important. In the tourism industry, national tourism organisations, tour operators and travel agents spend large budgets on advertising to make sure that their destinations or their package holidays will be stored in consumers' memory and as a result will be included in the consideration sets. Advertising for holiday products appear in various forms such as newspapers, magazines, Internet, and TV programmes. Whether the media exposure to the destinations can affect the choice of destinations has so far received very little attention in tourism research.

Consideration sets may be entirely memory based when products are not externally available for consideration and thus must be recalled from memory (Nedungadi, 1990). Alternatively, consideration sets can be stimulus based, when products are available in the purchase environment (cf. Shapiro et al., 1997). Exposure can increase accessibility to the alternatives and also the likelihood of the alternatives being included in the memory-based consideration set while increasing more familiarity, more likelihood of being noticed and likelihood of being included in a stimulus-based consideration set (Shapiro et al., 1997). Since consideration sets are important for choice, it is very important to examine the effects of exposure in determining the consideration sets.

Judgements depend on the availability of information and the liking towards that information (Obermiller, 1985). Mere exposure can decrease the perceived risks associated with the brand and increase familiarity i.e. "I have seen it frequently, so it must be good" (Baker, 1999). If a brand is encountered at a later point in time, familiarity with the brand can lead to recognition and liking (Vanhuele, 1995) and this may be perceived as the uncertainty reduction (Obermiller, 1985). Stimuli, which have been encountered repeatedly without ill effects are more approachable 
than new stimuli (Baker et al., 1986). In advertising, mere exposure requires only the exposure to the presentation of a brand name (Baker, 1999). This implies that exposure without any associated information may be enough to provide advantages for a brand over the competitors since the exposure makes the consumers feel more comfortable when approaching a brand.

Janiszewski (1993) suggests that the familiarity created via exposure provides three important implications. First, familiarity promotes liking. Several studies (Cox and Cox, 1988; Janiszewski, 1993) provide the evidence that mere exposure to a brand name or product package can improve liking and result in a more favourable view towards the brand. Second, familiarity promotes attention. Exposure makes the stimulus easier to perceive. Third, familiarity promotes memory illusions and faulty references including the assessment of the information. The findings of Baker (1999) indicate that mere exposure can directly influence consumer choice.

Familiarity is likely to enhance perceptual identification of a brand, increase probability of inclusion in a consideration set, generate a positive effect towards the brand and motivate purchase behaviour (Baker et al., 1986). However, familiarity may not have the effects on consumers' decisions when extensive product knowledge is available or when the involvement is high (Baker et al., 1986). A novel stimulus may initially be arousing and initial exposure make the stimulus familiar and appealing but there may be a point where little relating to that stimuli is new and additional exposures can cause the evaluation to drop (Cox and Cox, 1988).

A study by Simonson and Tversky (1992) demonstrates that consumer evaluation of and preference for a product can be influenced by the exposure. Several studies indicate that the exposure affects consumer judgement. Shapiro et al. (1997) studied the effect of advertising exposure on consideration formation in which the advertisement receives minimal attention resources while other more relevant information is being processed. Their findings suggest that exposure can increase the chance of a product being included in consideration sets even when the buying situation is unfamiliar. The findings of Mitra (1995) also reveal that exposure 
affects the composition of consideration set. Burton et al. (1999) conducted a study on the effect of exposure to promoted products on purchase behaviour. Their results indicate that exposure increases the number of advertised products purchased and the amount spent on those products. The results suggest that exposure result in accessibility of the information of the available alternatives. The study by Deighton et al. (1994) further suggests that exposure affects brand switching. The study by Tellis (1988) reveals that loyalty is a significant moderator of the effects of exposure in which the consumers respond more strongly to the brands that they are more loyal to.

An important message gained from the previous research is that there is a need to incorporate the effects of exposure in the present study. Without such effects, the findings of the study would be purely drawn from the limited effects of presentation format. The study would then ignore the real world situation where consumers are surrounded by various kinds of exposures before purchasing their holidays. Although the previous research provide insights into the effects of exposure, it is not yet clear whether and when it can help less-preferred destinations to become a final choice particularly in the context of a holiday purchase.

\subsection{Conclusion}

In today's market, packaging is used not only to convey information to consumers but it has also become part of consumer decision-making process which provides the means for consumers to make significant choice decisions (Fill, 1995). Based on the view that purchasing package holidays is viewed as less dependent on destination (Burkart, 1984), this study asserts that the way the information about package holidays is presented may enhance the importance of other package attributes and thus reduce the importance of destination. Given that there are very limited opportunities to develop the physical attributes of beach holiday destinations, the presentation of information for package holidays is one of the potentially effective means of achieving product differentiation. 
This chapter has highlighted the significance of tourism research on bundling and has reviewed literature relating to the information presentation strategies. The chapter has discussed the potential effects of the presentation of information for package holidays in three major areas namely: completeness of information, information format and mere exposure. Having reviewed the existing literature, there are four implications for the present study to fill the gaps in tourism research.

The first is that the effects of presentation of information for package holidays have hardly received any attention in tourism research. Despite the prevalence of information about package holidays in various forms of travel stimuli, little is known about the effective ways to present the information in such a way to help lesspreferred destinations become a final choice.

The second is that there seems to be no studies testing whether presenting detailed package holiday information can reduce the importance of destination and affect the destination choice. To date, there is a very limited understanding of the effects that the amount of package information presented has on the destination choice.

The third is that there is a lack of research into the effects of the overall package holiday heading. Whether the presentation of package holiday heading can decrease the importance of destination and help less-preferred destinations become a final choice has not yet been examined.

The fourth is that studies on the effects of exposure are very limited in the context of holiday purchase. Given the enormous advertising budget required for the destination marketing, it is not yet clear whether and when the exposure can effectively help less-preferred destinations to become a final choice.

The literature review presented in this chapter and Chapter 2 has provided a conceptual underpinning for the present study. The next chapter illustrates a theoretical framework and the formulation of hypotheses for the present study. It 
identifies the research gaps, the research questions, the conceptual model and the formulation of the hypotheses. 


\section{Chapter Four}

\section{Theoretical Framework and Hypotheses}

\subsection{Introduction}

Following the literature review in Chapter 2 and Chapter 3, this chapter outlines a theoretical framework and the hypotheses for the present study. The development of a theoretical framework is considered as the most important part of the research project (Veal, 1997). A theoretical framework is the foundation on which the entire research is based and is a logically developed and described network of associations among the variables relevant to the research problem (Sekaran, 2000). Its purposes are to bring clarity and focus to the research and to help postulating hypotheses (Punch, 1998). Hypotheses are expressed as the predictions of outcome and are logically linked with the research questions and theories (Neuman, 2000).

This chapter is organised into four sections. The first section highlights the research gaps in tourist decision-making theories. The second section formulates the research questions for the present study. The third section outlines a conceptual model of the study. The final section presents the formulation of the research hypotheses. The chapter ends with a conclusion section.

\subsection{Research Gaps}

Compared with other fields of research, tourism is considered as a relatively new area of research. Theories related to consumer decision-making about goods, for example, are directly applied to tourism to explain the tourist decision-making. 
Although many tourism authors (Wahab et al., 1976; Mathieson and Wall, 1982; Moutinho, 1987) claim that the purchases of tourism product are unique and different from those of other consumer products, empirical evidence to support theories of tourist decision-making is still very limited. Ritchie (1994) comments that there are still many dark sides in tourism theories that need to be further researched. $\mathrm{He}$ refers to two major research gaps in tourism relevant to the present study. First, it is suggested that there is still a lack of empirical studies on the tourist decision-making. Second, there have been very few tourism studies focusing on the role of package holidays in consumer choice.

Having reviewed the previous literature on both tourism and marketing disciplines, several research gaps emerge for further research. First, many studies in tourist decision-making overlook the fact that destination choice is only part of a tourist decision. Much attention, however, has focused on proposing the destination choice models to explain how a final destination is selected (e.g. Um and Crompton, 1990; Goodall, 1991; Crompton and Ankomah, 1993; Botha et al., 1999) or exploring the consideration set size (e.g. Woodside and Sherrell, 1977; Woodside and Ronkainen, 1980; Crompton et al., 1998). Although these studies provide insights into how a destination choice is selected, many tourist decisions are not independent choices of separate elements such as destination, accommodation, and transportation, but are in fact multi-faceted decisions in which choices of separate elements are interrelated (Summers and McColl-Kennedy, 1995; Dellaert et al., 1998; Fesenmaier and Jeng, 2000). When one thinks of taking an overseas holiday, one would think of where to go, where to stay and which airline to fly with. An obvious example of these interrelations is the package holiday purchase. Considering such interrelations, this study, therefore, posits that destination choice should not be studied separately from other sub-decisions. Studies focusing on destination choice alone do not explain actual tourist decisions. When destination choice is related to the choices of other components, the findings on destination choice alone can be limited and misleading (Dellaert et al., 1997). 
Second, the empirical findings to support the effects of travel stimuli on the destination choice are limited. Information relating to package holidays is presented in various types of travel stimuli. Examples of travel stimuli are advertising, promotion and travel literature (Schmoll, 1977; Moutinho, 1987). Although it has long been acknowledged that travel stimuli can influence the destination choice (Woodside and Sherrell, 1977; Woodside and Lysonski, 1989; Um and Crompton, 1990), there is very little attention paid to such effects in tourism research. The lack of research is apparent on the effects of information presentation relating to package holidays on the destination choice.

Third, the assumption that the purchase of package holidays is less dependent on the destination and consumers are willing to substitute one destination for the other (Burkart, 1984; Woodside and Carr, 1988; Mill, 1990) needs to be examined. In the context of package holidays, destination is typically combined with other attributes and it is possible that those attributes may play the dominant role (Burkart, 1984). Information presentation strategies can enhance the power of holiday packaging. Several studies show that the way the information is presented can influence the importance of attributes (Simonson, 1999; Areni et al., 1999) and consumer choice (Simonson and Winer, 1992; Bettman et al., 1998). Despite the prevalence of package holidays and the growth of Internet where there is a great control over the information, whether the way the information relating to package holidays is presented can reduce the importance of destination has received very little attention. Such a decrease can be very helpful for less-preferred destinations to become a final choice.

Finally, little is known about the effective timing of exposure to less-preferred destinations so as to help them become a final choice. Although it is widely accepted that mere exposure can create liking and familiarity (Janiszewski, 1993), there are contrasting views on the timing of exposure to alternatives in determining the consideration sets. Details of these views are discussed in section 4.3. A widely held assumption in tourism literature, however, is that the alternatives should be presented as early as possible to allow them to be included in an early consideration 
set and become a final choice (Crompton and Ankomah, 1993). To date, there seems to be no evidence to support such an assumption.

This study aims to fill those aforementioned gaps found from the literature. It studies the tourist decision-making in a situation where the destination is bundled with other package components. In such a context, destination is considered as a part of the tourist decision. The study intends to provide theoretical development by testing several assumptions held in tourism. The first is that the travel stimuli can influence the destination choice process. The second is that the purchase of package holidays is less dependent on destination. The third is that the exposure to alternatives should be as early as possible. The next section outlines the research questions of the present study.

\subsection{Research Questions}

A research question is a question which guides the project, gives directions to and shows the boundaries of the study (Punch, 1998). Referring to the research aim (see section 1.2), there are two issues relating to the information presentation of package holidays. These are formulated here as the two key research questions for this study.

The first research question concerns the presentation format of package holidays to help less-preferred destinations. This includes the amount of information given and the information format. Previous research suggests that the amount of information given can affect consumer choice (Kivetz and Simonson, 2000). Missing information is a source of uncertainty (Meyer, 1981). The greater the amount of missing information, the less favourable the evaluation (Johnson and Levin, 1985). Missing information is sometimes used as a reason to reject the inferior products (Kivetz and Simonson, 2000). Besides, displaying products with a specific attribute increases the importance of that particular attribute and facilitates choice processing by that particular attribute (Areni et al., 1999). Therefore, providing detailed information relating to other package attributes or highlighting an alternative attribute rather than destination as a package heading may turn consumers' attention 
towards other attribute(s) and thus reduce the importance of the destination. Consequently, this may increase the chances for less-preferred destinations to be included in the consideration set and become a final choice. The first research question is formulated as follows:

Research Question 1: For less-preferred destinations, to what extent does presenting detailed information of package holidays or highlighting an alternative attribute rather than destination as a package heading have effects on a) intention to visit $b$ ) their likelihood of being included in late consideration and c) their likelihood of becoming a final choice?

The second research question concerns the timing of exposure to less-preferred destinations. Previous studies indicate that mere exposure leads to recognition and liking (Janiszewski, 1993; Vanhuele; 1995). However, there are three contrasting views on the exposure to alternatives in determining the consideration sets. The first is that the consideration sets are stable and this implies that the exposure to lesspreferred destinations should occur as early as possible (Crompton and Ankomah, 1993). The second is that the consideration sets are unstable over time and exposure to alternatives may add new alternatives to and delete existing alternatives from a consideration set at any point in time (Shocker et al., 1991; Roberts and Nedungadi, 1995). This indicates that whenever the existing alternatives are no longer attractive, exposure to less-preferred destinations can add such destinations to the consideration sets. The third suggests that the consideration sets are unstable but the rejected alternatives are unlikely to be reconsidered (Hulland, 1992). This suggests that early entrant alternatives have a greater chance of being rejected than late entrant ones. Therefore, exposure to less-preferred destinations would benefit when they are presented as close to the time of choice as possible. Given these contrasting views, it is important to investigate the effective timing of exposure to less-preferred destinations in order to increase their chances of being included in the late consideration set and becoming a final choice. The second research question is therefore formulated as follows: 
Research question 2: To what extent does the timing of exposure to less-preferred destinations have effects on a) intention to visit b) their likelihood of being included in late consideration and c) their likelihood of becoming a final choice?

This section has outlined the two main research questions for the present study. The next section illustrates a conceptual model of the study.

\subsection{Conceptual Model}

Figure 4.1 shows the conceptual model for this study. It presents the variables relevant to the research questions and the hypothesised relationships among these variables.

Figure 4.1: Conceptual Model

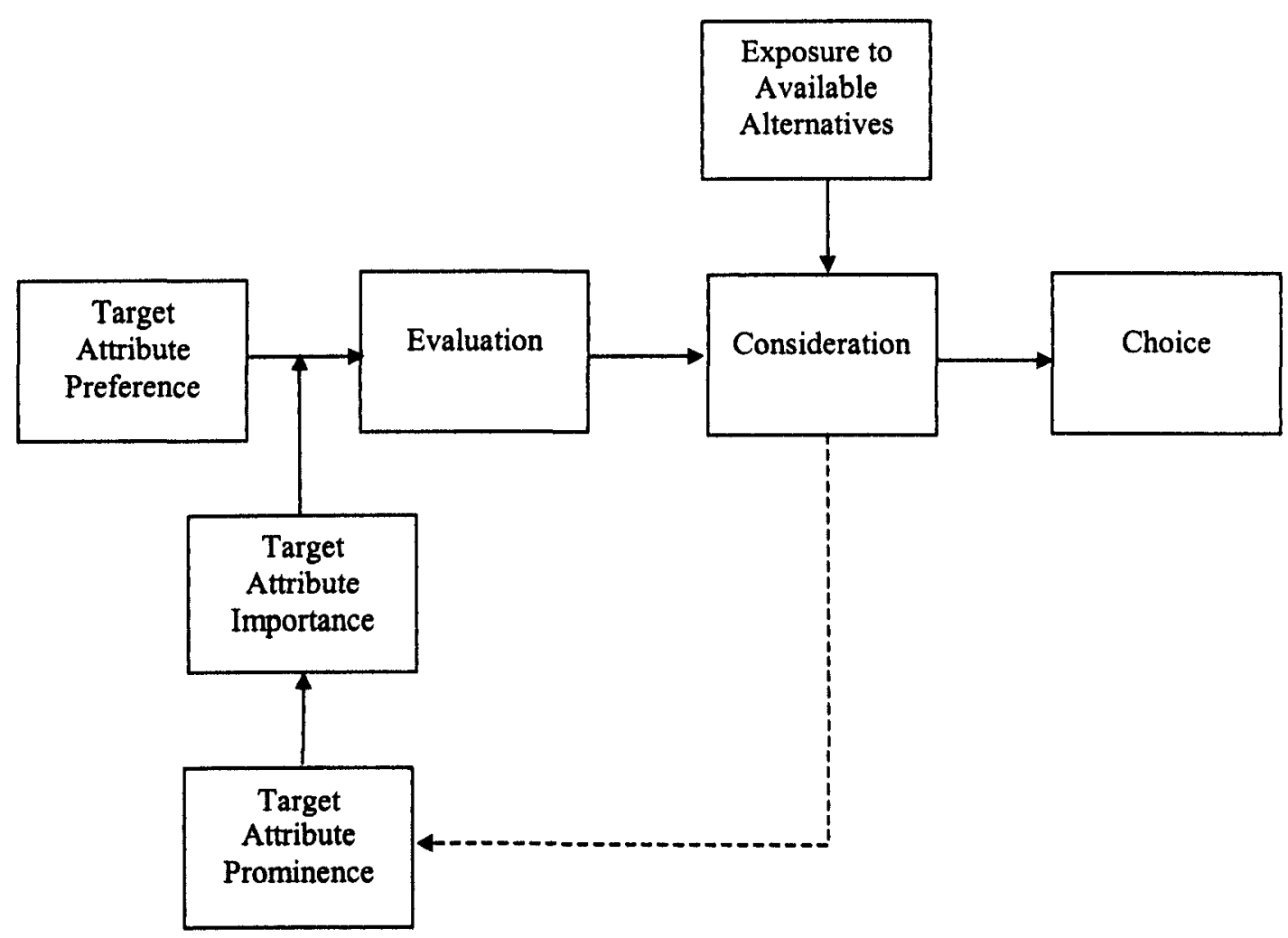


The conceptual model shows that there are three independent variables (target attribute preference, target attribute prominence and exposure to available alternatives), two dependent variables (evaluation and choice), a moderating variable (target attribute importance) and a mediating variable (consideration). In this study, the target attribute refers to the destination.

From the left, the model suggests that destination preference directly influences evaluation. It illustrates the notion that evaluation affects consideration and, in turn, affects choice. An independent variable assumed to influence the destination importance is the way the information is presented to highlight the destination prominence. In this study, it is referred to as the presentation format. The more prominently the destination is presented, the more important it will become. For the destinations that are rated highly in terms of preference, this would increase the positive evaluation and the probability of becoming a final choice. Presenting information in such a way to reduce the prominence of the destination may result in a decrease in destination importance. Less-preferred destinations should benefit from such a decrease.

Another independent variable determining the consideration sets is the exposure to available alternatives. Exposure leads to liking and the likelihood of alternatives being included in the consideration sets. Choice processing depends on the availability of information regarding the alternatives and liking. As a result, exposure to less-preferred destinations may increase their likelihood of becoming a final choice.

The feedback loop in this model illustrates the consideration set formation process. In different timing, consumers are exposed to various sources of information before making a final choice. During this process, they may be exposed to various presentation formats of information and multiple exposures to both new and old alternatives. 
This section has described the conceptual model of the study and the idea underlying this model. The next section presents the hypotheses developed for the present study.

\subsection{Hypotheses}

The conceptual model discussed in the previous section leads to the formulation of the hypotheses. The purpose of this section is to present the six hypotheses to be tested in this study. Discussions and formulation of these hypotheses are presented in this section.

There are two predictions aiming at presenting the information in a way to reduce the prominence of destination. The first hypothesis examines the effect of the amount of information presented. Previous studies show that missing information can harm the inferior products with the results that it is a reason to reject these options (Kivetz and Simonson, 2000). For less-preferred destinations, missing information is therefore a source of uncertainty (Meyer, 1981). The greater the amount of missing information, the less favourable the evaluation (Johnson and Levin, 1985). Since tourism products have characteristics of services, which are intangible, providing more detailed information on tangible evidence would help reduce the uncertainty (Palmer, 2001). As previously discussed, it may also reduce the importance of destination.

Presenting the package holidays with the name of destination only would increase the prominence of destination, enhance its importance and therefore harm lesspreferred destinations. For less-preferred destinations, it is expected that presenting other attributes along with the destination name would turn attention away from the destination name to those attributes. Then, the consumers would be willing to consider new alternatives such as less-preferred destinations. The first hypothesis is formulated as follows: 
H1: For less-preferred destinations, presenting the destination name along with other attributes increases (a) intention to visit (b) their probability of entering late consideration (c) their probability of becoming a choice.

The second hypothesis also focuses on presenting the information in a way to reduce the prominence of destination by investigating the effect of package heading. Previous research suggests that the information format affects the way consumers acquire and process information (Bettman and Kakkar, 1977). Consumers will process information in ways which are congruent with the format in which it is presented (Bettman and Kakkar, 1977; Bettman and Zins, 1979; Stoddard and Fern, 1996). Displaying products by a specific attribute increases the importance of that particular attribute and makes it easier for consumers to compare the alternatives by that attribute (Areni et al., 1999).

An implication from the previous studies is that less-preferred destinations should highlight the attribute on which they can compete favourably rather than focusing on the inferior attribute such as the destination name. For less-preferred destinations, it is expected that presenting price as a package heading will turn attention away from the destination name towards price. In line with the first hypothesis, this would encourage consumers to consider other alternatives such as less-preferred destinations. The second hypothesis is formulated as follows:

H2: For less-preferred destinations, presenting price as a package heading increases (a) intention to visit (b) their probability of entering late consideration (c) their probability of becoming a choice.

As a corollary to the above two hypotheses, the third hypothesis examines the effects of presentation format as formulated in the previous two hypotheses on the importance of destination. It is predicted that presenting the destination name along with other attributes will turn attention to those attributes and thus reduce the importance of destination. Also, presenting price as a package heading will increase 
the importance of price while decreasing the importance of destination. The third hypothesis is formulated as follows:

H3: Destination importance decreases when presenting (a) destination name along with other attributes (b) price as a package heading.

Another factor related to the information presentation is the exposure to alternatives. As previously discussed in section 4.3 , there are three contrasting views of the exposure to alternatives in determining the consideration sets. This study aims to test these contradicting ideas with three hypotheses so as to help less-preferred destinations. The first is that the consideration sets are stable in which the destinations should be presented as early as possible (Crompton and Ankomah, 1993). The fourth hypothesis predicts that early exposure to less-preferred destinations would benefit such destinations. The fourth hypothesis is therefore formulated as follows:

H4: Early exposure to less-preferred destinations increases (a) intention to visit (b) their probability of entering late consideration (c) their probability of becoming a choice.

The second is that the consideration sets are unstable over time and the exposure to alternatives may add the new alternatives to and delete the existing alternatives from the consideration sets at any point in time (Shocker et al., 1991; Roberts and Nedungadi, 1995). Regardless of the early exposure, this suggests that late exposure to less-preferred destinations would be beneficial for such destinations. The fifth hypothesis is therefore formulated as follows:

H5: Late exposure to less-preferred destinations increases (a) intention to visit (b) their probability of entering late consideration (c) their probability of becoming a choice. 
The third suggests that the consideration sets are unstable and the rejected alternatives are unlikely to be reconsidered (Hulland, 1992). To avoid being rejected, alternatives should be presented only once and as close to a time of choice as possible. Therefore, late exposure (without early exposure) to less-preferred destinations would benefit such destinations. The sixth hypothesis is therefore formulated as follows:

H6: Late exposure (without early exposure) to less-preferred destinations increases (a) intention to visit (b) their probability of entering late consideration (c) their probability of becoming a choice.

This section has provided discussions and formulation of the six research hypotheses related to the presentation of information for package holidays in such a way to benefit the less-preferred destinations. The next section concludes the chapter.

\subsection{Conclusion}

This chapter has provided a focus and a direction of this study. This study aims to fill the gaps found in the literature of tourist decision-making. It examines the tourist decision particularly where a destination is bundled with other package attributes. It is an empirical study to test the several assumptions held in tourism. The first is the effects of travel stimuli on the destination choice. The second is that the purchase of package holidays is less dependent on destination. The third is that the exposure to alternatives should be as early as possible. Its purposes are to provide the theoretical contribution for the area of tourist decision-making as well as the marketing implications for less-preferred destinations.

In this study, there are two research questions aiming to examine the effects of information presentation of package holidays in such a way to help less-preferred destinations. The first concerns the presentation format of package holidays including the amount of information given and the information format. The second concerns the timing of exposure to the destinations. The conceptual model of the 
study has been proposed. It presents the variables relevant to the research questions and the hypothesised relationships among these variables. There are six hypotheses formulated for answering the two key research questions.

The next chapter focuses on the methodology of the study to test the proposed relationships. It describes the rationale for a selected research design, the research design, the instrumentation, the data collection process, the preparation for data analyses and the limitations of methodology. 


\section{Chapter Five Methodology}

\subsection{Introduction}

After the discussion of the theoretical framework and the formulation of hypotheses in the previous chapter, this chapter describes the methodology used to collect data for testing such hypotheses. The methodology is a very important element and should be carefully selected since it affects the direction, structure and process of the research (Sarantakos, 1998). There are numerous research designs from which one can choose. The nature of a research question will, in part, influence the specific research design. Further considerations such as the cost, the availability of the subjects and the amount of time available to conduct the study should also be taken into account (Grimm, 1993).

This study employs experiments to test the effects of package information presentation which covers the three major factors: amount of package information, package heading and timing of exposure to alternatives. To set up the experiments for such an investigation, the study developed an experimental setting and the treatments. It included a control group and two experimental groups. To enhance the replication of the findings, the study was conducted on the two sample groups: students and adults.

This chapter is organised into five main sections. First, it provides a justification for selecting the particular research design employed in the study. Second, it explains the design of the experiments. Third, it explains the development of the instrument. 
Fourth, it reports the data collection process. Fifth, it outlines the preparation for data analyses. Finally, it describes the limitations of the methodology used in the study. The chapter ends with a conclusion section.

\subsection{Research Design Rationale}

A research design involves a series of decisions. This section describes the rationale for the decisions that were made in this study concerning the purpose of the study, the data collection method, the time horizon and the study setting.

\subsubsection{Purpose of the Study}

The purposes of research can be exploratory, descriptive and explanatory. Table 5.1 summarises the goals of research by Neuman (2000).

Table 5.1: Goals of Research

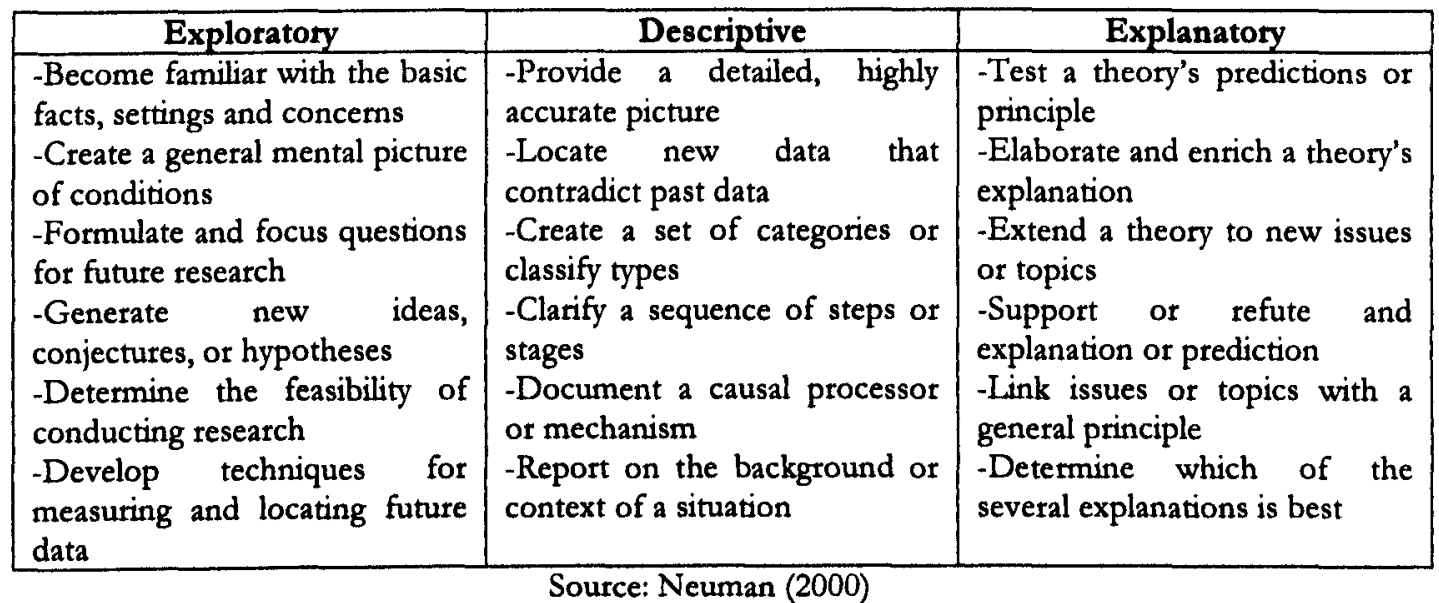

Exploratory research is undertaken to comprehend the nature of the problem and obtain a good grasp of the phenomena which are of interest while descriptive research is undertaken to ascertain or describe the characteristics of the variables of interest (Sekaran, 2000). The purpose of explanatory research is to answer 'why' things happen the way they do (Neuman, 2000). Explanatory research engages in the testing of hypotheses to establish cause and effect relationships among variables (Sekaran, 2000). 
Referring to the nature of the research questions and the hypotheses specified in Chapter 4, the investigation carried out in this study concerns the cause and effect relationships. Thus, this study can be classified as an explanatory research. The study attempts to test the predictions for tourism which are derived from the marketing theories as discussed in Chapter 4. Such predictions need to be tested since the nature of tourism products as mentioned in section 2.2 is regarded as different from other consumer goods (Wahab et al., 1976; Moutinho,1987; Mathieson and Wall, 1982). By doing so, this study aims to provide further insights relevant to tourism and enrich the theories of tourist decision-making.

\subsubsection{Data Collection Method}

Data collection methods can be grouped into two categories: quantitative and qualitative. The quantitative method collects data in the form of numbers while the qualitative method collects data in the form of words and pictures (Neuman, 2000). The quantitative method includes experiments, surveys, and existing statistics while the qualitative method includes interviews, observations and historical-comparative research (Neuman, 2000).

Although it is acknowledged that the quantitative and qualitative methods complement each other very well, limited availability of time and resources restricted this study to the quantitative method. This study applies the experimental design to test the hypotheses developed from the previous chapters. Experiments are considered as an appropriate method since they are capable of providing more convincing evidence of causal relationships than other designs and they can provide the necessary control to infer that causal relationships do exist (Churchill, 1999; Hakim, 2000). They are the only method which has the power to reveal cause and effect relationships in an unambiguous way (Miller, 1996) and provide the most rigorous test of hypotheses which specifies that $\mathrm{X}$ causes $\mathrm{Y}$ (Bouma and Atkinson, 1995). Furthermore, experiments are considered as a 'blueprint' for the collection of data which would allow a researcher to confirm or refute the predictions being tested (Miller, 1996) and they are also essential for the development of soundly based explanations of behaviour (Hakim, 2000). Therefore, experiments as a scientific 
approach in explaining consumer behaviour was used as a data collection method for the present study.

\subsubsection{Time Horizon}

There are two types of time dimension in research: cross-sectional and longituditional. Cross-sectional research is a snapshot approach (Neuman, 2000) where data are collected at one point in time while the longituditional approach examines more than one time. Although the latter approach is powerful, it requires a large amount of time and financial resources. Considering the limitations of time and available budget, only a cross-sectional design could be employed in this study. Therefore, data were collected only once during a period of time.

\subsubsection{Study Setting}

The study was planned to test the respondents' decision-making in a hypothetical setting of purchasing holidays. In such a setting, the necessary controls and manipulations could then be achieved (Sekaran, 2000). Details of the hypothetical setting are described in section 5.3.1.1. Extraneous variables such as budget and time constraints or the influence of friends and family might either confound the relationship of variables in the study or cause a false interpretation of the relationship. While controlling for these variables, the researcher can manipulate some variables and consequently observe and measure the effects of the manipulation of independent variables on one or more dependent variables. Manipulation here refers to 'the creation of different levels of independent variable to assess the impact on the dependent variable' (Sekaran, 2000, p.148). The manipulation of the independent variable is also known as 'treatment' and the results of the treatment are called 'treatment effects' (Sekaran, 2000).

\subsection{Experiments}

Experiments are widespread in natural science and engineering studies. In social science, experiments are also very popular in marketing and behavioural studies 
(Louviere et al., 2000). The term 'experiments' refer to 'an investigation where the system under study is under the control of the investigator (Cox and Reid, 2000, p.1). A crucial factor in experimental design is that a researcher changes a situation and has control over the setting in which the change is introduced to. Only those research questions that let the researcher manipulate the conditions are appropriate for the experiments (Neuman, 2000).

This section is divided into two parts. The first part describes the experimental design in terms of the experimental setting, the design overview, the advantages and the disadvantages of the design, and the treatments. The second part outlines the validity of the experimental design regarding the internal validity, the external validity and the construct validity.

\subsubsection{Experimental Design}

An experimental design is a method of planning experiments in such a way that the results are minimally affected by either random error or confused by other factors (Rothman, 1972). When conducting an experiment, an appropriate research design is crucial. Paying careful attention to the research design process in this type of research is an important step in ensuring that alternative explanations of the data are eliminated and giving more confidence in the conclusions drawn from the causal processes (De Vaus, 2002).

This section describes the design of the experiments carried out in this study and is divided into four sections. First, it describes the experimental setting. Second, it provides the overview of the design. Third, it discusses the advantages and disadvantages of the design. Finally, it explains the development of the treatments.

\subsubsection{Experimental Setting}

In order to make a precise causal inference, it must be ensured that the independent variable is the only thing that changes in the experiment. To accomplish this aim, the experiment setting should be able to hold all the alternative causes (extraneous 
variables) of rival explanations constant (Harris, 1986). Considering the accurate causal inference of the findings, it was decided that this study employed a laboratory experiment setting by bringing the research problem into an environment outside the subjects' normal routines where the outside influences are eliminated (Christensen, 1988). To control all possible factors that may influence tourist decisions, the study developed a hypothetical situation as an experimental setting. The hypothetical situation is shown in Figure 5.1.

Figure 5.1: Hypothetical Situation

\section{IMAGINE THIS SITUATION...}

\section{(IMPORTANT- PLEASE READ)}

Suppose you have won an overseas beach holiday voucher worth $£ 1,000$. This voucher must be spent on flights and accommodation for two persons. It must be used for booking holidays departing between June and August 2003. Assume that you are able to arrange a suitable time for this trip. You are free to take anyone with you. Assume that your travel companion will be happy to go to any destination and will let you decide.

Please note that the voucher cannot be transferred to other persons. If you do not wish to use the $£ 1,000$ voucher at all, you can exchange it for $£ 50$ cash. If you do not spend all of $£ 1,000$ at once, you will be given the remainder as a voucher for an overseas holiday next year.

The hypothetical situation shown in Figure 5.1 introduces the respondents to the experimental setting which controls for several factors suspected of having the influences on their decisions. Based on the theories of tourist decision-making, these variables are the constraints of travel such as cost, time, trip duration (Schmoll, 1977; Mathieson and Wall, 1982; Moutinho, 1987; Dellaert et al., 1998; Botha et al., 1999) and social influences such as friends and families (Schmoll, 1977; Moutinho, 1987; Middleton, 1994). Considering these issues, the hypothetical situation of this study 
specifies the availability of budget, time and travel companion to allow the respondents make decisions without such travel constraints. The situation further indicates that independent decision-making is involved without the influence of friends and families. Regarding the use of the voucher, the situation also provides an option for not using the voucher if the respondents do not feel like taking holidays. Rebates are available so as to discourage the respondents from purchasing the most expensive package holidays in order to use up the entire voucher at once.

\subsubsection{Design Overview}

This study employs a mixed design experiment including between-subjects and within-subjects factors. Between-subjects design takes different subjects for each of the experimental condition while within-subjects design employs the same subjects (Harris, 1986). The between-subject factors are the presentation format including the amount of package information (destination name only or destination name along with other attributes) and package heading (destination heading or price heading). The within-subject factors are the timing of exposures including early exposure (absent, present) and late exposure (absent, present).

The design consists of three groups with six waves of measurement. This includes a control group and two experimental groups as illustrated in the overall design of the study in Figure 5.2. The figure uses a design notation which refers to ' $a$ shorthand system for symbolising parts of the experimental design' (Neuman, 2000, p.230). There are three elements in the overall design. First, $R$ refers to random assignment. It indicates that allocation of the subjects to a group is done by random assignment. Second, $O$ refers to observation of dependent variable. Third, $X$ refers to the experimental treatment. Subjects who receive the experimental treatment are called 'the experimental group' while those who do not receive the experimental treatment are called 'the control group' (Mitchell and Jolley, 1988). 
Figure 5.2: Overall Design

$\begin{array}{ccccccccc}\mathrm{R} & & & & & \mathrm{O}_{3} & \mathrm{O}_{4} & \mathrm{O}_{5} & \mathrm{O}_{6} \\ \mathrm{R} & \mathrm{X}_{1} & \mathrm{O}_{1} & \mathrm{O}_{2} & \mathrm{X}_{2} & \mathrm{O}_{3} & \mathrm{O}_{4} & \mathrm{O}_{5} & \mathrm{O}_{6} \\ \mathrm{R} & \mathrm{X}_{1} & \mathrm{O}_{1} & \mathrm{O}_{2} & \mathrm{X}_{3} & \mathrm{O}_{3} & \mathrm{O}_{4} & \mathrm{O}_{5} & \mathrm{O}_{6}\end{array}$

Measures:

Time 1: $\mathrm{O}_{1}=$ intention to visit, $\mathrm{O}_{2}=$ early consideration

Time 2: $\mathrm{O}_{3}=$ intention to visit, $\mathrm{O}_{4}=$ late consideration

$\mathrm{O}_{5}=$ choice

$\mathrm{O}_{6}=$ attribute importance

Treatments:

$\mathrm{X}_{1}=$ early exposure

$\mathrm{X}_{2}=$ destination name along with other attributes and with destination as a heading, late exposure

$\mathrm{X}_{3}=$ destination name along with other attributes and with price as a heading, late exposure

Figure 5.2 shows that there are three conditions in the design. The first condition is a control group while the last two conditions are the experimental groups. Only the subjects in the experimental groups are exposed to the treatment $(X)$. The effects of presentation format are examined between these three conditions. To test the effects of amount of information given, the control group is presented with the destination name only at $\mathrm{O}_{3}$ while the experimental groups are presented with the destination name along with other attributes $\left(\mathrm{X}_{2}, \mathrm{X}_{3}\right)$. To investigate the effects of package heading, the experimental group 1 receives the destination as a package heading $\left(\mathrm{X}_{2}\right)$ while the experimental group 2 receives the price as a package heading $\left(\mathrm{X}_{3}\right)$. Figure 5.3 shows the differences in the package heading presented to the two experimental groups. 
Figure 5.3: Package Heading of Two Experimental Groups

Experimental Group 1 (destination as a package heading)

\section{Spain}

3 star hotel

7 nights

$£ 410$

Thomas Cook

Experimental Group 2 (price as a package heading)

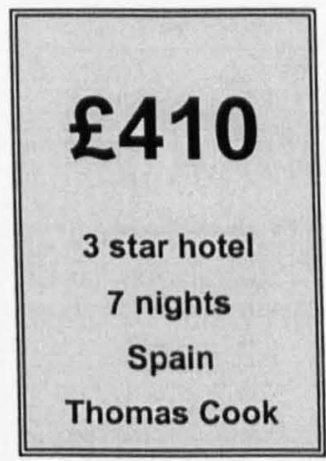

The effects of timing of the exposure are tested on only the experimental groups. Details of the hypotheses relating to the exposures are discussed in section 4.5. Early exposure $\left(\mathrm{X}_{1}\right)$ presents four destinations. Late exposure $\left(\mathrm{X}_{2}\right.$ or $\left.\mathrm{X}_{3}\right)$ presents four destinations consisting of two destinations previously presented in the early exposure and two new destinations.

There are six measures in the design. Intention to visit is measured twice, at time 1 $\left(\mathrm{O}_{1}\right)$ and at time $2\left(\mathrm{O}_{3}\right)$. Consideration is also measured twice at time 1 for early consideration $\left(\mathrm{O}_{2}\right)$ and at time 2 for late consideration $\left(\mathrm{O}_{4}\right)$. Choice $\left(\mathrm{O}_{5}\right)$ is measured after the measures of intention to visit and consideration. Attribute importance $\left(\mathrm{O}_{6}\right)$ is a final measure after the experimental treatment and all the measures. Details of these measures are discussed in section 5.4.2. 


\subsubsection{Advantages and Disadvantages of the Design}

This part discusses the advantages and the disadvantages of the use of betweensubjects design and within-subjects design in the experiments. It begins with between-subjects design and then within-subjects design. Finally, it explains why the study adopted these two approaches to strengthen the experimental design.

For between-subjects design, an advantage is that each respondent is exposed to a new condition. Using different subjects is always the best option when one experimental condition may have an effect on another experimental condition. However, this design has the disadvantage in that different subjects may be likely to differ in their reaction to each of the experimental conditions. Harris (1986) suggests that there are two possible ways of dealing with the individual differences arising from using different subjects: matching the subjects and random assignment. Due to the restriction of resources, time and information, it is often not possible to match the groups of subjects by their individual variability in each condition. Under these circumstances, the only possible way of dealing with the problem of individual variability was to allocate different people at random to the experimental conditions. Randomisation is a statistical control technique that has the purpose of providing assurance that extraneous variables, known or unknown, will not systematically bias the results of the study (Christensen, 1988). Random assignment here means that 'it is purely a matter of chance which subjects are assigned to the condition' (Greene and D'Oliveira, 1999). The justification of using this technique is that if subjects are randomly allocated to the experimental conditions, then people of different characteristics are likely to be found in all groups.

For within-subject design, an advantage is that it eliminates the individual differences by using the same subjects repeatedly to measure scores on the dependent variable. However, the main disadvantage is that the subjects will be doing the same tasks in the same order and the previous task may have an effect on the later task. These effects are called 'order effects' (Greene and D'Oliveira, 1999). Harris (1986) explains that the order effects can lead to the improvement in the subjects' performance (e.g. familiarity and awareness of the tasks) and the deterioration in 
their performance (e.g. fatigue and boredom). Thus, it is normal practice for the experimenter to vary the order of the tasks so that the order effects and other carryover effects will be equalised and counterbalanced. Carry-over effect is 'a sequencing effect that occurs when a performance in one treatment affects that in another treatment' (Christensen, 1988). The best option of controlling for these effects is to employ a technique known as counterbalancing (Harris, 1986). This technique ensures that each condition in the experiment is preceded by every other condition in an equal number of times. For each subject who does one particular sequence of conditions, there are other subjects who perform the conditions in all the other possible combinations of the orders.

Considering the advantages and the disadvantages of between-subjects and withinsubjects designs, this study employed both designs to gain the maximum advantages while eliminating as many disadvantages as possible. A between-subjects design was used to avoid the effect of one experimental condition on another experimental condition when examining the effects of amount of information provided and package heading. A within-subjects design was employed to reduce the individual differences when testing the effects of early and late exposures.

\subsubsection{Treatments}

The treatments $(\mathrm{X})$ or the stimuli in the study is the package information presentation including the following factors: the amount of package information, the package heading, early and late exposures. The treatments are specifically designed for the experimental groups. To create the treatments such as $X_{1}, X_{2}$ and $X_{3}$, there is a need to select the destinations and incorporate further designs. Three types of designs are employed to create the treatments for this study: Solomon four-group design, Latin square design and fractional factorial design. The Solomon four-group design and the Latin square design are used for counterbalancing the destination appearance as discussed in section 5.3.1.3. The fractional factorial design is employed to systematically create variations for the package holiday information. This section first presents the eight destinations included in the treatment and then discusses the three designs concerning Solomon four-group, Latin square and fractional factorial. 


\section{Destinations Included in the Treatments}

There are eight beach holiday destinations included in the study. These destinations were selected on the basis of number of UK residents' visits. Table 5.2 shows the number of UK residents visiting these eight destinations in the year 2001.

Table 5.2: Number of UK Residents' Visits by Destination

\begin{tabular}{|c|c|}
\hline Destinations & $\begin{array}{c}\text { Number of Visits (thousands) } \\
\mathbf{2 0 0 1}\end{array}$ \\
\hline Spain & 11,790 \\
\hline Greece & 3,215 \\
\hline Italy & 2,471 \\
\hline Portugal & 1,598 \\
\hline Cyprus & 1,476 \\
\hline Turkey & 878 \\
\hline Malta & 443 \\
\hline Tunisia & 228 \\
\hline \multicolumn{2}{|c|}{ Source: National Statistics } \\
\hline
\end{tabular}

For UK residents, Table 5.2 shows that Spain, Greece, Italy and Portugal are the top four destinations in terms of number of UK residents' visits and are regarded here as high-preferred destinations. Cyprus, Turkey, Malta and Tunisia have lower number of UK residents' visits and are therefore considered here as less-preferred destinations. For the purpose of this study, the four high-preferred destinations are grouped into a high preference level $(\mathrm{H})$ and the four less-preferred destinations are grouped into a low preference level (L). Table 5.3 presents the UK residents' destination preference.

Table 5.3: UK Residents' Destination Preference

\begin{tabular}{|c|c|}
\hline High & Low \\
\hline Spain (H1) & Cyprus (L1) \\
\hline Greece (H2) & Turkey (L2) \\
\hline Italy (H3) & Malta (L3) \\
\hline Portugal (H4) & Tunisia (L4) \\
\hline
\end{tabular}

This section presented the eight destinations categorised into high and low preference levels based on the number of UK residents' visits to the destinations. The next section discusses the first design incorporated in the treatment, Solomon four-group. 


\section{Solomon Four-Group Design}

One of the problems in the design is to overcome the effects of having a consistent order of destination appearance in early exposure $\left(X_{1}\right)$, late exposure $\left(X_{2}, X_{3}\right)$ and the exposure after the experimental stage for the measures at time 2 . Such a consistent sequence may influence the results in some ways due to the order effects and carryover effects as discussed in section 5.3.1.3. A possible way of eliminating such effects is to use a Solomon four-group design. With this design, those effects will be equalised out due to the fact that similar measures at time 1 and time 2 are arranged in a different order (Greene and D'Oliveira, 1999). Furthermore, this design adds a control condition where some destinations have no measures at time 1 . Of all the designs, Solomon four group is regarded as the most comprehensive design since it can control for all the effects of extraneous variables on internal validity (Kinnear and Taylor, 1996). Table 5.4 illustrates the Solomon four-group design for the appearance of a destination for the experimental conditions.

Table 5.4: Solomon Four Group Design

\begin{tabular}{|c|c|c|c|}
\hline & \multicolumn{2}{|c|}{$\begin{array}{c}\text { Treatment } \\
\text { (experimental groups only) }\end{array}$} & $\begin{array}{l}\text { Post-treatment } \\
\text { (all groups) }\end{array}$ \\
\hline Level & Early exposure & Late exposure & Exposure \\
\hline 1 & $\mathrm{D}$ & $\vec{D}$ & $\mathrm{D}$ \\
\hline 2 & $\mathrm{D}$ & - & $\mathrm{D}$ \\
\hline 3 & - & $\bar{D}$ & $\mathrm{D}$ \\
\hline 4 & - & - & $\mathrm{D}$ \\
\hline
\end{tabular}

Table 5.4 shows that the design is divided into four levels. The differences between these levels are the order of destination appearance (D) in the early and late exposures. A destination can appear in four different ways: early and late exposures (level 1) or early exposure only (level 2) or late exposure only (level 3 ) or none of the exposures (level 4). Each respondent in the experimental groups receives a complete set of Solomon four-group design as shown in Table 5.4. The design is applied to all the eight destinations shown in Table 5.3. It should also be noted that all eight destinations appear at the post-treatment stage and all groups are exposed to these destinations since this stage presents the measure at time 2, that is, intention to visit, late consideration and choice. 


\section{Latin Square Design}

To ensure the complete rotation of the order for all eight destinations across the respondents in each experimental group or counterbalancing, there is a need to add on another design to Solomon four-group. Latin square is one method considered as a suitable design since it allows such control without expanding the sample (Aaker et al., 2001). Each cell requires only one treatment level, which appears only once in each row and column and has a separate sample (Myers, 1972). Furthermore, this design allows an observation on how several treatments in different sequences affect a dependent variable (Neuman, 2000). Given the limitations in budget and time as previously mentioned, the potential advantage of this design was its ability to investigate the problem with less expenditure of time and less number of subjects (Myers, 1972). It should be noted however that the constraint on Latin square design is the requirement for the same number of rows and columns.

Considering that there are four levels of Solomon four-group design and the requirement of Latin square design as previously mentioned, the design needs to consist of four rows and four columns. To fit these eight destinations into the design, the eight high and low destinations shown in Table 5.3 are first paired as (HL)1, (HL)2, (HL)3 and (HL)4. Next, there are three major steps required to fit the eight destinations into the Latin Square Design. To provide the overall picture, those three steps taken are shown in Table 5.5. This is followed by an explanation of each step.

Table 5.5: Steps of Fitting Eight Destinations into Latin Square Design

Step 1

\begin{tabular}{|l|c|c|c|c|}
\cline { 2 - 5 } \multicolumn{1}{c|}{} & A & B & C & D \\
\hline$($ HL)1 & 1 & 2 & 3 & 4 \\
\hline$($ HL)2 & 2 & 3 & 4 & 1 \\
\hline$($ HL)3 & 3 & 4 & 1 & 2 \\
\hline$($ HL)4 & 4 & 1 & 2 & 3 \\
\hline
\end{tabular}


Step 2

\begin{tabular}{|c|c|c|}
\hline Block & Early exposure & Late exposure \\
\hline A & $(\mathrm{HL}) 1(\mathrm{HL}) 2$ & $(\mathrm{HL}) 1(\mathrm{HL}) 3$ \\
\hline B & $(\mathrm{HL}) 4(\mathrm{HL}) 1$ & $(\mathrm{HL}) 4(\mathrm{HL}) 2$ \\
\hline C & $(\mathrm{HL}) 3(\mathrm{HL}) 4$ & $(\mathrm{HL}) 3(\mathrm{HL}) 1$ \\
\hline D & $(\mathrm{HL}) 2(\mathrm{HL}) 3$ & $(\mathrm{HL}) 2(\mathrm{HL}) 4$ \\
\hline
\end{tabular}

Step 3

\begin{tabular}{|c|c|c|}
\hline Block & Early exposure & Late exposure \\
\hline A & Spain, Cyprus, Greece, Turkey & Spain, Cyprus, Italy, Malta \\
\hline B & Portugal, Tunisia, Spain, Cyprus & Portugal, Tunisia, Greece, Turkey \\
\hline C & Italy, Malta, Portugal, Tunisia & Italy, Malta, Spain, Cyprus \\
\hline D & Greece, Turkey, Italy, Malta & Greece, Turkey, Portugal, Tunisia \\
\hline
\end{tabular}

Step 1 shows that each block (A, B, C, D) consists of a complete Solomon fourgroup design, which contains four levels $(1,2,3,4)$ as shown in Table 5.4. The difference between these four blocks is the order in which the level or the destination appears. Each level appears in each column and row only once. Each subject is exposed to only one block of treatment, which has four pairs of destinations or eight destinations. Across the respondents in the experimental group, there is a complete rotation of all the orders of destination appearance.

Step 2 merges Step 1 with the Solomon four-group design shown in Table 5.4. In block A, for example, level 1 means that the destinations appear in both early exposure and late exposure and thus (HL)1 appears in early exposure and late exposure. Level 2 means that the destinations appear in only early exposure and thus (HL) 2 only appears once in the early exposure. For level 3, the destinations appear only in the late exposure and thus (HL)3 appears once in the late exposure. Regarding level 4, the destinations do not appear in either the early exposure or the late exposure. Therefore, there is no appearance of (HL)4 in block A.

Step 3 demonstrates the presence of all destinations by replacing (HL)1, (HL)2, (HL) 3 and (HL) 4 in Step 2 with the name of the destinations (see Table 5.3). These destinations are categorised into high preference level $(\mathrm{H})$ and low preference level 
(L) according to the actual UK residents' visits to the destinations as presented in Table 5.2.

There are two experimental groups in the design and each experimental group has four blocks of the destination appearance as shown in Step 3. Since early exposure only presents the destination name, the destination shown in early exposure can be placed in the questionnaires straight away. Late exposure presents destination name along with other package attributes such as quality of accommodation, number of nights, price and name of travel agent. Therefore, late exposure needs a systematic design to present such information.

This section has explained the Latin square design which ensures the complete rotation for all eight destinations across the respondents in the group. The next section discusses the fractional factorial design to create the late exposure, which systematically presents the destination name along with the information of other package attributes.

\section{Fractional Factorial Design}

Besides the destination name, there are other four package attributes to be included in the presentation of package holidays in the late exposure stage. Each of the four attributes has two levels. Detail regarding the selection of these attributes and their levels are presented in section 5.4.1.1 and 5.4.1.2. These four package attributes and their levels are shown in Table 5.6.

Table 5.6: Attributes and Levels

\begin{tabular}{|c|c|}
\hline Attributes & Levels \\
\hline Att1 - hotel star rating & $1=3$ stars \\
& $2=4$ stars \\
\hline Att2 - number of nights & $1=7$ nights \\
& $2=9$ nights \\
\hline Att3 - price & $1=f 410$ \\
& $2=f 470$ \\
\hline Att 4 - name of travel agent & $1=$ Thomas Cook \\
& $2=$ Lunn Poly \\
\hline
\end{tabular}


To present such information in a systematic way, an additional design based on conjoint analysis was used. Conjoint analysis is a multivariate technique to create a series of real or hypothetical products by combining the selected levels of each attribute specifically to understand how the respondents develop preferences for products or services and their intention to buy (Hair et al., 1998; Green et al., 2001). The hypothetical products are described as profiles of product features or 'attributes', which are treated as 'experimental factors' and the values in each attribute are called 'factor levels' or 'attribute levels' (Louviere et al., 2000). Each combination of attribute levels are so called 'profiles' or 'treatment combinations' (Louviere et al., 2000). With these profiles, the importance of each factor or each level within each factor can be revealed. However, it should be noted that the purpose of adding conjoint analysis into the design is to present systematically the information of other package attributes as shown in Table 5.6 to allow the investigation of the hypotheses rather than to determine the evaluation of the overall preference of the treatment combinations.

A complete factorial design in which each level of each attribute is combined with every level of all other attribute levels (Louviere et al., 2000) can be applied. However, complete factorial designs are rarely used because the number of possible combinations would be extremely large making it impractical to conduct the experiments (Louviere and Timmermans, 1990; Hair et al., 1998). For this study, a fractional factorial design is employed since it yields much of the same information provided by the complete factorial with a small number of experimental runs (Holland and Cravens, 1973). The design is termed a fractional factorial design since a fraction of a full factorial experiment is used (Holland and Cravens, 1973).

Considering respondents' fatigue and other resource constraints, the fractional factorial design is used to limit the treatment to 8 profiles. Table 5.7 illustrates the fractional factorial design for four attributes, each with two levels, for a total of eight profiles produced by Holland and Cravens (1973). 
Table 5.7: Treatment Combinations and Effects

\begin{tabular}{|c|c|c|c|c|c|c|c|}
\hline \multirow{2}{*}{$\begin{array}{l}\text { Treatment } \\
\text { combination }\end{array}$} & \multicolumn{3}{|c|}{ factor } & \multicolumn{3}{|c|}{2 factor interaction } & \multirow{2}{*}{$\begin{array}{c}\begin{array}{c}3 \text { factor } \\
\text { interaction }\end{array} \\
\mathrm{ABC}=\mathrm{D}\end{array}$} \\
\hline & $\mathbf{A}$ & $\mathbf{B}$ & C & $\mathbf{A B}$ & $\mathbf{A C}$ & BC & \\
\hline (1) & - & - & - & + & + & + & - \\
\hline $\mathbf{a}$ & + & - & - & - & - & + & + \\
\hline b & - & + & - & - & + & - & + \\
\hline $\mathrm{ab}$ & + & + & - & + & - & - & - \\
\hline c & - & - & + & + & - & - & + \\
\hline $\mathrm{ac}$ & + & - & + & - & $t$ & - & - \\
\hline $\mathrm{bc}$ & - & $\begin{array}{c}+ \\
+\end{array}$ & + & - & - & + & - \\
\hline$a b c$ & + & + & + & t & + & + & + \\
\hline
\end{tabular}

In Table 5.7, the "+" signs indicate that the factor is at its high level and " - " signs indicate that the factor is at its low level. The signs in different interaction columns are obtained by taking the product of the signs in the corresponding factor columns. To create the profiles, the signs of Factors A, B, C and D are used (Holland and Cravens, 1973).

Next, the treatment combinations and effects shown in Table 5.7 can be applied to the present study which has four attributes, each with two levels. The signs " - " and "t" shown in Table 5.7 can be converted to 1 (low) and 2 (high) for each attribute. Destinations are also added to the design by combining the destinations appearing in the late exposure column (see Table 5.5 Step 3 ) to the profiles. In Block A, for example, 1 refers to Spain, 2 refers to Cyprus, 3 refers to Italy and 4 refers to Malta accordingly. The first version of the treatment profiles is shown in Table 5.8.

Table 5.8: Profiles (Version 1)

\begin{tabular}{|c|c|c|c|c|c|}
\hline Profile & Destination & Att1 & Att2 & Att3 & Att4 \\
\hline 1 & 1 & 1 & 1 & 1 & 1 \\
\hline 2 & 2 & 1 & 1 & 2 & 2 \\
\hline 3 & 3 & 1 & 2 & 1 & 2 \\
\hline 4 & 4 & 1 & 2 & 2 & 1 \\
\hline 5 & 1 & 2 & 2 & 2 & 2 \\
\hline 6 & 2 & 2 & 2 & 1 & 1 \\
\hline 7 & 3 & 2 & 1 & 2 & 1 \\
\hline 8 & 4 & 2 & 1 & 1 & 2 \\
\hline
\end{tabular}

To vary the attributes and their levels systematically and comply with Latin square design that produces four blocks of destination appearance, the profiles should also 
have four versions. The first version of profiles is presented in Table 5.8. The second version is the mirror image of version 1 . It is obtained by reversing the sign of the all the columns of the first version e.g. 1 to 2 or 2 to 1 . Version 3 and version 4 are the copies of version 1 and version 2 . A complete design of the treatment combinations and effects of all four versions is shown in Appendix A.

The final stage is to replace the specified levels with destination names and attribute levels. Destination levels are directly taken from the late exposure column of Table 5.5 (Step 3). Table 5.9 assigns the levels of destinations to each block.

Table 5.9: Levels of Destinations in Each Block of Profiles

\begin{tabular}{|c|c|c|c|}
\hline Block & Levels & Block & Levels \\
\hline A & 1 = Spain & C & 1 = Italy \\
& $2=$ Cyprus & & $2=$ Malta \\
& $3=$ Italy & & $3=$ Spain \\
& $4=$ Malta & & $4=$ Cyprus \\
\hline B & 1 = Portugal & D & $1=$ Greece \\
& 2= Tunisia & & $2=$ Turkey \\
& $3=$ Greece & & $3=$ Portugal \\
& 4= Turkey & & $4=$ Tunisia \\
\hline
\end{tabular}

Based on the creation of profiles (see Table 5.8), levels of destinations in each block of the profiles (see Table 5.9) and attributes and levels (see Table 5.6) can be combined to create the complete profiles. Figure 5.4 shows the eight profiles of version 1. 
Figure 5.4: Profiles (Version 1)

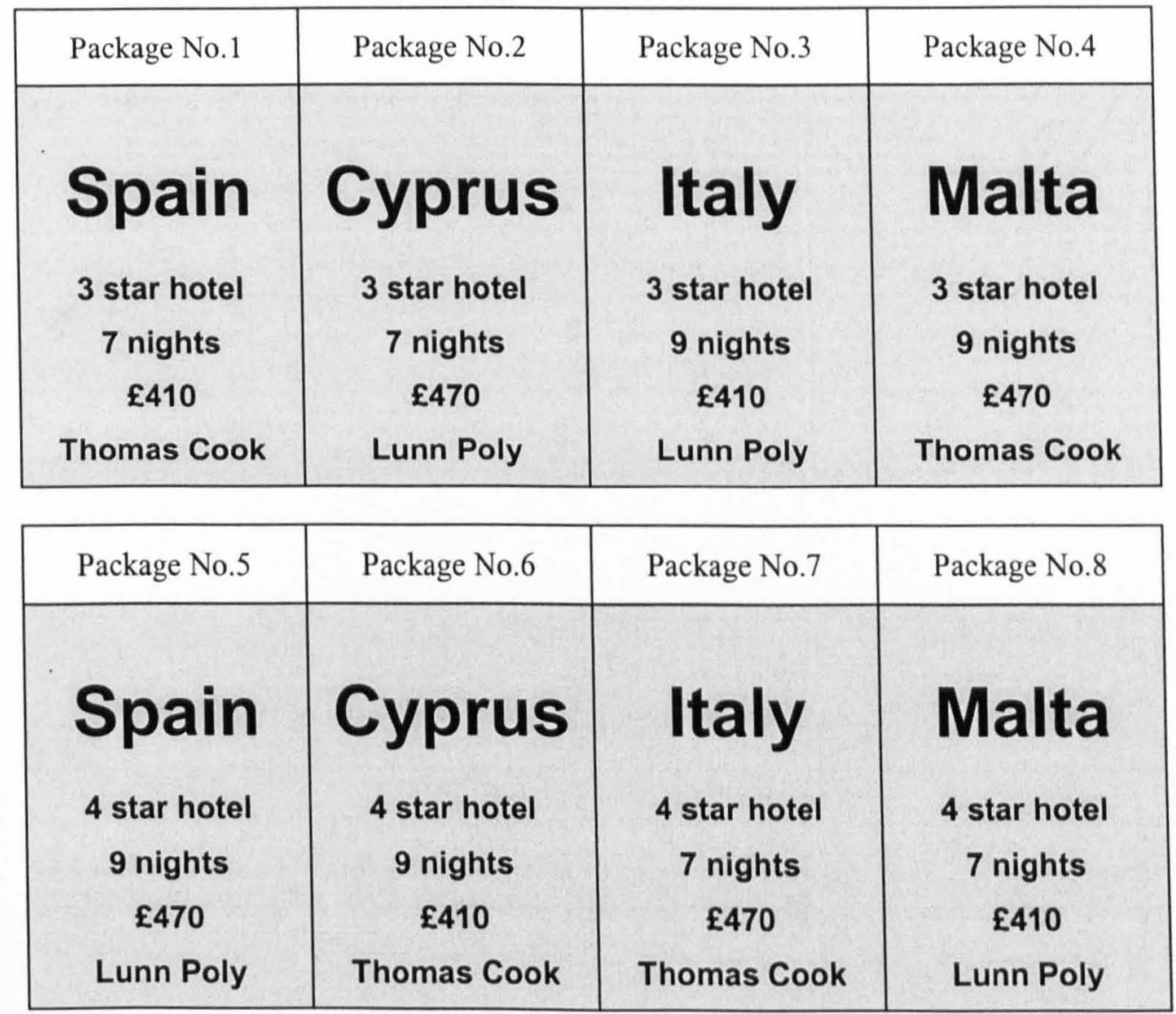

For each experimental group, there are four blocks of different order of destination appearance (see Table 5.5 Step 3) and four versions of profiles as shown in Appendix A. In total, there are sixteen different versions of profiles $(4 \times 4)$ of the appearance of destinations and attribute levels.

\subsubsection{Validity of the Design}

The validity of the design is extremely important since the purpose of an experiment is to detect the causal relationships and quantify them. Enhanced validity brings associated costs and the goal of experiments is to make the appropriate trade-off between validity and costs (Aaker et al., 2001). Furthermore, there should be a trade-off between internal validity and external validity. If high internal validity is an aim, one should be willing to settle for lower external validity and vice-versa (Sekaran, 2000). This section outlines three types of validity: internal validity, external validity and construct validity. 


\subsubsection{Internal Validity}

Internal validity of an experiment refers to 'the degree to which a design successfully demonstrates that changes in a dependent variable are caused by changes in an independent variable' (Clark-Carter, 1997, p.41). In other words, internal validity refers to 'the extent to which the research design accurately identifies causal relationships' (Hair et al., 2000, p.291). For a study that assesses the cause and effects of the treatment, internal validity is the primary concern since the key question in internal validity is whether observed changes can be attributed to the treatment and not to other causes (Trochim, 2002a). Unless one is sure what one has observed actually happened, there is nothing to generalise about it at all (Bechhofer and Paterson, 2000).

There are eight major threats to internal validity; namely, history, maturation, testing, instrumentation, statistical regression, selection bias, mortality and selectionmaturation interaction. (Aaker et al., 2001). Clark-Carter (1997) recommends two ways to lessen the threats to internal validity. First, a control group which does not receive any treatments can be added to the design. In this way, any changes in a dependent variable will only occur in a treatment group if the independent variable is affecting the dependent variable. Second, randomisation of subjects to different conditions will lessen the threats of selection.

Considering the threats to internal validity, this study adopted the two methods previously discussed to ensure the internal validity. First, a control condition is included in the design since such a condition represents the greatest strength of the experiment and the best way to ensure internal validity (Hair et al., 2000). Second, random assignment or randomisation of the subjects to the experimental groups and control group has been used. This means that on average, different groups are likely to be similar (Wright, 1997). Therefore, different groups would be balanced with respect to any characteristics that one can imagine and the results will not be confounded by extraneous factors (Bechhofer and Paterson, 2000). Bechhofer and Paterson (2000) further suggest that the noise (variations that are not of interest) will be less if the respondents are similar. When the noise is less, the conclusion will be 
more reliable and the experiment will have greater power to detect a real difference due to the effects of the treatments.

\subsubsection{External Validity}

Another type of validity is external validity. External validity refers to 'the extent to which a causal relationship found in a study can be expected to be found in the entire target population' (Hair et al., 2000, p.293). The question of generalisation is inescapable with experiments but is second to the internal validity (Bechhofer and Paterson, 2000; Trochim, 2002b).

Most experiments are not based on a statistically representative sample (De Vaus, 2002). Instead, the generalisation of the experimental findings can be tested by repeating the experiment in different circumstances and with different types of participants. If the findings can be replicated regardless of context, method and respondents' characteristics, then the results can be applied widely (De Vaus, 2002). Replication is a common method used in experimental research and the best approach to criticisms of generalisation on experimental research is simply to conduct the study with different age groups, different people and in different settings (Clark-Carter, 1997; De Vaus, 2002). The more the study can be replicated, the stronger the external validity or the ability to generalise will be. To achieve external validity, this study was conducted with two different sample groups to help ensure that the design could be replicated.

\subsubsection{Construct Validity}

In addition to the internal validity and the external validity, the construct validity should also be assessed. The questions regarding the construct validity are whether the experimental operations represent the conceptual variable or whether the variation of an independent variable makes the subjects react differently (Christensen, 1988). This section focuses on the construct validity of the three independent variables: the destination preference, the prominence of the destination and the exposure to the alternatives. 
First, the levels of destination preference (high and low) are based on the actual intention to visit ratings for each of the eight destinations across the three groups. For the experimental groups, such ratings are measured prior to the experimental treatments. This also serves as a manipulation check against the initial design regarding the high-preferred and less-preferred destinations of UK residents (see Table 5.3). Manipulation checks are 'the tests on the manipulation of the independent variable' (Christensen, 1988).

Second, the variation of the destination prominence is manipulated in two ways: amount of information given and package heading. There are two levels of presenting the amount of information: presenting the name of destination only or presenting the name of destination along with other package attributes. Within the latter condition, there are two levels of presenting the package heading: highlighting destination as a package heading or embedding destination with the package description while highlighting price as a package heading. This design allows different comparisons between levels of destination prominence.

Third, the variation of exposures is manipulated through early and late exposures (see Figure 5.2) and the use of time pressure for the respondents to make decisions. At the early exposure, there are four destinations presented. At the late exposure, there are also four destinations presented including two previously presented alternatives and two new alternatives. This can help explain whether alternatives should be presented only at early exposure or only at late exposure or all the time or none of the exposures. None exposures would reveal that the consumers know exactly what they look for without being influenced by the experimental exposures.

\subsection{Instrumentation}

This section describes the instrument employed in this study. For this study, the instrument is a questionnaire. A questionnaire is an efficient data collection mechanism when the researcher knows which variables are required and how to measure the variables of interest (Sekaran, 2000). This section is divided into three 
parts: the questionnaire development, the questionnaire structure and the reliability of the measurement scales.

\subsubsection{Questionnaire Development}

There are four major stages in the questionnaire development for this study. The four stages described in this section are the exploratory study, the secondary data collection, the pre-tests and adjustment, and finally the problems and suggestions for the main data collection.

\subsubsection{Exploratory Study}

The earliest stage of the study is likely to be exploratory. This stage provides a researcher with 'the feel of the problem' and helps a researcher on the construction of the questionnaire (Oppenheim, 1992). An exploratory study can be used at the first phase of the study for the development of the design and a systematic study (Neuman, 2000). The exploratory study here has been conducted in three major ways.

First, statistics regarding the overseas holidays taken by UK residents were researched. It appears that the preferred type of UK residents' overseas holiday is a beach holiday with a total of $46 \%$ market share (WTO, 1999b). The UK holiday market is regarded as one of the most developed outbound package holiday markets in the world (Keynote, 1999). Each year, over $50 \%$ of UK residents' overseas holiday visits are through package holidays (National Statistics, 2001). This suggests that effective presentation of package holiday information may help promote lesspreferred beach holiday destinations to the UK tourists. Details of the UK holiday market are presented in Chapter 1.

Second, semi-structured individual interviews with UK passengers waiting to depart for their overseas holidays at Heathrow airport were conducted. This exploratory study helped formulate the research questions and developing the questionnaire. The results of the interviews suggest that destination and price are the important attributes 
in purchasing package holidays. There are two main reasons for purchasing package holidays. First, package holidays are considered as a safe method to visit unfamiliar destinations. Second, they are regarded as a convenient way of taking holidays since flights and accommodation could be bought in one holiday purchase. These two main reasons are consistent with the study on the demand for package holidays by Sheldon and Mak (1987).

Finally, holiday brochures, travel agents' window displays as well as holiday websites were surveyed to observe the attributes used for describing package holidays and the presentation format of the package holidays. It was found that attributes commonly used to describe package holidays were destination, number of nights, type of accommodation and price. Most package holidays appeared to have destination as an overall heading.

\subsubsection{Secondary Data Collection}

The second stage of questionnaire development is the secondary data collection. The first purpose of this stage is to select eight appropriate overseas beach destinations for the study. The second purpose is to find the appropriate levels for two following attributes: number of nights and price.

For the first purpose, the tourism statistics concerning UK residents' overseas holidays and the approximate price of each destination were considered. The price survey suggested that overseas beach destinations should be divided into two groups; namely, long haul and short haul. However, long haul was excluded from the study due to the terrorism in Bali during October 2002 and the threat of war in Iraq. These incidents might have heightened the perceived risks to visit long haul destinations. The only option left was to conduct the study on short haul destinations. The chosen short haul beach destinations were Cyprus, Greece, Italy, Malta, Portugal, Spain, Tunisia and Turkey, based on the fact that these destinations were within a similar price range. 
For the second purpose, two attributes were surveyed from holiday brochures and holiday websites for the beach holidays departing between June and August 2003. These two attributes were number of nights and price of package holidays. The purpose of the survey was to find two appropriate levels for each of the two attributes. For number of nights, overseas beach holidays mostly fit into two categories: 7 nights or 14 nights. However, 7 nights and 9 nights were selected for the two levels based on the fact that there should not be a big gap between the two attribute levels in order to rotate each level in the design sensibly. As far as the price of the package holidays was concerned, a mean price for a total of eight destinations was calculated based on 7 nights and 9 nights at a three star hotel selected from holiday brochures and websites. As a result, the mean holiday price for 7 nights was $£ 410$ and that for 9 nights was $£ 470$. It should be noted that these prices are referred to as level 1 and level 2 in the design (see Table 5.6). These two price levels were applied to all the eight destinations included in the design.

\subsubsection{Pre-tests and Adjustment}

This section describes how the questionnaire was developed. The duration of the questionnaire development was 12 months. There are three pre-tests and a pilot study. In each stage of pre-testing, comments from respondents were carefully considered and adjustments were performed to ensure that the subjects understood the hypothetical situation and the questions they were being asked to do. This section is divided into four parts as follows: the pre-test I, the pre-test II, the pre-test III and the pilot study.

\section{Pre-test I}

Pre-tests are small tests of single elements of the research instrument and are used to check the 'mechanical' problems of the instrument (Sarantakos, 1998). There were three purposes in testing the questionnaire at this stage. The first purpose was to evaluate the respondents' interpretation and understanding of questions. The second was to check the response format. The third purpose was to ensure that the study cover the important attributes affecting the holiday decision. 
The pre-test stage I was conducted with twenty respondents in October 2001. At this stage, respondents were told that the questionnaire was being developed and they were asked to help improving it. Respondents were asked to comment on each individual question. They were also asked how they would rephrase the questions and whether there were any other alternatives they wished to include. Due to the intensive nature of the questions, a short version of the questionnaire was conducted.

This version of the questionnaire mainly tested the destination attributes and the package holiday attributes. The duration taken to complete the questionnaire was 10 14 minutes. The results reflected three main points. First, the instructions for some sections were not clear and needed further pre-testing and the hypothetical situation needed further revision. Second, the response format needed to be rearranged and instructions needed further revisions. Third, package holiday attributes and destination attributes included in the questionnaire were considered as important and sufficient for the decision-making.

\section{Pre-test II}

Pre-test II was conducted with twenty respondents in May 2002. This version of the questionnaires included measures at time 1, measures at time 2 and perception of destinations. The questionnaire at this stage was longer than that for the Pre-test $\mathrm{I}$. The purpose of testing the questionnaire at this stage was to evaluate individual questions and the overall picture of the questionnaire. Five factors were observed in this pre-test: instruction, flow, skip patterns, timing, and respondents' interest and attention.

Respondents found the questionnaire in this stage exhausting and time consuming. Some respondents quitted in the middle of the questionnaire as they found it too long. The duration taken to complete the questionnaire was 23-30 minutes. There were three main points suggested for further pre-testing. First, a question regarding the destinations that the respondents consider visiting should not be open-ended since they would become problematic for data analyses. Second, measures included in any stage should be kept to a minimum to avoid the respondents' boredom. Priority 
should be given to the dependent variables. Although it was acknowledged that an experiment should measure as many extraneous variables as possible, this pre-test suggested that respondents' fatigue should take into account since they might affect the results of the study. Third, the response format needed further revision. Although several measures needed to be arranged in one table, the table layout should be kept as simple as possible. Furthermore, the instructions in the table should be clearly stated within itself to save the respondents' time.

\section{Pre-test III}

In the last pre-test stage, twenty respondents participated. It was conducted in August 2002. A hypothetical situation, instructions and format were three main areas to be observed at this stage.

The duration taken to complete the questionnaire at this stage was between 10-14 minutes. The results at this stage were encouraging showing that the adjustments from the last two pre-tests had been effective. Respondents indicated that a hypothetical situation was very clear. Instructions and questions in each section were very well understood. There was a good flow in the questionnaire structure. Some of the respondents found completing the questionnaire an enjoyable experience.

\section{Pilot Study}

The pilot study is a small-scale replica and a rehearsal of the main study. While pretests help to solve isolated mechanical problems of an instrument, a pilot study is concerned with the administrative and organisational problems related to the whole study and the respondents (Sarantakos, 1998). Considering that the duration taken to complete the questionnaire in pre-test III was not too long, a few questions relating to perception of destinations were added to help later explaining the results of the study. At this stage, the skip patterns and the final layouts of the questionnaire were carefully considered to ensure that it was as clear as possible. This stage was the final check prior to the main data collection. 
Thirty respondents participated in the pilot study conducted in October 2002. The duration taken to complete the questionnaire was between 12-16 minutes. The results of the pilot study were satisfactory in terms of instruction, questions, response format, skip pattern, layout, timing and the respondents' interest. Therefore, it was decided to proceed with the main data collection.

\subsubsection{Problems and Suggestions for Main Data Collection}

An advantage of this study was that the research topic readily interested the respondents once they were approached. However, the major problem found during the early stages of questionnaire development was the length of questionnaire. This was especially true for the experimental groups since these groups needed to be exposed to measures and treatments. Nevertheless, these items were the important parts of the design, which was crucial to answer the research question. Thus, the main concerns of the main data collection were to keep the respondents motivated in completing the questionnaire and getting all the questionnaires returned. As discussed in section 5.3.1.4, each questionnaire was considered as a unique treatment level and so it was crucial that each level should be returned.

Different stages of questionnaire development provide several suggestions for the main data collection. First, the exploratory study suggested that questionnaires should not be conducted at the airport. There were not enough seats available for the respondents to fill in the questionnaire and another concerning issue was the level of sound. Furthermore, it did not seem appropriate to conduct the study with the people who had already chosen a destination for their next holiday. Therefore, it was considered that the use of an artificial environment with the given hypothetical situation would yield more internal validity and better chances of accessibility.

Second, the distribution and collection of the questionnaires needed to be carefully considered. With the constraints of the design demanding that every treatment level should be returned in equal numbers (see section 5.3.1.4, Latin square design), a mail questionnaire would certainly be problematic in terms of the response rate. The most efficient way to guarantee the returned questionnaires would be that the researcher 
distributed and collected directly by herself. By doing so, equal numbers for each treatment level would not be too difficult to achieve.

Third, respondents within the sample should be homogeneous to ensure the power of the results. Therefore, it was necessary to target the places where people had the same characteristics such as universities, meetings or social events.

\subsubsection{Questionnaire Structure}

This section explains the structure of the questionnaire used in the study. There are nine sections in the complete version of the questionnaire. The respondents in the experimental groups had a complete version which consists of nine sections. Respondents in the control group had only eight sections from which the early exposure (part of section 2) and the late exposure (section 3 ) were excluded. Copies of the questionnaires for a control group, an experimental group 1 and an experimental group 2 are shown in Appendix B, Appendix C and Appendix D. Each section of the questionnaire is discussed here accordingly.

\subsubsection{Section 1}

The purpose of this section is to capture the respondents' preference for the next overseas holiday as well as past experience about overseas holidays. An overseas holiday here refers to a visit to any other countries outside UK for holiday purposes for a period of less than 12 months. This section contains four questions. The first question asks about the preferred type of their next overseas holiday. The second question is about their preferred month for taking a next overseas holiday. The last two questions in this section intend to measure travel experience. Experience as defined by Punj and Srinivasan (1989) has two dimensions: width and depth of experience. Width of experience denotes the diversity of an individual's purchase history while depth of experience signifies the total number of purchases an individual has made in the product category (Punj and Srinivasan, 1989). The third question therefore measures the width of travel experience by asking the frequency of taking overseas holidays in the past five years. The final question measures the 
depth of travel experience by asking the frequency of taking overseas beach holidays in the past five years.

\subsubsection{Section 2}

The aim of this section is to introduce the respondents to a hypothetical situation, describing a situation that they have won an overseas beach holiday voucher worth $£ 1,000$. Details and discussions relating to the hypothetical situation are presented in section 5.3.1.1. There are two questions asking whether they would use the holiday voucher they have won and with whom they would like to spend their overseas beach holiday. These two questions are included to ensure that the respondents have read the hypothetical situation.

Next, a list of four destinations is presented at this early exposure stage. As previously mentioned, only the respondents assigned to the experimental groups are exposed to these destinations. First, they are asked to rank the four destinations from the most preferred to the least preferred. Next, they are asked to rate their intention to visit to each destination. Then, they are instructed to tick the destinations that they consider as possible destinations and finally select those that they would consider visiting. The measures used in this section are adopted from previous studies on destination choice and consideration sets. The measure of intention to visit is from Woodside and Lysonski (1989). There are two early consideration measures. The first definition regarding the destinations considered as possible destinations is from Crompton (1992). The second definition that refers to the destinations considered visiting is adopted from Roberts and Lattin (1991).

\subsubsection{Section 3}

This section concerns the preference for overseas beach package holidays presenting destination name along with other attributes. Referring to Figure 5.2, only the experimental groups are exposed to these treatments $\left(X_{2}\right.$ or $\left.X_{3}\right)$ depending on the package heading. The respondents in the experimental group 1 are exposed to destination as a package heading while those in the experimental group 2 are exposed 
to price as a package heading. This section also refers to as late exposure. As mentioned in section 5.3.1.2, late exposure presents four destinations consisting of two destinations previously presented in the early exposure and two new alternatives. There are two scenarios in this section (see Appendix C and Appendix D). Each scenario has 4 profiles or package holidays. The presence of destinations and attribute levels is systematically varied as presented in Appendix A. Only the respondents in the experimental groups are asked to rate the attractiveness of each of the package holidays by indicating how attractive they find each package holiday on a seven-point scale anchored by 'not at all attractive' (1) and 'very attractive' (7). Furthermore, they are asked to select the most preferred package holiday and the least preferred package holiday for each scenario.

\subsubsection{Section 4}

The purpose of this section is to measure the dependent variables at time 2 including intention to visit, late consideration and choice. This section presents the respondents with a list of all eight destinations for using the overseas beach holiday voucher today to book their holidays departing between June and August 2003. For experimental groups, these eight destinations include another two new alternatives that the respondents have not seen in either early or late exposures. This introduces a new context where the respondents need to make a decision to use their voucher.

The situation introduced in this section allows the measurement for the dependent variables. First, the respondents are asked to rate their intention to visit to each destination. Next, they are asked to select up to four destinations that they would consider visiting. Four destinations are limited for consideration since previous studies (Woodside and Sherrell, 1977; Thompson and Cooper, 1979; Um and Crompton, 1990) suggest that most tourists actively consider approximately four destinations. The measures for intention to visit and late consideration set here are similar to those discussed in section 5.4.2.2. Finally, they are asked to select only one destination as their final choice. 


\subsubsection{Section 5}

After the treatments, this section is designed to measure the importance of the presented attributes when choosing overseas beach holidays. There are six major attributes including airline, destination, number of nights, price, quality of accommodation and name of travel agent. Respondents are asked to indicate to what extent each of these attributes is important when choosing an overseas beach holiday on a 7-point scale from a scale of 1 (not at all important) to 7 (very important). The measurement scale is adopted from Sujan and Bettman (1989).

\subsubsection{Section 6}

This section is intended to capture the respondents' knowledge of and past visits to eight overseas holiday destinations. The knowledge measurement is adopted from Oliver and Bearden (1985) which has a three-item scale. For destination knowledge, it is considered that two items are appropriate. First, respondents are asked to indicate the extent to which they are informed by friends, television and magazines etc. about each as an overseas beach holiday destination on a scale ranging from 1 (not at all informed) to 7 (very well informed). Second, respondents are asked to specify how familiar they are with each as an overseas beach holiday destination on a 7-point scale from 1 (not at all familiar) to 7 (very familiar). For past visits, the respondents are asked to indicate the number of their visits to each destination regardless of the purpose of visit.

\subsubsection{Section 7}

The main purpose of this section is to measure the perception of destinations. This section is divided into three sub-sections. The first sub-section asks the respondents to select only one destination that they think offers the best in each of the ten attributes. These ten attributes are local food, beaches, friendliness of local people, climate, nightlife and entertainment, quality of accommodation, quality of infrastructure, safety, hygiene and cleanliness and value for money. Attributes included in this section are adopted from the previous studies of destination image 
(Gearing et al., 1974; Haahti, 1986; Calantone et al., 1989; Mok and Armstrong, 1995; Turner and Reisinger, 1999; Baloglu and McCleary, 1999).

In the second sub-section, the respondents are asked to rate the extent to which they perceived the overall image of each overseas beach holiday destination by using the scale from 1 (very negative) to 7 (very positive). The scale used in this section is adopted from the study of destination image by Baloglu and McCleary (1999).

The last question measures the perception of price to eight destinations. The respondents are given the condition that each of these eight destinations are offered in package holidays including the return scheduled flights for 7 nights at a three star hotel with breakfast and dinner, departing between June and August 2003. Then, they are asked to select a destination they think would offer the most expensive package holidays and a destination that would offer the cheapest package holidays.

\subsubsection{Section 8}

This section is designed to measure consumer expertise, the ability to perform the task successfully (Alba and Hutchinson, 1987). The expertise measurement scale is adopted from Kleiser and Mantel (1994) to measure the four dimensions of expertise; namely, cognitive effort, analysis, elaboration and memory. Cognitive effort refers to decision-making that is performed with minimal effort and without conscious control. Analysis represents the extent to which consumers access all relevant information for a particular task. Elaboration represents the number of intervening facts that must be computed in order for an inference to be made. Memory refers to one's ability to remember product-related information.

Kleiser and Mantel (1994) produce multi-items for each dimension: cognitive effort (five-item scale), analysis (three-item scale), elaboration (three-item scale) and memory (four-item scale). Considering the length of questionnaire and duration taken to complete the questionnaire, one item relating to each dimension is used. Thus, respondents are asked to indicate to what extent they agree with the four 
statements representing the four dimensions of the expertise. The 7-point scale anchoring 1 (strongly disagree) to 7 (strongly agree) is used.

\subsubsection{Section 9}

The main purpose of this section is to measure socio-demographic factors. For the sample group 1 (students), there are three items as follows: gender, age and nationality. For the sample group 2 (adults), there are seven items: gender, age, marital status, age of the youngest child in household, education, household income and UK residency. Another item included in this section is an item in which the respondents can make comments and suggestions.

\subsubsection{Reliability of the Measurement Scales}

This section reports the internal consistency of the measurement scale in the study. There was only a measurement on knowledge, which needed to be investigated since this scale had more than one item. One of the most commonly used indicators of the internal consistency is Cronbach's alpha coefficient. Ideally, the Cronbach's alpha coefficient should be above 7 (Pallant, 2001).

According to Oliver and Bearden (1985), knowledge measurement scale with three items has a good internal consistency, with a Cronbach alpha coefficient of .85 . In this study, the Cronbach alpha coefficient of the knowledge with two items was .82 for sample group 1 (students) and .72 for sample group 2 (adults). However, the knowledge scale was still considered as reliable since it was above .7 .

\subsection{Data Collection}

Once the study has been designed and the instrument has been developed, the next stage is to collect data. This section describes how data was collected and is divided into five parts. These five parts cover sampling, method, ethics, procedure and response rate. 


\subsubsection{Sampling}

Sampling is the process of selecting a sufficient number of elements from the population so that by studying the sample, and understanding the properties or characteristics of the sample, it would be possible to generalise the properties and characteristics to the population (Sekaran, 2000, p.267). This section discusses the three main issues regarding the sampling: design, sample and size.

There are two major types of sampling designs: probability and non-probability. In non- probability sampling, the probability of selection of each sampling unit is not known (Hair et al., 2000). In probability sampling, each sampling unit in the defined target population has a known, non-zero probability of being selected from the sample (Hair et al., 2000). Ideally, the preferred approach is to use probability sampling. Therefore, probability sampling requires a sampling frame, a list of sampling units or a procedure to reach the respondents with a known probability. Information on sampling units is necessary prior to employing the sampling process. However, not all research can establish a sampling frame. The problem involved with data collection in tourism is the difficulty of finding a representative group of tourists as a whole due to seasonality and individual judgement of whether to take a holiday (Swarbrooke and Horner, 1999). Therefore, the sampling frame for studies on pre-purchase behaviour would be hard to define. Abdullah (2002) further addresses the problem of establishing a sampling frame for consumer behaviour studies in tourism of UK residents and concludes that it is rather impossible. The Data Protection Act is a major obstacle for establishing a sampling frame. Tour operators, airlines and national tourism offices would not reveal lists of their customers. For this study, the Data Protection Act also proved to be problematic when a list of customer contact details was requested from any organisations. Nevertheless, attempts were made to contact airlines and national tourism organisations. Holiday websites were also approached for the purpose of purchasing their customers' email addresses. However, these attempts were unsuccessful.

The only feasible option for the study was the use of non-probability sampling which did not require a sampling frame. The advantage of non-probability sampling for the 
experiments such as this study is that it allows the study to deal with a homogeneous population (Aaker et al., 2001). A homogeneous sample is very useful for providing more control over extraneous factors (Sirakaya et al., 2001). To overcome the problems relating to the sampling frame and the homogeneity of the sample, this study therefore adopted a non-probability sampling design. Concerning the existing constraints of resources and time, this study employed convenience sampling. For experimental research on human subjects, this sampling technique is generally used due to the limited availability of subjects (Christensen, 1988). The procedure employed was to contact the individuals that were readily available and willing to volunteer from various places e.g. classrooms, a social event of a particular organisation or social club. The assumptions were that the target population was homogeneous and the individuals interviewed were similar to the overall defined target population (Hair et al., 2000).

To ensure the replication, there are two samples included in the study. The first sample consists of two hundred students. All subjects are full-time undergraduate management students at the University of Surrey. Subjects were recruited from the class having been advised a week in advance. The second sample consists of two hundred Guildford residents. Subjects were recruited from school Christmas fairs and a shopping centre in Guildford. Participation was voluntary and none of the subjects were acquaintances of the researcher.

Regarding the sample size, Roscoe (1975) suggests that the minimum sample size of 30 for each category is needed where the sample is divided into sub-samples (i.e. control group, experimental groups). Another requirement for experimental studies employing Latin square design is that it requires an equal number of subjects in rows, columns and treatment levels (Aaker et al., 2001). Considering these issues, the sample size for each of the studies was decided at 200 subjects. These 200 subjects were randomly distributed into three groups as follows: control group (40 respondents), experimental group 1 (80 respondents) and experimental group 2 (80 respondents). Table 5.10 demonstrates the equal number of subjects in rows, columns and treatment levels for the experimental group. 
Table 5.10: Questionnaire Distribution for Experimental Group

\begin{tabular}{|c|c|c|c|c|c|}
\cline { 2 - 6 } \multicolumn{1}{c|}{} & V1 & V2 & V3 & V4 & Total \\
\hline Block A & 5 & 5 & 5 & 5 & 20 \\
\hline Block B & 5 & 5 & 5 & 5 & 20 \\
\hline Block C & 5 & 5 & 5 & 5 & 20 \\
\hline Block D & 5 & 5 & 5 & 5 & 20 \\
\hline Total & 20 & 20 & 20 & 20 & 80 \\
\hline
\end{tabular}

For each of the experimental groups, it can be seen from Table 5.10 that there are 5 respondents within each treatment level or cell. The number of respondents made a total of 20 respondents in each row and column. The total of respondents in each of the experimental group is 80 respondents.

\subsubsection{Method}

One of the most important decisions a researcher must make is the way in which the data will be collected. Factors affecting the choice of method should be taken into account. Aaker et al. (2001) mention several factors affecting the choice of method: sampling, type of population, question form, question content, response rate, cost, available facilities and duration of data collection. In this study, there are four major factors affecting the choice of data collection method.

First, the design of the experiment led to the limitation of data collection methods. As previously discussed in section 5.4.1.4, every questionnaire represents each treatment level. Therefore, not only is a high response rate crucial but also every treatment level in each cell must be returned. Distribution and collection of the questionnaire on the same day was considered an ideal option to ensure that the two requirements were met.

Second, the questionnaire for the experimental groups covering treatment and measures at time 1 and time 2 leads to a lengthy questionnaire. Pre-tests during the questionnaire development suggested that lengthy questionnaires affected the 
response rate and uncompleted questionnaires. The selected method should lead to a high response rate and encourage the completion of the questionnaires.

Third, financial resources and time constraints influenced the choice of data collection method. A mail questionnaire was initially considered to be an option. Although this method may seem to be less expensive, the cost of postage, clerical time and the copies of the questionnaires do not seem to be trivial. Pu (2000) used the combination of 'drop-off and mail back technique' with Guildford residents but the response reported was only $36 \%$. Such a response rate from this data collection method would be considered as problematic for this study.

Finally, the duration of data collection was limited to two months (November and December 2002). Considering the uncertainty caused by the impending wars in Iraq, it was necessary for this study to complete the data collection as soon as possible before any unexpected events would happen. These unforeseen events, to a certain extent, might affect the destinations being studied.

Taking all the above factors into account, a self-administered questionnaire was considered as the appropriate data collection method. The questionnaires were distributed and collected by the researcher on the same day. The fact that the respondents were face to face with the researcher increased their attention on the questionnaires and the rate of participation. Furthermore, the incentives of prize draws such as cash and T-shirts also encouraged the respondents to complete the entire questionnaires.

\subsubsection{Ethics}

Ethics is an integral part of the research process. If research is to be carried out in a proper way, full account of the ethical issues has to be taken (Neuman, 2000). This study took the ethical issues into consideration in designing the questionnaire, before and after the data collection process. There are two main issues considered as fundamental principles in this study: informed consent and confidentiality. 
Informed consent was placed as a priority in this study. Participation in the study was voluntary. Furthermore, there is a covering letter on the first page of the questionnaire clearly stating the name of the researcher, organisation, contact details and more importantly the purpose of the study (see Appendix B, Appendix C and Appendix D). The expected duration of the study is included. The respondents are requested to read the first page before they agreed to proceed completing the questionnaires.

There is also a statement protecting their confidentiality on the covering letter. The information provided is to guarantee the respondents that their personal details will not be made public or used for any other purposes. The information will not be released in a way that permits linking a specific individual to responses but will only be presented in an aggregate form.

\subsubsection{Procedure}

Data were collected from two samples during November and December 2002. The first sample was undergraduate full-time management students of University of Surrey and the second sample was UK residents in Guildford. The data collection was completed well before Iraq war, which began in March 2003. Therefore, the results should not be severely affected by the perceived risks relating to the destinations included in the study.

For the first sample, students were told one week in advance that there would be a questionnaire survey at the end of the class. Students were briefly told about the purpose of the study. Only students who were interested in participating were requested to stay after the lecture. On the day that the data were collected, the purpose of the questionnaire was first explained and students were asked to sit one chair away from one another to avoid the discussions. Then, the students were randomly assigned to each condition and treatment level. They were told that there were no right or wrong answers and they were free to express their opinion. The researcher collected the completed questionnaires from the students on the same day. 
For the second sample, there were two ways to reach the sample. The first method was to attend school Christmas fairs where there were parents of pupils and nearby residents attending the event. There were posters around the fairs explaining the research purpose and the importance of their contribution. Respondents were approached individually and the questionnaires were distributed to those who were willing to participate. Tables were reserved in the coffee room and other quiet rooms for respondents to sit and complete the questionnaires. The second method of collecting data from the second sample was by approaching them in the shopping centre dining area, where they are plenty of tables and chairs for completing the questionnaire. Respondents were approached individually and the purpose of the study was explained. Similarly, only those who agreed to participate were given questionnaires. For both methods, the respondents were asked to return the questionnaires to the researcher on that day. Subjects in both methods were randomly assigned to each condition and treatment level.

It should be noted that random assignment is a major consideration for this study. Random assignment is a process to assign the subjects to groups in such a way that each subject has an equal chance of being placed in any of the conditions to ensure that the subjects' characteristics are equivalent (Drew and Hardman, 1985).

\subsubsection{Response Rate}

The response rate for the distribution of the questionnaire by the methods discussed in the previous section was highly successful since the questionnaires were only distributed to those who were interested and were returned to a researcher on the same day. The total number of questionnaires returned was 200 for each sample group. The 200 questionnaires fulfilled the sample size of the three conditions as follows: control condition (40), experimental condition 1 (80) and experimental condition $2(80)$. For each experimental condition, all cells contained exactly five subjects (see Table 5.10). This suggests that the selected method proves to be very efficient in terms of the limitations of time and resources. Furthermore, it helps fulfilling the design requirement that there should be an equal number in each cell. 


\subsection{Preparation for Data Analyses}

SPSS version 11.5 was used for data analyses of the study. Four major steps were prepared before the analyses began. This section explains the four steps of preparation for the data analyses. These steps are data coding, data entry, data screening and planned statistical analyses.

\subsubsection{Data Coding}

A codebook was prepared prior to data collection. A codebook is a summary of the instructions that help convert the information obtained from each respondent into the format that SPSS can understand (Pallant, 2001). This process involved the defining and labelling of each variable as well as assigning numbers to each of the possible responses before the data entry could begin.

\subsubsection{Data Entry}

Once the variable names were defined and value labels were given to each response, data entry into the SPSS software was performed. This task involved the direct input of the coded data into the programme, which allowed the data analyses process. At this stage, the codebook, which had been prepared at the previous stage, was used as a reference.

\subsubsection{Data Screening}

After all the data were entered to SPSS and before the analysis began, data screening to detect any errors from entering the data were thoroughly checked. The main purpose of this process was to find values that fell outside the range of possible values of both categorical and continuous variables. Descriptive statistics were run to check values of each variable against the codebook. Any errors found were corrected before the data analyses began. 


\subsubsection{Planned Statistical Analyses}

There are different factors involved in choosing the statistical methods to analyse the data. Pallant (2001) suggests that these considerations include the type of question, the types of items and scales included in the questionnaire, the nature of data available for each of the variables and the assumptions that must be met for each statistical technique.

There are two major statistical techniques available to analyse the data: parametric or non-parametric tests. Parametric tests are used to analyse the data of this study since they can handle experimental designs in which more than one independent variable can be varied at the same time (Greene and D'Oliveira, 1999). Furthermore, parametric tests are fairly robust even when their assumptions are broken (Robson, 1983; Clark-Carter, 1997; Greene and D'Oliveira, 1999). With large enough sample sizes $(30+)$, the violation of assumptions should not cause any major problems (Stevens, 1996; Gravetter and Wallnau, 2000).

This study involves two types of statistical techniques. The first statistical technique is to explore the difference among groups. Analysis of variance (ANOVA) is the appropriate method for two reasons. First, it can be employed to deal with complicated experiment design in order to test the causal relationships between the independent and dependent variables (Wright and Fowler, 1986). Second, ANOVA can cope with two or more independent variables simultaneously, which does not only show the effects of each variable separately but also the interaction of two or more variables (Howell, 1989). When using factorial design, there are no other tests that yield as much information as ANOVA (Grimm, 1993). Although ANOVA is based upon assumptions of normality and homogeneity of variance, Howell (1989) suggests that it is a very robust statistical procedure and the assumptions can be violated with relatively minor effects. F statistic is robust with respect to type I error against non-normality and this also extends to MANOVA (Stevens, 1986). Therefore, ANOVA can be a valid test with contravention of some of its assumptions (Clark-Carter, 1997). 
The second statistical technique is to explore relationships. Logistic regression is used to explore the predictive ability of the independent variables which may be continuous or categorical or a mixture of both while the dependent variable is a categorical variable (Pallant, 2001). Logistic regression has no assumptions about the distribution of the predictors and the predictors do not have to be normally distributed (Tabanick and Fidell, 1996).

There are six hypotheses in the study. The planned statistical techniques to test the hypotheses are summarised in Table 5.11 .

Table 5.11: Planned Statistical Tests

\begin{tabular}{|c|c|}
\hline Hypotheses & $\begin{array}{c}\text { Planned } \\
\text { Statistical Tests }\end{array}$ \\
\hline $\begin{array}{l}\text { H1: For less-preferred destinations, presenting the destination name along with } \\
\text { other attributes increases (a) intention to visit (b) their probability of entering late } \\
\text { consideration (c) their probability of becoming a choice. }\end{array}$ & \multirow{2}{*}{$\begin{array}{l}- \text { ANOVA } \\
\text { - Logistic } \\
\text { Regression }\end{array}$} \\
\hline $\begin{array}{l}\text { H2: For less-preferred destinations, presenting price as a package heading } \\
\text { increases (a) intention to visit (b) their probability of entering late consideration } \\
\text { (c) their probability of becoming a choice. }\end{array}$ & \\
\hline $\begin{array}{l}\text { H3: Destination importance decreases when presenting (a) destination name along } \\
\text { with other attributes (b) price as a package heading. }\end{array}$ & MANOVA \\
\hline $\begin{array}{l}\text { H4: Early exposure to less-preferred destinations increases (a) intention to visit (b) } \\
\text { their probability of entering late consideration (c) their probability of becoming a } \\
\text { choice. }\end{array}$ & \multirow{3}{*}{$\begin{array}{l}\text { - ANOVA } \\
\text { - Logistic } \\
\text { Regression }\end{array}$} \\
\hline $\begin{array}{l}\text { H5: Late exposure to less-preferred destinations increases (a) intention to visit (b) } \\
\text { their probability of entering late consideration (c) their probability of becoming a } \\
\text { choice. }\end{array}$ & \\
\hline $\begin{array}{l}\text { H6: Late exposure (without early exposure) to less-preferred destinations increases } \\
\text { (a) intention to visit (b) their probability of entering late consideration (c) their } \\
\text { probability of becoming a choice. }\end{array}$ & \\
\hline
\end{tabular}

\subsection{Limitations of Methodology}

The methodology for this study was carefully considered to answer the research questions and to test the hypotheses presented in Chapter 4. Other considerations were budget, time frame and the interest of the respondents when completing the 
questions. In light of these considerations, as with other research projects, the methodology designed for this study has several limitations.

First, the study was conducted in the available samples in Guildford due to the limitations of time and resources. Sampling on wider UK geographical locations would enhance the generalisability of the results.

Second, this study adopted the attributes from exploratory research, discussions with respondents and secondary data collection for the important attributes in choosing an overseas beach holiday. The major attributes were then selected for the study. If time and budget permitted, a qualitative method should be included in the study.

Third, this study was conducted with the cross-sectional method. Longitudinal data collection may be another useful method where there is an actual time gap between the exposures to the treatments. More time and financial resources would be required. Drop out rate of the respondents might also be a problem.

Finally, the present study could only include eight short-haul beach destinations since they offered similar price range. The design for profiles of eight destinations is within the capability of the researcher to handle. A separate study on long haul beach destinations was unable to be conducted due to the terrorism attack in Bali, Indonesia which was among the long haul beach destinations for UK residents. Increasing number of beach destinations could be incorporated into the study. However, a much more complex design would have to be adopted.

\subsection{Conclusion}

This chapter has explained the methodological framework of the study. Since the nature of this study is explanatory, experiments are therefore considered as the appropriate method that has the power to reveal cause and effect relationships in an unambiguous way. This study employed between-subjects and within-subjects designs. The between-subjects design was used to avoid the effect of one 
experimental condition on another experimental condition when testing the effects of presentation format. The within-subjects design was employed to reduce the individual differences when testing the effects of exposure.

The study developed an experimental setting to hold all the extraneous variables constant such that the effects can only be observed from the independent variables. Furthermore, the study also developed the treatment to test the hypotheses with a combination of three designs, namely, Solomon four-group design, Latin square design and fractional factorial design. These designs are included to ensure that the appearance of destinations is counterbalanced and the package information is systematically varied.

This chapter outlined the development of the questionnaire including the exploratory study, the secondary data and several pre-tests. The questionnaire structure and the purpose of each section were discussed in detail. It also explained the data collection process which proved to be successful in terms of the response rate and the design requirements. The chapter has described the preparation for data analyses for Chapter 7 and acknowledged the limitations of the methodology used in the study.

The next chapter presents the descriptive findings of the experiment conducted on sample group 1 (students) and sample group 2 (adults). 


\section{Chapter Six}

\section{Descriptive Findings}

\subsection{Introduction}

This chapter presents the first part of the results showing the descriptive findings. The experiment was conducted with two different sample groups. The first sample group were students and the second sample group were adults. This chapter deals with both sample groups in that order. The chapter ends with a conclusion section.

In each sample group, there are seven sections of descriptive findings. The first section reports preferences in terms of type of overseas holiday, month of taking next overseas holiday and destination. The second section describes travel experience. The third section presents past visits and destination knowledge. The fourth section reports perception of destinations. The fifth section describes expertise. The sixth section shows the experiment manipulation check on destination preference. The final section illustrates the selected destination choice.

\subsection{Sample Group 1 (Students)}

The first sample group consists of 200 University of Surrey full time undergraduate students in the School of Management. In this sample group, almost one third of the respondents $(32.5 \%)$ are male while almost two thirds of the respondents $(67.5 \%)$ are female. The proportion of female students of 2002 , which consists of $60 \%$, in part influences the distribution of gender for this sample group. The average age of the 
respondents is 21 years with 19 years as the youngest and 31 years as the oldest. The majority of the respondents $(90.5 \%)$ fall in the age range of 19 to 23 years.

Random assignment was employed to rule out the variability of the respondents in each group. The number of the respondents were randomly assigned into each of the three groups: experimental group $1(80)$, experimental group $2(80)$ and control group (40). Table 6.1 shows the distribution of respondents between group by gender.

Table 6.1: Number of Respondents between Group by Gender (Students)

\begin{tabular}{|c|c|c|c|c|c|c|c|c|}
\hline \multirow{2}{*}{ Gender } & \multicolumn{2}{|c|}{ Experimental 1 } & \multicolumn{2}{|c|}{ Experimental 2 } & \multicolumn{2}{c|}{ Control } & \multicolumn{2}{c|}{ Total } \\
\cline { 2 - 9 } & Frequency & $\%$ & Frequency & $\%$ & Frequency & $\%$ & Frequency & $\%$ \\
\hline Male & 28 & 35.0 & 25 & 31.3 & 12 & 30.0 & 65 & 32.5 \\
\hline Female & 52 & 65.0 & 55 & 68.7 & 28 & 70.0 & 135 & 67.5 \\
\hline Total & $\mathbf{8 0}$ & 100 & $\mathbf{8 0}$ & $\mathbf{1 0 0}$ & $\mathbf{4 0}$ & $\mathbf{1 0 0}$ & $\mathbf{2 0 0}$ & $\mathbf{1 0 0}$ \\
\hline
\end{tabular}

Table 6.1 shows that the percentage of the respondents randomly assigned to each condition is approximately in the ratio of $1: 2$ between male and female. This ratio is congruent to that of gender in this sample. These findings suggest that random assignment to a certain extent successfully balances the variability of the respondents regarding gender. Therefore, the respondents in the three groups can reasonably be compared. Furthermore, the sample is homogeneous due to the fact that all the respondents are university students.

\subsubsection{Preferences}

The aim of this section is to describe the preferences of the sample. This section is divided into three parts: preferred type of holiday, preferred month of next overseas holiday and preferred destination. 


\subsubsection{Preferred Type of Overseas Holiday}

Respondents were asked to select only one type of holiday they most preferred for their next overseas holiday from the followings: beach, city, cruise, ski and other. Figure 6.1 summarises the respondents' preferred type of holiday.

\section{Figure 6.1: Preferred Type of Overseas Holiday (Students)} $(\mathrm{n}=200)$

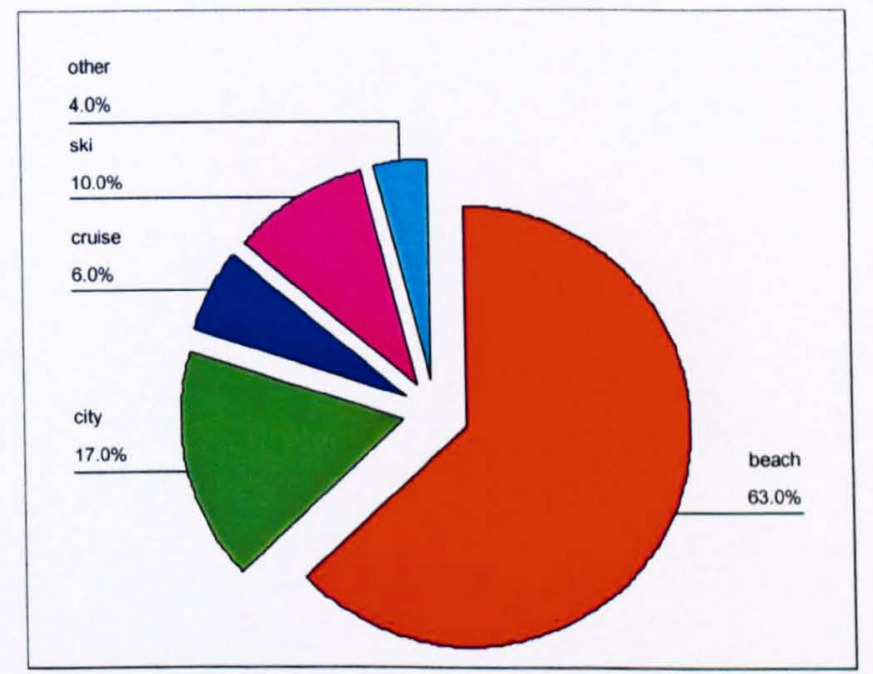

Figure 6.1 shows that the most preferred type of holiday for the student sample group is beach holiday $(63.0 \%)$. The second most preferred type of overseas holiday is city $(17.0 \%)$. Only $4 \%$ of the respondents specified that they preferred other types of holidays such as sightseeing or culture. The result here shows that a beach holiday is the most preferred type of holiday and confirms that it is relevant for this study to focus on this type of holiday.

\subsubsection{Preferred Month for Next Overseas Holiday}

The respondents were asked to select only one from a list of twelve months that they most preferred to take their next overseas holiday. It should be noted that data were collected in November 2002. Figure 6.2 shows preferred month of next overseas holiday. 
Figure 6.2: Preferred Month of Next Overseas Holiday (Students)

$(\mathrm{n}=200)$

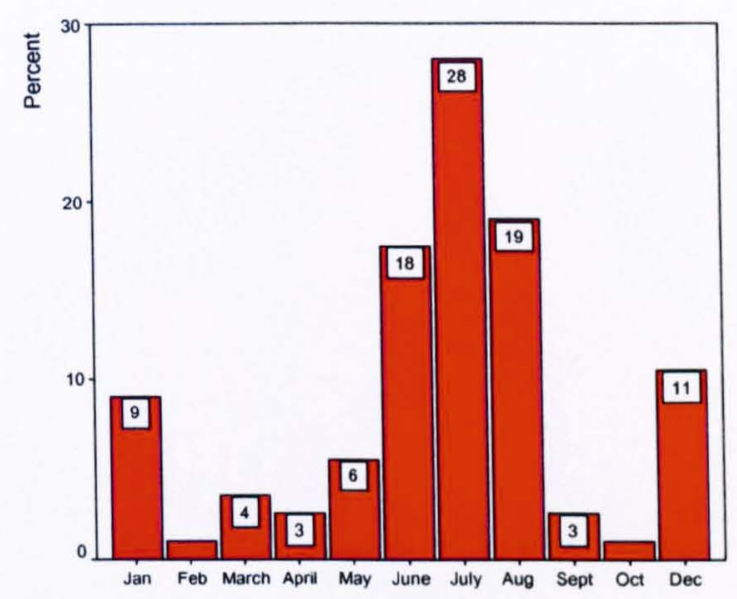

The results in Figure 6.2 show that June (18\%), July (28\%) and August (19\%) are the top three preferred months of next overseas holidays. The university vacation period may influence the selected months. It is observed that the results are congruent with those from the National Statistics (2001) reporting that June, July and August are the most popular period for UK residents to take overseas holidays. Furthermore, it supports the hypothetical situation in the experiment which specifies that the holiday voucher must be booked for these three months.

\subsubsection{Preferred Destination}

The respondents were asked to rank the presented four destinations according to their preference from 1 (the most preferred destination) and so on to 4 (the least preferred destination). The preference ranking was placed at time 1 in which four destinations were presented to only the respondents in experimental groups. Figure 6.3 illustrates the most preferred destination and the least preferred destination. 
Figure 6.3: Preferred Destination (Students)

$(\mathrm{n}=159)$

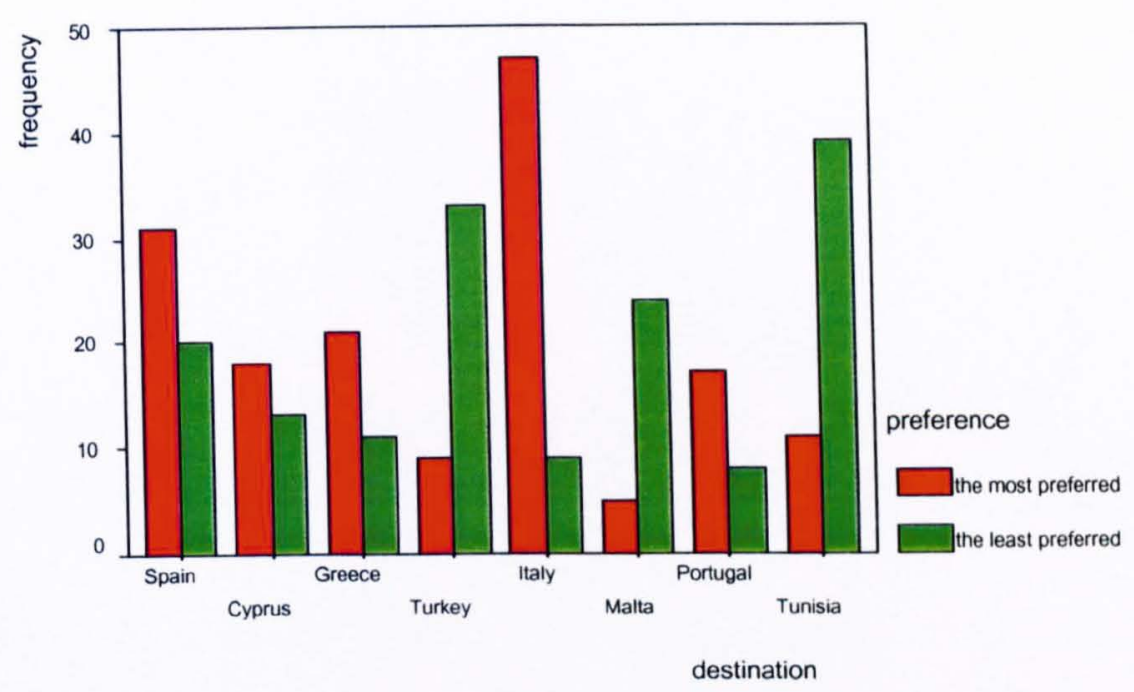

Figure 6.3 shows that a majority of the respondents (47) ranked Italy as their most preferred destination. On the other hand, most respondents (39) ranked Tunisia as their least preferred destination.

\subsubsection{Travel Experience}

Travel experience was measured in two dimensions: width of travel experience and depth of travel experience. For width of experience, respondents were asked how many times they had been away for any overseas holidays in the past five years. To capture the depth of travel experience, respondents were asked how many times they had been away specifically for overseas beach holidays. The alternatives available to them were listed as follows: none, 1-2, 3-4, 5-6 and more than 6. Table 6.2 illustrates travel experience.

Table 6.2: Travel Experience (Students)

\begin{tabular}{|c|c|c|c|c|}
\hline \multirow{2}{*}{$\begin{array}{c}\text { Number of } \\
\text { visits }\end{array}$} & \multicolumn{2}{|c|}{ Width } & \multicolumn{2}{c|}{ Depth } \\
\cline { 2 - 5 } & Frequency & $\%$ & Frequency & $\%$ \\
\hline None & 5 & 2.5 & 23 & 11.5 \\
\hline $1-2$ & 31 & 15.5 & 73 & 36.5 \\
\hline $3-4$ & 46 & 23.0 & 39 & 19.5 \\
\hline $5-6$ & 32 & 16.0 & 32 & 16.0 \\
\hline more than 6 & 86 & 43.0 & 33 & 16.5 \\
\hline Total & $\mathbf{2 0 0}$ & $\mathbf{1 0 0}$ & $\mathbf{2 0 0}$ & $\mathbf{1 0 0}$ \\
\hline
\end{tabular}


For width of travel experience, Table 6.2 shows that a majority of the respondents $(97.5 \%)$ had taken at least one overseas holiday in the past five years. Almost half of the respondents $(43.0 \%)$ had travelled more than six times in the past five years. In terms of depth of travel experience, a majority of the respondents $(88.5 \%)$ had taken overseas beach holidays at least once in the past five years. Over half (52\%) had taken an overseas beach holiday at least three times in the past five years. The findings relating to the width and depth of travel experience show that this sample group is made up not only of experienced holidaymakers but also of experienced beach holidaymakers.

\subsubsection{Past Visits and Destination Knowledge}

This section examines the background information the respondents had on the eight destinations included in the study in terms of past visits to destinations and knowledge of destination. This section is divided into two parts: past visits and destination knowledge.

\subsubsection{Past Visits}

For information on past visits to destinations, respondents were asked to indicate the number of times they had visited each destination for any purposes. From the eight destinations, the results in Table 6.3 shows the mean number of visits to each destination.

Table 6.3: Mean Number of Visits (Students)

$(n=196)$

\begin{tabular}{|c|c|c|}
\hline Destination & Mean & SD \\
\hline Spain & 2.94 & 4.989 \\
\hline Cyprus & 0.36 & .921 \\
\hline Greece & 1.01 & 1.575 \\
\hline Turkey & 0.54 & 2.345 \\
\hline Italy & 1.00 & 1.919 \\
\hline Malta & 0.15 & .651 \\
\hline Portugal & 1.03 & 2.837 \\
\hline Tunisia & 0.11 & .332 \\
\hline
\end{tabular}


Table 6.3 shows that Spain is the most visited destination $(M=2.94)$. Other destinations which are highly visited are Portugal $(\mathrm{M}=1.03)$, Greece (1.01) and Italy (1.00). Tunisia $(M=0.11)$ is the least visited destination. Table 6.4 further shows the number of respondents visiting the destination at least once.

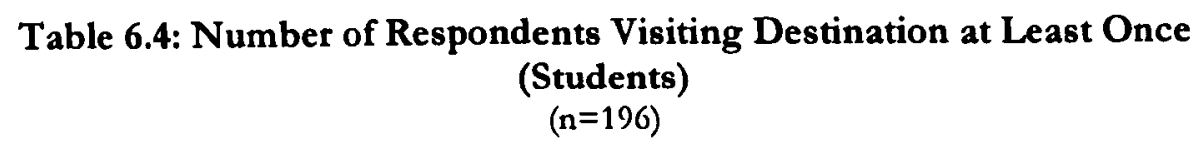

\begin{tabular}{|c|c|c|}
\hline Destination & Frequency & $\%$ \\
\hline Spain & 132 & 67.3 \\
\hline Cyprus & 41 & 20.9 \\
\hline Greece & 96 & 49.0 \\
\hline Turkey & 41 & 20.9 \\
\hline Italy & 85 & 43.4 \\
\hline Malta & 21 & 10.7 \\
\hline Portugal & 67 & 34.2 \\
\hline Tunisia & 21 & 10.7 \\
\hline
\end{tabular}

It can be seen from Table 6.4 that a majority of respondents $(67.3 \%)$ had visited Spain at least once. Only one tenth of the respondents (10.7\%) had visited Malta and Tunisia at least once. Based on these findings, Spain is a very popular overseas beach holiday destination among this sample group.

\subsubsection{Destination Knowledge}

There are two dimensions in measuring the knowledge of destination. The first dimension is to measure how well the respondents are informed by other sources such as friends, televisions, magazines etc. about each as a beach holiday destination on a seven-point scale from 1 (not at all informed) to 7 (very well informed). The second dimension is to ask how familiar they are with each as a beach holiday destination on a seven-point scale from 1 (not at all familiar) to 7 (very familiar). Table 6.5 shows the results of the destination knowledge. 
Table 6.5: Mean Destination Knowledge (Students)

\begin{tabular}{|c|c|c|c|c|c|}
\hline \multirow{2}{*}{ Destination } & \multicolumn{2}{|c|}{ Information } & \multicolumn{2}{c|}{ Familiarity } & \multirow{2}{*}{$\begin{array}{c}\text { Correlation } \\
\end{array}$} \\
\cline { 2 - 5 } & Mean & SD & Mean & SD & .63 \\
\hline Spain & $5.72(\mathrm{n}=199)$ & 1.279 & $5.85(\mathrm{n}=196)$ & 1.581 & .59 \\
\hline Cyprus & $4.73(\mathrm{n}=198)$ & 1.654 & $4.48(\mathrm{n}=194)$ & 2.143 & .72 \\
\hline Greece & $5.23(\mathrm{n}=199)$ & 1.620 & $5.09(\mathrm{n}=196)$ & 2.026 & .54 \\
\hline Turkey & $4.15(\mathrm{n}=199)$ & 1.648 & $3.92(\mathrm{n}=196)$ & 2.018 & .58 \\
\hline Italy & $4.83(\mathrm{n}=199)$ & 1.702 & $4.30(\mathrm{n}=195)$ & 1.873 & .69 \\
\hline Malta & $3.65(\mathrm{n}=199)$ & 1.757 & $3.54(\mathrm{n}=196)$ & 2.029 & .73 \\
\hline Portugal & $4.68(\mathrm{n}=199)$ & 1.714 & $4.55(\mathrm{n}=195)$ & 2.061 & .71 \\
\hline Tunisia & $3.53(\mathrm{n}=199)$ & 1.794 & $3.36(\mathrm{n}=196)$ & 2.032 & \\
\hline
\end{tabular}

The results from Table 6.5 show that the respondents are well informed about Spain $(M=5.72)$ and Greece $(M=5.23)$ as beach holiday destinations. However, they are less informed about Malta $(M=3.65)$ and Tunisia $(M=3.53)$. The respondents are most well informed about Spain and least well informed about Tunisia. The respondents are very familiar with Spain $(M=5.85)$ and Greece $(M=5.09)$ as beach holiday destinations. The respondents are less familiar with Malta $(M=3.54)$ and Tunisia $(M=3.36)$. The respondents are most familiar with Spain and least familiar with Tunisia as beach holiday destinations.

The relationship between information about and familiarity with the eight destinations was investigated using the Pearson product-moment correlation coefficient. Overall, the results in Table 6.5 show that there is a strong positive correlation between the two variables with high levels of information associated with high levels of familiarity.

\subsubsection{Perception of Destinations}

There are three dimensions capturing perception of the destinations. The first dimension is to measure which destination is the best in offering each of the listed ten destination attributes. The second dimension is to check the overall image of the destination. The last dimension is to measure the perception of the price of travelling to the destinations. This section is divided into three sub-sections as follows: destination attributes, overall destination image and perception of the price of travelling to the destinations. 


\subsubsection{Destination Attributes}

This section describes perception of destination attributes. Respondents were asked to select only one destination offering the best on each of the listed ten attributes. Table 6.6 presents the results of the perception of destination attributes by destination.

Table 6.6: Perception of Destination Attributes by Destination (Students)

\begin{tabular}{|c|c|c|c|c|c|c|c|c|c|}
\hline Attributes & Spain & Cyprus & Greece & Turkey & Italy & Malta & Portugal & Tunisia & Total \\
\hline Local Food & 42 & 5 & 16 & 12 & 100 & 2 & 7 & 5 & 189 \\
& $(22.2 \%)$ & $(2.6 \%)$ & $(8.5 \%)$ & $(6.3 \%)$ & $(52.9 \%)$ & $(1.1 \%)$ & $(3.7 \%)$ & $(2.6 \%)$ & $(100 \%)$ \\
\hline Beaches & 55 & 27 & 58 & 5 & 4 & 4 & 18 & 13 & 184 \\
& $(29.9 \%)$ & $14.7 \%)$ & $(31.5 \%)$ & $(2.7 \%)$ & $(2.2 \%)$ & $(2.2 \%)$ & $(9.8 \%)$ & $(7.1 \%)$ & $(100 \%)$ \\
\hline Friendliness of & 52 & 11 & 28 & 14 & 45 & 11 & 14 & 8 & 183 \\
Local People & $(28.4 \%)$ & $(6.0 \%)$ & $(15.3 \%)$ & $(7.7 \%)$ & $(24.6 \%)$ & $(6.0 \%)$ & $(7.7 \%)$ & $(4.4 \%)$ & $(100 \%)$ \\
\hline Climate & 32 & 23 & 50 & 13 & 17 & 10 & 11 & 30 & 186 \\
& $(17.2 \%)$ & $(12.4 \%)$ & $(26.9 \%)$ & $(7.0 \%)$ & $(9.1 \%)$ & $(5.4 \%)$ & $(5.9 \%)$ & $(16.1 \%)$ & $(100 \%)$ \\
\hline Nightlife and & 80 & 24 & 51 & 3 & 17 & 2 & 3 & 2 & 182 \\
Entertainment & $(44.0 \%)$ & $(13.2 \%)$ & $(28.0 \%)$ & $(1.6 \%)$ & $(9.3 \%)$ & $(1.1 \%)$ & $(1.6 \%)$ & $(1.1 \%)$ & $(100 \%)$ \\
\hline Quality of & 27 & 11 & 12 & 5 & 91 & 8 & 16 & 12 & 182 \\
Accommodation & $(14.8 \%)$ & $(6.0 \%)$ & $(6.6 \%)$ & $(2.7 \%)$ & $(50.0 \%)$ & $(4.4 \%)$ & $(8.8 \%)$ & $(6.6 \%)$ & $(100 \%)$ \\
\hline Quality of & 55 & 1 & 15 & 3 & 85 & 8 & 8 & 2 & 177 \\
Infrastructure & $(31.1 \%)$ & $(0.6 \%)$ & $(8.5 \%)$ & $(1.7 \%)$ & $(48.0 \%)$ & $(4.5 \%)$ & $(4.5 \%)$ & $(1.1 \%)$ & $(100 \%)$ \\
\hline Safety & 47 & 8 & 10 & 3 & 59 & 22 & 30 & 2 & 181 \\
& $(26.0 \%)$ & $(4.4 \%)$ & $(5.5 \%)$ & $(1.7 \%)$ & $(32.6 \%)$ & $(12.2 \%)$ & $(16.6 \%)$ & $(1.1 \%)$ & $(100 \%)$ \\
\hline Hygiene and & 40 & 11 & 12 & 7 & 74 & 10 & 24 & 5 & 183 \\
Cleanliness & $(21.9 \%)$ & $(6.0 \%)$ & $(6.6 \%)$ & $(3.8 \%)$ & $(40.4 \%)$ & $(5.5 \%)$ & $(13.1 \%)$ & $(2.7 \%)$ & $(100 \%)$ \\
\hline Value for Money & 73 & 10 & 38 & 20 & 17 & 2 & 9 & 15 & 184 \\
& $(39.7 \%)$ & $(5.4 \%)$ & $(20.7 \%)$ & $(10.9 \%)$ & $(9.2 \%)$ & $(1.1 \%)$ & $(4.9 \%)$ & $(8.2 \%)$ & $(100 \%)$ \\
\hline
\end{tabular}

The results in Table 6.6 show that for five attributes, most of the respondents selected Italy as the best destination. These attributes are local food (52.9\%), quality of accommodation (50.0\%), quality of infrastructure (48.0\%), safety $(32.6 \%)$ and hygiene and cleanliness (40.4\%). Spain is perceived most often as the best destination in terms of friendliness of local people (28.4\%), nightlife and entertainment (44.0\%) and value for money (39.7\%). Greece is also perceived most often as the best destination offering beaches (31.5\%) and climate $(26.9 \%)$.

\subsubsection{Overall Destination Image}

For their evaluation of the overall destination image, respondents were asked to indicate how they perceived the overall image of each destination as an overseas beach holiday destination on a seven-point scale ranging from 1 (very negative) and 7 (very positive). The results are shown in Table 6.7 . 
Table 6.7: Overall Destination Image (Students)

\begin{tabular}{|c|c|c|}
\hline Destinations & Mean & SD \\
\hline Spain & $5.23(\mathrm{n}=199)$ & 1.626 \\
\hline Cyprus & $5.01(\mathrm{n}=200)$ & 1.339 \\
\hline Greece & $5.25(\mathrm{n}=199)$ & 1.354 \\
\hline Turkey & $4.18(\mathrm{n}=200)$ & 1.524 \\
\hline Italy & $5.29(\mathrm{n}=200)$ & 1.444 \\
\hline Malta & $4.50(\mathrm{n}=200)$ & 1.334 \\
\hline Portugal & $5.14(\mathrm{n}=200)$ & 1.303 \\
\hline Tunisia & $4.17(\mathrm{n}=198)$ & 1.439 \\
\hline
\end{tabular}

The results in Table 6.7 indicate that Italy $(M=5.29)$ is perceived as having the highest positive overall destination image. They show that Tunisia $(M=4.17)$ is perceived as having the lowest positive overall destination image.

\subsubsection{Perception of Price of Travelling to Destinations}

Respondents were asked to select the most expensive and the cheapest destinations assuming that the features of the package holiday (flights, number of nights and quality of accommodation) were similar for each destination. Table 6.8 shows the results.

Table 6.8: Frequency of the Most Expensive and the Cheapest Destinations (Students)

\begin{tabular}{|c|c|c|c|c|}
\hline \multirow{2}{*}{ Destinations } & \multicolumn{2}{|c|}{ The most expensive } & \multicolumn{2}{c|}{ The cheapest } \\
\cline { 2 - 5 } & Frequency & $\%$ & Frequency & $\%$ \\
\hline Spain & 14 & 7.2 & 82 & 41.8 \\
\hline Cyprus & 15 & 7.7 & 6 & 3.1 \\
\hline Greece & 7 & 3.6 & 27 & 13.8 \\
\hline Turkey & - & - & 20 & 10.2 \\
\hline Italy & 94 & 48.2 & 8 & 4.1 \\
\hline Malta & 27 & 13.8 & 10 & 5.1 \\
\hline Portugal & 14 & 7.2 & 9 & 4.6 \\
\hline Tunisia & 24 & 12.3 & 34 & 17.3 \\
\hline Total & 195 & 100 & 196 & 100 \\
\hline
\end{tabular}

The results presented in Table 6.8 show that almost half of the respondents $(48.2 \%)$ perceived Italy as the most expensive destination. On the other hand, over two fifths $(41.8 \%)$ perceived Spain as the cheapest destination. 


\subsubsection{Expertise}

As discussed in section 5.4.2.8, there are four dimensions relating to expertise in terms of cognitive effort, analysis, elaboration and memory. Cognitive effort refers to the decision-making that is performed with minimal effort and without conscious control. Analysis represents the extent to which consumers access all relevant information for a particular task. Elaboration represents the number of intervening facts that must be computed in order for an inference to be made. Memory refers to one's ability to remember product-related information. Four statements were used to capture each dimension of the expertise respectively. Respondents were asked to indicate the extent to which they agreed with the statements on a seven-point scale from 1 (strongly disagree) to 7 (strongly agree). Table 6.9 presents the results of the expertise.

Table 6.9: Expertise (Students)

$(n=200)$

\begin{tabular}{|c|c|c|c|}
\hline Dimension & Statement & Mean & SD \\
\hline $\begin{array}{c}\text { Cognitive } \\
\text { effort }\end{array}$ & $\begin{array}{c}\text { I can easily choose my preferred } \\
\text { destination without much effort. }\end{array}$ & 4.84 & 1.725 \\
\hline Analysis & $\begin{array}{c}\text { I will search for the latest } \\
\text { information before I book my } \\
\text { holiday. }\end{array}$ & 5.53 & 1.382 \\
\hline Elaboration & $\begin{array}{c}\text { I consider myself knowledgeable } \\
\text { about overseas beach holiday } \\
\text { destinations. }\end{array}$ & 4.45 & 1.552 \\
\hline Memory & $\begin{array}{c}\text { I can recall almost all overseas } \\
\text { beach holiday destinations from } \\
\text { memory. }\end{array}$ & 4.64 & 1.716 \\
\hline
\end{tabular}

Of all the dimensions of expertise, Table 6.9 shows that the respondents have the highest score for analysis $(M=5.53)$ which explains that they have high access to all relevant and important information for the given task. However, they considered themselves as having a lower ability to make inferences $(M=4.45)$.

\subsubsection{Experiment Manipulation Check on Destination Preference}

This section demonstrates a manipulation test which was carried out to confirm the initial ideas on the destination preference (see Table 5.3). The manipulation check sought to classify four destinations into a high preference level and the other four 
destinations into a low preference level. It should be noted that destination preference is only one part of the manipulations in the study. The focus of the thesis, however, is on destination preference since it is at the heart to the hypothesis testing. The experiment manipulation check was performed prior any hypothesis tests to ensure that the destination preference levels (high and low) represent the actual preference of the sample group.

Intention to visit scores from the three groups: control group, experimental group 1 and experimental group 2 were used for classifying high and low preference levels. Referring to the overall design (see Figure 5.2), intention to visit for the control group was only measured once since this group was not exposed to experimental treatment. Each respondent in this group rated their intention to visit for eight destinations. For experimental groups, intention to visit was measured twice (time 1 and time 2). To ensure that intention to visit was not influenced by the experimental treatment (destination name along with other attributes), intention to visit at time 1 was used as a manipulation check. It should be noted that each respondent in the experimental groups only rated four destinations at time 1. Therefore, the manipulation check on destination preference included intention to visit ratings of the control group and the experimental groups at time 1. Details of these measures are presented in the questionnaires (see Appendix B, Appendix C and Appendix D). Table 6.10 shows mean intention to visit by preference.

Table 6.10: Mean Intention to Visit by Preference (Students)

\begin{tabular}{|c|c|c|c|c|c|c|c|}
\hline $\begin{array}{c}\text { High Preference } \\
\text { Level }\end{array}$ & Mean & SD & $\mathbf{n}$ & $\begin{array}{c}\text { Low Preference } \\
\text { Level }\end{array}$ & Mean & SD & $\mathbf{n}$ \\
\hline Italy & 5.55 & 1.55 & 116 & Cyprus & 4.76 & 1.78 & 119 \\
\hline Spain & 5.08 & 1.94 & 118 & Malta & 4.05 & 1.47 & 117 \\
\hline Greece & 4.92 & 1.79 & 118 & Turkey & 3.99 & 1.85 & 116 \\
\hline Portugal & 4.86 & 1.44 & 116 & Tunisia & 3.84 & 1.63 & 118 \\
\hline
\end{tabular}

Table 6.10 shows that Italy, Spain, Greece and Portugal are the top four destinations in terms of intention to visit while Cyprus, Malta, Turkey and Tunisia receive lower scores on intention to visit. As expected, the results of Table 6.10 confirm the design of the study which classified Italy, Spain, Greece and Portugal into a high preference 
level and included Cyprus, Malta, Turkey and Tunisia in a low preference level (see Table 5.3).

An independent-sample t-test was conducted to compare the intention to visit scores for these two preference levels. An independent variable was preference level (high and low) and a dependent variable was intention to visit anchored by 1 (will definitely not visit) to 7 (will definitely visit). The results showed that there was a significant difference in intention to visit between these two preference levels, $t(936)=-8.40, p<.01$. The results of an independent-sample t-test suggested that intention to visit high-preferred destinations $(M=5.10)$ was significantly higher than that for less-preferred destinations $(M=4.16)$. This experimental manipulation on destination preference is therefore successful. Destinations included in the two preference levels of the design represented the actual preference of the sample.

\subsubsection{Destination Choice}

The respondents were asked to select only one destination from the list of eight that they would choose. The results are shown in Figure 6.4.

Figure 6.4: Choice (Students) ( $n=198)$

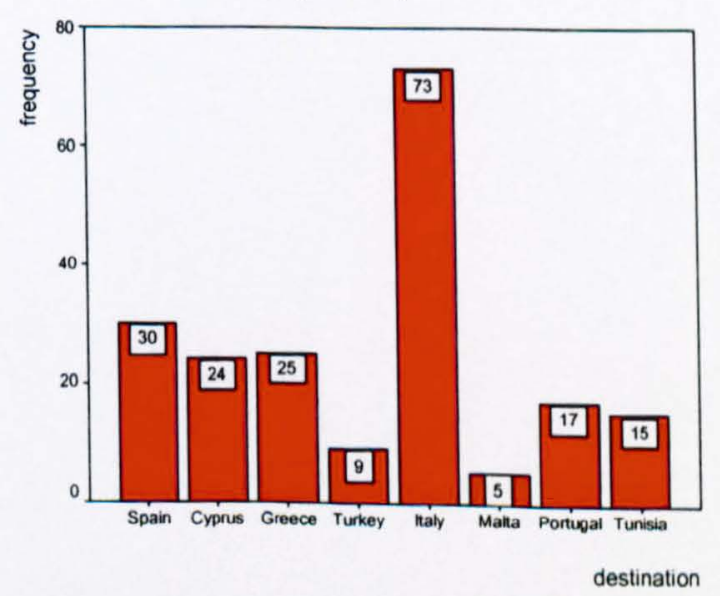

The results in Figure 6.4 demonstrate that a majority of the respondents (73) selected Italy as their final destination choice. Malta (5) is the destination that very few respondents decided as their final choice. 


\subsection{Sample Group 2 (Adults)}

This section presents the descriptive findings of the sample group 2 (adults). This sample consists of 200 Guildford residents. Table 6.11 summarises the sample profiles.

Table 6.11: Sample Profile (Adults)

\begin{tabular}{|c|c|c|}
\hline Variables & Frequency & $\%$ \\
\hline $\begin{array}{c}\text { Gender }(n=200) \\
\text { Male } \\
\text { Female } \\
\end{array}$ & $\begin{array}{c}68 \\
132 \\
\end{array}$ & $\begin{array}{l}34.0 \\
66.0 \\
\end{array}$ \\
\hline $\begin{array}{c}\text { Age }(n=200) \\
15-24 \\
25-34 \\
35-44 \\
45-54 \\
55-64 \\
\end{array}$ & $\begin{array}{l}17 \\
30 \\
66 \\
70 \\
17\end{array}$ & $\begin{array}{c}8.5 \\
15.0 \\
33.0 \\
35.0 \\
8.5\end{array}$ \\
\hline $\begin{array}{l}\text { Marital Status }(n=199) \\
\text { Single } \\
\text { Living with a partner/married } \\
\text { Widowed } / \text { divorced } / \text { separated }\end{array}$ & $\begin{array}{c}28 \\
161 \\
10\end{array}$ & $\begin{array}{c}14.1 \\
80.9 \\
5.0\end{array}$ \\
\hline $\begin{array}{c}\text { Education ( } \mathrm{n}=197) \\
\text { GCSEs grade A-C or equivalent } \\
\text { GCE A levels or equivalent } \\
\text { Vocational qualification } \\
\text { First degree } \\
\text { Higher degree } \\
\text { Other qualifications }\end{array}$ & $\begin{array}{l}19 \\
19 \\
18 \\
55 \\
45 \\
41\end{array}$ & $\begin{array}{c}9.6 \\
9.6 \\
9.1 \\
27.9 \\
22.8 \\
20.8\end{array}$ \\
\hline $\begin{array}{c}\text { Income }(n=199) \\
\text { Under } £ 10,000 \\
10,001-£ 20,000 \\
20,001-£ 30,000 \\
30,001-£ 40,000 \\
40,001-£ 50,000 \\
50,001-£ 60,000 \\
60,001-£ 70,000 \\
70,001 \text { or over } \\
\text { not disclose }\end{array}$ & $\begin{array}{l}2 \\
21 \\
32 \\
30 \\
24 \\
19 \\
17 \\
27 \\
27 \\
\end{array}$ & $\begin{array}{c}1.0 \\
10.6 \\
16.1 \\
15.1 \\
12.1 \\
9.5 \\
8.5 \\
13.6 \\
13.6 \\
\end{array}$ \\
\hline $\begin{array}{l}\text { Age of the Youngest child in Household }(n=129) \\
1-10 \text { years old } \\
11-20 \text { years old } \\
21-30 \text { years old }\end{array}$ & $\begin{array}{l}64 \\
50 \\
15 \\
\end{array}$ & $\begin{array}{l}49.6 \\
38.8 \\
11.6\end{array}$ \\
\hline
\end{tabular}

Table 6.11 shows that one third of the respondents (34.0\%) are male while two thirds $(66.0 \%)$ are female. In terms of age, the majority of respondents $(76.5 \%)$ are above 34 years old. Regarding marital status, most respondents (80.9\%) are either married or living with a partner. Half of the respondents $(50.7 \%)$ have degree qualifications. Over half of the respondents $(58.8 \%)$ have annual household income higher than 
$£ 30,000$. Of all the respondents, over half of the respondents $(64.5 \%)$ have children. Of those who have children, a half $(50.4 \%)$ have children aged over 10 years.

Random assignment was used in the experiment to rule out the variability of the respondents in each group. Respondents were randomly assigned into each of the three groups. Table 6.12 breaks down the number of respondents in each group according to gender.

Table 6.12: Number of Respondents between Group by Gender (Adults)

\begin{tabular}{|c|c|c|c|c|c|c|c|c|}
\hline \multirow{2}{*}{ Gender } & \multicolumn{2}{|c|}{ Experimental 1 } & \multicolumn{2}{c|}{ Experimental 2 } & \multicolumn{2}{c|}{ Control } & \multicolumn{2}{c|}{ Total } \\
\cline { 2 - 9 } & Frequency & $\%$ & Frequency & $\%$ & Frequency & $\%$ & Frequency & $\%$ \\
\hline Male & 29 & 36.3 & 28 & 35.0 & 11 & 27.5 & 68 & 34.0 \\
\hline Female & 51 & 63.8 & 52 & 65.0 & 29 & 72.5 & 132 & 66.0 \\
\hline Total & $\mathbf{8 0}$ & 100 & $\mathbf{8 0}$ & 100 & $\mathbf{4 0}$ & 100 & $\mathbf{2 0 0}$ & 100 \\
\hline
\end{tabular}

Similar to the sample group 1 (students), Table 6.12 shows that the percentage of the respondents randomly assigned to each group is reflected approximately in the ratio of $1: 2$ between male and female. This ratio is congruent to that of the gender in this sample. These findings suggest that random assignment to a certain extent successfully balances the variability of the respondents regarding gender. Therefore, the respondents in the three groups can be reasonably compared.

\subsubsection{Preferences}

The aim of this section is to describe the preferences of the sample. This section is divided into three parts: preferred type of holiday, preferred month of next overseas holiday and preferred destination.

\subsubsection{Preferred Type of Overseas Holiday}

Respondents were asked to select only one type of holiday which they most preferred for their next overseas holiday from the followings: beach, city, cruise, ski and other. Figure 6.5 summarises the respondents' preferred type of holiday. 
Figure 6.5: Preferred Type of Overseas Holiday (Adults) $(\mathrm{n}=200)$

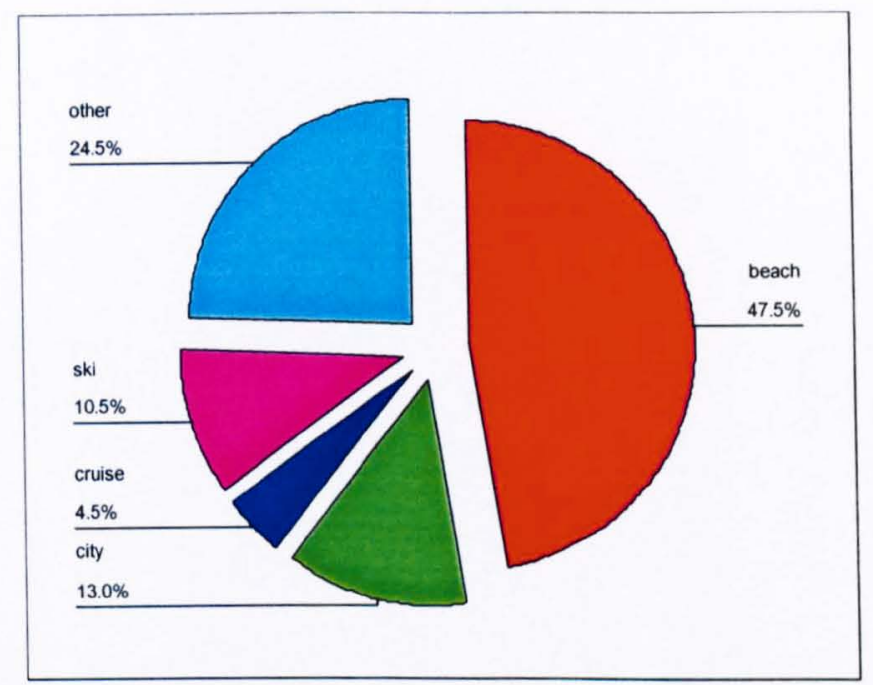

Figure 6.5 shows that the most preferred type of holiday for the majority of respondents $(47.5 \%)$ is a beach holiday. Almost a quarter of the respondents $(24.5 \%)$ prefers other types of holiday such as sightseeing, culture and history. Similar to the results of the sample group 1 (students), the results of the second sample group also show that beach holiday is the most preferred type of holiday and it is relevant for this study to focus on this type of holiday.

\subsubsection{Preferred Month for Next Overseas Holiday}

The respondents were asked to select only one from a list of twelve months that they most preferred to take the next overseas holiday. It should be noted that data were collected in November and December 2002. Figure 6.6 shows preferred month for taking next overseas holiday. 
Figure 6.6: Preferred Month for Next Overseas Holiday (Adults)

$(\mathrm{n}=198)$

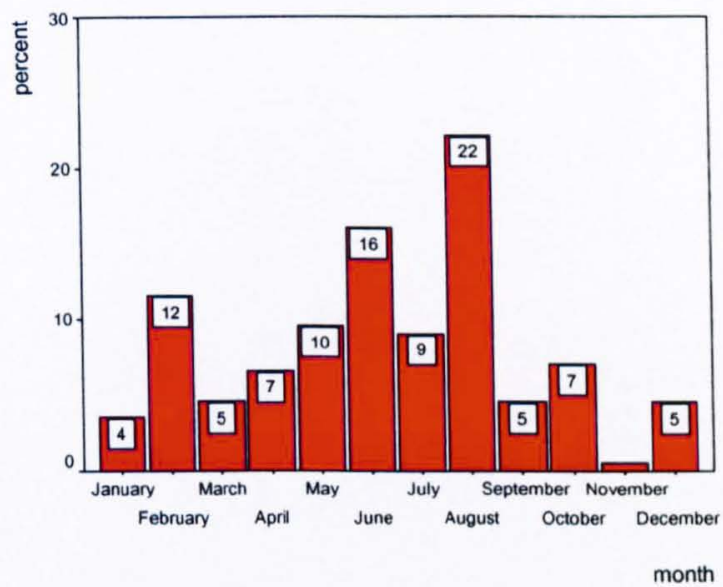

The results in Figure 6.6 show that the preferred month for taking next overseas holidays appear to spread throughout the year. However, nearly half of the respondents $(47 \%)$ preferred to take their next overseas holidays during a period of June, July and August. The results support the hypothetical situation used in the experiment that it is sensible to provide respondents with a holiday voucher for booking holidays for these three months.

\subsubsection{Preferred Destination}

The respondents were asked to rank the presented four destinations according to their preference from 1 (the most preferred destination) and so on to 4 (the least preferred destination). The preference ranking was placed at time 1 and only the respondents in the experimental groups were exposed to these four destinations. Figure 6.7 illustrates the results for the most preferred and the least preferred destinations. 
Figure 6.7: Preferred Destination (Adults)

$(\mathrm{n}=157)$

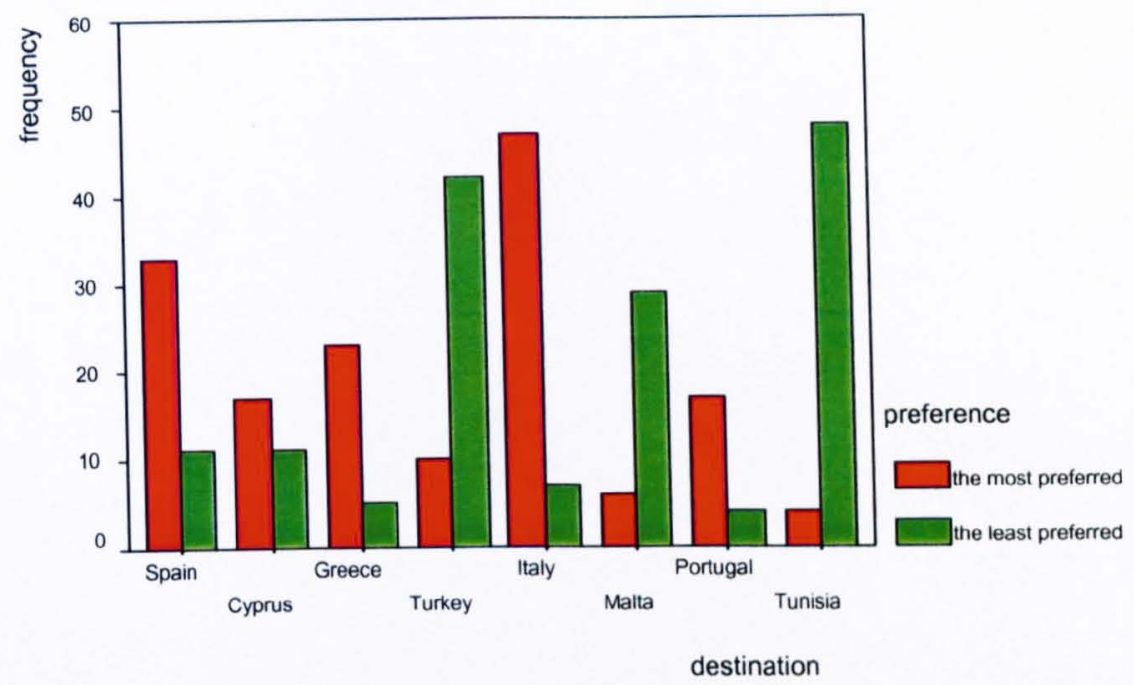

Figure 6.7 shows that a majority of the respondents (47) ranked Italy as their most preferred destination while most respondents (48) ranked Tunisia as their least preferred destination.

\subsubsection{Travel Experience}

Travel experience was measured in two dimensions: width of travel experience and depth of travel experience. To measure the width of experience, respondents were asked how many times they had been away for any overseas holidays in the past five years. To capture the depth of travel experience, respondents were asked how many times they had been away for specifically overseas beach holidays. Table 6.13 illustrates the travel experience.

Table 6.13: Travel Experience (Adults)

\begin{tabular}{|c|c|c|c|c|}
\hline \multirow{2}{*}{ Number of visits } & \multicolumn{2}{|c|}{ Width } & \multicolumn{2}{c|}{ Depth } \\
\cline { 2 - 5 } & Frequency & $\mathbf{\%}$ & Frequency & $\%$ \\
\hline None & 11 & 5.5 & 54 & 27.0 \\
\hline $1-2$ & 33 & 16.5 & 64 & 32.0 \\
\hline $3-4$ & 41 & 20.5 & 50 & 25.0 \\
\hline $5-6$ & 52 & 26.0 & 24 & 12.0 \\
\hline more than 6 & 63 & 31.5 & 8 & 4.0 \\
\hline Total & $\mathbf{2 0 0}$ & $\mathbf{1 0 0}$ & $\mathbf{2 0 0}$ & $\mathbf{1 0 0}$ \\
\hline
\end{tabular}

For the width of travel experience, Table 6.13 suggests that a majority of the respondents $(94.5 \%)$ had taken at least one overseas holiday in the past five years. 
Almost half of the respondents (57.5\%) had taken at least five overseas holidays in the past five years. In terms of the depth of travel experience, a majority of the respondents $(73 \%)$ had taken at least one overseas beach holiday in the past five years. Almost half $(41 \%)$ of the respondents had taken at least three overseas beach holidays in the past five years. The findings relating to the width and depth of travel experience show that this sample group is made up not only of experienced holidaymakers but also of experienced beach holidaymakers.

\subsubsection{Past Visits and Destination Knowledge}

This section examines the background information of the respondents had on the eight destinations included in the study in terms of past visits to destinations and destination knowledge. This section is divided into two parts: past visits and destination knowledge.

\subsubsection{Past Visits}

Respondents were asked to indicate the number of times they had visited each destination for any purposes. From the eight destinations, the results in Table 6.14 show the mean number of visits to the destinations.

Table 6.14: Mean Number of Visits to Destinations (Adults) $(n=197)$

\begin{tabular}{|c|c|c|}
\hline Destination & Mean & SD \\
\hline Spain & 3.05 & 4.158 \\
\hline Cyprus & 0.58 & 1.922 \\
\hline Greece & 1.74 & 2.839 \\
\hline Turkey & 0.48 & 1.662 \\
\hline Italy & 1.49 & 2.082 \\
\hline Malta & 0.42 & 1.040 \\
\hline Portugal & 0.80 & 1.837 \\
\hline Tunisia & 0.20 & .562 \\
\hline
\end{tabular}

Table 6.14 shows that Spain is the most visited destination $(M=3.05)$. Other destinations which are highly visited are Greece $(M=1.74)$ and Italy (1.49). Tunisia $(M=.20)$ is the least visited destination by the respondents. Table 6.15 further shows the number of respondents visiting the destination at least once. 
Table 6.15: Number of Respondents Visiting Destination at Least Once

(Adults)

$(\mathbf{n}=197)$

\begin{tabular}{|c|c|c|}
\hline Destination & Frequency & $\%$ \\
\hline Spain & 144 & 73.1 \\
\hline Cyprus & 45 & 22.8 \\
\hline Greece & 110 & 55.8 \\
\hline Turkey & 44 & 22.3 \\
\hline Italy & 109 & 55.3 \\
\hline Malta & 47 & 23.9 \\
\hline Portugal & 80 & 40.6 \\
\hline Tunisia & 32 & 16.2 \\
\hline
\end{tabular}

It can be seen from Table 6.15 that a majority of respondents $(73.1 \%)$ had visited Spain at least once. Only $16.2 \%$ of the respondents had visited Tunisia at least once. Spain is obviously a very popular beach holiday destination for this sample group.

\subsubsection{Destination Knowledge}

The knowledge of destinations was measured with two dimensions. The first dimension was to measure how well the respondents were informed by other sources such as friends, television, magazines etc. about each as a beach holiday destination on a seven-point scale ranged from 1 (not at all informed) to 7 (very well informed). The second dimension was to ask how familiar they were with each as a beach holiday destination on a seven-point scale from 1 (not at all familiar) to 7 (very familiar). Table 6.16 shows the results of destination knowledge.

Table 6.16: Mean Destination Knowledge (Adults)

\begin{tabular}{|c|c|c|c|c|c|}
\hline \multirow{2}{*}{ Destination } & \multicolumn{2}{|c|}{ Information } & \multicolumn{2}{c|}{ Familiarity } & Correlation \\
\cline { 2 - 5 } & Mean & SD & Mean & SD & $(\mathbf{r})$ \\
\hline Spain & $5.06(\mathrm{n}=199)$ & 1.564 & $4.53(\mathrm{n}=199)$ & 2.361 & .60 \\
\hline Cyprus & $4.37(\mathrm{n}=199)$ & 1.676 & $3.23(\mathrm{n}=198)$ & 2.310 & .49 \\
\hline Greece & $4.91(\mathrm{n}=199)$ & 1.572 & $4.15(\mathrm{n}=197)$ & 2.336 & .58 \\
\hline Turkey & $4.10(\mathrm{n}=197)$ & 1.618 & $2.95(\mathrm{n}=197)$ & 2.046 & .51 \\
\hline Italy & $4.67(\mathrm{n}=200)$ & 1.713 & $3.65(\mathrm{n}=196)$ & 2.233 & .59 \\
\hline Malta & $3.91(\mathrm{n}=197)$ & 1.816 & $3.02(\mathrm{n}=197)$ & 2.114 & .48 \\
\hline Portugal & $4.68(\mathrm{n}=199)$ & 1.632 & $3.64(\mathrm{n}=197)$ & 2.265 & .55 \\
\hline Tunisia & $3.40(\mathrm{n}=198)$ & 1.701 & $2.63(\mathrm{n}=199)$ & 1.941 & .61 \\
\hline
\end{tabular}

The results from Table 6.16 show that the respondents are well informed about Spain $(M=5.06)$ and Greece $(M=4.91)$ as beach holiday destinations. However, they are 
less informed about Malta $(M=3.91)$ and Tunisia $(M=3.40)$. The respondents are most well informed about Spain and least informed about Tunisia as beach holiday destinations. The respondents are very familiar with Spain $(\mathrm{M}=4.53)$ and Greece $(M=4.15)$ as beach holiday destinations. The respondents are less familiar with Turkey $(\mathrm{M}=2.95)$ and Tunisia $(\mathrm{M}=2.63)$. The respondents are most familiar with Spain and least familiar with Tunisia as beach holiday destinations.

The relationship between the information and the familiarity that the respondents had relating to the eight destinations was investigated using the Pearson product-moment correlation coefficient. Overall, the results in Table 6.15 show that there is a strong positive correlation between the two variables with high levels of information associated with high levels of familiarity.

\subsubsection{Perception of Destinations}

There are three dimensions to capture the perception of destinations. The first dimension is to measure which destination offers the best on each of the ten attributes listed. The second dimension is to check the overall image of the destination. The last dimension is to measure perception of the price of travelling to the destinations. This section is divided into three sub-sections as follows: destination attributes, overall destination image and perception of the price of travelling to the destinations.

\subsubsection{Destination Attributes}

This section describes the perception of destination attributes. Respondents were asked to select only one destination offering the best on each of the ten attributes listed. Table 6.17 presents the results of the perception of destination attributes by destination. 
Table 6.17: Perception of Destination Attributes by Destination (Adults)

\begin{tabular}{|c|c|c|c|c|c|c|c|c|c|}
\hline Attributes & Spain & Cyprus & Greece & Turkey & Italy & Malta & Portugal & Tunisia & Total \\
\hline Local food & 24 & 10 & 31 & 13 & 92 & 2 & 18 & 5 & $\begin{array}{c}195 \\
(2.6 \%)\end{array}$ \\
& $(12.3 \%)$ & $(5.1 \%)$ & $(15.9 \%)$ & $(6.7 \%)$ & $(47.2 \%)$ & $(1.0 \%)$ & $(9.2 \%)$ & $(2 \%)$ \\
\hline Beaches & 63 & 21 & 51 & 13 & 12 & 4 & 22 & 10 & 196 \\
& $(32.1 \%)$ & $(10.7 \%)$ & $(26.0 \%)$ & $(6.6 \%)$ & $(6.1 \%)$ & $(2.0 \%)$ & $(11.2 \%)$ & $(5.1 \%)$ & $(100 \%)$ \\
\hline Friendliness of & 29 & 24 & 46 & 16 & 30 & 30 & 15 & 5 & 195 \\
Local People & $(14.9 \%)$ & $(12.3 \%)$ & $(23.6 \%)$ & $(8.2 \%)$ & $(15.4 \%)$ & $(15.4 \%)$ & $(7.7 \%)$ & $(2.6 \%)$ & $(100 \%)$ \\
\hline Climate & 36 & 22 & 49 & 13 & 37 & 5 & 14 & 18 & 194 \\
& $(18.6 \%)$ & $(11.3 \%)$ & $(25.3 \%)$ & $(6.7 \%)$ & $(19.1 \%)$ & $(2.6 \%)$ & $(7.2 \%)$ & $(9.3 \%)$ & $(100 \%)$ \\
\hline Nightlife and & 99 & 21 & 26 & 4 & 27 & 7 & 4 & 3 & 191 \\
Entertainment & $(51.8 \%)$ & $(11.0 \%)$ & $(13.6 \%)$ & $(2.1 \%)$ & $(14.1 \%)$ & $(3.7 \%)$ & $(2.1 \%)$ & $(1.6 \%)$ & $(100 \%)$ \\
\hline Quality of & 37 & 11 & 8 & 4 & 69 & 19 & 29 & 10 & 187 \\
Accommodation & $(19.8 \%)$ & $(5.9 \%)$ & $(4.3 \%)$ & $(2.1 \%)$ & $(36.9 \%)$ & $(10.2 \%)$ & $(15.5 \%)$ & $(5.3 \%)$ & $(100 \%)$ \\
\hline Quality of & 46 & 11 & 11 & 3 & 80 & 11 & 21 & 3 & 186 \\
Infrastructure & $(24.7 \%)$ & $(5.9 \%)$ & $(5.9 \%)$ & $(1.6 \%)$ & $(43.0 \%)$ & $(5.9 \%)$ & $(11.3 \%)$ & $(1.6 \%)$ & $(100 \%)$ \\
\hline Safety & 32 & 18 & 11 & 4 & 69 & 23 & 27 & 0 & 184 \\
& $(17.4 \%)$ & $(9.8 \%)$ & $(6.0 \%)$ & $(2.2 \%)$ & $(37.5 \%)$ & $(12.5 \%)$ & $(14.7 \%)$ & $(0 \%)$ & $(100 \%)$ \\
\hline Hygiene and & 31 & 13 & 9 & 2 & 74 & 31 & 24 & 2 & 186 \\
Cleanliness & $(16.7 \%)$ & $(7.0 \%)$ & $(4.8 \%)$ & $(1.1 \%)$ & $(39.8 \%)$ & $(16.7 \%)$ & $(12.9 \%)$ & $(1.1 \%)$ & $(100 \%)$ \\
\hline Value for Money & 53 & 8 & 32 & 31 & 18 & 8 & 20 & 22 & 192 \\
& $(27.6 \%)$ & $(4.2 \%)$ & $(16.7 \%)$ & $(16.1 \%)$ & $(9.4 \%)$ & $(4.2 \%)$ & $(10.4 \%)$ & $(11.5 \%)$ & $(100 \%)$ \\
\hline
\end{tabular}

The results in Table 6.17 show that for five attributes, most of the respondents selected Italy as the best destination. These attributes are local food (47.2\%), quality of accommodation (36.9\%), quality of infrastructure $(43.0 \%)$, safety $(37.5 \%)$ and hygiene and cleanliness (39.8\%). Spain is perceived most often as the best destination offering the following three destination attributes: beaches $(32.1 \%)$, nightlife and entertainment $(51.8 \%)$ and value for money $(27.6 \%)$. Greece is perceived most often as the best destination offering friendliness of local people $(23.6 \%)$ and climate $(25.3 \%)$.

\subsubsection{Overall Destination Image}

Respondents were asked to indicate how they perceived the overall image of each destination as an overseas beach holiday destination on a seven-point scale ranging from 1 (very negative) and 7 (very positive). The results are shown in Table 6.18.

Table 6.18: Overall Destination Image (Adults)

\begin{tabular}{|c|c|c|}
\hline Destination & Mean & SD \\
\hline Spain & $4.69(\mathrm{n}=200)$ & 1.799 \\
\hline Cyprus & $4.76(\mathrm{n}=198)$ & 1.422 \\
\hline Greece & $5.12(\mathrm{n}=199)$ & 1.404 \\
\hline Turkey & $4.16(\mathrm{n}=197)$ & 1.582 \\
\hline Italy & $5.32(\mathrm{n}=200)$ & 1.506 \\
\hline Malta & $4.24(\mathrm{n}=196)$ & 1.498 \\
\hline Portugal & $5.19(\mathrm{n}=198)$ & 1.240 \\
\hline Tunisia & $3.63(\mathrm{n}=197)$ & 1.666 \\
\hline
\end{tabular}


The results in Table 6.18 indicate that Italy $(M=5.32)$ is perceived as having the highest positive overall destination image while Tunisia $(M=3.63)$ is perceived as having the lowest positive overall destination image.

\subsubsection{Perception of Price of Travelling to Destinations}

Respondents were asked to select the most expensive and the cheapest destinations assuming that the features of the package holiday (flights, number of nights and quality of accommodation) were similar for each destination. Table 6.19 shows the results.

Table 6.19: Frequency of the Most Expensive and the Cheapest Destinations (Adults)

\begin{tabular}{|c|c|c|c|c|}
\hline \multirow{2}{*}{ Destination } & \multicolumn{2}{|c|}{$\begin{array}{c}\text { The most } \\
\text { expensive }\end{array}$} & \multicolumn{2}{c|}{ The cheapest } \\
\cline { 2 - 5 } & Frequency & $\%$ & Frequency & $\%$ \\
\hline Spain & 7 & 3.6 & 72 & 36.5 \\
\hline Cyprus & 22 & 11.2 & 7 & 3.6 \\
\hline Greece & 7 & 3.6 & 20 & 10.2 \\
\hline Turkey & 1 & 0.5 & 32 & 16.2 \\
\hline Italy & 104 & 52.8 & 2 & 1.0 \\
\hline Malta & 18 & 9.1 & 5 & 2.5 \\
\hline Portugal & 17 & 8.6 & 4 & 2.0 \\
\hline Tunisia & 21 & 10.7 & 55 & 27.9 \\
\hline Total & 197 & 100 & 197 & 100 \\
\hline
\end{tabular}

The results in Table 6.19 illustrate that over half of the respondents $(52.8 \%)$ perceived Italy as the most expensive destination while over one third of the respondents $(36.5 \%)$ perceived Spain as the cheapest destination.

\subsubsection{Expertise}

As discussed in section 5.4.2.8, there are four dimensions measured for expertise in terms of cognitive effort, analysis, elaboration and memory. Four statements were used to capture each dimension of the expertise respectively. Respondents were asked to indicate the extent to which they agreed with the statements on a sevenpoint scale from 1 (strongly disagree) to 7 (strongly agree). Table 6.20 presents the results of the expertise. 
Table 6.20: Expertise (Adults)

\begin{tabular}{|c|c|c|c|}
\hline Dimension & Statement & $\begin{array}{c}\text { Mean } \\
(\mathbf{n = 2 0 0})\end{array}$ & SD \\
\hline $\begin{array}{c}\text { Cognitive } \\
\text { effort }\end{array}$ & $\begin{array}{c}\text { I can easily choose my preferred } \\
\text { destination without much effort. }\end{array}$ & 5.19 & 1.628 \\
\hline Analysis & $\begin{array}{c}\text { I will search for the latest } \\
\text { information before I book my } \\
\text { holiday. }\end{array}$ & 5.65 & 1.519 \\
\hline Elaboration & $\begin{array}{c}\text { I consider myself knowledgeable } \\
\text { about overseas beach holiday } \\
\text { destinations. }\end{array}$ & 3.84 & 1.705 \\
\hline Memory & $\begin{array}{c}\text { I can recall almost all overseas } \\
\text { beach holiday destinations from } \\
\text { memory. }\end{array}$ & 4.56 & 2.054 \\
\hline
\end{tabular}

Of all the dimensions of expertise, Table 6.20 shows that the respondents have the highest score for analysis $(M=5.65)$ which explains that they have high access to all relevant and important information for the given task. However, they considered themselves as having a lower ability to make inference $(M=3.84)$.

\subsubsection{Experiment Manipulation Check on Destination Preference}

This section presents the results of the manipulation check on destination preference for sample group 2 (adults). The purpose and details of the manipulation check are discussed in section 6.2.6. Table 6.21 shows mean intention to visit by preference.

Table 6.21: Mean Intention to Visit by Preference (Adults)

\begin{tabular}{|c|c|c|c|c|c|c|c|}
\hline $\begin{array}{c}\text { High } \\
\text { Preference } \\
\text { Level }\end{array}$ & Mean & SD & n & $\begin{array}{c}\text { Low } \\
\text { Preference } \\
\text { Level }\end{array}$ & Mean & SD & n \\
\hline Italy & 5.53 & 1.76 & 117 & Spain & 4.63 & 2.10 & 117 \\
\hline Greece & 5.10 & 1.76 & 117 & Malta & 3.93 & 1.79 & 116 \\
\hline Portugal & 4.82 & 1.64 & 117 & Turkey & 3.85 & 1.87 & 115 \\
\hline Cyprus & 4.74 & 1.66 & 117 & Tunisia & 3.38 & 1.77 & 117 \\
\hline
\end{tabular}

Table 6.21 shows that Italy, Greece, Portugal and Cyprus are the top four destinations in terms of intention to visit while Spain, Malta, Turkey and Tunisia receive lower intention to visit. In this sample group, the results of Spain and Cyprus are not as anticipated. In the design (see Table 5.3), Spain is regarded as a destination in a high preference category while Cyprus is regarded as a destination in a low preference category. However, the design allows for the changing of the 
positions of Spain and Cyprus for further analyses. A manipulation check at the early stage of the analyses is therefore helpful to reorganise these destinations into the actual preference of the sample group for the hypothesis tests. For further analyses in the following chapter for this sample group, destinations included in high and low preference levels are based on the results shown in Table 6.21. Therefore, the high preference level refers to Italy, Greece, Portugal and Cyprus while low preference level refers to Spain, Malta, Turkey and Tunisia.

An independent-sample t-test was conducted to compare intention to visit scores for these two preference levels. The results showed that there was a significant difference in intention to visit between these two preference levels, $\mathrm{t}(931)=-9.13, \mathrm{p}<$ .01 . The results of an independent-sample t-test suggested that intention to visit high-preferred destinations $(M=5.05)$ was significantly higher than that for lesspreferred destinations $(\mathrm{M}=3.95)$.

\subsubsection{Destination Choice}

The respondents were asked to select only one destination from the list of eight that they would choose. The results are shown in Figure 6.8.

Figure 6.8: Choice (Adults) $(\mathrm{n}=197)$

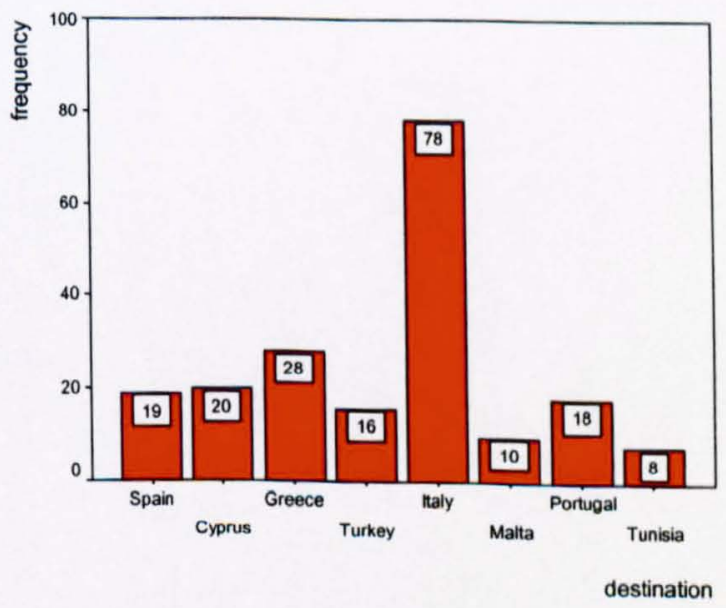

The results in Figure 6.8 demonstrate that a majority of the respondents (78) selected Italy as their final choice. Tunisia (8) is the destination that very few respondents selected as their final choice. 


\subsection{Conclusion}

This chapter has presented the descriptive findings to provide the background information for the two sample groups: sample group 1 (students) and sample group 2 (adults). The results of these two sample groups reinforced each other. Beach holidays were the most popular type of holiday among the two sample groups. Therefore, it was very relevant for this study to focus on this type of holiday. A period of June, July and August was the most popular period for taking next overseas holidays. This supported the hypothetical situation of the experiment. The results further showed that most of the respondents were not only experienced holidaymakers but also experienced beach holidaymakers.

Among other destinations, Italy was selected as the most preferred destination and the most expensive destination. Italy was also perceived as having the most overall positive destination image and was selected most often as a destination offering the best in most of the destination attributes. This resulted in Italy being the most selected destination choice. However, most of the respondents were most knowledgeable about Spain as a beach holiday destination and Spain was the most visited destination.

The experiment manipulation check on destination preference divided the four destinations into the high and low preference levels for further analyses. For the sample group 1 (students), high preference level included Italy, Spain, Greece and Portugal while low preference level includes Cyprus, Malta, Turkey and Tunisia. For the sample group 2, there was a change in the position of Spain and Cyprus in which Spain was included in a low preference level while Cyprus was included in a high preference level. The next chapter tests the six hypotheses formulated in Chapter 4. 


\section{Chapter Seven}

\section{Hypothesis Testing}

\subsection{Introduction}

This chapter presents results of the hypothesis testing for the two sample groups. The results of sample group 1 (students) are first presented and followed immediately by those of sample group 2 (adults). The chapter is organised in four main parts. The first part focuses on the effects of presentation format on the destination choice process $(\mathrm{H} 1$ and $\mathrm{H} 2)$. The second part tests the effects of presentation format on destination importance (H3). The third part examines the effects of exposure on the destination choice process (H4, H5 and H6). The fourth part provides the additional analyses. The chapter ends with a conclusion section.

Except for H3, the analyses are first conducted on eight destinations (four highpreferred destinations and four less-preferred destinations) and then on four destinations (two extreme high-preferred destinations and two extreme less-preferred destinations). The purpose of the latter analysis is to check the predicted effects when the destinations in the middle of the preference range are eliminated as it is suspected that those destinations may obscure the results. The results of both analyses reinforce each other. The analyses for eight destinations are discussed in detail while those of the four destinations are presented only when providing different findings. 


\subsection{Effects of Presentation Format on Destination Choice Process}

As discussed in section 4.5 , there are two predictions relating to the presentation of information in such a way as to reduce the prominence of destination. The first is related to the amount of information given. It is expected that presenting the destination name along with other attributes will turn the consumers' attention to these attributes and thus provide chances for less-preferred destinations to be positively evaluated, included in a late consideration and selected as a final choice. The first hypothesis is as follows:

H1: For less-preferred destinations, presenting the destination name along with other attributes increases (a) intention to visit (b) their probability of entering late consideration (c) their probability of becoming a choice.

The second is related to the package heading. It is expected that presenting an alternative attribute (price) as a package heading will draw attention to that specific attribute (price) and thus provide chances for less-preferred destinations to be positively evaluated, included in a late consideration and selected as a final choice. The second hypothesis is as follows:

H2: For less-preferred destinations, presenting price as a package heading increases (a) intention to visit (b) their probability of entering late consideration (c) their probability of becoming a choice.

Since these two hypotheses share the same dependent variables, the analysis for testing such hypotheses can be performed together. This analysis includes three groups or presentation formats; namely control group (destination name only), experimental group 1 (destination name along with other attributes and with destination as a heading) and experimental group 2 (destination name along with other attributes and with price as a heading). For the control group, intention to visit and consideration are only measured once since this group is not exposed to the experimental treatment. Measures are taken for all eight destinations. For the 
experimental groups, intention to visit and consideration are measured twice at time 1 and time 2 (see Figure 5.2). At time 1, each respondent in the experimental groups is presented with four destinations. At time 2, each respondent in the experimental groups is presented with eight destinations. Intention to visit and consideration measures included in these analyses are the measure at time 2 which is presented after the experimental treatment. For all the three groups, there is only one measure for choice presented after the intention to visit and consideration measures (see Figure 5.2). Details of the measures presented in the questionnaires for these three groups are included in Appendix B, Appendix C and Appendix D.

This section presents results for both hypotheses and is organised into three subsections for each dependent variable. This section is outlined as follows: the effects of presentation format on intention to visit $(\mathrm{Hla}$ and $\mathrm{H} 2 \mathrm{a})$, the effects of presentation format on late consideration ( $\mathrm{H} 1 \mathrm{~b}$ and $\mathrm{H} 2 \mathrm{~b}$ ) and the effects of presentation format on choice (H1c and $\mathrm{H} 2 \mathrm{c})$.

\subsubsection{Effects of Presentation Format on Intention to Visit}

This section aims to test the effects of presentation format on intention to visit $(\mathrm{H} 1 \mathrm{a}$ and $\mathrm{H} 2 \mathrm{a}$ ). As previously mentioned, it is expected that presenting the destination name along with other attributes will turn attention to those attributes or presenting price as a package heading will draw attention to price. This presentation format is predicted to draw attention away from the destination name and thus increase intention to visit less-preferred destinations.

A two-way analysis of variance (ANOVA) was conducted to test the impact of preference and presentation format on intention to visit. Two independent variables are preference level and presentation format. There are three presentation formats or groups: control group (destination name only), experimental group 1 (destination name along with other attributes and with destination as a heading) and experimental group 2 (destination name along with other attributes and with price as a heading). The dependent variable is intention to visit anchoring by 1 (will definitely not visit) 
to 7 (will definitely visit). The focus of these two hypotheses is on the interaction between preference and group.

\subsubsection{Sample Group 1 (Students)}

This section presents the results of presentation format effects on intention to visit for the sample group 1 (students). Table 7.1 shows mean intention to visit between group by preference.

Table 7.1: Mean Intention to Visit between Group by Preference (Students)

Dependent Variable: intention to visit-time2
\begin{tabular}{|ll|r|r|r|}
\hline preference & group & Mean & \multicolumn{1}{|c|}{ SD } & N \\
\hline low & exp1 (destination heading) & 4.2774 & 1.62718 & 310 \\
& exp2 (price heading) & 4.5016 & 1.61338 & 319 \\
& control (destination only) & 4.4276 & 1.69378 & 152 \\
& Total & 4.3982 & 1.63580 & 781 \\
\hline high & exp1 (destination heading) & 5.2412 & 1.46454 & 311 \\
& exp2 (price heading) & 5.4245 & 1.49625 & 318 \\
& control (destination only) & 5.2450 & 1.56617 & 151 \\
& Total & 5.3167 & 1.49830 & 780 \\
\hline Total & exp1 (destination heading) & 4.7601 & 1.62006 & 621 \\
& exp2 (price heading) & 4.9623 & 1.62193 & 637 \\
& control (destination only) & 4.8350 & 1.67939 & 303 \\
& Total & 4.8571 & 1.63400 & 1561 \\
\hline
\end{tabular}

The results in Table 7.1 show that when the destination is presented along with other attributes and with price as a heading (experimental group 2), mean intention to visit less-preferred destinations $(M=4.50)$ and high-preferred destinations $(M=5.42)$ are the highest. Two-way ANOVA was performed to test the effects and the results are shown in Table 7.2. 
Table 7.2: Two-way ANOVA (Students)

Dependent Variable: intention to visit-time2

\begin{tabular}{|l|r|r|r|r|r|}
\hline Source & $\begin{array}{c}\text { Type III Sum } \\
\text { of Squares }\end{array}$ & df & Mean Square & \multicolumn{1}{c|}{ F } & \multicolumn{1}{|c|}{ Sig. } \\
\hline Corrected Model & $343.512^{\mathrm{a}}$ & 5 & 68.702 & 27.955 & .000 \\
Intercept & 32706.360 & 1 & 32706.360 & 13308.034 & .000 \\
PREF & 282.081 & 1 & 282.081 & 114.777 & .000 \\
GROUP & 13.222 & 2 & 6.611 & 2.690 & .068 \\
PREF * GROUP & 1.095 & 2 & .548 & .223 & .800 \\
Error & 3821.631 & 1555 & 2.458 & & \\
Total & 40992.000 & 1561 & & & \\
Corrected Total & 4165.143 & 1560 & & & \\
\hline
\end{tabular}

a. R Squared $=.082$ (Adjusted $R$ Squared $=.080$ )

The results of a two-way ANOVA in Table 7.2 show that there is no significant interaction between preference and group, $\mathrm{F}(2,1555)=.22$, ns. There is a significant difference in intention to visit between the two preference levels, $F(1,1555)=114.78$, $p=.00$. Table 7.1 shows that mean intention to visit high-preferred destinations $(M=5.32)$ is higher than that for less-preferred destinations $(M=4.40)$.

To examine further the difference between specific groups or presentation formats, one-way ANOVA with planned comparisons was performed twice. The first comparison was between the control group and experimental groups to check the effects of the amount of information given. The second comparison was between the experimental group 1 and experimental group 2 to check the effects of package heading. The results suggested that mean intention to visit for the control group (destination name only) was not significantly different from the experimental groups (destination name along with other attributes), $\mathrm{F}(1,1558)=.06$, ns. However, mean intention to visit for experimental group 1 (destination name along with other attributes and with destination as a heading) was significantly different from experimental group 2 (destination name along with other attributes and with price as a heading), $F(1,1558)=4.83, p=.03$. Table 7.1 shows that mean intention to visit for experimental group 2, the destination name along with other attributes and with price as a heading $(M=4.96)$ is higher than that for the experimental group 1 , the destination name along with other attributes and with destination as a heading $(\mathrm{M}=4.76)$. 


\subsubsection{Sample Group 2 (Adults)}

This section presents the results of presentation format effects on intention to visit for sample group 2 (adults). Table 7.3 shows mean intention to visit between group by preference.

Table 7.3: Mean Intention to Visit between Group by Preference

(Adults)

Dependent Variable: intention to visit-time2
\begin{tabular}{|ll|r|r|r|}
\hline preference & group & Mean & \multicolumn{1}{c|}{ SD } & N \\
\hline low & exp1 (destination heading) & 4.1010 & 1.91065 & 287 \\
& exp2 (price heading) & 3.8935 & 1.93132 & 291 \\
& control (destination only) & 3.9276 & 1.87030 & 152 \\
& Total & 3.9822 & 1.91047 & 730 \\
\hline high & exp1 (destination heading) & 5.1275 & 1.53868 & 298 \\
& exp2 (price heading) & 5.0867 & 1.74240 & 300 \\
& control (destination only) & 5.0588 & 1.69843 & 153 \\
& Total & 5.0972 & 1.65324 & 751 \\
\hline Total & exp1 (destination heading) & 4.6239 & 1.80433 & 585 \\
& exp2 (price heading) & 4.4992 & 1.93090 & 591 \\
& control (destination only) & 4.4951 & 1.87104 & 305 \\
& Total & 4.5476 & 1.86918 & 1481 \\
\hline
\end{tabular}

The results in Table 7.3 show that when the destination name is presented along with other attributes and with destination as a heading (experimental group 1), mean intention to visit less-preferred destinations $(M=4.10)$ and high-preferred destinations $(M=5.13)$ are the highest. Two-way ANOVA was performed to test the effects and the results are shown in Table 7.4 .

\section{Table 7.4: Two-way ANOVA (Adults)}

Dependent Variable: Intention to visit-time2
\begin{tabular}{|l|r|r|r|r|r|}
\hline Source & $\begin{array}{c}\text { Type III Sum } \\
\text { of Squares }\end{array}$ & df & Mean Square & \multicolumn{1}{|c|}{ F } & \multicolumn{1}{c|}{ Sig. } \\
\hline Corrected Model & $467.551^{2}$ & 5 & 93.510 & 29.325 & .000 \\
Intercept & 27673.912 & 1 & 27673.812 & 8678.725 & .000 \\
PREF & 420.146 & 1 & 420.146 & 131.761 & .000 \\
GROUP & 5.367 & 2 & 2.683 & .842 & .431 \\
PREF - GROUP & 2.069 & 2 & 1.034 & .324 & .723 \\
Error & 4703.343 & 1475 & 3.189 & & \\
Total & 35799.000 & 1481 & & & \\
Corrected Total & 5170.894 & 1480 & & & \\
\hline
\end{tabular}

a. $R$ Squared $=.090$ (Adjusted R Squared $=.087$ )

The results in Table 7.4 show that there is no significant interaction between preference and group, $F(2,1475)=.32$, ns. There is a significant difference in 
intention to visit between the two preference levels, $F(1,1475)=131.76, p=.00$. Table 7.3 shows that mean intention to visit high-preferred destinations $(M=5.10)$ is higher than that for less-preferred destinations $(M=3.98)$.

As previously described in the analyses for sample group 1 (students), one-way ANOVA with planned comparisons was also performed twice for sample group 2 to examine further the difference between specific groups or presentation formats. The results suggested that mean intention to visit for the control group (destination name only) was not significantly different from that for the experimental groups (destination name along with other attributes), $F(1,1478)=.31$, ns. Furthermore, mean intention to visit for the experimental group 1 (destination name along with other attributes and with destination as a heading) was not significantly different from that for the experimental group 2 (destination name along with other attributes and with price as a heading), $F(1,1478)=1.30$, ns.

The results of two-way ANOVA for the two sample groups show that neither presenting the destination name along with other attributes nor presenting price as a package heading increases intention to visit less-preferred destinations. Therefore, $\mathrm{H} 1 \mathrm{a}$ and $\mathrm{H} 2 \mathrm{a}$ are not supported.

\subsubsection{Effects of Presentation Format on Late Consideration}

This section aims to test the effects of presentation format on the probability of entering late consideration ( $\mathrm{H} 1 \mathrm{~b}$ and $\mathrm{H} 2 \mathrm{~b}$ ). As previously mentioned, it is expected that presenting the destination name along with other attributes will turn attention to those attributes or presenting price as a package heading will draw attention to price. This presentation format is predicted to draw attention away from the destination name and thus increase probability of entering late consideration for less-preferred destinations.

Logistic regression was employed to test the above two hypotheses. Probability of entering late consideration $(0=$ no, $1=$ yes) was a dependent variable. The predictors were preference $(0=$ low, $1=$ high $)$, amount of information given $(0=$ destination name 
only, 1=destination name along with other attributes), package heading ($1=$ destination, $0=$ none, 1 -price). The focus of these two hypotheses is on the interactions between preference and amount of information given as well as preference and package heading.

\subsubsection{Sample Group 1 (Students)}

This section presents the results of presentation format effects on the probability of entering late consideration for sample group 1 (students). Table 7.5 shows the probability of entering late consideration between group by preference.

Table 7.5: Probability of Entering Late Consideration between Group by Preference (Students)

\begin{tabular}{|c|c|c|c|c|c|c|}
\hline \multirow[b]{2}{*}{ group } & & & & \multicolumn{2}{|c|}{ late consideration } & \multirow[b]{2}{*}{ Total } \\
\hline & & & & no & yes & \\
\hline \multirow[t]{6}{*}{ exp1 (destination heading) } & preference & low & Count & 206 & 114 & 320 \\
\hline & & & $\%$ within preference & $64.4 \%$ & $35.6 \%$ & $100.0 \%$ \\
\hline & & high & Count & 127 & 193 & 320 \\
\hline & & & $\%$ within preference & $39.7 \%$ & $60.3 \%$ & $100.0 \%$ \\
\hline & Total & & Count & 333 & 307 & 640 \\
\hline & & & $\%$ within preference & $52.0 \%$ & $48.0 \%$ & $100.0 \%$ \\
\hline \multirow[t]{6}{*}{ exp2 (price heading) } & preference & low & Count & 215 & 105 & 320 \\
\hline & & & $\%$ within preference & $67.2 \%$ & $32.8 \%$ & $100.0 \%$ \\
\hline & & high & Count & 115 & 205 & 320 \\
\hline & & & $\%$ within preference & $35.9 \%$ & $64.1 \%$ & $100.0 \%$ \\
\hline & Total & & Count & 330 & 310 & 640 \\
\hline & & & $\%$ within preference & $51.6 \%$ & $48.4 \%$ & $100.0 \%$ \\
\hline \multirow[t]{6}{*}{ control (destination only) } & preference & low & Count & 108 & 52 & 160 \\
\hline & & & $\%$ within preference & $67.5 \%$ & $32.5 \%$ & $100.0 \%$ \\
\hline & & high & Count & 52 & 108 & 160 \\
\hline & & & $\%$ within preference & $32.5 \%$ & $67.5 \%$ & $100.0 \%$ \\
\hline & Total & & Count & 160 & 160 & 320 \\
\hline & & & $\%$ within preference & $50.0 \%$ & $50.0 \%$ & $100.0 \%$ \\
\hline
\end{tabular}

Table 7.5 shows that less-preferred destinations have the highest probability of being included in late consideration (35.6\%) when the destination name is presented along with other attributes and with destination as a heading (experimental group 1). On the other hand, high-preferred destinations have the highest probability of being included in late consideration $(67.5 \%)$ when only the destination name was presented (control group). Logistic regression was performed to test the effects and parameter estimates for probability of entering late consideration are presented in Table 7.6. 
Table 7.6: Parameter Estimates for Probability of Entering Late Consideration (Students)

\begin{tabular}{|l|r|r|r|r|}
\hline & \multicolumn{1}{|c|}{ B } & \multicolumn{1}{c|}{ S.E. } & \multicolumn{1}{c|}{ Sig. } & \multicolumn{1}{c|}{ Exp(B) } \\
\hline PREF & 1.256 & .111 & .000 & 3.510 \\
INFORMATION & .026 & .063 & .684 & 1.026 \\
HEADING & -.062 & .083 & .453 & .939 \\
PREF by INFORMATION & -.103 & .089 & .244 & .902 \\
PREF by HEADING & .142 & .117 & .223 & 1.153 \\
\hline
\end{tabular}

A full model versus a model with intercept only is significant, $\chi^{2}(5,1600)=143.51$, $\mathrm{p}=.00$ with Nagelkerke $\mathrm{R}^{2}$ of .11 . Parameter estimates shown in Table 7.6 suggest that the interactions between preference and amount of information given (pref by information) or preference and package heading (pref by heading) are not significant. There is only a significant effect of preference which explains that being a highpreferred destination increases the likelihood of being included in the late consideration by 3.51 times, controlling for all factors.

\subsubsection{Sample Group 2 (Adults)}

This section presents the results of presentation format effects on probability of entering late consideration for sample group 2 (adults). Table 7.7 shows the probability of entering late consideration between group by preference.

Table 7.7: Probability of Entering Late Consideration between Group by Preference (Adults)

\begin{tabular}{|c|c|c|c|c|c|c|}
\hline \multirow[b]{2}{*}{ group } & & & & \multicolumn{2}{|c|}{ late consideration } & \multirow[b]{2}{*}{ Total } \\
\hline & & & & no & yes & \\
\hline \multirow[t]{6}{*}{ exp1 (destination heading) } & preference & low & Count & 208 & 104 & 312 \\
\hline & & & $\%$ within preference & $66.7 \%$ & $33.3 \%$ & $100.0 \%$ \\
\hline & & high & Count & 117 & 195 & 312 \\
\hline & & & $\%$ within preference & $37.5 \%$ & $62.5 \%$ & $100.0 \%$ \\
\hline & Total & & Count & 325 & 299 & 624 \\
\hline & & & $\%$ within preference & $52.1 \%$ & $47.9 \%$ & $100.0 \%$ \\
\hline \multirow[t]{6}{*}{ exp2 (price heading) } & preference & low & Count & 219 & 101 & 320 \\
\hline & & & $\%$ within preference & $68.4 \%$ & $31.6 \%$ & $100.0 \%$ \\
\hline & & high & Count & 118 & 202 & 320 \\
\hline & & & $\%$ within preference & $36.9 \%$ & $63.1 \%$ & $100.0 \%$ \\
\hline & Total & & Count & 337 & 303 & 640 \\
\hline & & & $\%$ within preference & $52.7 \%$ & $47.3 \%$ & $100.0 \%$ \\
\hline \multirow[t]{6}{*}{ control (destination only) } & preference & low & Count & 110 & 50 & 160 \\
\hline & & & $\%$ within preference & $68.8 \%$ & $31.3 \%$ & $100.0 \%$ \\
\hline & & high & Count & 53 & 107 & 160 \\
\hline & & & $\%$ within preference & $33.1 \%$ & $66.9 \%$ & $100.0 \%$ \\
\hline & Total & & Count & 163 & 157 & 320 \\
\hline & & & $\%$ within preference & $50.9 \%$ & $49.1 \%$ & $100.0 \%$ \\
\hline
\end{tabular}


Table 7.7 shows that less-preferred destinations have the highest probability of being included in late consideration (33.3\%) when the destination name is presented along with other attributes and with destination as a heading (experimental group 1). In contrast, high-preferred destinations have the highest probability of being included in late consideration $(66.9 \%)$ when only the destination name is presented (control group). Logistic regression was performed to test the effects and parameter estimates for probability of entering late consideration are presented in Table 7.8.

Table 7.8: Parameter Estimates for Probability of Entering Late Consideration (Adults)

\begin{tabular}{|l|r|r|r|r|}
\hline & \multicolumn{1}{|c|}{$\mathrm{B}$} & \multicolumn{1}{|c|}{ S.E. } & \multicolumn{1}{c|}{ Sig. } & \multicolumn{1}{c|}{ Exp(B) } \\
\hline PREF & 1.336 & .112 & .000 & 3.802 \\
INFORMATION & .018 & .064 & .773 & 1.018 \\
HEADING & -.040 & .085 & .635 & .960 \\
PREF by INFORMATION & -.078 & .089 & .382 & .925 \\
PREF by HEADING & .054 & .118 & .649 & 1.055 \\
\hline
\end{tabular}

A full model versus a model with intercept only is significant, $\chi^{2}(5,1584)=160.81$, $p=.00$ with Nagelkerke $R^{2}$ of .13 . Parameter estimates shown in Table 7.8 suggest that the interactions between preference and amount of information given (pref by information) or preference and package heading (pref by heading) are not significant. There is only a significant effect of preference which explains that being a highpreferred destination increases the likelihood of being included in the late consideration by 3.80 times, controlling for all factors.

The results of logistic regression of both sample groups reveal that neither presenting the destination name along with other attributes nor presenting price as a package heading increases the probability of entering late consideration for less-preferred destinations. Therefore, $\mathrm{H} 1 \mathrm{~b}$ and $\mathrm{H} 2 \mathrm{~b}$ are not supported.

\subsubsection{Effects of Presentation Format on Choice}

This section aims to test the effects of presentation format on probability of becoming a choice ( $\mathrm{H} 1 \mathrm{c}$ and $\mathrm{H} 2 \mathrm{c}$ ). As previously mentioned, it is expected that presenting destination name along with other attributes will turn attention to those 
attributes or presenting price as a package heading will draw attention to price. This presentation format is expected to draw attention away from the destination name and thus increase probability of becoming a choice for less-preferred destinations.

Logistic regression was performed to test the two hypotheses. Probability of becoming a choice $(0=$ no, $1=$ yes $)$ was a dependent variable. The predictors were preference $(0=$ low, $1=$ high $)$, amount of information given $(0=$ destination name only, $1=$ destination name along with other attributes), package heading $(-1=$ destination, $0=$ none, $1=$-price). The focus of these two hypotheses is on the interactions between preference and amount of information given as well as preference and package heading.

\subsubsection{Sample Group 1 (Students)}

This section presents the results of the presentation format effects on probability of becoming a choice for sample group 1 (students). Table 7.9 illustrates the probability of becoming a choice.

Table 7.9: Probability of Becoming a Choice between Group by Preference (Students)

\begin{tabular}{|c|c|c|c|c|c|c|}
\hline \multirow[b]{2}{*}{ group } & \multirow[b]{3}{*}{ preference } & \multirow[b]{3}{*}{ low } & \multirow{4}{*}{$\begin{array}{l}\text { Count } \\
\% \text { within preference }\end{array}$} & \multicolumn{2}{|c|}{ final choice } & \multirow[b]{2}{*}{ Total } \\
\hline & & & & no & yes & \\
\hline \multirow[t]{6}{*}{ exp1 (destination heading) } & & & & 297 & 23 & 320 \\
\hline & & & & $92.8 \%$ & $7.2 \%$ & $100.0 \%$ \\
\hline & & high & Count & 263 & 57 & 320 \\
\hline & & & $\%$ within preference & $82.2 \%$ & $17.8 \%$ & $100.0 \%$ \\
\hline & Total & & Count & 560 & 80 & 640 \\
\hline & & & $\%$ within preference & $87.5 \%$ & $12.5 \%$ & $100.0 \%$ \\
\hline \multirow[t]{6}{*}{ exp2 (price heading) } & preference & low & Count & 293 & 19 & 312 \\
\hline & & & $\%$ within preference & $93.9 \%$ & $6.1 \%$ & $100.0 \%$ \\
\hline & & high & Count & 253 & 59 & 312 \\
\hline & & & $\%$ within preference & $81.1 \%$ & $18.9 \%$ & $100.0 \%$ \\
\hline & Total & & Count & 546 & 78 & 624 \\
\hline & & & $\%$ within preference & $87.5 \%$ & $12.5 \%$ & $100.0 \%$ \\
\hline \multirow[t]{6}{*}{ control (destination only) } & preference & low & Count & 149 & 11 & 160 \\
\hline & & & $\%$ within preference & $93.1 \%$ & $6.9 \%$ & $100.0 \%$ \\
\hline & & high & Count & 131 & 29 & 160 \\
\hline & & & $\%$ within preference & $81.9 \%$ & $18.1 \%$ & $100.0 \%$ \\
\hline & Total & & Count & 280 & 40 & 320 \\
\hline & & & $\%$ within preference & $87.5 \%$ & $12.5 \%$ & $100.0 \%$ \\
\hline
\end{tabular}

Table 7.9 shows that when the destination name is presented with other attributes and with destination as a heading (experimental group 1), less-preferred destinations have 
the highest probability of becoming a choice (7.2\%). When presenting the destination name along with other attributes and with price as a heading (experimental group 2), high-preferred destinations have the highest probability of becoming a choice (18.9\%). Logistic regression was performed and parameter estimates for probability of becoming a choice are presented in Table 7.10.

Table 7.10: Parameter Estimates for Probability of Becoming a Choice (Students)

\begin{tabular}{|l|r|r|r|r|}
\hline & \multicolumn{1}{|c|}{ B } & \multicolumn{1}{|c|}{ S.E. } & \multicolumn{1}{c|}{ Sig. } & \multicolumn{1}{|c|}{ Exp(B) } \\
\hline PREF & 1.136 & .178 & .000 & 3.113 \\
INFORMATION & -.014 & .117 & .907 & .986 \\
HEADING & -.089 & .160 & .580 & .915 \\
PREF by INFORMATION & .019 & .140 & .893 & 1.019 \\
PREF by HEADING & .125 & .190 & .510 & 1.134 \\
\hline
\end{tabular}

A full model versus a model with intercept only is significant, $\chi^{2}(5,1584)=51.00$, $p=.00$ with Nagelkerke $R^{2}$ of .06 . The results in Table 7.10 suggest that the interactions between preference and amount of information given (pref by information) as well as preference and package heading (pref by heading) are not significant. There is only a significant effect of preference which explains that being a high-preferred destination increases the likelihood of becoming a choice by 3.11 times, controlling for all factors.

\subsubsection{Sample Group 2 (Adults)}

This section presents the results of presentation format effects on probability of becoming a choice for sample group 2 (adults). Table 7.11 illustrates probability of becoming a choice between group by preference. 
Table 7.11: Probability of Becoming a Choice between Group by Preference (Adults)

\begin{tabular}{|c|c|c|c|c|c|c|}
\hline \multirow[b]{2}{*}{ group } & & & & \multicolumn{2}{|c|}{ final choice } & \multirow[b]{2}{*}{ Total } \\
\hline & & & & no & yes & \\
\hline \multirow[t]{6}{*}{ exp1 (destination heading) } & preference & low & Count & 295 & 17 & 312 \\
\hline & & & $\%$ within preference & $94.6 \%$ & $5.4 \%$ & $100.0 \%$ \\
\hline & & high & Count & 251 & 61 & 312 \\
\hline & & & $\%$ within preference & $80.4 \%$ & $19.6 \%$ & $100.0 \%$ \\
\hline & Total & & Count & 546 & 78 & 624 \\
\hline & & & $\%$ within preference & $87.5 \%$ & $12.5 \%$ & $100.0 \%$ \\
\hline \multirow[t]{6}{*}{ exp2 (price heading) } & preference & low & Count & 291 & 25 & 316 \\
\hline & & & $\%$ within preference & $92.1 \%$ & $7.9 \%$ & $100.0 \%$ \\
\hline & & high & Count & 262 & 54 & 316 \\
\hline & & & $\%$ within preference & $82.9 \%$ & $17.1 \%$ & $100.0 \%$ \\
\hline & Total & & Count & 553 & 79 & 632 \\
\hline & & & $\%$ within preference & $87.5 \%$ & $12.5 \%$ & $100.0 \%$ \\
\hline \multirow[t]{6}{*}{ control (destination only) } & preference & low & Count & 149 & 11 & 160 \\
\hline & & & $\%$ within preference & $93.1 \%$ & $6.9 \%$ & $100.0 \%$ \\
\hline & & high & Count & 131 & 29 & 160 \\
\hline & & & $\%$ within preference & $81.9 \%$ & $18.1 \%$ & $100.0 \%$ \\
\hline & Total & & Count & 280 & 40 & 320 \\
\hline & & & $\%$ within preference & $87.5 \%$ & $12.5 \%$ & $100.0 \%$ \\
\hline
\end{tabular}

Table 7.11 shows that when presenting the destination name along with other attributes and with price as a heading (experimental group 2), less-preferred destinations have the highest probability of becoming a choice $(7.9 \%)$. When presenting the destination name along with other attributes and with destination as a heading (experimental group 1), high-preferred destinations have the highest probability of becoming a choice (19.6\%). Logistic regression was performed and parameter estimates for probability of becoming a choice are presented in Table 7.12.

Table 7.12: Parameter Estimates for Probability of Becoming a Choice (Adults)

\begin{tabular}{|l|r|r|r|r|}
\hline & \multicolumn{1}{|c|}{ B } & \multicolumn{1}{|c|}{ S.E. } & \multicolumn{1}{c|}{ Sig. } & \multicolumn{1}{c|}{ Exp(B) } \\
\hline PREF & 1.137 & .179 & .000 & 3.119 \\
INFORMATION & -.016 & .117 & .891 & .984 \\
HEADING & .200 & .163 & .219 & 1.221 \\
PREF by INFORMATION & .020 & .140 & .888 & 1.020 \\
PREF by HEADING & -.282 & .193 & .143 & .754 \\
\hline
\end{tabular}

A full model versus a model with intercept only is significant, $\chi^{2}(5,1576)=51.87$, $\mathrm{p}=.00$ with Nagelkerke $\mathrm{R}^{2}$ of .06 . The results in Table 7.12 suggest that the interactions between preference and amount of information given (pref by information) as well as preference and package heading (pref by heading) are not significant. There is only a significant effect of preference which explains that being 
a high-preferred destination increases the likelihood of becoming a choice by 3.12 times, controlling for all factors.

The results of logistic regression for both sample groups reveal that neither presenting the destination name along with other attributes nor presenting price as a package heading increases the probability of becoming a choice for less-preferred destinations. Therefore, $\mathrm{H} 1 \mathrm{c}$ and $\mathrm{H} 2 \mathrm{c}$ are not supported.

\subsection{Effects of Presentation Format on Destination Importance}

The study predicted that the presentation format would influence the destination choice process if it can reduce the importance of destination. The third hypothesis examines whether the presentation format has any influences on the destination importance. It is expected that presenting the destination name along with other attributes will increase the importance of those attributes and in turn reduce the destination importance. Also, presenting price as a package heading will increase price importance while decreasing destination importance. The third hypothesis is as follows:

H3: Destination importance decreases when presenting (a) destination name along with other attributes (b) price as a package heading.

A one-way between-groups multivariate analysis of variance (MANOVA) was performed to investigate the differences in the importance ratings for each of the six attributes. These six attributes are airline, destination, number of nights, price, accommodation quality and travel agent. The importance ratings are measured after the measures at time 2 (intention to visit, probability of entering late consideration and probability of becoming a choice). An independent variable is the presentation format or group consisting of control group (destination name only), experimental group 1 (destination name along with other attributes and with destination as a heading) and experimental group 2 (destination name along with other attributes and with price as a heading). The focus of this hypothesis is on the differences between 
groups or presentation formats in terms of importance ratings for destination. In addition, those differences for other attributes are observed.

\subsubsection{Sample Group 1 (Students)}

This section presents the results of presentation format effects on importance ratings of six attributes for sample group 1 (students). Table 7.13 shows the results of attribute importance between group.

Table 7.13: Mean Attribute Importance between Group (Students)

\begin{tabular}{|c|c|c|c|c|}
\hline & group & Mean & SD & $\mathrm{N}$ \\
\hline \multirow[t]{4}{*}{ airline } & exp1 (destination heading) & 3.93 & 1.565 & 80 \\
\hline & exp2 (price heading) & 4.24 & 1.745 & 80 \\
\hline & control (destination only) & 4.13 & 1.856 & 40 \\
\hline & Total & 4.09 & 1.696 & 200 \\
\hline \multirow{4}{*}{ destination } & exp1 (destination heading) & 6.70 & .582 & 80 \\
\hline & exp2 (price heading) & 6.70 & .833 & 80 \\
\hline & control (destination only) & 6.73 & .554 & 40 \\
\hline & Total & 6.70 & 686 & 200 \\
\hline \multirow[t]{4}{*}{ number of nights } & exp1 (destination heading) & 5.57 & 1.156 & 80 \\
\hline & exp2 (price heading) & 5.74 & 1.088 & 80 \\
\hline & control (destination only) & 5.83 & 1.174 & 40 \\
\hline & Total & 5.69 & 1.132 & 200 \\
\hline \multirow[t]{4}{*}{ price } & exp1 (destination heading) & 6.00 & 1.102 & 80 \\
\hline & exp2 (price heading) & 6.14 & 1.099 & 80 \\
\hline & control (destination only) & 6.28 & 1.037 & 40 \\
\hline & Total & 6.11 & 1.088 & 200 \\
\hline \multirow[t]{4}{*}{ accommodation } & exp1 (destination heading) & 5.86 & 1.028 & 80 \\
\hline & exp2 (price heading) & 5.70 & 1.326 & 80 \\
\hline & control (destination only) & 5.83 & 1.107 & 40 \\
\hline & Total & 5.79 & 1.167 & 200 \\
\hline \multirow[t]{4}{*}{ travel agent } & exp1 (destination heading) & 3.16 & 1.554 & 80 \\
\hline & exp2 (price heading) & 3.39 & 1.626 & 80 \\
\hline & control (destination only) & 3.33 & 1.575 & 40 \\
\hline & Total & 3.29 & 1.583 & 200 \\
\hline
\end{tabular}

The results in Table 7.13 show that the three most important attributes in choosing an overseas beach holiday are destination $(M=6.70)$, price $(M=6.11)$ and quality of accommodation $(\mathrm{M}=5.79)$. Travel agent is perceived as the least important $(M=3.29)$. The results also show that destination is regarded as the most important attribute across the three groups or presentation formats: experimental group $1(\mathrm{M}=$ $6.70)$, experimental group $2(M=6.70)$ and control group $(M=6.73)$. A one-way MANOVA was performed and Table 7.14 shows multivariate analysis of variance for attribute importance. 
Table 7.14: MANOVA for Attribute Importance (Students)

\begin{tabular}{|ll|r|r|r|r|r|}
\hline Effect & & \multicolumn{1}{|c|}{ Value } & \multicolumn{1}{c|}{ F } & Hypothesis df & Error df & \multicolumn{1}{c|}{ Sig. } \\
\hline Intercept & Pillai's Trace & .991 & 3533.869 & 6.000 & 192.000 & .000 \\
& Wilks' Lambda & .009 & 3533.869 & 6.000 & 192.000 & .000 \\
& Hotelling's Trace & 110.433 & 3533.869 & 6.000 & 192.000 & .000 \\
& Roy's Largest Root & 110.433 & 3533.869 & 6.000 & 192.000 & .000 \\
\hline GROUP & Pillai's Trace & .030 & .492 & 12.000 & 386.000 & .919 \\
& Wilks' Lambda & .970 & .491 & 12.000 & 384.000 & .920 \\
& Hotelling's Trace & .031 & .491 & 12.000 & 382.000 & .920 \\
& Roy's Largest Root & .026 & .839 & 6.000 & 193.000 & .541 \\
\hline
\end{tabular}

Table 7.14 shows that there is no significant difference between groups on the combined dependent variables, $F(12,384)=.49$, ns, Wilks' Lambda $=.97$. The findings suggest that there is no significant difference between the presentation format (group) on the importance ratings of six attributes.

One-way ANOVA with planned comparisons was further performed to examine the differences between the importance ratings of the two specific attributes; namely destination and price. The first analysis conducted on the difference between the control group (destination name only) and the experimental groups (destination name along with other attributes) showed that there was no significant difference in destination importance, $F(1,197)=.04$, ns. The second analysis conducted on the difference between experimental group 1 (destination as a package heading) and the experimental group 2 (price as a package heading) showed that there were no significant differences in destination importance, $F(1,197)=.00$, ns and price importance, $F(1,197)=.64$, ns.

\subsubsection{Sample Group 2 (Adults)}

This section presents the results of presentation format effects on destination importance ratings of six attributes for sample group 2 (adults). Table 7.15 shows the results of attribute importance between group. 
Table 7.15: Mean Attribute Importance between Group (Adults)

\begin{tabular}{|ll|r|r|r|}
\hline & group & Mean & Std. Deviation & N \\
\hline airline & exp1(destination heading) & 3.88 & 1.694 & 80 \\
& exp2 (price heading) & 3.83 & 1.734 & 80 \\
& control (destination only) & 4.10 & 1.582 & 40 \\
& Total & 3.90 & 1.683 & 200 \\
\hline destination & exp1(destination heading) & 6.62 & 1.048 & 80 \\
& exp2 (price heading) & 6.56 & 1.200 & 80 \\
& control (destination only) & 6.58 & 1.174 & 40 \\
& Total & 6.59 & 1.131 & 200 \\
\hline number of nights & exp1(destination heading) & 5.54 & 1.449 & 80 \\
& exp2 (price heading) & 5.48 & 1.302 & 80 \\
& control (destination only) & 5.75 & 1.235 & 40 \\
& Total & 5.55 & 1.348 & 200 \\
\hline price & exp1(destination heading) & 5.70 & 1.216 & 80 \\
& exp2 (price heading) & 5.86 & 1.240 & 80 \\
& control (destination only) & 5.90 & 1.297 & 40 \\
& Total & 5.81 & 1.239 & 200 \\
\hline accommodation & exp1(destination heading) & 6.07 & 1.230 & 80 \\
& exp2 (price heading) & 6.13 & 1.162 & 80 \\
& control (destination only) & 6.40 & 1.033 & 40 \\
& Total & 6.16 & 1.167 & 200 \\
\hline travel agent & exp1(destination heading) & 3.04 & 1.831 & 80 \\
& exp2 (price heading) & 2.91 & 1.663 & 80 \\
& control (destination only) & 3.20 & 1.667 & 40 \\
& Total & 3.02 & 1.728 & 200 \\
\hline
\end{tabular}

The results in Table 7.15 show that the three most important attributes in choosing an overseas beach holiday for this sample group are destination $(M=6.59)$, quality of accommodation $(M=6.16)$ and price $(M=5.81)$. Travel agent is perceived as the least important $(M=3.02)$. The results also show that destination is regarded as the most important attribute across the three groups or presentation formats: experimental group $1(\mathrm{M}=6.62)$, experimental group $2(\mathrm{M}=6.56)$ and control group $(\mathrm{M}=6.58)$. A one-way between-groups MANOVA was performed to test the effects and the results are shown in Table 7.16.

Table 7.16: MANOVA for Attribute Importance (Adults)

\begin{tabular}{|ll|r|r|r|r|r|}
\hline Effect & \multicolumn{1}{|c|}{ Value } & \multicolumn{1}{c|}{ F } & Hypothesis df & Error df & \multicolumn{1}{c|}{ Sig. } \\
\hline Intercept & Pillai's Trace & .979 & 1479.999 & 6.000 & 192.000 & .000 \\
& Wilks' Lambda & .021 & 1479.999 & 6.000 & 192.000 & .000 \\
& Hotelling's Trace & 46.250 & 1479.999 & 6.000 & 192.000 & .000 \\
& Roy's Largest Root & 46.250 & 1479.999 & 6.000 & 192.000 & .000 \\
\hline GROUP & Pillai's Trace & .033 & .540 & 12.000 & 386.000 & .888 \\
& Wilks' Lambda & .967 & .538 & 12.000 & 384.000 & .890 \\
& Hotelling's Trace & .034 & .535 & 12.000 & 382.000 & .891 \\
& Roy's Largest Root & .022 & .709 & 6.000 & 193.000 & .643 \\
\hline
\end{tabular}


Table 7.16 shows that there is no significant difference between groups on the combined dependent variables, $F(12,384)=.54$, ns, Wilks' Lambda=.97. The findings suggest that there is no significant difference between the presentation format on the importance ratings of six attributes.

One-way ANOVA with planned comparisons was further performed to examine the differences between the importance ratings of two specific attributes; namely destination and price. The first analysis on the difference between the control group (destination name only) and the experimental groups (destination name along with other attributes) showed that there was no significant difference in destination importance, $F(1,197)=.01$, ns. The second analysis on the difference between experimental group 1 (destination as a package heading) and the experimental group 2 (price as a package heading) also revealed that there was no significant difference in destination importance, $F(1,197)=.12$, ns and price importance, $F(1,197)=.68$, ns.

Based on the findings of the two sample groups, neither presenting destination name along with other attributes nor presenting price as a package heading decreases the destination importance. Therefore, $\mathrm{H} 3$ is not supported.

\subsection{Effects of Exposure on Destination Choice Process}

As discussed in Chapter 4, there are three contrasting views on the timing of exposure in determining the consideration sets. This study aims to test the effective timing of exposure to less-preferred destinations such that it can benefit such destinations. The first assumes that the consideration sets are stable in which the destinations should be presented as early as possible (Crompton and Ankomah, 1993). Based on this notion, the fourth hypothesis is as follows:

H4: Early exposure to less-preferred destinations increases (a) intention to visit (b) their probability of entering late consideration (c) their probability of becoming $a$ choice. 
The second notion is that the consideration sets are unstable over time and the exposure may add or delete the alternatives from the consideration set at any point in time (Shocker et al., 1991; Roberts and Nedungadi, 1995). Regardless of the early exposure, this notion suggests that late exposure can be beneficial for less-preferred destinations. The fifth hypothesis is as follows:

H5: Late exposure to less-preferred destinations increases (a) intention to visit (b) their probability of entering late consideration (c) their probability of becoming a choice.

The third notion suggests that not only are the consideration sets unstable but the rejected alternatives are also unlikely to be considered (Hulland, 1992). To avoid being rejected, alternatives should be presented only once and as close to a time of choice as possible. Based on this notion, the sixth hypothesis is as follows:

H6: Late exposure (without early exposure) to less-preferred destinations increases (a) intention to visit (b) their probability of entering late consideration (c) their probability of becoming a choice.

These three hypotheses share the same dependent variables in which the analyses for testing such hypotheses can be performed together. For this section, the analyses include only the experimental groups. The control group is not included since it is not presented with early or late exposures (treatments). Referring to the overall design (see Figure 5.2), there are two stages of exposure. Early exposure presents four destinations. Late exposure also presents four destinations including two seen alternatives and two new alternatives. As discussed in section 7.2, intention to visit and consideration measures included in the analyses are also the measures at time 2 presented after the experimental treatment. There is only one measure for choice. For these measures at time 2 , the respondents are presented with eight destinations including seen alternatives and two new alternatives (see Table 5.4). Details of the exposures and measures of the two experimental groups are shown in Appendix C and Appendix D. 
This section presents the results for the three hypotheses and is organised into three sub-sections for each dependent variable. This section is outlined as follows: the effects of exposure on intention to visit ( $\mathrm{H} 4 \mathrm{a}, \mathrm{H} 5 \mathrm{a}$ and $\mathrm{H6a}$ ), the effects of exposure on late consideration ( $\mathrm{H} 4 \mathrm{~b}, \mathrm{H} 5 \mathrm{~b}$ and $\mathrm{H} 6 \mathrm{~b}$ ) and the effects of exposure on choice (H4c, H5c and H6c).

\subsubsection{Effects of Exposure on Intention to Visit}

This section aims to test the effects of exposure on intention to visit ( $\mathrm{H} 4 \mathrm{a}, \mathrm{H} 5 \mathrm{a}$ and H6a). It particularly examines the effective timing of exposure to less-preferred destinations so as to help increase intention to visit such destinations.

Four-way between-groups ANOVA was conducted to examine the impact of four independent variables on intention to visit. The dependent variable is intention to visit anchoring 1 (will definitely not visit) to 7 (will definitely visit). Four independent variables are preference (high, low), package heading (destination, price), early exposure (yes, no) and late exposure (yes, no). The focus of the three hypotheses are on the interaction between preference and early exposure, that between preference and late exposure, and that between preference, early exposure and late exposure respectively.

\subsubsection{Sample Group 1 (Students)}

This section presents the results of the effects of exposure on intention to visit for sample group 1 (students). Table 7.17 shows mean intention to visit between exposure by preference. 
Table 7.17: Mean Intention to Visit between Exposure by Preference (Students)

\begin{tabular}{|c|c|c|c|c|c|}
\hline preference & early exposure & late exposure & Mean & SD & $\mathrm{N}$ \\
\hline \multirow[t]{9}{*}{ low } & \multirow[t]{3}{*}{ no } & no & 4.4937 & 1.67692 & 158 \\
\hline & & yes & 4.3333 & 1.63562 & 156 \\
\hline & & Total & 4.4140 & 1.65583 & 314 \\
\hline & \multirow[t]{3}{*}{ yes } & no & 4.4114 & 1.62045 & 158 \\
\hline & & yes & 4.3248 & 1.56572 & 157 \\
\hline & & Total & 4.3683 & 1.59146 & 315 \\
\hline & \multirow[t]{3}{*}{ Total } & no & 4.4525 & 1.64682 & 316 \\
\hline & & yes & 4.3291 & 1.59838 & 313 \\
\hline & & Total & 4.3911 & 1.62278 & 629 \\
\hline \multirow[t]{9}{*}{ high } & \multirow[t]{3}{*}{ no } & no & 5.2675 & 1.57457 & 157 \\
\hline & & yes & 5.4241 & 1.46420 & 158 \\
\hline & & Total & 5.3460 & 1.51981 & 315 \\
\hline & \multirow[t]{3}{*}{ yes } & no & 5.4013 & 1.39991 & 157 \\
\hline & & yes & 5.2420 & 1.49100 & 157 \\
\hline & & Total & 5.3217 & 1.44606 & 314 \\
\hline & \multirow[t]{3}{*}{ Total } & no & 5.3344 & 1.48892 & 314 \\
\hline & & yes & 5.3333 & 1.47808 & 315 \\
\hline & & Total & 5.3339 & 1.48232 & 629 \\
\hline \multirow[t]{9}{*}{ Total } & \multirow[t]{3}{*}{ no } & no & 4.8794 & 1.66972 & 315 \\
\hline & & yes & 4.8822 & 1.64272 & 314 \\
\hline & & Total & 4.8808 & 1.65498 & 629 \\
\hline & \multirow[t]{3}{*}{ yes } & no & 4.9048 & 1.59132 & 315 \\
\hline & & yes & 4.7834 & 1.59399 & 314 \\
\hline & & Total & 4.8442 & 1.59254 & 629 \\
\hline & \multirow[t]{3}{*}{ Total } & no & 4.8921 & 1.62974 & 630 \\
\hline & & yes & 4.8328 & 1.61800 & 628 \\
\hline & & Total & 4.8625 & 1.62352 & 1258 \\
\hline
\end{tabular}

The results in Table 7.17 show that when there are no exposures to less-preferred destinations, mean intention to visit such destinations was the highest $(M=4.49)$. As mentioned in section 7.4, it should be noted that the eight destinations at time 2 include two new alternatives that the respondents have not seen in the previous exposures. When having only late exposure (without early exposure) to highpreferred destinations, mean intention to visit such destinations was the highest $(\mathrm{M}=5.42)$. Four-way ANOVA was performed and the results are shown in Table 7.18 . 
Table 7.18: Four-way ANOVA (Students)

\begin{tabular}{|c|c|c|c|c|c|}
\hline Source & $\begin{array}{c}\text { Type III Sum } \\
\text { of Squares }\end{array}$ & df & Mean Square & $\mathrm{F}$ & Sig. \\
\hline Corrected Model & $312.683^{a}$ & 15 & 20.846 & 8.629 & .000 \\
\hline Intercept & 29724.634 & 1 & 29724.634 & 12303.843 & .000 \\
\hline PREF & 279.643 & 1 & 279.643 & 115.752 & .000 \\
\hline HEADING & 12.938 & 1 & 12.938 & 5.355 & .021 \\
\hline EARLY & .392 & 1 & .392 & .162 & .687 \\
\hline LATE & 1.196 & 1 & 1.196 & .495 & .482 \\
\hline PREF * HEADING & .130 & 1 & .130 & .054 & 817 \\
\hline PREF * EARLY & .042 & 1 & .042 & .017 & .895 \\
\hline HEADING * EARLY & 1.345 & 1 & 1.345 & .557 & .456 \\
\hline PREF * HEADING * EARLY & .693 & 1 & .693 & .287 & .592 \\
\hline PREF * LATE & 1.087 & 1 & 1.087 & .450 & .502 \\
\hline HEADING * LATE & .006 & 1 & .006 & .002 & .961 \\
\hline PREF * HEADING * LATE & 7.631 & 1 & 7.631 & 3.159 & .076 \\
\hline EARLY* LATE & 1.186 & 1 & 1.186 & .491 & .484 \\
\hline$P R E F \cdot E A R L Y \cdot L A T E$ & 2.934 & 1 & 2.934 & 1.214 & 271 \\
\hline HEADING * EARLY* LATE & 3.123 & 1 & 3.123 & 1.293 & .256 \\
\hline PREF * HEADING * EARLY * LATE & .296 & 1 & .296 & .122 & .727 \\
\hline Error & 3000.526 & 1242 & 2.416 & & \\
\hline Total & 33057.000 & 1258 & & & \\
\hline Corrected Total & 3313.209 & 1257 & & & \\
\hline
\end{tabular}

a. R Squared $=.094$ (Adjusted R Squared $=.083$ )

The results in Table 7.18 suggest that there are no significant interactions between preference and early exposure, $\mathrm{F}(1,1242)=.02$, ns or preference and late exposure $\mathrm{F}(1,1242)=.45$, ns or preference, early exposure and late exposure, $\mathrm{F}(1,1242)=1.21$, ns. However, there is a significant effect of preference, $F(1,1242)=115.75, p=.00$ and package heading, $F(1,1242)=5.36, p=.02$. The results of the significant findings are presented in section 7.2.1.1. The three-way interaction between preference, heading and late exposure, $\mathrm{F}(1,1242)=3.16, \mathrm{p}=.08$, approaching significant is examined. Figure 7.1 illustrates the mean plot of intention to visit of late exposure by preference. 
Figure 7.1: Mean Intention to Visit of Late Exposure by Preference (Students)- 8 Destinations
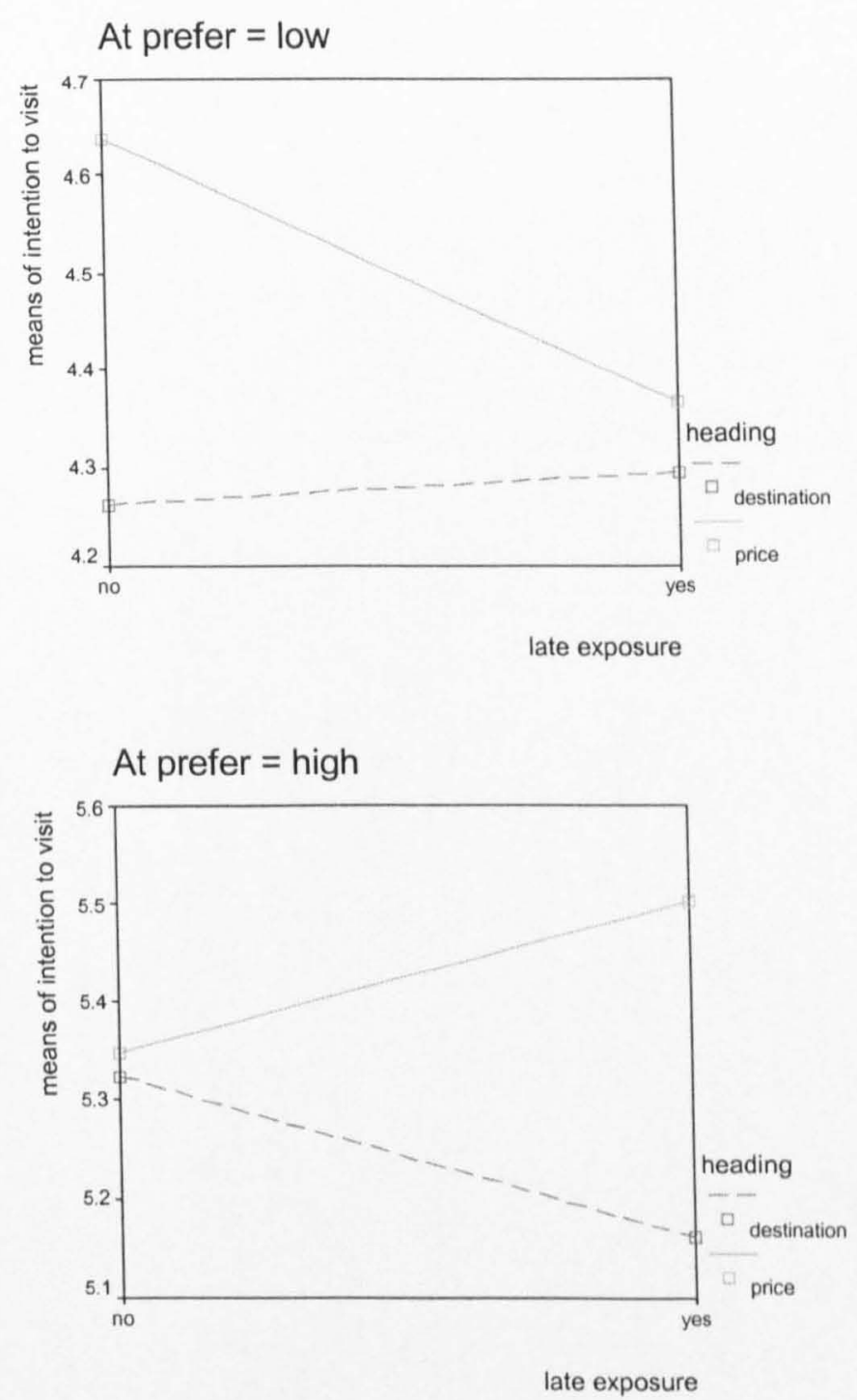

Figure 7.1 suggests that late exposure with price as a heading increases intention to visit high-preferred destinations. Late exposure with price as a heading appears to decrease intention to visit less-preferred destinations. These results are not in an anticipated direction predicting that late exposure would increase intention to visit less-preferred destinations.

The results of four-way ANOVA for the four destinations (two extreme highpreferred destinations, two extreme less-preferred destinations) show that the threeway interaction between preference, package heading and late exposure $\mathrm{F}(1,615)=15.91, \mathrm{p}=.00$ is significant. These results are similar to those of the eight 
destinations in that late exposure with price as a heading increases intention to visit extreme high-preferred destinations but it does not increase intention to visit extreme less-preferred destinations.

\subsubsection{Sample Group 2 (Adults)}

This section presents the results of the effects of exposure on intention to visit for sample group 2 (adults). Table 7.19 shows mean intention to visit between exposure by preference.

Table 7.19: Mean Intention to Visit between Exposure by Preference (Adults)

\begin{tabular}{|c|c|c|c|c|c|}
\hline preference & early exposure & late exposure & Mean & SD & $\mathrm{N}$ \\
\hline \multirow[t]{9}{*}{ low } & \multirow[t]{3}{*}{ no } & no & 4.1507 & 1.92745 & 146 \\
\hline & & yes & 3.9231 & 1.92492 & 143 \\
\hline & & Total & 4.0381 & 1.92623 & 289 \\
\hline & \multirow[t]{3}{*}{ yes } & no & 3.8819 & 1.93783 & 144 \\
\hline & & yes & 4.0276 & 1.90739 & 145 \\
\hline & & Total & 3.9550 & 1.92066 & 289 \\
\hline & \multirow[t]{3}{*}{ Total } & no & 4.0172 & 1.93396 & 290 \\
\hline & & yes & 3.9757 & 1.91349 & 288 \\
\hline & & Total & 3.9965 & 1.92223 & 578 \\
\hline \multirow[t]{9}{*}{ high } & \multirow[t]{3}{*}{ no } & no & 5.1533 & 1.64556 & 150 \\
\hline & & yes & 5.0336 & 1.62504 & 149 \\
\hline & & Total & 5.0936 & 1.63372 & 299 \\
\hline & \multirow[t]{3}{*}{ yes } & no & 5.1333 & 1.61647 & 150 \\
\hline & & yes & 5.1074 & 1.69714 & 149 \\
\hline & & Total & 5.1204 & 1.65443 & 299 \\
\hline & \multirow[t]{3}{*}{ Total } & no & 5.1433 & 1.62838 & 300 \\
\hline & & yes & 5.0705 & 1.65909 & 298 \\
\hline & & Total & 5.1070 & 1.64279 & 598 \\
\hline \multirow[t]{9}{*}{ Total } & \multirow[t]{3}{*}{ no } & no & 4.6588 & 1.85631 & 296 \\
\hline & & yes & 4.4897 & 1.86021 & 292 \\
\hline & & Total & 4.5748 & 1.85859 & 588 \\
\hline & \multirow[t]{3}{*}{ yes } & no & 4.5204 & 1.88526 & 294 \\
\hline & & yes & 4.5748 & 1.88025 & 294 \\
\hline & & Total & 4.5476 & 1.88135 & 588 \\
\hline & \multirow[t]{3}{*}{ Total } & no & 4.5898 & 1.87048 & 590 \\
\hline & & yes & 4.5324 & 1.86918 & 586 \\
\hline & & Total & 4.5612 & 1.86926 & 1176 \\
\hline
\end{tabular}

The results in Table 7.19 show that mean intention to visit less-preferred destinations $(M=4.15)$ and high-preferred destinations $(M=5.15)$ are the highest when there are no early or late exposures to such destinations. As mentioned in section 7.4.1.1, eight destinations presented at time 2 include two new alternatives which the respondents have not seen in the previous exposures. Four-way ANOVA was performed to test the effects and the results are shown in Table 7.20. 
Table 7.20: Four-way ANOVA (Adults)

\begin{tabular}{|c|c|c|c|c|c|}
\hline Source & $\begin{array}{c}\text { Type III Sum } \\
\text { of Squares }\end{array}$ & df & Mean Square & $\mathrm{F}$ & Sig. \\
\hline Corrected Model & $393.728^{a}$ & 15 & 26.249 & 8.203 & .000 \\
\hline Intercept & 24355.076 & 1 & 24355.076 & 7611.240 & .000 \\
\hline PREF & 362.664 & 1 & 362.664 & 113.337 & .000 \\
\hline HEADING & 4.557 & 1 & 4.557 & 1.424 & .233 \\
\hline EARLY & .214 & 1 & .214 & .067 & .796 \\
\hline LATE & .951 & 1 & .951 & .297 & .586 \\
\hline PREF * HEADING & 2.014 & 1 & 2.014 & .629 & .428 \\
\hline PREF * EARLY & 899 & 1 & .899 & .281 & .596 \\
\hline HEADING * EARLY & .108 & 1 & .108 & .034 & 854 \\
\hline PREF * HEADING * EARLY & 8.198 & 1 & 8.198 & 2.562 & .110 \\
\hline PREF * LATE & .084 & 1 & .084 & .026 & 871 \\
\hline HEADING * LATE & 1.629 & 1 & 1.629 & .509 & .476 \\
\hline PREF * HEADING * LATE & 1.261 & 1 & 1.261 & .394 & .530 \\
\hline EARLY * LATE & 3.994 & 1 & 3.994 & 1.248 & 264 \\
\hline PREF ' EARLY 'LATE & 1.435 & 1 & 1.435 & .448 & .503 \\
\hline HEADING * EARLY * LATE & 1.442 & 1 & 1.442 & .451 & .502 \\
\hline PREF * HEADING * EARLY * LATE & 4.510 & 1 & 4.510 & 1.409 & 235 \\
\hline Error & 3711.864 & 1160 & 3.200 & & \\
\hline Total & 28572.000 & 1176 & & & \\
\hline Corrected Total & 4105.592 & 1175 & & & \\
\hline
\end{tabular}

The results in Table 7.20 suggest that there are no significant interactions between preference and early exposure, $\mathrm{F}(1,1160)=.28$, ns or preference and late exposure $\mathrm{F}(1,1160)=.03$, ns or preference, early exposure and late exposure, $\mathrm{F}(1,1160)=.45$, ns. However, there is a significant effect of preference, $F(1,1160)=113.34, p=.00$. The results of the significant effects are presented in section 7.2.1.2.

The results of four-way ANOVA for the four destinations (two extreme highpreferred destinations, two extreme less-preferred destinations) show that three-way interaction between preference, package heading and late exposure, $F(1,570)=4.09$, $\mathrm{p}=.04$ is significant. Figure 7.2 shows mean plot of intention to visit of late exposure by preference. 
Figure 7.2: Mean Intention to Visit of Late Exposure by Preference (Adults)- 4 Destinations
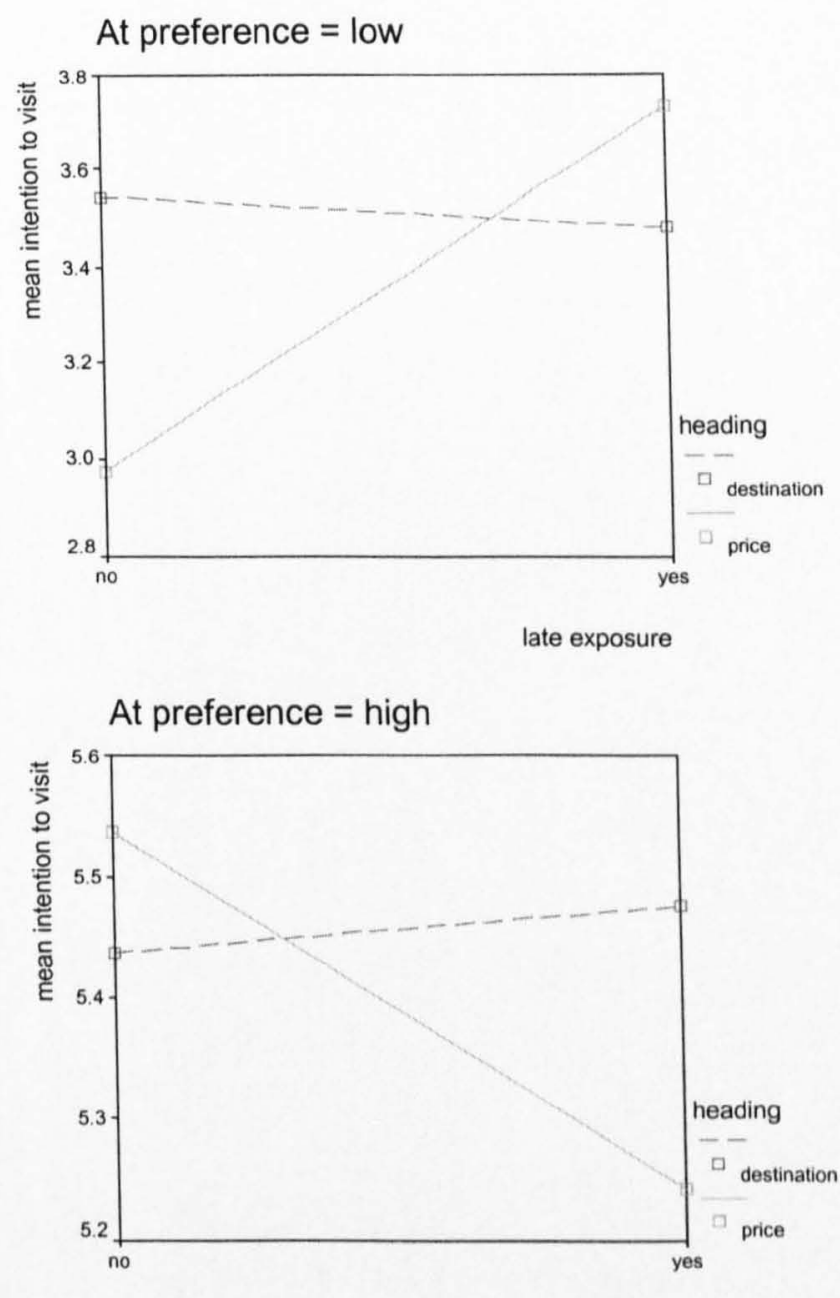

late exposure

Figure 7.2 suggests that late exposure with price as a package heading increases intention to visit less-preferred destinations $(M=3.73)$ but decreases intention to visit high-preferred destinations $(\mathrm{M}=5.23)$.

The results of four-way ANOVA of the two sample groups showed that early exposure or late exposure (without early exposure) to less-preferred destinations did not increase intention to visit to such destinations. Therefore, $\mathrm{H} 4 \mathrm{a}$ and $\mathrm{H} 6 \mathrm{a}$ are not supported. Although late exposure did not increase intention to visit for lesspreferred destinations in the sample group 1 (students), the results of sample group 2 (adults) for four destinations suggested that late exposure could not have an effect on 
intention to visit extreme less-preferred destinations on its own but would depend on price as a package heading, a level of another independent variable.

\subsubsection{Effects of Exposure on Late Consideration}

This section aims to test the effects of exposure on probability of entering late consideration (H4b, H5b, H6b). It particularly examines the effective timing of exposure to less-preferred destinations so as to increase their probability of entering late consideration.

Logistic regression was performed for testing the above hypotheses. A dependent variable was probability of entering late consideration $(0=$ no, $1=y e s)$. The predictors included in the analysis were preference $(0=$ low, $1=$ high $)$, early exposure $(0=$ no, $1=$ yes $)$, late exposure $(0=$ no, $1=$ yes $)$. The focus of these three hypotheses are on the interaction between preference and early exposure, that between preference and late exposure, and that between preference, early exposure and late exposure.

\subsubsection{Sample Group 1 (Students)}

This section presents the results regarding the effects of exposure on probability of entering late consideration for sample group 1 (students). Table 7.21 shows probability of entering late consideration between exposure by preference. 
Table 7.21: Probability of Entering Late Consideration between Exposure by Preference (Students)

\begin{tabular}{|c|c|c|c|c|c|c|c|}
\hline \multirow[b]{2}{*}{ early exposure } & \multirow[b]{2}{*}{ late exposure } & & & & \multicolumn{2}{|c|}{ late consideration } & \multirow[b]{2}{*}{ Total } \\
\hline & & & & & no & yes & \\
\hline \multirow[t]{12}{*}{ no } & no & preference & low & Count & 103 & 57 & 160 \\
\hline & & & & $\%$ within preference & $64.4 \%$ & $35.6 \%$ & $100.0 \%$ \\
\hline & & & high & Count & 61 & 99 & 160 \\
\hline & & & & $\%$ within preference & $38.1 \%$ & $61.9 \%$ & $100.0 \%$ \\
\hline & & Total & & Count & 164 & 156 & 320 \\
\hline & & & & $\%$ within preference & $51.3 \%$ & $48.8 \%$ & $100.0 \%$ \\
\hline & yes & preference & low & Count & 107 & 53 & 160 \\
\hline & & & & $\%$ within preference & $66.9 \%$ & $33.1 \%$ & $100.0 \%$ \\
\hline & & & high & Count & 54 & 106 & 160 \\
\hline & & & & $\%$ within preference & $33.8 \%$ & $66.3 \%$ & $100.0 \%$ \\
\hline & & Total & & Count & 161 & 159 & 320 \\
\hline & & & & $\%$ within preference & $50.3 \%$ & $49.7 \%$ & $100.0 \%$ \\
\hline \multirow[t]{12}{*}{ yes } & no & preference & low & Count & 107 & 53 & 160 \\
\hline & & & & $\%$ within preference & $66.9 \%$ & $33.1 \%$ & $100.0 \%$ \\
\hline & & & high & Count & 62 & 98 & 160 \\
\hline & & & & $\%$ within preference & $38.8 \%$ & $61.3 \%$ & $100.0 \%$ \\
\hline & & Total & & Count & 169 & 151 & 320 \\
\hline & & & & $\%$ within preference & $52.8 \%$ & $47.2 \%$ & $100.0 \%$ \\
\hline & yes & preference & low & Count & 104 & 56 & 160 \\
\hline & & & & $\%$ within preference & $65.0 \%$ & $35.0 \%$ & $100.0 \%$ \\
\hline & & & high & Count & 65 & 95 & 160 \\
\hline & & & & $\%$ within preference & $40.6 \%$ & $59.4 \%$ & $100.0 \%$ \\
\hline & & Total & & Count & 169 & 151 & 320 \\
\hline & & & & $\%$ within preference & $52.8 \%$ & $47.2 \%$ & $100.0 \%$ \\
\hline
\end{tabular}

Table 7.21 shows that having a late exposure (without early exposure) to highpreferred destinations results in the highest probability of being included in the late consideration for such destinations (66.3\%). The timing of exposures to lesspreferred destinations, however, does not seem to show much difference on the probability of entering late consideration for such destinations. Logistic regression was performed to test the effects and the parameter estimates for probability of entering late consideration are shown in Table 7.22.

Table 7.22: Parameter Estimates for Probability of Entering Late Consideration (Students)

\begin{tabular}{|l|r|r|r|r|}
\hline & \multicolumn{1}{|c|}{ B } & \multicolumn{1}{|c|}{ S.E. } & \multicolumn{1}{|c|}{ Slo. } & \multicolumn{1}{|c|}{ Exp(B) } \\
\hline PREF & 1.076 & .232 & .000 & 2.933 \\
EARLY & -.111 & .236 & .638 & .895 \\
LATE &. .111 & .236 & .638 & .895 \\
PREF by EARLY & .084 & .329 & .797 & 1.088 \\
PREF by LATE & .301 & .332 & .364 & 1.351 \\
EARLY by LATE & .194 & .333 & .560 & 1.215 \\
PREF by EARLY by LATE &. .463 & .467 & .321 & .629 \\
\hline
\end{tabular}


A full model versus a model with intercept only is significant, $\chi^{2}(7,1280)=103.71$, $\mathrm{p}=.00$ with Nagelkerke $\mathrm{R}^{2}$ of .10 . The results shown in Table 7.22 suggest that the interactions between preference and early exposure (pref by early) or preference and late exposure (pref by late) or preference, early exposure and late exposure (pref by early by late) are not significant. There is only a significant effect of preference which explains that being a high-preferred destination increases the likelihood of being included in late consideration set by 2.93 times, controlling for all factors.

\subsubsection{Sample Group 2 (Adults)}

This section presents the results of the effects of exposure on probability of entering late consideration for sample group 2 (adults). Table 7.23 shows the probability of entering late consideration between exposure by preference.

Table 7.23: Probability of Entering Late Consideration between Exposure by Preference (Adults)

\begin{tabular}{|c|c|c|c|c|c|c|c|}
\hline \multirow[b]{2}{*}{ early exposure } & \multirow[b]{2}{*}{ late exposure } & & & & \multicolumn{2}{|c|}{ late consideration } & \multirow[b]{2}{*}{ Total } \\
\hline & & & & & no & yes & \\
\hline \multirow[t]{12}{*}{ no } & no & preference & low & Count & 102 & 56 & 158 \\
\hline & & & & $\%$ within preference & $64.6 \%$ & $35.4 \%$ & $100.0 \%$ \\
\hline & & & high & Count & 56 & 102 & 158 \\
\hline & & & & $\%$ within preference & $35.4 \%$ & $64.6 \%$ & $100.0 \%$ \\
\hline & & Total & & Count & 158 & 158 & 316 \\
\hline & & & & $\%$ within preference & $50.0 \%$ & $50.0 \%$ & $100.0 \%$ \\
\hline & yes & preference & low & Count & 105 & 53 & 158 \\
\hline & & & & $\%$ within preference & $66.5 \%$ & $33.5 \%$ & $100.0 \%$ \\
\hline & & & high & Count & 58 & 100 & 158 \\
\hline & & & & $\%$ within preference & $36.7 \%$ & $63.3 \%$ & $100.0 \%$ \\
\hline & & Total & & Count & 163 & 153 & 316 \\
\hline & & & & $\%$ within preference & $51.6 \%$ & $48.4 \%$ & $100.0 \%$ \\
\hline \multirow[t]{12}{*}{ yes } & no & preference & low & Count & 115 & 43 & 158 \\
\hline & & & & $\%$ within preference & $72.8 \%$ & $27.2 \%$ & $100.0 \%$ \\
\hline & & & high & Count & 60 & 98 & 158 \\
\hline & & & & $\%$ within preference & $38.0 \%$ & $62.0 \%$ & $100.0 \%$ \\
\hline & & Total & & Count & 175 & 141 & 316 \\
\hline & & & & $\%$ within preference & $55.4 \%$ & $44.6 \%$ & $100.0 \%$ \\
\hline & yes & preference & low & Count & 105 & 53 & 158 \\
\hline & & & & $\%$ within preference & $66.5 \%$ & $33.5 \%$ & $100.0 \%$ \\
\hline & & & high & Count & 61 & 97 & 158 \\
\hline & & & & $\%$ within preference & $38.6 \%$ & $61.4 \%$ & $100.0 \%$ \\
\hline & & Total & & Count & 166 & 150 & 316 \\
\hline & & & & $\%$ within preference & $52.5 \%$ & $47.5 \%$ & $100.0 \%$ \\
\hline
\end{tabular}

Table 7.23 shows that not having any exposures yields the highest probability of being included in the late consideration for both less-preferred destinations $(35.4 \%)$ and high-preferred destinations (64.6\%). Logistic regression was performed to test the effects and the parameter estimates are shown in Table 7.24. 
Table 7.24: Parameter Estimates for Probability of Entering Late Consideration (Adults)

\begin{tabular}{|l|r|r|r|r|}
\hline & \multicolumn{1}{|c|}{ B } & \multicolumn{1}{|c|}{ S.E. } & \multicolumn{1}{c|}{ Sig. } & \multicolumn{1}{|c|}{ Exp(B) } \\
\hline PREF & 1.199 & .235 & .000 & 3.318 \\
EARLY &. .384 & .244 & .116 & .681 \\
LATE & -.084 & .237 & .723 & .919 \\
PREF by EARLY & .275 & .338 & .415 & 1.317 \\
PREF by LATE & .029 & .333 & .930 & 1.030 \\
EARLY by LATE & .384 & .341 & .260 & 1.468 \\
PREF by EARLY by LATE &. .356 & .474 & .453 & .700 \\
\hline
\end{tabular}

A full model versus a model with intercept only is significant, $\chi^{2}(7,1264)=122.06$, $p=.00$ with Nagelkerke $R^{2}$ of .12 . The results shown in Table 7.24 suggest that the interactions between preference and early exposure (pref by early) or preference and late exposure (pref by late) or preference, early exposure and late exposure (pref by early by late) are not significant. There is only a significant effect of preference which explains that being a high-preferred destination increases the likelihood of being included in late consideration set by 3.32 times, controlling for all factors.

The results of the two sample groups showed that the predicted interactions were not significant. Based on the findings, neither early exposure nor late exposure nor only late exposure (without early exposure) increased the probability of entering late consideration for less-preferred destinations. Therefore, $\mathrm{H} 4 \mathrm{~b}, \mathrm{H} 5 \mathrm{~b}$ and $\mathrm{H} 6 \mathrm{~b}$ are not supported.

\subsubsection{Effects of Exposure on Choice}

This section aims to test the effects of exposure on probability of becoming a choice (H4c, H5c and H6c). It particularly examines the effective timing of exposure to less-preferred destinations so as to increase their probability of becoming a choice.

Logistic regression was performed to test the three hypotheses. The dependent variable is probability of becoming a choice $(0=$ no, $1=$ yes). The predictors included in the analysis are preference $(0=$ low, $1=$ high $)$, early exposure $(0=$ no, $1=y e s)$, late exposure $(0=$ no, $1=y e s)$. The focus of these three hypotheses is on the interactions 
between preference and early exposure, that between preference and late exposure and that between preference, early exposure and late exposure.

\subsubsection{Sample Group 1 (Students)}

This section presents the results of exposure effects on probability of becoming a choice for the sample group 1 (students). Table 7.25 shows the probability of becoming a choice between exposure by preference.

Table 7.25: Probability of Becoming a Choice between Exposure by Preference (Students)

\begin{tabular}{|c|c|c|c|c|c|c|c|}
\hline \multirow[b]{2}{*}{ early exposure } & \multirow[b]{2}{*}{ late exposure } & & & & \multicolumn{2}{|c|}{ final choice } & \multirow[b]{2}{*}{ Total } \\
\hline & & & & & no & yes & \\
\hline \multirow[t]{12}{*}{ no } & no & preference & low & Count & 143 & 15 & 158 \\
\hline & & & & $\%$ within preference & $90.5 \%$ & $9.5 \%$ & $100.0 \%$ \\
\hline & & & high & Count & 132 & 26 & 158 \\
\hline & & & & $\%$ within preference & $83.5 \%$ & $16.5 \%$ & $100.0 \%$ \\
\hline & & Total & & Count & 275 & 41 & 316 \\
\hline & & & & $\%$ within preference & $87.0 \%$ & $13.0 \%$ & $100.0 \%$ \\
\hline & yes & preference & low & Count & 150 & 8 & 158 \\
\hline & & & & $\%$ within preference & $94.9 \%$ & $5.1 \%$ & $100.0 \%$ \\
\hline & & & high & Count & 122 & 36 & 158 \\
\hline & & & & $\%$ within preference & $77.2 \%$ & $22.8 \%$ & $100.0 \%$ \\
\hline & & Total & & Count & 272 & 44 & 316 \\
\hline & & & & $\%$ within preference & $86.1 \%$ & $13.9 \%$ & $100.0 \%$ \\
\hline \multirow[t]{12}{*}{ yes } & no & preference & low & Count & 150 & 8 & 158 \\
\hline & & & & $\%$ within preference & $94.9 \%$ & $5.1 \%$ & $100.0 \%$ \\
\hline & & & high & Count & 135 & 23 & 158 \\
\hline & & & & $\%$ within preference & $85.4 \%$ & $14.6 \%$ & $100.0 \%$ \\
\hline & & Total & & Count & 285 & 31 & 316 \\
\hline & & & & $\%$ within preference & $90.2 \%$ & $9.8 \%$ & $100.0 \%$ \\
\hline & yes & preference & low & Count & 147 & 11 & 158 \\
\hline & & & & $\%$ within preference & $93.0 \%$ & $7.0 \%$ & $100.0 \%$ \\
\hline & & & high & Count & 127 & 31 & 158 \\
\hline & & & & $\%$ within preference & $80.4 \%$ & $19.6 \%$ & $100.0 \%$ \\
\hline & & Total & & Count & 274 & 42 & 316 \\
\hline & & & & $\%$ within preference & $86.7 \%$ & $13.3 \%$ & $100.0 \%$ \\
\hline
\end{tabular}

Table 7.25 shows that less-preferred destinations have the highest probability of becoming choice $(9.5 \%)$ when there are no exposures to such destinations. When there is only late exposure (without early exposure), high-preferred destinations have the highest probability of becoming a final choice $(22.8 \%)$. As previously explained in section 7.4 , the results show that choice may have been selected from the two new alternatives appearing at the measures at time 2. Logistic regression was performed to test the effects and the parameter estimates are shown in Table 7.26. 
Table 7.26: Parameter Estimates for Probability of Becoming a Choice (Students)

\begin{tabular}{|l|r|r|r|r|}
\hline & \multicolumn{1}{|c|}{ B } & \multicolumn{1}{|c|}{ S.E. } & \multicolumn{1}{c|}{ Sig. } & \multicolumn{1}{c|}{ Exp(B) } \\
\hline PREF & .630 & .346 & .069 & 1.878 \\
EARLY & -.676 & .453 & .136 & .508 \\
LATE & -.676 & .453 & .136 & .508 \\
PREF by EARLY & .531 & .550 & .334 & 1.701 \\
PREF by LATE & 1.081 & .536 & .044 & 2.946 \\
EARLY by LATE & 1.015 & .659 & .124 & 2.760 \\
PREF by EARLY by LATE & -1.060 & .780 & .174 & .347 \\
\hline
\end{tabular}

A full model versus a model with intercept only is significantly reliable, $\chi^{2}(7,1264)=$ 48.38, $\mathrm{p}=.00$ with Nagelkerke $\mathrm{R}^{2}$ of .07 . The results shown in Table 7.26 suggest that the interactions between preference and early exposure (pref by early) or preference, early exposure and late exposure (pref by early by late) are not significant. There is a significant interaction between preference and late exposure (pref by late). Table 7.27 illustrates the probability of becoming a choice for late exposure by preference.

Table 7.27: Probability of Becoming a Choice for Late Exposure by Preference (Students)

\begin{tabular}{|c|c|c|c|c|c|c|}
\hline \multirow{2}{*}{\multicolumn{4}{|c|}{ late exposure }} & \multicolumn{2}{|c|}{ final choice } & \multirow[b]{2}{*}{ Total } \\
\hline & & & & no & yes & \\
\hline \multirow[t]{6}{*}{ no } & preference & Tow & Count & 293 & 23 & 316 \\
\hline & & & $\%$ within preference & $92.7 \%$ & $7.3 \%$ & $100.0 \%$ \\
\hline & & high & Count & 267 & 49 & 316 \\
\hline & & & $\%$ within preference & $84.5 \%$ & $15.5 \%$ & $100.0 \%$ \\
\hline & Total & & Count & 560 & 72 & 632 \\
\hline & & & $\%$ within preference & $88.6 \%$ & $11.4 \%$ & $100.0 \%$ \\
\hline \multirow[t]{6}{*}{ yes } & preference & low & Count & 297 & 10 & 316 \\
\hline & & & $\%$ within preference & $94.0 \%$ & $6.0 \%$ & $100.0 \%$ \\
\hline & & high & Count & 249 & 67 & 316 \\
\hline & & & $\%$ within preference & $78.8 \%$ & $21.2 \%$ & $100.0 \%$ \\
\hline & Total & & Count & 546 & 86 & 632 \\
\hline & & & $\%$ within preference & $86.4 \%$ & $13.6 \%$ & $100.0 \%$ \\
\hline
\end{tabular}

Table 7.27 explains that having a late exposure to high-preferred destinations provides the highest probability of becoming a choice $(21.2 \%)$ for such destinations. On the contrary, not having a late exposure to less-preferred destinations yields the highest probability of becoming a choice $(7.3 \%)$ for such destinations. It appears 
that late exposure benefits high-preferred destinations rather than less-preferred destinations.

\subsubsection{Sample Group 2 (Adults)}

This section presents the results of exposure effects on probability of becoming a choice for sample group 2 (adults). Table 7.28 shows the probability of becoming a choice between exposure by preference.

Table 7.28: Probability of Becoming a Choice between Exposure by Preference (Adults)

\begin{tabular}{|c|c|c|c|c|c|c|c|}
\hline \multirow[b]{2}{*}{ early exposure } & \multirow[b]{2}{*}{ late exposure } & & & & \multicolumn{2}{|c|}{ final choice } & \multirow[b]{2}{*}{ Total } \\
\hline & & & & & no & yes & \\
\hline \multirow[t]{12}{*}{ no } & no & preference & low & Count & 149 & 8 & 157 \\
\hline & & & & $\%$ within preference & $94.9 \%$ & $5.1 \%$ & $100.0 \%$ \\
\hline & & & high & Count & 132 & 25 & 157 \\
\hline & & & & $\%$ within preference & $84.1 \%$ & $15.9 \%$ & $100.0 \%$ \\
\hline & & Total & & Count & 281 & 33 & 314 \\
\hline & & & & $\%$ within preference & $89.5 \%$ & $10.5 \%$ & $100.0 \%$ \\
\hline & yes & preference & low & Count & 144 & 13 & 157 \\
\hline & & & & $\%$ within preference & $91.7 \%$ & $8.3 \%$ & $100.0 \%$ \\
\hline & & & high & Count & 126 & 31 & 157 \\
\hline & & & & $\%$ within preference & $80.3 \%$ & $19.7 \%$ & $100.0 \%$ \\
\hline & & Total & & Count & 270 & 44 & 314 \\
\hline & & & & $\%$ within preference & $86.0 \%$ & $14.0 \%$ & $100.0 \%$ \\
\hline \multirow[t]{12}{*}{ yes } & no & preference & low & Count & 149 & 8 & 157 \\
\hline & & & & $\%$ within preference & $94.9 \%$ & $5.1 \%$ & $100.0 \%$ \\
\hline & & & high & Count & 131 & 26 & 157 \\
\hline & & & & $\%$ within preference & $83.4 \%$ & $16.6 \%$ & $100.0 \%$ \\
\hline & & Total & & Count & 280 & 34 & 314 \\
\hline & & & & $\%$ within preference & $89.2 \%$ & $10.8 \%$ & $100.0 \%$ \\
\hline & yes & preference & low & Count & 144 & 13 & 157 \\
\hline & & & & $\%$ within preference & $91.7 \%$ & $8.3 \%$ & $100.0 \%$ \\
\hline & & & high & Count & 124 & 33 & 157 \\
\hline & & & & $\%$ within preference & $79.0 \%$ & $21.0 \%$ & $100.0 \%$ \\
\hline & & Total & & Count & 268 & 46 & 314 \\
\hline & & & & $\%$ within preference & $85.4 \%$ & $14.6 \%$ & $100.0 \%$ \\
\hline
\end{tabular}

Regardless of the early exposure, Table 7.28 shows that late exposure yields the highest probability of being choice for less-preferred destinations (8.3\%). Having both early exposure and late exposure provides the highest probability of becoming a choice for high-preferred destinations $(21.0 \%)$. Logistic regression was performed to test the effects and parameter estimates are shown in Table 7.29. 
Table 7.29: Parameter Estimates for Probability of Becoming a Choice (Adults)

\begin{tabular}{|l|r|r|r|r|}
\hline & \multicolumn{1}{|c|}{ B } & \multicolumn{1}{c|}{ S.E. } & \multicolumn{1}{c|}{ Sig. } & \multicolumn{1}{c|}{ Exp(B) } \\
\hline PREF & 1.261 & .423 & .003 & 3.527 \\
EARLY & .000 & .513 & 1.000 & 1.000 \\
LATE & .520 & .464 & .263 & 1.681 \\
PREF by EARLY & .047 & .598 & .938 & 1.048 \\
PREF by LATE &. .258 & .551 & .639 & .773 \\
EARLY by LATE & .000 & .657 & 1.000 & 1.000 \\
PREF by EARLY by LATE & .032 & .777 & .967 & 1.032 \\
\hline
\end{tabular}

A full model versus a model with intercept only is significantly reliable, $\chi^{2}(7,1256)=$ 44.62, $p=.00$ with Nagelkerke $R^{2}$ of .07 . The results shown in Table 7.29 suggest that the interactions between preference and early exposure (pref by early) or preference and late exposure (pref by late) or preference, early exposure and late exposure (pref by early by late) are not significant. There is a significant effect of preference which explains that being a high-preferred destination increases the likelihood of becoming a choice by 3.53 times, controlling for all factors.

Overall, the results of the two sample groups suggested that early exposure, late exposure and late exposure (without early exposure) did not increase the probability of becoming a choice for less-preferred destinations. As such, H4c, H5c and H6c are not supported.

\subsection{Additional Analyses}

This section presents the refinement of the tests and additional analyses which are beyond the purpose of hypothesis testing but are considered useful to understand further the possible factors affecting the destination choice process. This section is divided into two parts; namely intention to visit and choice.

\subsubsection{Intention to Visit}

This section discusses the analysis of covariance (ANCOVA) as a further analysis of ANOVA for intention to visit by statistically controlling for the possible effects of an additional confounding variable (covariate). ANCOVA can be used to remove the 
effect of the covariate to ensure that the independent variable actually influences the dependent variable (Pallant, 2001).

Two-way ANCOVA was conducted to explore further the impact of preference and presentation format on intention to visit for H1a and H2a. Subjects were divided into three groups or presentation formats: control group (destination name only), experimental group 1 (destination name along with other attributes and with destination as a heading) and experimental group 2 (destination name along with other attributes and with price as a heading).

Four-way ANCOVA was also conducted to explore further the impact of preference, early exposure, late exposure and package heading on intention to visit for $\mathrm{H} 4 \mathrm{a}, \mathrm{H} 5 \mathrm{a}$ and H6a. The dependent variable was intention to visit anchoring 1 (will definitely not visit) to 7 (will definitely visit). Four independent variables are preference (high, low), package heading (destination, price), early exposure (yes, no) and late exposure (yes, no).

\subsubsection{Sample Group 1 (Students)}

Before performing ANCOVA, covariates need to be carefully chosen. Preliminary analysis on correlation was conducted to select the appropriate covariates for performing ANCOVA. The results of intercorrelations are shown in Table 7.30.

Table 7.30: Intercorrelations between Intention to Visit and Control Variables for Sample Group 1 (Students)

\begin{tabular}{|ll|r|r|r|r|}
\hline & & $\begin{array}{c}\text { intention to } \\
\text { visit-time2 }\end{array}$ & $\begin{array}{c}\text { destination } \\
\text { image }\end{array}$ & past visits & $\begin{array}{c}\text { destination } \\
\text { knowledge }\end{array}$ \\
\hline intention to visit-time2 & Pearson Correlation & 1 & $.616^{* *}$ & $.164^{* *}$ & $.395^{*-}$ \\
& Sig. (2-tailed) &. & .000 & .000 & .000 \\
& $\mathrm{~N}$ & 1561 & 1559 & 1529 & 1534 \\
\hline destination image & Pearson Correlation & $.616^{* *}$ & 1 & $.172^{* *}$ & $.467^{* *}$ \\
& Sig. (2-tailed) & .000 & .000 & .000 \\
& $\mathrm{~N}$ & 1559 & 1598 & 1566 & 1561 \\
\hline visits & Pearson Correlation & $.164^{* *}$ & $.172^{* *}$ & 1 & $.321^{* *}$ \\
& Sig. (2-tailed) & .000 & .000 &. & .000 \\
& $\mathrm{~N}$ & 1529 & 1566 & 1568 & 1531 \\
\hline destination & Pearson Correlation & $.395^{* *}$ & $.467^{* *}$ & $.321^{* *}$ & 1 \\
knowledge & Sig. (2-tailed) & .000 & .000 & .000 & 1531 \\
& $\mathrm{~N}$ & 1534 & 1561 & 1563 \\
\hline
\end{tabular}

*. Correlation is significant at the 0.01 level (2-tailed). 
The appropriate covariates are a small set of covariates that are uncorrelated with each other but correlated with dependent variable (Tabachnick and Fidell, 1996). From the results of correlation shown in Table 7.30, destination image appears to be the most appropriate covariate for ANCOVA. There is a strong positive correlation between destination image and intention to visit $[\mathrm{r}=.62, \mathrm{n}=1559, \mathrm{p}=.00]$. Although there is a moderate positive correlation between destination knowledge and intention to visit $[\mathrm{r}=.40, \mathrm{n}=1534, \mathrm{p}=.00]$, destination knowledge is discarded since it quite strongly correlates with destination image $[\mathrm{r}=.47, \mathrm{n}=1561, \mathrm{p}=.00]$. Two-way ANCOVA was performed by using destination image as a covariate and the results for the eight destinations are shown in Table 7.31.

Table 7.31: Two-way ANCOVA for Intention to Visit for Sample Group 1 (Students)

\begin{tabular}{|c|c|c|c|c|c|}
\hline Source & $\begin{array}{l}\text { Type III Sum } \\
\text { of Squares }\end{array}$ & df & Mean Square & $F$ & Sig. \\
\hline Corrected Model & $1650.759^{b}$ & 6 & 275.126 & 170.376 & .000 \\
\hline Intercept & 392.247 & 1 & 392.247 & 242.905 & .000 \\
\hline IMAGE & 1304.836 & 1 & 1304.836 & 808.040 & .000 \\
\hline PREF & 58.504 & 1 & 58.504 & 36.229 & .000 \\
\hline GROUP & .979 & 2 & .490 & .303 & .739 \\
\hline PREF * GROUP & .691 & 2 & .346 & .214 & .807 \\
\hline Error & 2506.195 & 1552 & 1.615 & & \\
\hline Total & 40963.000 & 1559 & & & \\
\hline Corrected Total & 4156.954 & 1558 & & & \\
\hline
\end{tabular}

After adjusting for destination image, Table 7.31 shows that there is no significant interaction between preference and group, $\mathrm{F}(2,1552)=.21$, ns. There are only significant effects of destination image, $F(1,1552)=808.04, p=.00$ and preference, $F(1,1552)=36.23, p=.00$. The results of a four-way ANCOVA for sample group 1 (students) are shown below in Table 7.32. 
Table 7.32: Four-way ANCOVA for Intention to Visit for Sample Group1 (Students)

\begin{tabular}{|c|c|c|c|c|c|}
\hline Source & $\begin{array}{l}\text { Type III Sum } \\
\text { of Squares }\end{array}$ & df & Mean Square & $\mathrm{F}$ & Sig. \\
\hline Corrected Model & $1310.718^{6}$ & 16 & 81.920 & 50.936 & .000 \\
\hline Intercept & 343.479 & 1 & 343.479 & 213.567 & .000 \\
\hline IMAGE & 996.962 & 1 & 996.962 & 619.886 & .000 \\
\hline PREF & 64.605 & 1 & 64.605 & 40.170 & .000 \\
\hline EARLY & .852 & 1 & .852 & .530 & .467 \\
\hline LATE & 2.199 & 1 & 2.199 & 1.367 & .243 \\
\hline HEADING & 1.034 & 1 & 1.034 & 643 & .423 \\
\hline PREF * EARLY & .073 & 1 & .073 & .045 & .832 \\
\hline PREF * LATE & .364 & 1 & .364 & .226 & .634 \\
\hline EARLY* LATE & .139 & 1 & 139 & .087 & .769 \\
\hline PREF * EARLY* LATE & 1.379 & 1 & 1.379 & .857 & .355 \\
\hline PREF * HEADING & .001 & 1 & .001 & .001 & 979 \\
\hline EARLY*HEADING & .362 & 1 & .362 & .225 & .635 \\
\hline PREF * EARLY * HEADING & .003 & 1 & .003 & .002 & .967 \\
\hline LATE * HEADING & .013 & 1 & .013 & .008 & .929 \\
\hline PREF * LATE* HEADING & 4.468 & 1 & 4.468 & 2.778 & .096 \\
\hline EARLY* LATE* HEADING & 1.472 & 1 & 1.472 & .915 & .339 \\
\hline PREF * EARLY * LATE * HEADING & 1.661 & 1 & 1.661 & 1.033 & .310 \\
\hline Error & 1994.290 & 1240 & 1.608 & & \\
\hline Total & 33053.000 & 1257 & & & \\
\hline Corrected Total & 3305.009 & 1256 & & & \\
\hline
\end{tabular}

a. Computed using alpha $=.05$

b. R Squared $=.397$ (Adjusted R Squared $=.389$ )

After adjusting for destination image, the results in Table 7.32 show that there are no significant effects between preference and early exposure, $\mathrm{F}(1,1240)=.05$, ns, between preference and late exposure, $\mathrm{F}(1,1240)=.23$, ns and between preference, early exposure and late exposure, $\mathrm{F}(1,1240)=.86$, ns. There are only significant effects of destination image, $\mathrm{F}(1,1240)=619.89, \mathrm{p}=.00$ and preference, $\mathrm{F}(1,1240)=40.17, \mathrm{p}=.00$.

\subsubsection{Sample Group 2 (Adults)}

Preliminary analysis on correlation was conducted to select the appropriate covariates for performing ANCOVA. The results of intercorrelations are shown in Table 7.33 . 
Table 7.33: Intercorrelations between Intention to Visit and Control Variables for Sample Group 2 (Adults)

\begin{tabular}{|ll|r|r|r|r|}
\hline & & $\begin{array}{c}\text { intention to } \\
\text { visit-time2 }\end{array}$ & $\begin{array}{c}\text { destination } \\
\text { image }\end{array}$ & past visits & $\begin{array}{c}\text { destination } \\
\text { knowledge }\end{array}$ \\
\hline intention to visit-time2 & Pearson Correlation & 1 & $.616^{* *}$ & $.232^{* *}$ & $.373^{*-1}$ \\
& Sig. (2-tailed) &. & .000 & .000 & .000 \\
& $\mathrm{~N}$ & 1481 & 1471 & 1458 & 1457 \\
\hline destination image & Pearson Correlation & $.616^{* *}$ & 1 & $.222^{* *}$ & $411^{*-}$ \\
& Sig. (2-tailed) & .000 &. & .000 & .000 \\
& $\mathrm{~N}$ & 1471 & 1585 & 1563 & 1559 \\
\hline past visits & Pearson Correlation & $.232^{* *}$ & $.222^{* *}$ & 1 & $.442^{* *}$ \\
& Sig. (2-tailed) & .000 & .000 &. & .000 \\
& $\mathrm{~N}$ & 1458 & 1563 & 1577 & 1546 \\
\hline destination & Pearson Correlation & $.373^{* *}$ & $.411^{* *}$ & $.442^{* *}$ & 1 \\
knowledge & Sig. (2-tailed) & .000 & .000 & .000 &. \\
& $\mathrm{~N}$ & 1457 & 1559 & 1546 & 1569 \\
\hline
\end{tabular}

${ }^{\star *}$. Correlation is significant at the 0.01 level (2-tailed)

From the results shown in Table 7.33, destination image appears to be the most appropriate covariate for ANCOVA. There is a strong positive correlation between destination image and intention to visit $[\mathrm{r}=.62, \mathrm{n}=1471, \mathrm{p}=.00]$. Two-way ANCOVA was performed by using destination image as a covariate and the results are shown in Table 7.34.

Table 7.34: Two-way ANCOVA for Intention to Visit for Sample Group 2 (Adults)

Dependent Variable: intention to visit-time2
\begin{tabular}{|l|r|r|r|r|r|}
\hline Source & $\begin{array}{c}\text { Type III Sum } \\
\text { of Squares }\end{array}$ & df & Mean Square & F & Sig. \\
\hline Corrected Model & $2055.355^{\circ}$ & 6 & 342.559 & 162.990 & .000 \\
Intercept & 315.436 & 1 & 315.436 & 150.085 & .000 \\
IMAGE & 1588.044 & 1 & 1588.044 & 755.592 & .000 \\
PREF & 87.951 & 1 & 87.951 & 41.847 & .000 \\
GROUP & 12.398 & 2 & 6.199 & 2.950 & .053 \\
PREF * GROUP & 3.532 & 2 & 1.766 & .840 & .432 \\
Error & 3076.920 & 1464 & 2.102 & & \\
Total & 35567.000 & 1471 & & & \\
Corrected Total & 5132.275 & 1470 & & \\
\hline
\end{tabular}
a. Computed using alpha $=.05$
b. R Squared $=.400$ (Adjusted R Squared = .398)

After adjusting for destination image, Table 7.34 shows that there is no significant interaction between preference and group, $\mathrm{F}(2,1464)=.84$, ns. There are only significant effects of destination image, $F(1,1464)=755.59, p=.00$ and preference, $\mathrm{F}(1,1464)=41.85, \mathrm{p}=.00$. The results of a four-way ANCOVA for the eight destinations are shown below in Table 7.35. 
Table 7.35: Four-way ANCOVA for Intention to Visit for Sample Group2 (Adults)

Dependent Variable: intention to visit-time2

\begin{tabular}{|c|c|c|c|c|c|}
\hline Source & $\begin{array}{l}\text { Type III Sum } \\
\text { of Squares }\end{array}$ & df & Mean Square & $F$ & Sig. \\
\hline Corrected Model & $1634.807^{\circ}$ & 16 & 102.175 & 48.169 & .000 \\
\hline Intercept & 254.528 & 1 & 254.528 & 119.992 & .000 \\
\hline IMAGE & 1243.762 & 1 & 1243.762 & 586.349 & .000 \\
\hline PREF & 68.120 & 1 & 68.120 & 32.114 & .000 \\
\hline EARLY & 1.957 & 1 & 1.957 & .923 & .337 \\
\hline LATE & 2.666 & 1 & 2.666 & 1.257 & .262 \\
\hline HEADING & 11.803 & 1 & 11.803 & 5.565 & .018 \\
\hline PREF * EARLY & .101 & 1 & .101 & .048 & .827 \\
\hline PREF * LATE & .988 & 1 & .988 & .466 & .495 \\
\hline EARLY * LATE & 1.716 & 1 & 1.716 & .809 & .369 \\
\hline PREF * EARLY* LATE & .086 & 1 & .086 & .040 & .841 \\
\hline PREF * HEADING & 3.067 & 1 & 3.067 & 1.446 & .229 \\
\hline EARLY* HEADING & .275 & 1 & .275 & .130 & .719 \\
\hline PREF * EARLY * HEADING & 1.506 & 1 & 1.506 & .710 & .400 \\
\hline LATE * HEADING & .229 & 1 & .229 & .108 & .743 \\
\hline PREF * LATE * HEADING & .028 & 1 & .028 & .013 & .908 \\
\hline EARLY* LATE * HEADING & .693 & 1 & .693 & .327 & .568 \\
\hline PREF ${ }^{*}$ EARLY ${ }^{*}$ LATE * HEADING & .011 & 1 & .011 & .005 & 942 \\
\hline Error & 2445.741 & 1153 & 2.121 & & \\
\hline Total & 28389.000 & 1170 & & & \\
\hline Corrected Total & 4080.548 & 1169 & & & \\
\hline
\end{tabular}

a. Computed using alpha $=.05$

b. $\mathrm{R}$ Squared $=.401$ (Adjusted $\mathrm{R}$ Squared $=.392$ )

The results in Table 7.35 show that there are no significant effects between preference and early exposure, $\mathrm{F}(1,1153)=.05$, ns, between preference and late exposure, $\mathrm{F}(1,1153)=.47$, ns, and between preference, early exposure and late exposure, $\mathrm{F}(1,1153)=.04$, ns. There are only the significant effects of destination image, $\mathrm{F}(1,1153)=586.35, \mathrm{p}=.00$, preference, $\mathrm{F}(1,1153)=32.11, \mathrm{p}=.00$ and package heading, $\mathrm{F}(1,1153)=5.57, \mathrm{p}=.02$.

After adjusting for destination image, the results of two sample groups showed that presenting the destination name along with other attributes or presenting price as a package heading did not increase intention to visit less-preferred destinations. Also, the results showed that early exposure, late exposure or late exposure (without early exposure) did not increase intention to visit less-preferred destinations.

\subsubsection{Choice}

Besides an investigation of the information presentation effects, this section examines other factors that may affect the choice of destinations. Previous 
researchers suggest that destination image (Chon, 1990; Um and Crompton 1993) and previous visits (Oppermann, 2000) can influence a choice of destinations. However, most studies focus on the tourists at a particular destination. This section provides the findings regarding the effects of those factors on the pre-purchase stage.

Logistic regression was performed to examine the factors affecting a choice of destinations. Probability of becoming a choice $(0=$ no, $1=y e s)$ is a dependent variable. The predictors are destination image, previous visits and destination knowledge.

\subsubsection{Sample Group 1 (Students)}

This section presents the results of factors affecting choice for sample group 1 (students). Parameter estimates are shown in Table 7.36.

\section{Table 7.36: Parameter Estimates for Probability of Becoming a Choice for Sample Group 1 (Students)}

\begin{tabular}{|l|r|r|r|r|}
\hline & \multicolumn{1}{|c|}{ B } & \multicolumn{1}{c|}{ S.E. } & \multicolumn{1}{c|}{ Sig. } & Exp(B) \\
\hline IMAGE & .721 & .082 & .000 & 2.056 \\
VISITS & .021 & .026 & .419 & 1.022 \\
KNOWLEDGE & .004 & .028 & .895 & 1.004 \\
\hline
\end{tabular}

A full model is significantly reliable, $\chi^{2}(3,1527)=132.36, p=.00$ with Nagelkerke $R^{2}$ of .16. The results shown in Table 7.36 suggest that destination image reliably predicts the probability of becoming a final choice which explains that each unit increases in the destination image score, the likelihood of becoming a choice increases by 2.06 times, controlling for all factors.

\subsubsection{Sample Group 2 (Adults)}

This section presents the results of factors affecting choice for sample group 2 (adults). Parameter estimates are shown in Table 7.37. 
Table 7.37: Parameter Estimates for Probability of Becoming a Choice for Sample Group 2 (Adults)

\begin{tabular}{|l|r|r|r|r|}
\hline & \multicolumn{1}{|c|}{ B } & \multicolumn{1}{c|}{ S.E. } & \multicolumn{1}{c|}{ Sig. } & \multicolumn{1}{|c|}{$\operatorname{Exp}(\mathrm{B})$} \\
\hline IMAGE & .770 & .082 & .000 & 2.159 \\
VISITS & .069 & .029 & .019 & 1.071 \\
KNOWLEDGE & .046 & .029 & .112 & 1.047 \\
\hline
\end{tabular}

A full model is significantly reliable, $\chi^{2}(3,1513)=197.46, p=.00$ with Nagelkerke $R^{2}$ of .23. The results shown in Table 7.37 suggest that destination image and previous visits reliably predict the probability of becoming a final choice. Controlling for all factors, each unit increases in the destination image score, the likelihood of becoming a choice increases by 2.16 times. Also, an increase in each visit to the destination, the likelihood of becoming a choice increases by 1.07 times.

\subsection{Conclusion}

This chapter sought answers to the two research questions regarding the effects of presentation format and the effects of exposure by means of testing the six formulated hypotheses. The results of the two sample groups reinforce each other. Package heading can influence the evaluation of sample group 1 (students). Presenting price as a package heading results in higher intention to visit all destinations including high-preferred destinations and less-preferred destinations than presenting destination as a package heading. For less-preferred destinations, there is no evidence from both sample groups that presenting the destination name along with other attributes or presenting price as a package heading has any effects on their probability of being included in late consideration and their probability of becoming a choice. These unanticipated results are explained by the findings that presenting detailed information or highlighting price as a heading cannot reduce the importance of destination.

Regarding the effects of exposure, there is no evidence from the two sample groups that early exposure or late exposure or late exposure (without early exposure) can increase the probability of being included in late consideration or the probability of 
becoming a choice for less-preferred destinations. However, the results of the sample group 2 (adults) show that late exposure to extreme less-preferred destinations can increase intention to visit such destinations only when it is presented with price as a package heading.

In the context of the study, it appears that it is rather difficult to present the information of package holidays in such a way as to help less-preferred destinations to become a final choice. The additional analyses show that the destination image is a very powerful factor affecting the destination choice. This suggests that the attempts to turn consumers' attention away from the destination name which is attached to the image seem to be an extremely challenging task for marketing the holiday products.

The next chapter discusses main findings of this chapter and the descriptive findings (Chapter 6) in relation to the two research questions and places them in the theoretical context. It describes the limitations of the findings and the contributions of the study in terms of theory, methodology and practice. It also provides the conclusions and directions for future research. 


\section{Chapter Eight}

\section{Discussion and Conclusions}

\subsection{Introduction}

The aims of this chapter are to interpret the main findings, to place them in the theoretical context, to examine their limitations and contributions, and finally to provide directions for further work. The chapter draws upon the findings of the two sample groups, students and adults. In most parts, the results from these two sample groups reinforce each other and are dealt with together.

The chapter is divided into four sections. The first section discusses the main findings of the study to answer the research questions and place them in the context of the previous literature. The second section describes the limitations of the findings. The third section outlines the contributions of the study in terms of theory, methodology and practice. The final section provides the conclusions and the recommendations for future research.

\subsection{Discussion of the Main Findings}

This section focuses on answering the two key research questions outlined in section 4.3. The findings in relation to these research questions are discussed here accordingly. This section is divided into four sections to unfold the findings of the hypothesis testing (Chapter 7) together with the descriptive findings (Chapter 6). The first section discusses the effects of presentation format on the destination choice process. The second section explains the effects of presentation format on 
destination importance. The third section discusses the effects of exposure on the destination choice process. The final section describes the factors influencing the destination choice.

\subsubsection{Effects of Presentation Format on Destination Choice Process}

This section discusses the findings in relation to the first research question. The aim of the first research question is to test for less-preferred destinations whether presenting detailed information of package holidays or highlighting an alternative attribute rather than destination as a package heading increases intention to visit, their likelihood of being included in a late consideration set and their likelihood of becoming a final choice. It was expected that presenting the destination name along with the information of other attributes or highlighting price as a package heading would draw attention from the destination name to other attribute(s) and thus decrease the destination importance. Therefore, less-preferred destinations can benefit from such a decrease.

There are two hypotheses formulated to answer the first research question. The first hypothesis predicts for less-preferred destinations that presenting the destination name along with information of other attributes would increase intention to visit, their probability of entering late consideration and their probability of becoming a choice. The findings of the two sample groups however suggest for less-preferred destinations that presenting the detailed information of other attributes does not increase either intention to visit or their probability of entering the late consideration set or their probability of becoming a chosen destination.

The second hypothesis predicts for less-preferred destinations that highlighting price as a package heading would increase intention to visit, their probability of entering late consideration and their probability of becoming a choice. The results of the sample group 1 (students) show that highlighting price as a package heading indeed increases intention to visit across all destinations including high-preferred and lesspreferred destinations. Such findings do not occur in sample group 2 (adults). The findings of both sample groups also reveal for less-preferred destinations that 
highlighting price as a package heading does not increase their probability of entering the late consideration set or their probability of becoming a chosen destination.

These particular results, if confirmed in further studies, provide two implications for the theories in tourist decision-making regarding to the effects of presentation format of package holidays. The first implication of this study concerns the details of package holiday information. A previous study (Kivetz and Simonson, 2000) shows that incomplete information does not affect high-preferred products but it is frequently used as a reason to reject the less-preferred products. The greater the amount of incomplete information, the less favourable the evaluation (Johnson and Levin, 1985). To increase positive consumer evaluation of the less-preferred products, it is expected that information of such products should be presented in detail. In other words, less-preferred destinations should benefit from being presented with other attributes rather than with the destination name only. In the context of purchasing beach package holidays, the findings of this study do not support that presenting the information in detail can increase positive evaluation of less-preferred destinations. An alternative explanation is that the tourist decisions appear to rely heavily on the destination name rather than the information of other attributes or the package components. In this study, the destination name refers to the country. This presents a particular challenge for this study and tourism marketing in general. Countries have particular connotations related to, for example, history, current policies, religion, culture and facilities. As a result, it is likely that the consumers will have particularly strong views towards the countries.

The second implication of this study is related to the heading of package holidays. Previous research (Harlam et al., 1995) suggests that different formats of presenting bundle information can affect consumer evaluation. Furthermore, displaying the products with a specific attribute increases the importance of that particular attribute and affects the consumer evaluation (Areni et al., 1999; Miyazaki et al., 2000). Lesspreferred products should display the attribute that can be compared favourably (Areni et al., 1999). Therefore, it is expected that highlighting price as a package 
heading would be more beneficial to less-preferred destinations than highlighting an inferior attribute such as price. The results of the sample group 1 (students) reveal that presenting price as a package heading instead of destination name can increase positive evaluation of students not only for less-preferred destinations but also for high-preferred destinations. Such effects observed for the student sample may be due to the fact that the students are sensitive to price and perceive price as a package heading as an indication that the package holidays are good deals regardless of the actual price displayed. Previous research (Sirakaya et al., 2001) conducted on a student sample also shows that price is a major determinant of holiday decision for this particular segment. Similar findings, however, do not occur with the sample group 2 (adults). For this sample group, quality of accommodation is perceived as the second most important attribute while price is the third most important attribute for choosing beach holidays. This perhaps explains why highlighting a lesser important attribute such as price as a package heading does not influence the evaluation of the adult sample. This further suggests that an attribute presented as a package holiday heading should be carefully selected for a particular market segment.

\subsubsection{Effects of Presentation Format on Destination Importance}

As discussed in section 8.2.1, the presentation format would have effects on the destination choice process on a condition that it can decrease the importance of destination. To reiterate, this study focuses on two types of presentation format. The first is to present the destination name along with other attributes and the second is to highlight price as a package heading. This section explains whether the presentation format can decrease the importance of destination.

The findings of both sample groups suggest that neither presenting the destination name along with other attributes nor highlighting price as a package heading can decrease the destination importance. Furthermore, presenting price as a package heading does not increase the importance of price. As previously discussed in section 8.2.1, these results provide the evidence that the name of destination is such a powerful factor that the presentation format cannot decrease its importance and 
therefore cannot influence the choice of destination particularly in the context of this study.

The results of this section provide two main insights into the existing theories of tourist decision-making. First, tourism products rely heavily on the destination name in which it appears that the presentation format cannot easily reduce the importance of destination. This may be due to the fact that holiday products have the distinctive features of intangibility to an extent which increases levels of uncertainty (Palmer, 2001), high perceived risks, considerable expenditure and emotional significance (Goodall, 1988; Maser and Weiermair, 1998; Cooper et al., 1998; Swarbrooke and Horner, 1999). In the context of this study, it may be that the destination itself occupies a potentially important position on which consumers firmly base their evaluation. Thus, the destination choice is more likely to be influenced by the factors related to the name of destination such as destination image (Chon, 1990; Um, 1993) or destination attributes (Dann, 1977; Crompton, 1979; Gartner, 1989) than the way the information of package holidays is presented.

Since the name of the destination is a very powerful factor influencing choice, the second implication for beach package holidays is that highlighting an alternative attribute rather than the name of destination as a package heading can neither decrease the importance of destination nor increase the importance of that specific attribute. Although a previous study (Areni et al., 1999) suggests that displaying the products with a specific attribute can increase the importance of that specific attribute, this does not seem to be the case for beach package holidays. The results of this study show that presenting price as a package heading does not increase the importance of price. However, it should be noted that the study by Areni et al. (1999) was carried out in the real store setting rather than the hypothetical situation such as this study. Considering the difference in terms of study setting, a possible alternative explanation for the results of this study is that the hypothetical situation and the given treatment may not be strong enough to influence the tourist decisions. 


\subsubsection{Effects of Exposure on Destination Choice Process}

This section discusses the findings in relation to the second research question. The aim of this research question is to examine for less-preferred destinations whether the timing of exposure to such destinations can increase intention to visit, their likelihood of being included in a late consideration set and their likelihood of becoming a final choice.

Previous studies (Janiszewski, 1993; Mitra, 1995; Shapiro et al., 1997; Baker, 1999) suggest that the exposure can increase familiarity, liking and the likelihood of being included in the consideration set. However, there are three contrasting views on the timing of exposure in determining the consideration sets. The first is that the consideration sets are stable and the alternatives should be presented as early as possible to allow them to be included in the early consideration set and become a final choice (Crompton and Ankomah, 1993). The second is that the consideration sets are unstable and the exposure to alternatives may add new alternatives to the consideration sets at any point in time until the final choice is made (Shocker et al., 1991; Roberts and Nedungadi, 1995). The third is that the consideration sets are unstable but the exposure to alternatives should be only once before the time of choice since the consumers are unwilling to reconsider the rejected alternatives (Hulland, 1992).

Due to these contrasting views, this study tested the timing of exposure to benefit the less-preferred destinations namely; early exposure, late exposure and late exposure (without early exposure). Referring to the overall design (see Figure 5.2), there are two stages of exposures. Early exposure presents four destinations. Late exposure also presents four destinations including two new alternatives and two seen alternatives. For the measures (time 2), all eight destinations are presented including two new alternatives to allow the respondents to choose the available destinations which they have not been previously presented. In each exposure, there is an equal number of high-preferred and less-preferred destinations. 
The results of both sample groups suggest that none of the three exposures can help less-preferred destinations become included in the late consideration set or become a final choice. Late exposure, highlighting price as a package heading increases intention to visit extreme high-preferred destinations (Italy and Spain) of the sample group 1 (students) but increases intention to visit extreme less-preferred destinations (Turkey and Tunisia) of the sample group 2 (adults). Furthermore, late exposure increases probability of becoming a choice for only high-preferred destinations in sample group 1 (students).

The results of this section provide two implications for the theories on tourist decision-making regarding the effects of exposure. The first implication concerns the effects of exposure on consumer evaluation. Previous studies (Cox and Cox, 1988; Janiszewski, 1993) find that the exposure can result in the positive evaluation towards the alternatives. The results of this study further suggest that such effects would also depend upon several factors such as the timing of exposure, the information format, the market segment and the preference towards the alternatives. In the context of this study, late exposure with price as a heading seems to increase intention to visit extreme high-preferred destinations in the student sample but increase intention to visit extreme less-preferred destinations in the adult sample.

The second implication relates to the effects of exposure on choice of destinations. The findings of both sample groups do not support that the timing of exposure can help less-preferred destinations to become a final choice. There are at least two possible alternative explanations to such results. First, the name of destination is a very powerful factor influencing choice as previously discussed in section 8.2.1 regardless of the exposures. Second, the experiment itself has a limited number of the exposures and there is only a small time gap between early exposure and late exposure. The results of sample group 1 (students), however, appear to support the view that the consideration sets are unstable in which the exposure to alternatives can add them into the consideration set at any point in time (Shocker et al., 1991; Roberts and Nedungadi, 1995). Such results only occur with high-preferred destinations. This implies that attractive package holidays to high-preferred destinations such as 
last minute deals offering low price with close departure time can be promoted to this particular market segment as they will have high chances of becoming a final choice.

\subsubsection{Factors Influencing Destination Choice}

Previous tourism research suggests three main factors influencing the destination choice. These factors are destination attributes (Dann, 1977; Crompton, 1979; Gartner 1989; Uysal and Jurowski, 1994), destination image (Chon, 1990; Um, 1993) and previous visits to the destinations (Oppermann, 2000). Besides the observation on the presentation of information, attention is also paid to these three variables regarded as the important factors influencing the destination choice. In fact, these factors can help explain why the results are not in the anticipated directions.

The results of both sample groups show that destination image affects the destination choice. An implication here is that building a positive destination image is a very important destination marketing strategy to influence choice. Italy, for example, receives the highest overall destination image among the eight destinations and is therefore the most selected destination. In terms of destination attributes, Italy alone is perceived as providing the best five out of ten destination attributes. These five destination attributes are local food, quality of accommodation, quality of infrastructure, safety and hygiene and cleanliness. It is interesting to note that Italy is not perceived as offering the best beaches but it is mostly selected as an overseas beach holiday destination. The results for Italy suggest for advertising strategies for beach holiday destinations that they should not only emphasise the beauty of beaches but also other destination attributes as previously mentioned. The results of sample group 2 (adults) further show that past visits to the destination influence the destination choice while these results do not occur in sample group 1 (students). This suggests that adults tend to be more loyal to their previously visited destinations than the students.

Another possible reason explaining the unanticipated results is the perception of price to the destinations. For both sample groups, Italy is perceived as the most expensive destination of all eight destinations. Presenting price of package holidays 
to Italy lower than the expected price or at the same level as other destinations may result in a better chance for Italy to be selected as a final choice. Such a difference between the actual price and the displayed price may influence the observed effects of the information presentation.

\subsection{Limitations of the Findings}

The findings of this study should be considered in light of its limitations. This section discusses the limitations of the study in terms of the internal validity, the external validity and the construct validity.

\subsubsection{Internal Validity}

Internal validity refers to 'the degree of confidence in the causal effects' (Sekaran, 2000, p.153). Much effort has focused on improving the internal validity of the study with the use of the control group to compare with the experimental groups so that the change in a dependent variable will only occur in the experimental groups if the independent variables affect the dependent variable. Moreover, random assignment was employed in the study to lessen the threats of selection and rule out the variability between groups.

Despite these efforts, there are several limitations in terms of the internal validity. First, a hypothetical situation (see Figure 5.1) introducing the voucher for two persons may not reflect the independent choice of the respondents. Although the situation allows an independent decision, the respondents may also consider their companions' preferences when making the decisions. This will partly influence their choice of destinations. Second, this study does not control for variables such as the purchase experience of package holidays and the attitudes towards the destinations in terms of religion and political stability. These variables can perhaps explain why the treatments do not show the effects on the less-preferred destinations e.g. Turkey. Third, the length of questionnaire may lead to the respondents' fatigue and boredom. If that were the case, such factors could have a significant impact on the findings regardless of the experimental design or the treatments given. Notably, respondents 
may not provide "serious" answers thereby preventing the appearance of the anticipated effects. This might provide an explanation for the lack of clear differences in the findings in this study. The problem here is to balance the length and complexity of the questionnaire against the need to control all possible rival explanations and to include necessary measures so that only the effects of independent variables can be clearly observed. This is one of the problems inherent in the experimental method.

\subsubsection{External Validity}

External validity refers to "the extent to which the results of the experiment can be generalised to and across different persons, settings and times' (Christensen, 1988, p.399). The aim of this study, however, is not to generalise but to establish that the phenomenon exists in a relevant context. Homogeneity of the sample is therefore a primary concern to increase the internal validity for this study since it allows the control over the sample characteristics (Christensen, 1988). To improve the external validity of the experiment, further attempts have been made to replicate the study by using two sample groups with different demographic factors such as age and income. The first sample group was conducted with University of Surrey students and the second sample group was conducted with Guildford residents.

Despite an attempt to replicate the experiment, there are several limitations in terms of the external validity. First, the hypothetical situation raises concerns about the external validity of this study. The situation introduces the use of a winning voucher and discounts the joint decision-making to rule out other influences. An advantage of such a situation is to hold the experiment setting constant so that the independent variables can be observed without being influenced by other extraneous variables. In a real world situation where consumers spend their own money for holidays, perceived risks and involvement may play a major part in their decisions. In such a context, perceived risks are expected to be higher due to the intangible nature of the tourism products and the considerable cost of holidays. As a consequence, an involvement such as the interactive nature between consumers and travel agent salespersons would also be very high. These factors may yield different findings 
from those of the hypothetical situation used in this study. Furthermore, friends and families can influence the decision-making and may alter the decisions. Second, the closed list of destinations may limit the results of the study. As far as the similar price range is concerned, this study only includes short haul beach destinations such that they can be comparable. However, such a list may not resemble the real destination choice process since it has a limited number of available beach destinations. Third, a concern about the respondents' fatigue means that this study limits the levels of treatment for package heading (destination or price) and the number of exposures (early and late). In the real market situation, there is much more variety of presentation format and number of exposures. Fourth, the information about package holidays in this study may not resemble the real package holidays available in the market such as it has only two attribute levels e.g. price ( $£ 410$ and $£ 470$ ), quality of accommodation ( 3 star and 4 star hotels). The price levels in particular may be lower or higher than the consumers' expectation. Finally, the findings may be the consequences of the response bias due to the convenience sampling employed with the residents in Guildford, one of the wealthy regions in the UK. This reflects in the descriptive findings showing that this sample group tends to have high income and high education. Price may therefore have less influence for this particular sample than for other samples from less wealthy groups. Furthermore, it is observed that the sample distribution of both sample groups is likely to be biased towards female. It is therefore recommended that the replication of the study is needed before any generalisation can be made.

\subsubsection{Construct Validity}

Construct validity testifies how well the results obtained from the measure fit the theories around which the test is designed (Sekaran, 2000). Although attempts have been made to capture the concepts as proposed in the model by employing the operational definitions and scales from previous studies, there are several limitations of construct validity that need to be addressed. First, the measures of dependent variables such as intention to visit ratings and importance ratings by means of selfreported scales may not truly represent the real evaluation of the respondents. Second, the time gap between the two measures (time 1 and time 2) is very minimal 
due to the limitations of time and resources as well as the concern of the uncontrolled factors appearing between the two periods of time. A disadvantage of this design is that it may not allow enough time for the information processing. Although it is acknowledged that allowing a longer period of time gap such as a longitudinal study would yield different results, such a design would bring many difficulties of controlling the extraneous factors occurring between such a time gap. Finally, the perception of destinations such as the perceived attractiveness of destination and the perceived cost to the destinations may be a difficult task for the respondents who are not knowledgeable of the destinations and as a result may not successfully capture their real perception towards the destinations.

\subsection{Contributions of the Study}

The findings of this study provide the contribution in three aspects. These three aspects are theoretical contribution, methodological contribution and practical contribution.

\subsubsection{Theoretical Contribution}

Referring to the research gaps outlined in section 4.2 , this study has achieved its aims to provide the theoretical contribution for the theories of tourist decision-making in several aspects. First, it provides empirical evidence of the effects of travel stimuli on the destination choice process. The present understanding of such effects is still very limited. Various tourism authors assume that travel stimuli can influence the destination choice process (Woodside and Sherrell, 1977; Woodside and Lysonski, 1989; Um and Crompton, 1990). This study has empirically tested the effects of information presentation of package holidays which appears in various forms of travel stimuli such as advertising, promotion and travel literature (Schmoll, 1977; Moutinho, 1987). The study shows that for students, package heading can affect their evaluation and the exposure to alternatives can influence their choice of destination. Information presentation appears to have very little effects on adults. 
Second, this study tested the view that package holidays are the products that are less dependent on the destination as other attributes may play a dominant role in the tourist decision-making (Burkart, 1984). Based on this idea, this study makes further attempts to present the information of package holidays in such a way to reduce the importance of destination. The results show that the name of the destination is such a powerful factor influencing choice that it is rather difficult to reduce its importance. The destination name appears to exercise such a potential influence that even the information presentation strategies applied to enhance the effect of package holidays cannot assist less-preferred destinations to become a final choice. In the context of this study, it appears that choice of package holidays is dependent on the destination name.

Third, the study tested the widely held assumption in tourism that the consideration sets are stable in which the destinations should be presented as early as possible so as to allow them to be included in early consideration set and become a final choice (Crompton and Ankomah, 1993). To date, there is no empirical evidence to support such an assumption. The findings of this study reveal that this is not the case. Early exposure to the destinations does not lead them to become a final choice.

Fourth, the study examined the effects of destination images and previous visits to the destinations on the destination choice at the pre-purchase stage. Although there is a wealth of such studies on the effects of destination image on the destination choice, those studies were conducted at the consumption stage by focusing at a particular destination or targeting the visitors at the destination itself (Pike, 2002). In fact, such studies do not explain the actual destination choice (Oppermann, 2000). At the pre-purchase stage, this study reveals that the destination image has an important role in the destination choice. The results further show that adults tend to have some loyalty to the previously visited destinations.

\subsubsection{Methodological Contribution}

The study provides the methodological contribution for tourism research in two ways. First, it draws attention to experimental methodology and demonstrates that 
experiments can be employed in the studies relating to the effects of travel stimuli on tourist decision-making. Details of the experimental design are presented in section 5.3.1. Experiments are popular in marketing research to investigate the cause and effect relationships (Holland and Cravens, 1973; Louviere et al., 2000). To date, there are very few tourism studies applying this particular methodology. These studies focus on either modelling the tourist choice (e.g. Haider and Ewing, 1990; Dellaert et al., 1997) or determining the tourism product development (e.g. Bojanic and Calantone, 1990). Experiments are tightly controlled and therefore very powerful to examine such causal relationships. There are plenty of opportunities to use experiments to investigate the effects of other types of travel stimuli. This particular kind of study addresses some of the limitations of other research methodologies.

Second, this study develops a hypothetical situation which controls as much as possible for the factors affecting the tourist decision-making to keep the experiment setting constant such that the effects of treatment can be directly observed. A hypothetical situation is presented in Figure 5.1. This hypothetical situation is carefully developed in attempts to control for all the possible travel constraints such that it can rule out all the differences in terms of variability and possible explanation. The situation controls for the availability in terms of money, travel companion, and time. This study has taken one further step in testing the effects of travel stimuli by developing the hypothetical situation for the experiment. Further work in this area can learn and benefit from this development and improve this hypothetical situation for specific research purposes. Improvement in terms of the experimental design can also be employed. Such improvement can be carried out on the design of treatment and control variables.

\subsubsection{Practical Contribution}

The study provides the practical contribution for tourism marketing in various aspects. First, the study suggests that presenting detailed information of package holiday cannot influence the destination choice. The name of destination itself at least in terms of country is the most important factor influencing the destination 
choice. Therefore, presenting other information e.g. accommodation or number of nights does not draw attention away from the name of destination.

Second, the findings suggest that presenting beach package holidays with price as a heading can be eye-catching for students especially on the travel agents' window display or Internet websites. For students, presenting price as a package heading can increase intention to visit all destinations. For adults, the information about the quality of accommodation should be presented and it is considered as more important than price.

Third, the findings show that the destinations do not have to be presented as early as possible to become a final choice. This is encouraging for the tourism marketers to put more efforts to influence the destination choice. Last minute deals or special offers can be useful to attract the consumers due to low price and time pressure.

Finally, the results suggest that building the positive destination image for a strong destination name is a very effective destination marketing strategy. Due to the power of destination name in influencing the destination choice and the intangibility of tourism products, there is a high tendency that the consumers will rely their decisions on the name of destination.

\subsection{Conclusions and Recommendations for Future Research}

The aim of this study is to examine whether the presentation of information about package holidays can influence consideration and choice of beach holiday destinations. By examining this issue, this study will contribute to the design of more effective marketing strategies for less-preferred destinations. This study focuses on two aspects of presenting the information about package holidays to the consumers. The first concerns the presentation format to reduce the importance of destination. Such a decrease would benefit less-preferred destinations. The presentation format includes the amount of information provided and the package 
heading. The second concerns the effective timing of exposure to less-preferred destinations.

The results suggest that for students, price as a package heading increases positive evaluation for all destinations including high-preferred and less-preferred destinations. For adults, late exposure to less-preferred destinations with price as a package heading can increase their positive evaluation towards such destinations. The findings further suggest that neither early nor late exposures to less-preferred destinations can help them to become a final choice. The name of destination appears to be such a strong factor influencing choice that the importance of destination cannot be easily reduced. Therefore, neither the presentation format nor the timing of exposure can help less-preferred destinations to become a final choice. In the context of purchasing package holidays, this study reveals that the tourist decisions seem to be dependent on the destination.

This study provides the theoretical contribution by empirically testing several assumptions held in tourism. The first is that the travel stimuli can influence the destination choice process (Woodside and Sherrell, 1977; Woodside and Lysonski, 1989; Um and Crompton, 1990). The second is that the purchase of package holidays is less dependent on destination (Burkart, 1984). The third is that the consideration sets are stable in which the destinations should be presented as early as possible (Crompton and Ankomah, 1993). It also provides a methodological basis for tourism research regarding the effects of travel stimuli with the use of experiments. The experiment setting has been developed for similar studies on the destination choice. The study further suggests practical implications for the destination marketing strategies.

There are various recommendations for future works. First, there are several opportunities for this study to be further analysed. Follow-up analyses could be conducted specifically on the differences between the levels of travel experience or the levels of expertise. Furthermore, the treatment at the late exposure could be further analysed to check the interaction between the preference level and price level. 
The study could also be further analysed for other purposes such as new product development and choice modelling. Within the time permits, this thesis focuses mainly on answering the key research questions.

Second, the experiments could be replicated in different aspects. The experiments could be conducted in different geographical locations in the UK and further on to different countries to examine whether such effects can be generalised more widely for the holiday markets. In addition, the experiments could be conducted at different periods of time. Although this study was conducted before the Iraq war, the pre-war fear can affect tourist decision-making since a holiday product is vulnerable to the world events. Also, the study could be conducted on a longitudinal design to test the effects of travel stimuli over a period of time.

Third, further studies could employ a more sophisticated treatment design and also create the shopping environment to simulate the real holiday market environment as much as possible. Further experiments could incorporate several attribute levels of price range, hotel quality or travel agents to re-examine the effects. Further studies could also examine inclusive package holidays that include other options such as meals and sightseeing. Also, different aspects of presentation format and frequency of exposures to alternatives can be improved. Web-based questionnaires that provide better control of the amount of information and exposures could be an improvement on the shopping environment. This method would closely resemble the holiday internet shopping. However, it should be noted that the more the design resembles the real market, the greater the research budget and the greater the demand on the respondents' participation rates.

Fourth, further studies could include long-haul destinations or resort locations or other types of overseas holidays. In the context of this study, the country name is used and it may be associated with many several factors such as history, culture and current policies. Further studies could focus on different resort locations in one country to re-examine the effects. 
Fifth, further works could employ the stated preference method for the whole process of decision-making i.e. asking the respondents to select the profiles to form the consideration sets and select one for their final choice. The results would not be directly measured by asking the respondents to select from the list but indirectly from the profiles they choose.

Sixth, further studies could examine other aspects of travel stimuli in the tourism market i.e. frequency of exposure to advertising or last minute deals. Such studies could benefit from the experimental design of this study.

Finally, future research could extend to other tourism sectors e.g. hotels, restaurants and tourist attractions. 


\section{References}

Aaker, D.V., Kumar, V., \& Day, G.S. (2001). Marketing research ( $7^{\text {th }}$ ed.). New York: John Wiley \& Sons.

Abdullah, J.L.B. (2002). A study on leisure travel and subjective well-being. Unpublished doctoral dissertation, University of Surrey.

Adams, W.J., \& Yellen, J.L. (1976). Commodity bundling and the burden of monopoly. Quarterly Journal of Economics, 90, 475-498.

Alba, J.W., \& Hutchinson, J.W. (1987). Dimensions of consumer expertise. Journal of Consumer Research, 13(March), 411-454.

Alba, J.W., Hutchinson, J.W., \& Lynch, J.G., Jr. (1991). Memory and decision making. In T.S. Robertson \& H.H. Kassarjian (Eds.), Handbook of consumer behavior (pp.1-49). NJ: Prentice Hall.

Allenby, G.M., \& Ginter, J.L. (1995). The effects of in-store displays and feature advertising on consideration sets. International Journal of Research in Marketing, $12,67-80$.

Ankomah, P.K., Crompton, J.L., \& Baker, D. (1996). Influences of cognitive distance in vacation choice. Annals of Tourism Research, 23(1), 138-150.

Areni, C.S., Duhan, D.F., \& Kiecker, P. (1999). Pöint-of-purchase displays, product organization and purchase likelihoods. Journal of the Academy of Marketing Science, $27(4), 428-441$.

Baker, W., Hutchinson, J.W., Burke, D.M., \& Nedungadi, P. (1986). Brand familiarity and advertising: Effects on the evoked set and brand preference. Advances in Consumer Research, 13, 637-642.

Baker, W.E. (1999). When can affective conditioning and mere exposure directly influence brand choice? Journal of Advertising, 28(4), 31-46. 
Baloglu, S., \& McCleary, K.W. (1999). US international pleasure travelers' images of four Mediterranean destinations: A comparison of visitor and nonvisitors. Journal of Travel Research, 38(November), 144-152.

Bechhofer, F., \& Paterson, L. (2000). Principles of research design in the social sciences. London: Routledge.

Belonax, J.A., Jr. (1979). Decision rule uncertainty, evoked set size, and task difficulty as a function of number of choice criteria and information variability. In W.L. Wilkie (Ed.), Advances in Consumer Research (pp.232-235). Provo, UT: Association for Consumer Research.

Bettman, J.R. (1979). An information processing theory of consumer choice. MA: Addison-Wesley.

Bettman, J.R., \& Kakkar, P. (1977). Effects of information presentation format on consumer information acquisition strategies. Journal of Consumer Research, 3 (March), 233-240.

Bettman, J.R., Luce, M.F., \& Payne, J.W. (1998). Constructive consumer choice processes. Journal of Consumer Research, 25(December), 187-217.

Bettman, J.R., \& Park, C.W. (1980). Effects of prior knowledge and experience and phase of the choice process on consumer decision processes: A protocol analysis. Journal of Consumer Research, 7, 234-248.

Bettman, J.R., \& Zins, M.A. (1979). Information format and choice task effects in decision making. Journal of Consumer Research, 6 (September), 141-153.

Biehal, G., \& Chakravarti, D. (1982). Information presentation format and learning goals as determinants of consumers' memory retrieval and choice processes. Journal of Consumer Research, 8(March), 431-441.

Bigne, J.E., Sanchez, M.I., \& Sanchez, J. (2001). Tourism image, evaluation variables and after purchase behaviour: Inter-relationship. Tourism Management, 22, 607-616.

Bojanic, D.C., \& Calantone, R.J. (1990). Price bundling in public recreation. Leisure Sciences, 12(1), 67-78.

Botha, C., Crompton, J.L., \& Kim, S.S. (1999). Developing a revised competitive position for Sun/Lost city, South Africa. Journal of Travel Research, 37(4), 341-352.

Bouma, G.D., \& Atkinson, G.B.J. (1995). A handbook of social science research $\left(2^{\text {nd }}\right.$ ed.). Oxford: Oxford University Press. 
Brisoux, J.E., \& Laroche, M. (1980). A proposed consumer strategy of simplification for categorizing brands. In J.H. Summey \& R.D. Taylor (Eds.), Evolving marketing thought for 1980 ( pp. 112-114). Carbondale, IL: Southern Marketing Association.

Brown, J.J., \& Wildt, A.R. (1992). Consideration set measurement. Journal of the Academy of Marketing Science, 20(3), 235-243.

Burkart, A.J. (1984). Marketing package holidays. Service Industries Journal, 4(3), 187-192.

Burke, S.J. (1990). The effects of missing information on decision strategy selection. Advances in Consumer Research, 17, 250-256.

Burke, S.J. (1995). The dimensional effects of missing information on choice processing. Journal of Behavioural Decision Making, 8, 223-244.

Burstein, M.L. (1960). The economics of tie-in sales. Review of Economics and Statistics, 42 (February), 68-73.

Burton, S., Lichtenstein, D.R., \& Netemeyer, R.G. (1999). Exposure to sales flyers and increased purchases in retail supermarkets. Journal of Advertising Research, September-October, 7-14.

Calantone, R.J., Benedetto, C.A., Hakham, A., \& Bojanic, D.C. (1989). Multiple multinational tourism positioning using correspondence analysis. Journal of Travel Research, 28(20), 25-32.

Chen, J.S. (1998). The tourists' cognitive decision making model. The Tourist Review, 53(1), 4-9.

Chen, J.S., \& Hsu, C.H.C. (2000). Measurement of Korean tourists' perceived images of overseas destinations. Journal of Travel Research, 38, 411-416.

Chen, S.S., Monroe, K.B., \& Lou, Y.C. (1998). The effects of framing price promotion messages on consumers' perceptions and purchase intentions. Journal of Retailing, 74(3), 353-372.

Chernev, A., \& Carpenter, G.S. (2001). The role of market efficiency intuitions in consumer choice: A case of compensatory inferences. Journal of Marketing Research, 38(August), 349-361.

Chon, , K. (1990). The role of destination image in tourism: A review and discussion. The Tourist Review, 45(2), 2-9.

Chritensen, L.B. (1988). Experimental Methodology (4 $4^{\text {th }}$ ed.). Newton, MA: Allyn \& Bacon. 
Church, N.J., Laroche, M., \& Rosenblatt, J.A. (1985). Consumer brand categorization for durables with limited problem solving: An empirical test and proposed extension of the Brisoux-Laroche Model. Journal of Economic Psychology, $6,231-253$.

Churchill, G.A., Jr., (1999). Marketing research: Methodological foundations ( $^{\text {th }}$ ed.). Orlando: Dryden.

Clark-Carter, D. (1997). Doing quantitative psychological research: From design to report. Hove: Psychology Press.

Cooper, C., Fletcher, J., Wanhill, S., Gilbert, D., \& Shepherd, R. (1998). Tourism: Principles and practice ( $2^{\text {nd }}$ ed.). New York: Addison Wesley Longman.

Cooper-Martin, E. (1993). Effects of information format and similarity among alternatives on consumer choice processes. Journal of Academy of Marketing Science, 21(3), 239-246.

Cox, D.R., \& Reid, N. (2000). The theory of the design of experiments. Florida: Chapman\&Hall/CRC.

Cox, D.S., \& Cox, A.D. (1988). What does familiarity breed? Complexity as a moderator of repetition effects in advertisement evaluation. Journal of Consumer Research, 15(June), 111-116.

Crompton, J. (1979). Motivations for pleasure vacation. Annals of Tourism Research, 6, 409-424.

Crompton, J. (1992). Structure of vacation destination. Annals of Tourism Research, 19(3), 420-434.

Crompton, J.L., \& Ankomah, P.K. (1993). Choice set propositions in destination decisions. Annals of Tourism Research, 20, 461-476.

Crompton, J.L., Botha, C., \& Kim, S.S. (1998). Testing selected choice propositions. Annals of Tourism Research, 25(4), 211-214.

Dann, G. (1977). Anomie, ego-enhancement and tourism. Annals of Tourism Research, 4, 184-194.

De Vaus, D.A. (2002). Surveys in social research $\left(5^{\text {th }}\right.$ ed.). London: Routledge.

Deighton, J., Henderson, C.M., \& Neslin, S.A. (1994). The effects of advertising on brand switching and repeat purchasing. Journal of Marketing Research, 31(February), 28-43.

Della Bitta, A.J., Monroe, K.B., \& McGinnis, J.M. (1981). Consumer perceptions of comparative price advertisements. Journal of Marketing Research, 18, 416-427. 
Dellaert, B.G.C, Borgers, A.W.J., \& Timmermans, H.J.P. (1997). Conjoint models of tourist portfolio choice: Theory and illustration, Leisure Sciences, 19(1), 31-58.

Dellaert, B.G.C., Ettema, D.F. \& Lindh, C. (1998). Multi-faceted tourist travel decisions: A constraint-based conceptual framework to describe tourists' sequential choices of travel components. Tourism Management, 19(4), 313-320.

Dick, A., Chakravarti, D., \& Biehal, G. (1990). Memory-based inferences during consumer choice. Journal of Consumer Research, 17(1), 82-93.

Drew, C.J., \& Hardman, M.L. (1985). Designing and conducting behavioral research. Oxford: Pergamon.

Engel, J.F., \& Blackwell, R.D. (1982). Consumer behavior $\left(4^{\text {th }}\right.$ ed.). Hinsdale: Dryden.

Engel, J.F., Blackwell, R.D., \& Miniard, P.W. (1995). Consumer behaviour ( $8^{\text {th }}$ ed.). Orlando: Dryden.

Estelami, H. (1999). Consumer savings in complementary product bundles. Journal of Marketing Theory and Practice, 7(3), 107-114.

Fesemaier, D.R., \& Jeng, J.M. (2000). Assessing structure in the pleasure trip planning process. Tourism Analysis, 5(1), 13-27.

Fill, C. (1995). Marketing communications: Contexts, contents and strategies $\left(2^{\text {nd }}\right.$ ed.). Hertfordshire: Prentice Hall Europe.

Ford, G.T., \& Smith, R.A. (1987). Inferential beliefs in consumer evaluations: An assessment of alternative processing strategies. Journal of Consumer Research, 14(December), 363-371.

Gartner, W.C. (1989). Tourism image: Attribute measurement of state tourism products using multidimensional scaling techniques. Journal of Travel Research, 28(2), 16-20.

Gearing, C.E., Swart, W.W., \& Var, T. (1974). Establishing a measure of touristic attractiveness. Journal of Travel Research, 22(spring), 1-8.

Gilbert, D.C. (1992). A study of factors of consumer behaviour related to overseas' holidays from the UK. Unpublished doctoral dissertation, University of Surrey.

Glass, A.L., \& Holyoak, K.J. (1986). Cognition. New York: Random House.

Goodall, B. (1988). How tourists choose their holidays: An analytical framework. In B. Goodall, \& G. Ashworth (Eds.), Marketing in the tourism industry: The promotion of destination regions (pp. 1-17). London: Routledge. 
Goodall, B. (1991). Understanding holiday choice. In C.P. Cooper (Ed.). Progress in tourism, recreation and hospitality management (pp. 58-77), Vol. 3, London: Belhaven.

Goodrich, J.N. (1978). The relationship between preferences and perceptions of vacation destinations: Application of a choice model. Journal of Travel Research, 17 (fall), 8-13.

Grant, D., \& Mason, S. (1994). The package travel, package holidays and package tours regulations. Northumbria: University of Northumbria at Newcastle Travel Law Centre Publication.

Gravetter, F.J., \& Wallnau, L.B. (2000). Statistics for the behavioral sciences $\left(5^{\text {th }}\right.$ ed.). Belmont, CA: Wadsworth.

Green, P.E., Krieger, A.M. \& Wind, Y. (2001). Thirty years of conjoint analysis: Reflections and prospects. Interfaces, 31(3), S56-S73.

Greene, J., \& D'oliveira, M. (1999). Learning to use statistical tests in psychology $\left(2^{\text {nd }}\right.$ ed.). Buckingham: Open University Press.

Grimm, L.G. (1993). Statistical applications for the behavioural sciences. New York: John Wiley \& Sons.

Guiltinan, J.P. (1987). The price bundling of services: A normative framework. Journal of Marketing, 51(2), 74-85.

Haahti, A.J. (1986). Finland's competitive position as a destination. Annals of Tourism Research, 13(1), 11-35.

Haider, W., \& Ewing, G.O. (1990). A model of tourist choices of hypothetical Caribbean destinations. Leisure Sciences, 12(1), 33-47.

Hair, J.F., Jr., Anderson, R.E., Tatham, R.L., \& Black, W.C. (1998). Multivariate data analysis ( $5^{\text {th }}$ ed.). New Jersey: Prentice-Hall.

Hair, J.F., Jr., Bush, R.P., \& Ortinau, D.J. (2000). Marketing research. Singapore: McGraw-Hill.

Hakim, C. (2000). Research design: Successful designs for social and economic research $\left(2^{\text {nd }}\right.$ ed.). London: Routledge.

Hanson, W., \& Martin, R.K. (1990). Optimal bundle pricing. Management Science, 36 (February), 155-174.

Harlam, B.A., Krishna, A., Lehman, D.R., \& Mela, C. (1995). Impact of bundle type, price framing and familiarity on purchase intention for the bundle. Journal of Business Research, 33(1), 57-66. 
Harris, J. (1997). The effects of promotional bundling on consumers' evaluations of product quality and risk of purchase. Advances in Consumer Research, 24, 168-172.

Harris, P. (1986). Designing and reporting experiments. Milton Keynes: Oxford University Press.

Hauser, J.R., \& Wernerfelt, B. (1990). An evaluation cost model of evoked sets. Journal of Consumer Research, 16, 393-408.

Herrman, A., Huber, F., \& Coulter, R.H. (1997). Product and service bundling decisions and their effects on purchase intention. Pricing Strategy \& Practice, 5(3), 99-107.

Holland, C.W., \& Cravens, D.W. (1973). Fractional factorial experimental designs in marketing research. Journal of Marketing Research, 10(August), 270-276.

Howard, J.A. (1963). Consumer behaviour: Application of theory. New York: McGraw-Hill.

Howard, J.A., \& Sheth, J.N. (1969). The theory of buyer behavior. New York: John Wiley.

Howell, D.C. (1989). Fundamental statistics for the behavioral sciences ( $2^{\text {nd }}$ ed.). Boston: PWS-Kent.

Hu, Y., \& Ritchie, J.R.B. (1993). Measuring destination attractiveness: A contextual approach. Journal of Travel Research, 32(2), 25-34.

Huber, J., \& McCann, J.W. (1982). The impacts of inferential beliefs on product evaluations. Journal of Marketing Research, 19 (August), 324-333.

Hudson, S. (1999). Consumer behavior related to tourism. In A. Pizam, \& Y. Mansfeld (Eds.), Consumer behavior in travel and tourism (pp.7-32). New York: Haworth Hospitality Press.

Hulland, J.S. (1992). An empirical investigation of consideration set formation. Advances in Consumer Research, 19, 253-254.

Hutchinson, J.W., \& Alba, J.W. (1991). Ignoring irrelevant information: Situational determinants of consumer learning. Journal of Consumer Research, 18, 346-357.

Janiszewski, C. (1993). Preattentive mere exposure effects. Journal of Consumer Research, 20, 376-392.

Johnson, M.D., Herrmann, A., \& Bauer, H.H. (1999). The effects of price bundling on consumer evaluations of product offerings. International Journal of Research in Marketing, 16, 129-142. 
Johnson, R.D., \& Levin, I.P. (1985). More than meet the eyes: The effect of missing information on purchase evaluations. Journal of Consumer Research, 12(September), 74-81.

Josiam, B.M., \& Hobson, J.S.P. (1995). Consumer choice in context: The decoy effect in travel and tourism. Journal of Travel Research, 34(1), 45-50.

Kardes, F.R., Sanbonsmatsu, D.M., \& Herr, P.M. (1990). Consumer expertise and the feature-positive effect: Implications for judgement and inference. Advances in Consumer Research, 17, 351-354.

Keynote. (1999). UK travel and tourism: 1999 market report $\left(7^{\text {th }}\right.$ ed.). Middlesex: Keynote.

Kim, H.B. (1998). Perceived attractiveness of Korean destinations. Annals of Tourism Research, 25(2), 340-361.

Kinberg, Y., \& Sudit, E.F. (1979). Country/service bundling in international tourism: Criteria for the selection of an efficient bundle mix and allocation of joint revenues. Journal of International Business Studies, 10 (Fall), 51-63.

Kinnear, T.C., \& Taylor, J.R. (1996). Marketing research: An applied approach $\left(5^{\text {th }}\right.$ ed.). New York: McGraw-Hill.

Kivetz, R., \& Simonson, I. (2000). The effects of incomplete information on consumer choice. Journal of Marketing Research, 37(November), 427-448.

Kleiser, S.B., \& Mantel, S.P. (1994). The dimensions of consumer expertise: A scale development. In R. Achrol \& A. Mitchell (Eds.), AMA summer educators' proceedings (pp.20-26). Vol.5, Chicago: AMA.

Klenosky, D.B., \& Rethans, A.J. (1988). The formation of consumer choice sets: A longtitudinal investigation at the product class level. Advances in Consumer Research, 15, 13-18.

Laws, E. (1997). Managing packaged tourism. London: International Thomson Business Press.

Louviere, J.J., Hensher, D.A., \& Swait, J.D. (2000). Stated choice methods: Analysis and application. Cambridge: Cambridge University Press.

Louviere, J., \& Timmermans, H. (1990). Stated preference and choice models applied to recreation research: A review. Leisure Sciences, 12(1), 9-32.

Lynch, J.G., \& Srull, T. (1982). Memory and attentional factors in consumer choices: Concepts and research methods. Journal of Consumer Research, 9, 18-37. 
MacKenzie, S.B. (1986). The role of attention in mediating the effect of advertising on attribute importance. Journal of Consumer Research, 13, 174-195.

Maser, B., \& Weiermair, K. (1998). Travel decision-making: From the vantage point of perceived risk and information preferences. Journal of Travel and Tourism Marketing, 7(4), 107-121.

Mathieson, A., \& Wall, G. (1982). Tourism: Economic, physical and social impacts. Essex: Longman.

Medlik, S. (Ed.). (1997). Dictionary of travel, tourism and hospitality (2 ${ }^{\text {nd }}$ ed.) Oxford: Butterworth-Heinemann.

Metelka, C.J. (Ed.). (1986). The dictionary of tourism $\left(2^{\text {nd }}\right.$ ed.) Illinois: Merton House Travel and Tourism Publishers.

Meyer, R.J. (1981). A model of multiattribute judgements under attribute uncertainty and informational constraints. Journal of Marketing Research, 18(November), 428441.

Middelcoop, M., Borgers, A.W.J., Arentze, T.A., \& Timmermans, H.J.P. (2001). Representing and predicting tourist choice behaviour: Rule-based vs. utility-based approach. In J.A. Mazanec, G.I.Crouch, J.R.B. Ritchie, \& A.G. Woodside (Eds.), Consumer psychology of tourism, hospitality and leisure Vol. 2 (pp. 107-121). Oxon: CABI.

Middleton, V.T.C. (1994). Marketing in travel and tourism (2 ${ }^{\text {nd }}$ ed.). Oxford: Butterworth-Heinemann.

Middleton, V.T.C., \& Clarke, J. (2001). Marketing in travel and tourism ( $3^{\text {rd }}$ ed.). Oxford: Butterworth-Heinemann.

Mill, R.C. (1990). Tourism: International business. NJ: Prentice-Hall.

Miller, S. (1996). Experimental design and statistics ( $2^{\text {nd }}$ ed.). London: Routledge.

Mitchell, M., \& Jolley, J. (1988). Research design explained. NewYork: Holt, Rinehart and Winston.

Mitra, A. (1995). Advertising and the stability of consideration sets over multiple purchase occasions. International Journal of Research in Marketing, 12, 81-94.

Miyazaki, A.D., Sprott, D.E., \& Manning, K.C. (2000). Unit prices on retail shelf labels: An assessment of information prominence. Journal of Retailing, 76(1), 93112.

Mok, C., \& Armstrong, R.W. (1995). Leisure travel destination choice criteria of Hong Kong residents. Journal of Travel \& Tourism Marketing, 4(1), 99-104. 
Money, R.B., \& Crotts, J.C. (2003). The effect of uncertainty avoidance on information search, planning and purchases of international travel vacations. Tourism Management, 24, 191-202.

Moutinho, L. (1987). Consumer behaviour in tourism. European Journal of Marketing, 21(10), 1-44.

Mulhern, F.J., \& Leone, R.P. (1991). Implicit price bundling of retail products: A multiproduct approach to maximizing store profitability. Journal of Marketing, 55(October), 63-76.

Munger, J.L., \& Grewal, D. (2001). The effects of alternative price promotional methods on consumers' product evaluations and purchase intentions. Journal of Product \& Brand Management, 10(3), 185-197.

Myers, J.H., \& Alpert, M.I. (1977). Semantic confusion in attitude research: Salience vs importance vs determinance. Advances in Consumer Research, 4, 106-110.

Myers, J.L. (1972). Fundamentals of experimental designs ( $2^{\text {nd }}$ ed.). Boston: Allyn and Bacon.

Narayana, C.L., \& Markin, R.J. (1975). Consumer behavior and product performance: An alternative conceptualization. Journal of Marketing, 39(4), 1-6.

National Statistics. (2001). Travel trends 2000. London: The Stationery Office.

National Statistics. (2002). Travel trends 2001. London: The Stationery Office.

Naylor, G., \& Frank, K.E. (2001). The effect of price bundling on consumer perceptions of value. Journal of Services Marketing, 15(4), 270-281.

Nedungadi, P. (1990). Recall and consumer consideration sets: Influencing choice without altering brand evaluations. Journal of Consumer Research, 17 (December), 263-276.

Neuman, W.L. (2000). Social research methods: Qualitative and quantitative approaches $\left(4^{\text {th }}\right.$ ed.). Needham Heights, MA: Allyn\&Bacon.

Nicosia, F.M. (1966). Consumer decision process: Marketing and advertising implications. New Jersey: Prentice-Hall.

Obermiller, C. (1985). Varieties of mere exposure: The effects of processing style and repetition on affective response. Journal of Consumer Research, 12, 17-30.

Oliver, R.L., \& Bearden, W.O. (1985). Crossover effects in the theory of reasoned action: A moderating influence attempt. Journal of Consumer Research, 12(December), 324-340. 
Oppenheim, A.N. (1992). Questionnaire design, interviewing and attitude measurement. London: Continuum.

Oppermann, M. (2000). Where psychology and geography interface in tourism research and theory. In A.G. Woodside, G.I. Crouch, J.A. Mazanec, M. Oppermann \& M.Y. Sakai (Eds.), Consumer psychology of tourism, hospitality and leisure (pp. 19-35), Vol. 2, Oxon: CABI.

Oppewal, H., \& Holyoake, B. (in press). Bundling and retail agglomeration effects on shopping behavior. Journal of Retailing and Consumer Services.

Pallant, J. (2001). SPSS survival manual. Buckingham: Open University Press.

Palmer, A. (2001). Principles of service marketing ( $3^{\text {rd }}$ ed.). Berkshire: McGrawHill.

Paroush, J., \& Peles, Y. (1981). A combined monopoly and optimal packaging. European Economic Review, 15, 373-383.

Pike, S. (2002). Destination image analysis-A review of 142 papers from 1973 to 2000. Tourism Management, 23, 541-549.

Pu, H.H. (2000). Tourists' choice of holiday destinations: The case of English seaside resorts. Unpublished doctoral dissertation, University of Surrey.

Punch, K.F. (1998). Introduction to social research: Quantitative and qualitative approaches. London: Sage.

Punj, G., \& Srinivasan, N. (1989). Influence of expertise and purchase experience on the formation of evoked sets. Advances in Consumer Research, 16, 507-514.

Ritchie, J.R.B. (1994). Research on leisure behaviour and tourism - State of the art. In R.V. Gasser \& K. Weiermair (Eds), Spoilt for choice: Decision making processes and preference changes of tourists - Intertemporal and intercountry perspectives (pp. 3-27). Thaur: Kulturverl.

Roberts, J. (1989). A grounded model of consideration set size and composition. Advances in Consumer Research, 16, 749-757.

Roberts, J.H., \& Lattin, J.M. (1991). Development and testing of a model of consideration set composition. Journal of Marketing Research, 28, 429-440.

Roberts, J.H., \& Lattin, J.M. (1997). Consideration: Review of research and prospects for future insights. Journal of Marketing Research, 34(3), 406-410.

Roberts, J.H., \& Nedungadi, P. (1995). Studying consideration in the consumer decision process: Progress and challenges. International Journal of Research in Marketing, 12, 3-7. 
Robson, C. (1983). Experiment, design and statistics in psychology ( $2^{\text {nd }}$ ed.). London: Penguin.

Roscoe, J.T. (1975). Fundamental research statistics for the behavioural science $\left(^{\text {nd }}\right.$ ed.). New York: Holt, Rinehart and Winston.

Rothman, J. (1972). Experimental designs and models. In R.M. Worcester (Ed.), Consumer market research handbook (pp.28-51). London: McGraw Hill.

Russo, J.W. (1977). The value of unit price information. Journal of Marketing Research, 14, 193-201.

Sanfey, A., \& Hastie, R. (1998). Does evidence presentation format affect judgement? An experimental evaluation of displays of data for judgements. Psychological Review, 9(2), 99-103.

Sarantakos, S. (1998). Social research ( $2^{\text {nd }}$ ed.). Basingstoke: Palgrave.

Schiffman, L.G., \& Kanuk, L.L. (1994). Consumer behavior $\left(5^{\text {th }}\right.$ ed.). New Jersey: Prentice-Hall.

Schmalensee, R. (1984). Gaussian demand and commodity bundling. Journal of Business, 57 (1), S211-230.

Schmoll, G.A. (1977). Tourism promotion. London: Tourism International Press.

Schwartz, Z., \& Cohen, E. (1999). The perceived value of value meals: An experimental investigation into product bundling and decoy pricing in restaurant menus. Journal of Restaurant \& Foodservice Marketing, 3(3/4), 19-33.

Seaton, A.V. (1996). Destination marketing. In A.V. Seaton \& M.M. Bennett (Eds.), Marketing tourism products: Concepts, issues and cases (pp. 350-376). London: International Thomson Business Press.

Seddighi, H.R., \& Theocharous, A.L. (2002). A model of tourism destination choice: A theoretical and empirical analysis. Tourism Management, 23, 475-487.

Sekaran, U. (2000). Research methods for business ( $3^{\text {rd }}$ ed.). New York: John Wiley \& Sons.

Shapiro, S., Macinnis, D.J., \& Heckler, S.E. (1997). The effects of incidental ad exposure on the formation of consideration sets. Journal of Consumer Research, 24(June), 94-104.

Sheldon, P.J., \& Mak, J. (1987). The demand for package tours: A mode choice model. Journal of Travel Research, 25(3), 13-17. 
Shocker, A.D., Ben-Akiva, M., Boccara, B., \& Negudungadi, P. (1991). Consideration set influences on consumer decision-making and choice: Issues, models, and suggestions. Marketing Letters, 2(3), 181-197.

Simmons, C.J., \& Lynch, J.G., Jr. (1991). Inference effects without inference making? Effects of missing information on discounting and use of presented information. Journal of Consumer Research, 17(March), 477-491.

Simonin, B.L., \& Ruth, J.A. (1995). Bundling as a strategy for new product introduction: Effects on consumers' reservation prices for the bundle, the new product and its tie-in. Journal of Business Research, 33, 219-230.

Simonson, I. (1999). The effect of product assortment on buyer preferences. Journal of Retailing, 75(3), 347-370.

Simonson, I., \& Tversky, A. (1992). Choice in context: Tradeoff contrast and extremeness aversion. Journal of Marketing Research, 29(August), 281-295.

Simonson, I., \& Winer, R.S. (1992). The influence of purchase quantity and display format on consumer preference for variety. Journal of Consumer Research, 19(June), 133-138.

Sirakaya, E., McLellan, R., \& Uysal, M. (1996). Modeling vacation destination decisions: A behavioral approach. Journal of Travel and Tourism Marketing, 5(4), 57-75.

Sirakaya, E., Sonmez, S.F., \& Choi, H. (2001). Do destination images really matter? Predicting destination choices of student travellers. Journal of Vacation Marketing, $7(2), 125-142$.

Sirdeshmukh, D. \& Unnava, H.R. (1992). The effects of missing information on consumer product evaluations. Advances on Consumer Research, 19, 284-289.

Sivakumaran, B., \& Kannan, P.K. (2002). Consideration sets under variety seeking conditions: An experimental investigation. Advances in Consumer Research, 29, 209-210.

Soman, D., \& Gourville, J.T. (2001). Transaction decoupling: How price bundling affects the decision to consume. Journal of Marketing Research, 38 (February), 3044.

Sonmez, S.F., \& Graefe, A.R. (1998). Influence of terrorism risk on foreign tourism decisions. Annals of Tourism Research, 25(1), 112-144.

Spiggle, S., \& Sewall, M.A. (1987). A choice sets model of retail selection. Journal of Marketing, 51, 97-111. 
Stevens, J. (1986). Applied multivariate statistics for the social sciences. Hillsdale, $\mathrm{NJ}$ : Lawrence Erlbaum.

Stigler, G.J. (1968). The organization of industry. Homewood, IL: Irwin.

Stoddard, J.E., \& Fern, E.F. (1996). The effect of information presentation format and decision frame on choice in an organizational buying context. Advances in Consumer Research, 23, 211-217.

Strahilevitz, M.A. (1995). Emerging issues in product bundling. Advances in Consumer Research, 22, 587.

Stremersch, S., \& Tellis, G.J. (2002). Strategic bundling of products and prices: A new synthesis for marketing. Journal of Marketing, 66 (January), 55-72.

Summers, J.M., \& McColl-Kennedy, J.R. (1995). Development of a measurement scale for analysing destination choice criteria in the tourist decision process. European Advances in Consumer Research, 2, 406-411.

Suri, R., \& Monroe, K.B. (1995). Effect of consumers' purchase plans on the evaluation of bundle offers. Advances in Consumer Research, 22, 588-593.

Swarbrooke, J., \& Horner, S. (1999). Consumer behaviour in tourism. Oxford: Butterworth-Heinemann.

Tabanick, B.G., \& Fidell, L.S. (1996). Using multivariate statistics $\left(3^{\text {rd }}\right.$ ed.). New York: HarperCollins.

Taylor, P. (1998). Mixed strategy pricing behaviour in the UK package tour industry. International Journal of the Economics of Business, 5(1), 29-46.

Tellis, G.J. (1988). Advertising exposure, loyalty, and brand purchase. Journal of Marketing Research, 25(May), 134-144.

Thaler, R. (1985). Mental accounting and consumer choice. Marketing Science, 4(3), 199-214.

Thompson, J.R., \& Cooper, R.D. (1979). Additional evidence on the limited size of evoked and inept sets of travel destinations. Journal of Travel Research, 18 (winter), 23-25.

Trochim, W.M.K. (2002a). Internal Validity. Retrieved January 31, 2002, from http://trochim.human.cornell.edu/kb/intval.htm

Trochim, W.M.K. (2002b). Experimental Design. Retrieved January 31, 2002, from http://trochim.human.cornell.edu/kb/desexper.htm 
Turner, L., \& Reisinger, Y. (1999). Importance and expectations of destination attributes for Japanese tourists to Hawaii and the Gold Coast compared. Asia Pacific Journal of Tourism Research, 4(2), 1-18.

Tversky, A. (1969). Intransitivity of preferences. Psychological Review, 76, 31-48.

Um, S. (1993). Pleasure destination choice. In M.A. Khan, M.D. Olsen \& T. Var (Eds.), VNR's encyclopedia of hospitality and tourism (pp. 811-821). New York: Van Nostrand Reinhold.

Um, S., \& Crompton, J.L. (1990). Attitude determinants in tourism destination choice. Annals of Tourism Research, 17, 432-448.

Uysal, M., \& Jurowski, M. (1994). Testing the push and pull factors. Annals of Tourism Research, 21(4), 844-846.

Van Raaij, W. F., \& Francken, D.A. (1984). Vacation decisions, activities and satisfactions. Annals of Tourism Research, 11(1), 101-112.

Vanhuele, M. (1994). Mere exposure and the cognitive-affective debate revisited. Advances in Consumer Research, 21, 264-269.

Vanhuele, M. (1995). Why familiar stimuli are better liked. A study on the cognitive dynamics linking recognition and the mere exposure effect, Advances in Consumer Research, 22, 171-175.

Veal, A.J. (1997). Research methods for leisure and tourism (2 ${ }^{\text {nd }}$ ed.). London: Pitman.

Wahab, S., Crampon, L.J., \& Rothfield, L.M. (1976). Tourism marketing. London: Tourism International.

Woodside, A.G., \& Carr, J.A. (1988). Consumer decision making and competitive marketing strategies: Applications for tourism planning. Journal of Travel Research, 26, 2-7.

Woodside, A.G., \& Lysonski, S. (1989). A general model of traveler destination choice. Journal of Travel Research, 27 (4), 8-14.

Woodside, A.G., \& Ronkainen, I.A. (1980). Tourism management strategies for competitive vacation destinations. In D.E. Hawkins, E.L. Shafter \& J.M. Rovelstad (Eds.), Tourism marketing and management issues (pp. 3-19), Washington: George Washington University.

Woodside, A.G., \& Sherrell, D. (1977). Traveler evoked, inept and inert sets of vacation destinations. Journal of Travel Research, 16 (winter), 14-18. 
World Tourism Organization. (1999a). Changes in leisure time: The impact on tourism. Madrid: WTO.

World Tourism Organization. (1999b). Tourism generating markets: Overview and country profiles. Madrid: WTO.

World Tourism Organization. (2001a). Tourism after 11 September 2001: Analysis, remedial actions and prospects. Madrid: WTO.

World Tourism Organization. (2001b). Tourism highlights. Madrid: WTO

World Tourism Organization. (2003). Tourism highlights. Madrid: WTO

Wright, D.B. (1997). Understanding statistics. London: Sage.

Wright, G., \& Fowler, C. (1986). Investigative design and statistics. Middlesex: Penguin.

Wright, P., \& Barbour, F. (1977). Phased decision strategies: Sequels to initial screening. In M. Starr \& M. Zeleny (Eds.), Multiple criteria decision making (pp. 91-109). Amsterdam: North-Holland.

Yadav, M.S., \& Monroe, K.B. (1993). How buyers perceive savings in a bundle price: An examination of a bundle's transaction value. Journal of Marketing Research, 30(August), 350-358.

Yadav, M.S. (1994). How buyers evaluate product bundles: A model of anchoring and adjustment. Journal of Consumer Research, 21(September), 342-353.

Yau, O.H.M., \& Chan, C.F. (1990). Hong Kong as a travel destination in South-east Asia: A multidimensional approach. Tourism Management, 11(2), 123-132.

Zajonc, R.B. (1968). Attitudinal effects of mere exposure. Journal of Personality and Social Psychology Monographs, 9 (No.2, Part 2), 1-27. 
Appendices 


\section{Appendix A \\ Profile Design}




\begin{tabular}{|c|c|c|c|c|c|c|c|c|}
\hline version & $\begin{array}{c}\text { Original } \\
\text { profile }\end{array}$ & scenario & profile & country & att1 & att2 & att3 & att4 \\
\hline 1 & 1 & 1 & 1 & 1 & 1 & 1 & 1 & 1 \\
\hline 1 & 2 & 1 & 2 & 2 & 1 & 1 & 2 & 2 \\
\hline 1 & 3 & 1 & 3 & 3 & 1 & 2 & 1 & 2 \\
\hline 1 & 4 & 1 & 4 & 4 & 1 & 2 & 2 & 1 \\
\hline 1 & 5 & 2 & 5 & 1 & 2 & 2 & 2 & 2 \\
\hline 1 & 6 & 2 & 6 & 2 & 2 & 2 & 1 & 1 \\
\hline 1 & 7 & 2 & 7 & 3 & 2 & 1 & 2 & 1 \\
\hline 1 & 8 & 2 & 8 & 4 & 2 & 1 & 1 & 2 \\
\hline 2 & 1 & 1 & 1 & 4 & 2 & 2 & 2 & 2 \\
\hline 2 & 2 & 1 & 2 & 3 & 2 & 2 & 1 & 1 \\
\hline 2 & 7 & 1 & 7 & 2 & 1 & 2 & 1 & 2 \\
\hline 2 & 8 & 1 & 8 & 1 & 1 & 2 & 2 & 1 \\
\hline 2 & 3 & 2 & 3 & 2 & 2 & 1 & 2 & 1 \\
\hline 2 & 4 & 2 & 4 & 1 & 2 & 1 & 1 & 2 \\
\hline 2 & 5 & 2 & 5 & 4 & 1 & 1 & 1 & 1 \\
\hline 2 & 6 & 2 & 6 & 3 & 1 & 1 & 2 & 2 \\
\hline 3 & 1 & 1 & 1 & 1 & 1 & 1 & 1 & 1 \\
\hline 3 & 8 & 1 & 8 & 4 & 2 & 1 & 1 & 2 \\
\hline 3 & 3 & 1 & 3 & 3 & 1 & 2 & 1 & 2 \\
\hline 3 & 6 & 1 & 6 & 2 & 2 & 2 & 1 & 1 \\
\hline 3 & 2 & 2 & 2 & 2 & 1 & 1 & 2 & 2 \\
\hline 3 & 7 & 2 & 7 & 3 & 2 & 1 & 2 & 1 \\
\hline 3 & 4 & 2 & 4 & 4 & 1 & 2 & 2 & 1 \\
\hline 3 & 5 & 2 & 5 & 1 & 2 & 2 & 2 & 2 \\
\hline 4 & 2 & 1 & 2 & 3 & 2 & 2 & 1 & 1 \\
\hline 4 & 8 & 1 & 8 & 1 & 1 & 2 & 2 & 1 \\
\hline 4 & 3 & 1 & 3 & 2 & 2 & 1 & 2 & 1 \\
\hline 4 & 5 & 1 & 5 & 4 & 1 & 1 & 1 & 1 \\
\hline 4 & 1 & 2 & 1 & 4 & 2 & 2 & 2 & 2 \\
\hline 4 & 7 & 2 & 7 & 2 & 1 & 2 & 1 & 2 \\
\hline 4 & 4 & 2 & 4 & 1 & 2 & 1 & 1 & 2 \\
\hline 4 & 6 & 2 & 6 & 3 & 1 & 1 & 2 & 2 \\
\hline
\end{tabular}


Appendix B

Questionnaire for Control Group 
November 2002

Dear respondent

Thank you for participating in this survey. My name is Walaiporn. I am a postgraduate research student in the School of Management at the University of Surrey. I am conducting this survey as part of a doctoral degree in tourism. This survey is about overseas holiday destinations and aims to increase our understanding of tourist decision making.

This survey will take approximately 10-15 minutes to complete. There are no right or wrong answers so please give the answers that most reflect your opinion. All your responses will be treated as strictly confidential and will be used for academic purposes only. If you have any questions or concerns, please feel free to email me at msp1wr@surrey.ac.uk or phone me at 01483689664 (Monday to Friday from 9.30 a.m. to 5.00 p.m.).

As an incentive, six prizes will be given to respondents who return their completed questionnalres. You have a chance to win these prizes:

- Two prizes of $£ 40$ cash

- Four cool T-shirts

- Four smart leather folders with A6 notepads

The winners will be chosen at random from the pool of returned questionnaires. The lucky winners will be notifled by their provided contact details.

Thank you for your time and co-operation.

Sincerely yours

Walaiporn Rewtrakunphaiboon

$\mathrm{PhD}$ research office

School of Management

University of Surrey

Guildford GU2 7XH 
Please tick $(\sqrt{ })$ only one answer in the appropriate box unless specified otherwise.

\section{Section 1 (your preference and experience of overseas holidays)}

By "overseas holiday", we mean a visit to any other countries outside the United Kingdom for holiday purposes for a period of less than 12 months.

Q.1 Which type of holiday do you most prefer for your next overseas holiday?
$\square$ Beach
$\square$ City
$\square$ Cruise
Ski
other, specify

Q.2 Which month do you most prefer to take your next overseas holiday?
$\square$ January
$\square$ February
$\square$ March
April
$\square$ May
$\square$ June
July
August
September
October
November
December

Q.3 In the past five years, how many times have you been away for any overseas holidays?
None
$1-2$
3-4
5-6
more than 6

Q.4 In the past five years, how many times have you been away for overseas beach holidays?
None
$1-2$
3-4
5-6
more than 6

\section{Section 2 (your preference for overseas beach holiday destinations)}

It is important to read the situation below and imagine that you are in this situation throughout this survey.

\section{IMAGINE THIS SITUATION... \\ (IMPORTANT- PLEASE READ)}

Suppose you have won an overseas beach holiday voucher worth $£ 1,000$. This voucher must be spent on flights and accommodation for two persons. It must be used for booking holidays departing between June and August 2003. Assume that you are able to arrange a suitable time for this trip. You are free to take anyone with you. Assume that your travel companion will be happy to go to any destination and will let you decide.

Please note that the voucher cannot be transferred to other persons. If you do not wish to use the $£ 1,000$ voucher at all, you can exchange it for $£ 50$ cash. If you do not spend all of $£ 1,000$ at once, you will be given the remainder as a voucher for an overseas holiday next year. 
Please read the situation on the previous page before answering the questions.

Q.5 Would you use the overseas beach holiday voucher you won?

$\square$ Yes $\square$ No, I prefer $£ 50$ cash.

Q.6 With whom would you most likely spend your overseas beach holiday?

$\begin{array}{lll}\square \text { boyfriend / girlfriend } & \square \text { friend } & \square \text { partner / spouse } \\ \square \text { sister/ brother } & \square \text { son / daughter } \quad \square \text { father/mother } \\ \square \text { other, specify } & \end{array}$

\section{Section 3 (using your overseas beach holiday voucher today)}

Now, assume that eight destinations listed in a table below are the options available for using your overseas beach holiday voucher. Assume that you can book any overseas beach holidays on offer from any travel agents to one of these eight destinations but you have to use your voucher today to book your holiday, departing between June and August 2003. For this situation, we would like to know your destination preference.

\section{Please answer Q.7 in the table below.}

Q.7 Assume that you have to use your overseas beach holiday voucher today and destinations listed in the table are the only options available,

7.1 how likely are you to visit each destination?

7.2 please tick $(\sqrt{ })$ up to 4 destinations that you would consider visiting

7.3 please tick $(\sqrt{ })$ the destination that you would choose by the end of today

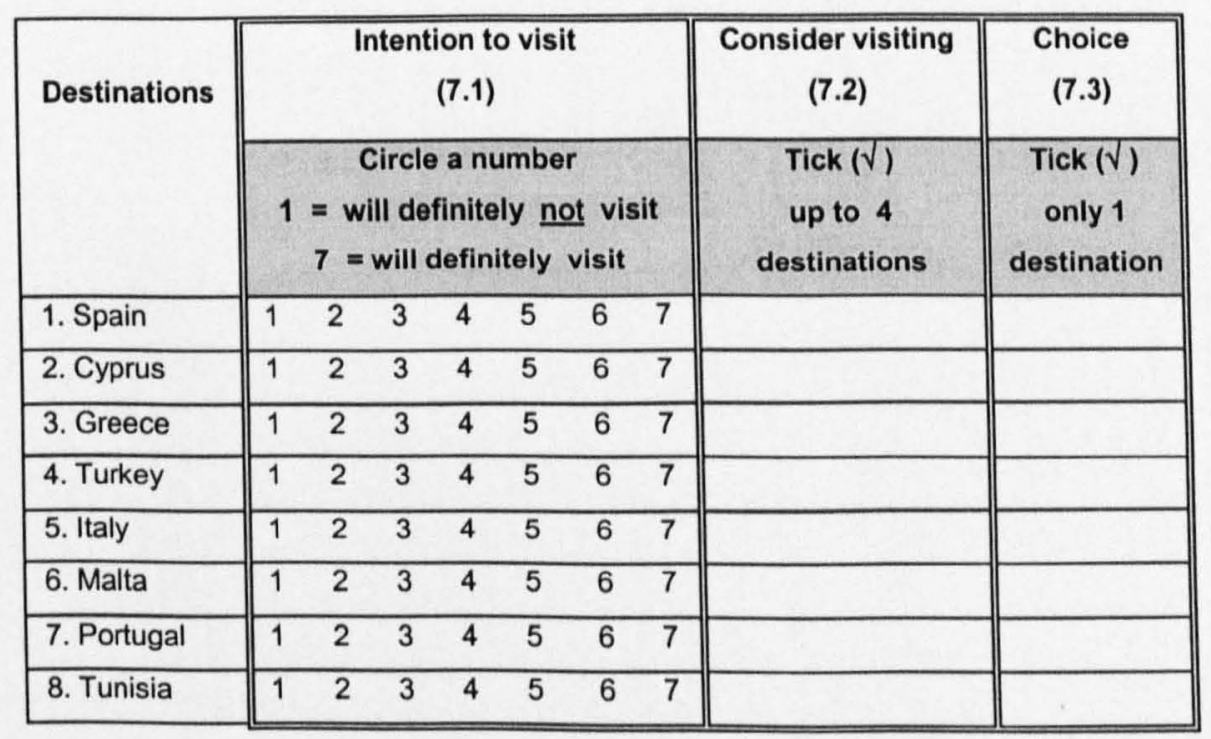




\section{Section 4 (importance of attributes in selecting overseas beach holidays)}

Q.8 Please indicate how you feel towards the following attributes when choosing an overseas beach holiday? Please circle a number in a table below.

\begin{tabular}{|l||lllllll||}
\hline \multicolumn{1}{|c||}{ Attributes } & \multicolumn{7}{c||}{$\begin{array}{c}\text { Circle a number } \\
\text { not at all important } \\
\text { 7 = very important }\end{array}$} \\
\hline 8.1 Airline & 1 & 2 & 3 & 4 & 5 & 6 & 7 \\
\hline 8.2 Destination & 1 & 2 & 3 & 4 & 5 & 6 & 7 \\
\hline 8.3 Number of nights & 1 & 2 & 3 & 4 & 5 & 6 & 7 \\
\hline 8.4 Price & 1 & 2 & 3 & 4 & 5 & 6 & 7 \\
\hline 8.5 Quality of accommodation & 1 & 2 & 3 & 4 & 5 & 6 & 7 \\
\hline 8.6 Name of travel agent & 1 & 2 & 3 & 4 & 5 & 6 & 7 \\
\hline
\end{tabular}

\section{Section 5 (knowledge and past visits of overseas beach holiday destinations)}

\section{Please answer Q.9 and Q.10 in a table below.}

Q.9 For all of the destinations listed in the table,

9.1 how well are you informed (by friends, television, magazine, etc.) about each as a beach holiday destination?

9.2 how familiar are you with each as a beach holiday destination?

Q.10 Please indicate number of times you have visited each destination in the list for any purposes. If you have never visited a destination before, please write " 0 ".

\begin{tabular}{|c|c|c|c|c|c|c|c|c|c|c|c|c|c|c|c|}
\hline \multirow{3}{*}{ Destinations } & \multicolumn{7}{|c|}{ Indicate all } & \multicolumn{7}{|c|}{ Indicate all } & Indicate all \\
\hline & \multicolumn{7}{|c|}{$\begin{array}{l}\text { Informed about each as a beach } \\
\text { holiday destination (9.1) }\end{array}$} & \multicolumn{7}{|c|}{$\begin{array}{l}\text { Familiar with each as a beach holiday } \\
\text { destination (9.2) }\end{array}$} & $\begin{array}{l}\text { Number of } \\
\text { visits (Q.10) }\end{array}$ \\
\hline & \multicolumn{7}{|c|}{$\begin{array}{c}\text { Circle a number } \\
1=\text { not at all informed } \\
7=\text { very well informed }\end{array}$} & \multicolumn{7}{|c|}{$\begin{array}{c}\text { Circle a number } \\
1=\text { not at all familiar } \\
7=\text { very familiar }\end{array}$} & $\begin{array}{l}\text { Write a } \\
\text { number }\end{array}$ \\
\hline 1. Spain & 1 & 2 & 3 & 4 & 5 & 6 & 7 & 1 & 2 & 3 & 4 & 5 & 6 & 7 & \\
\hline 2. Cyprus & 1 & 2 & 3 & 4 & 5 & 6 & 7 & 1 & 2 & 3 & 4 & 5 & 6 & 7 & \\
\hline 3. Greece & 1 & 2 & 3 & 4 & 5 & 6 & 7 & 1 & 2 & 3 & 4 & 5 & 6 & 7 & \\
\hline 4. Turkey & 1 & 2 & 3 & 4 & 5 & 6 & 7 & 1 & 2 & 3 & 4 & 5 & 6 & 7 & \\
\hline 5. Italy & 1 & 2 & 3 & 4 & 5 & 6 & 7 & 1 & 2 & 3 & 4 & 5 & 6 & 7 & \\
\hline 6. Malta & 1 & 2 & 3 & 4 & 5 & 6 & 7 & 1 & 2 & 3 & 4 & 5 & 6 & 7 & \\
\hline 7. Portugal & 1 & 2 & 3 & 4 & 5 & 6 & 7 & 1 & 2 & 3 & 4 & 5 & 6 & 7 & \\
\hline 8. Tunisia & 1 & 2 & 3 & 4 & 5 & 6 & 7 & 1 & 2 & 3 & 4 & 5 & 6 & 7 & \\
\hline
\end{tabular}




\section{Section 6 (perception of overseas beach holiday destinations)}

Q.11 Please tick $(\sqrt{ })$ the destination that you think it offers the best in each of the following attributes.

\begin{tabular}{|c|c|c|c|c|c|c|c|c|}
\hline \multirow[b]{2}{*}{ Attributes } & \multicolumn{8}{|c|}{ Tick $(\sqrt{ })$ only one destination for each attribute } \\
\hline & Spain & Cyprus & Greece & Turkey & Italy & Malta & Portugal & Tunisia \\
\hline \multicolumn{9}{|l|}{ 11.1 Local food } \\
\hline \multicolumn{9}{|l|}{11.2 Beaches } \\
\hline \multicolumn{9}{|l|}{ 11.3 Friendliness of local people } \\
\hline \multicolumn{9}{|l|}{ 11.4 Climate } \\
\hline \multicolumn{9}{|l|}{ 11.5 Nightlife and entertainment } \\
\hline \multicolumn{9}{|l|}{ 11.6 Quality of accommodation } \\
\hline \multicolumn{9}{|l|}{ 11.7 Quality of infrastructure } \\
\hline \multicolumn{9}{|l|}{ 11.8 Safety } \\
\hline \multicolumn{9}{|l|}{11.9 Hygiene and cleanliness } \\
\hline 11.10 Value for money & & & & & & & & \\
\hline
\end{tabular}

Q.12 Please indicate how you perceive the overall image of each as an overseas beach holiday destination? Please circle a number in a table below.

\begin{tabular}{|l||ccccccc||}
\hline \multicolumn{1}{|c||}{ Destinations } & \multicolumn{7}{|c||}{$\begin{array}{c}\text { Circle a number } \\
\text { 1 = very negative } \\
7 \text { = very positive }\end{array}$} \\
\hline 1. Spain & 1 & 2 & 3 & 4 & 5 & 6 & 7 \\
\hline 2. Cyprus & 1 & 2 & 3 & 4 & 5 & 6 & 7 \\
\hline 3. Greece & 1 & 2 & 3 & 4 & 5 & 6 & 7 \\
\hline 4. Turkey & 1 & 2 & 3 & 4 & 5 & 6 & 7 \\
\hline 5. Italy & 1 & 2 & 3 & 4 & 5 & 6 & 7 \\
\hline 6. Malta & 1 & 2 & 3 & 4 & 5 & 6 & 7 \\
\hline 7. Portugal & 1 & 2 & 3 & 4 & 5 & 6 & 7 \\
\hline 8. Tunisia & 1 & 2 & 3 & 4 & 5 & 6 & 7 \\
\hline
\end{tabular}

Q.13 If the destinations listed below are offered in package holidays that include return scheduled flights for 7 nights at a three star hotel including breakfast and dinner, departing between June and August 2003, please tick $(\sqrt{ })$ as you think will be the most expensive destination and the cheapest destination.

\begin{tabular}{|l||c|c|c|c|c|c|c|c||}
\hline \multicolumn{1}{|c|}{} & \multicolumn{7}{c||}{ Tick ( $)$ ) only one destination for each question } \\
\cline { 2 - 9 } & Spain & Cyprus & Greece & Turkey & Italy & Malta & Portugal & Tunisia \\
\hline 13.1 The most expensive destination & & & & & & & & \\
\hline 13.2 The cheapest destination & & & & & & & & \\
\hline
\end{tabular}




\section{Section 7 (your feeling about choosing an overseas beach holiday destination)}

Q.14 Please indicate how much you agree or disagree with the following statements. Please circle a number in a table below.

\begin{tabular}{|c|c|c|c|c|c|c|c|}
\hline Statements & \multicolumn{7}{|c|}{$\begin{array}{c}\text { Circle a number } \\
1=\text { strongly disagree } \\
7=\text { strongly agree }\end{array}$} \\
\hline destination without much effort. & 1 & 2 & 3 & 4 & 5 & 6 & 7 \\
\hline $\begin{array}{l}14.2 \text { I will search for the latest information } \\
\text { before I book my holiday. }\end{array}$ & 1 & 2 & 3 & 4 & 5 & 6 & 7 \\
\hline $\begin{array}{l}14.3 \text { I consider myself knowledgeable about } \\
\text { overseas beach holiday destinations. }\end{array}$ & 1 & 2 & 3 & 4 & 5 & 6 & 7 \\
\hline $\begin{array}{l}14.4 \text { I can recall almost all overseas beach } \\
\text { holiday destinations from memory. }\end{array}$ & 1 & 2 & 3 & 4 & 5 & 6 & 7 \\
\hline
\end{tabular}

\section{Section 8 (about you)}

Q.15 Which gender are you?
Male
$\square$ Female

Q.16 Which of these categories best describes your age?
15-24
25-34
$\square 35-44$
$45-54$
$55-64$
65 or over

Q.17 Which of these categories best describes you?
$\square$ single
$\square$ Living with a partner / Married
Widowed / Divorced / Separated

Q.18 How old is the youngest child in your household? years old

Q.19 Which is the highest qualification you have obtained?

$\square$ GCSEs grade A-C or equivalent

$\square$ GCE $A$ levels or equivalent

Vocational qualification

First degree (e.g. BA, BSc)

Higher degree (e.g. MA, MSc, $\mathrm{PhD}$, postgraduate certificate diplomas)

$\square$ Other qualifications (e.g. City and Guilds, RSAJOCR, BTEC/Edexcel) 
Q.20 Which of these categories best describes your annual household income before tax?
$\square$ None
$\square$ Under $£ 10,000$
$\square £ 10,001-£ 20,000$
$\square £ 20,001-£ 30,000$
$\square £ 30,001-£ 40,000$
$\square £ 40,001-£ 50,000$
$\square £ 50,001-£ 60,000$
$\square £ 60,001-£ 70,000$
$\square £ 70,001$ or over
$\square$ would rather not disclose

Q.21 Are you UK resident?
$\square$ Yes
$\square$ No, specify

If you have any comments or suggestions, please write them below.

TO ENTER THE PRIZE DRAW
Please provide your name and contact details i.e. email address, telephone number or
home address. This information will only be used for the purpose of informing you the
results of the prize draw.
Name:
Contact details:

Thank you very much for your time and co-operation. 


\section{Appendix C}

\section{Questionnaire for Experimental Group 1}


November 2002

Dear respondent

Thank you for participating in this survey. My name is Walaiporn. I am a postgraduate research student in the School of Management at the University of Surrey. I am conducting this survey as part of a doctoral degree in tourism. This survey is about overseas holiday destinations and aims to increase our understanding of tourist decision making.

This survey will take approximately 10-15 minutes to complete. There are no right or wrong answers so please give the answers that most reflect your opinion. All your responses will be treated as strictly confidential and will be used for academic purposes only. If you have any questions or concerns, please feel free to email me at msp1wr@surrey.ac.uk or phone me at 01483689664 (Monday to Friday from 9.30 a.m. to 5.00 p.m.).

As an incentive, six prizes will be given to respondents who return their completed questlonnaires. You have a chance to win these prizes:

- Two prizes of $£ 40$ cash

- Four cool T-shirts

- Four smart leather folders with A6 notepads

The winners will be chosen at random from the pool of returned questionnaires. The lucky winners will be notlfied by their provided contact details.

Thank you for your time and co-operation.

Sincerely yours

Walaiporn Rewtrakunphaiboon

PhD research office

School of Management

University of Surrey

Guildford GU2 7XH 
Please tick $(\sqrt{ })$ only one answer in the appropriate box unless specified otherwise.

\section{Section 1 (your preference and experience of overseas holidays)}

By "overseas holiday", we mean a visit to any other countries outside the United Kingdom for holiday purposes for a period of less than 12 months.

Q.1 Which type of holiday do you most prefer for your next overseas holiday?
$\square$ Beach
$\square$ City
$\square$ Cruise
$\square$ Ski
other, specify

Q.2 Which month do you most prefer to take your next overseas holiday?
$\square$ January
$\square$ February
$\square$ March
April
May
$\square$ June
$\square$ July
September
$\square$ October
November
August
December

Q.3 In the past five years, how many times have you been away for any overseas holidays?
None
$1-2$
3-4
5-6
more than 6

Q.4 In the past five years, how many times have you been away for overseas beach holidays?
None
$\square 1-2$
3-4
5-6
more than 6

\section{Section 2 (your preference for overseas beach holiday destinations)}

It is important to read the situation below and imagine that you are in this situation throughout this survey.

\section{IMAGINE THIS SITUATION... (IMPORTANT- PLEASE READ)}

Suppose you have won an overseas beach holiday voucher worth $£ 1,000$. This voucher must be spent on flights and accommodation for two persons. It must be used for booking holidays departing between June and August 2003. Assume that you are able to arrange a suitable time for this trip. You are free to take anyone with you. Assume that your travel companion will be happy to go to any destination and will let you decide.

Please note that the voucher cannot be transferred to other persons. If you do not wish to use the $£ 1,000$ voucher at all, you can exchange it for $£ 50$ cash. If you do not spend all of $£ 1,000$ at once, you will be given the remainder as a voucher for an overseas holiday next year. 
Please read the situation on the previous page before answering the questions.

Q.5 Would you use the overseas beach holiday voucher you won?
$\square$ Yes
No, I prefer $£ 50$ cash.

Q.6 With whom would you most likely spend your overseas beach holiday?

$\begin{array}{lll}\square \text { boyfriend / girlfriend } & \square \text { friend } & \square \text { partner / spouse } \\ \square \text { sister/ brother } & \square \text { son / daughter } & \square \text { father / mother }\end{array}$

\section{Please answer Q.7 in a table below.}

Q.7 Assume that the destinations listed in the table below are the only options available for using your overseas beach holiday voucher,

7.1 please rank them according to your preference from 1 (the most preferred destination) and so on to 4 (the least preferred destination).

7.2 how likely are you to visit each destination?

7.3 please tick $(\sqrt{ })$ for destinations that you.......

7.3.1 consider as possible destinations

7.3.2 would consider visiting

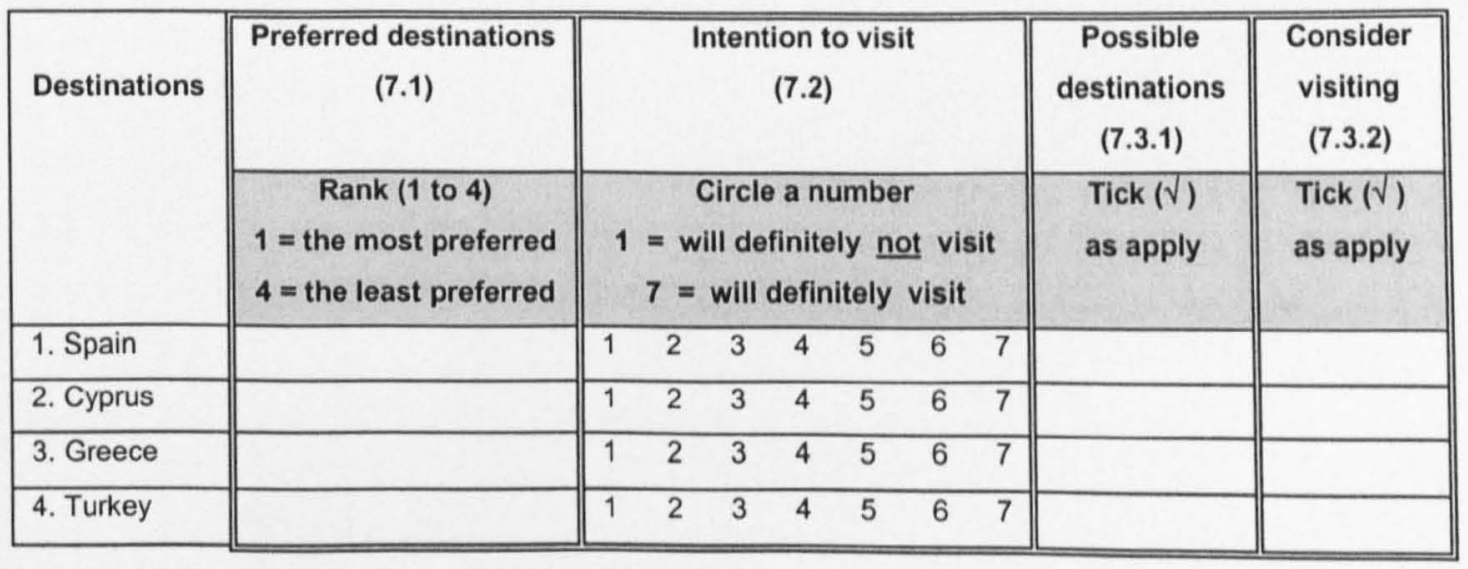




\section{Section 3 (vour preference for overseas beach package holidays)}

Package holiday prices shown are per person and include flights, accommodation based on two adults sharing and half board (breakfast and dinner). All prices include pre-paid taxes and are based on London departures.

\section{SCENARIO 1}

Suppose that these four package holidays are the only options available for using your overseas beach holiday voucher. Please indicate how attractive you find each package holiday by circling a number at the bottom of each package holiday ( $1=$ not at all attractive and $7=$ very attractive). Next, please tick $(\sqrt{ })$ your most preferred and your least preferred package holiday.

\begin{tabular}{|c|c|c|c|c|}
\hline & Package No.1 & Package No.2 & Package No.3 & Package No.4 \\
\hline & $\begin{array}{c}\text { Spain } \\
3 \text { star hotel } \\
7 \text { nights } \\
£ 410 \\
\text { Thomas Cook }\end{array}$ & $\begin{array}{l}3 \text { star hotel } \\
7 \text { nights } \\
£ 470 \\
\text { Lunn Poly }\end{array}$ & $\begin{array}{l}3 \text { star hotel } \\
9 \text { nights } \\
£ 410 \\
\text { Lunn Poly }\end{array}$ & $\begin{array}{c}3 \text { star hotel } \\
9 \text { nights } \\
£ 470 \\
\text { Thomas Cook }\end{array}$ \\
\hline Circle a number & $\begin{array}{lllllll}1 & 2 & 3 & 4 & 5 & 6 & 7\end{array}$ & $\begin{array}{lllllll}1 & 2 & 3 & 4 & 5 & 6 & 7\end{array}$ & $\begin{array}{lllllll}1 & 2 & 3 & 4 & 5 & 6 & 7\end{array}$ & $\begin{array}{lllllll}1 & 2 & 3 & 4 & 5 & 6 & 7\end{array}$ \\
\hline Tick $(\sqrt{ })$ only once & \multicolumn{2}{|c|}{ My most preferred package holiday is } & No.1 $\square$ No.2 & No.3 $\square$ No.4 \\
\hline Tick $(\sqrt{ })$ only once & \multicolumn{2}{|c|}{ My least preferred package holiday is } & No.1 $\square$ No.2 & No.3 $\square$ No.4 \\
\hline
\end{tabular}

\section{SCENARIO 2}

Suppose that these four package holidays are the only options available for using your overseas beach holiday voucher. Please indicate how attractive you find each package holiday by circling a number at the bottom of each package holiday $(1=$ not at all attractive and $7=$ very attractive). Next, please tick $(\sqrt{ })$ your most preferred and your least preferred package holiday.

\begin{tabular}{|c|c|c|c|c|}
\hline & Package No.5 & Package No.6 & Package No.7 & Package No.8 \\
\hline & $\begin{array}{c}\text { Spain } \\
4 \text { star hotel } \\
9 \text { nights } \\
£ 470 \\
\text { Lunn Poly }\end{array}$ & $\begin{array}{c}4 \text { star hotel } \\
9 \text { nights } \\
£ 410 \\
\text { Thomas Cook }\end{array}$ & $\begin{array}{c}\text { Ca } \\
4 \text { star hotel } \\
7 \text { nights } \\
£ 470 \\
\text { Thomas Cook }\end{array}$ & $\begin{array}{l}\text { Malta } \\
4 \text { star hotel } \\
7 \text { nights } \\
£ 410 \\
\text { Lunn Poly }\end{array}$ \\
\hline Circle a number & $\begin{array}{lllllll}1 & 2 & 3 & 4 & 5 & 6 & 7\end{array}$ & $\begin{array}{llllllll}1 & 2 & 3 & 4 & 5 & 6 & 7\end{array}$ & $\begin{array}{lllllll}1 & 2 & 3 & 4 & 5 & 6 & 7\end{array}$ & $\begin{array}{lllllll}1 & 2 & 3 & 4 & 5 & 6 & 7\end{array}$ \\
\hline Tick $(\sqrt{ })$ only once & \multicolumn{2}{|c|}{ My most preferred package holiday is } & No.5 $\square$ No.6 & $\square$ No.8 \\
\hline Tick $(\sqrt{ })$ ) only once & \multicolumn{2}{|c|}{ My least preferred package holiday is } & No.5 $\square$ No.6 & No.7 $\square$ No.8 \\
\hline
\end{tabular}




\section{Section 4 (using your overseas beach holiday voucher today)}

Now, assume that eight destinations listed in a table below are the options available for using your overseas beach holiday voucher. Assume that you can book any overseas beach holidays on offer from any travel agents to one of these eight destinations but you have to use your voucher today to book your holiday, departing between June and August 2003. For this situation, we would like to know your destination preference.

\section{Please answer Q.8 in the table below.}

Q.8 Assume that you have to use your overseas beach holiday voucher today and destinations listed in the table are the only options available,

8.1 how likely are you to visit each destination?

8.2 please tick $(\sqrt{ })$ up to 4 destinations that you would consider visiting

8.3 please tick $(\sqrt{ })$ the destination that you would choose by the end of today

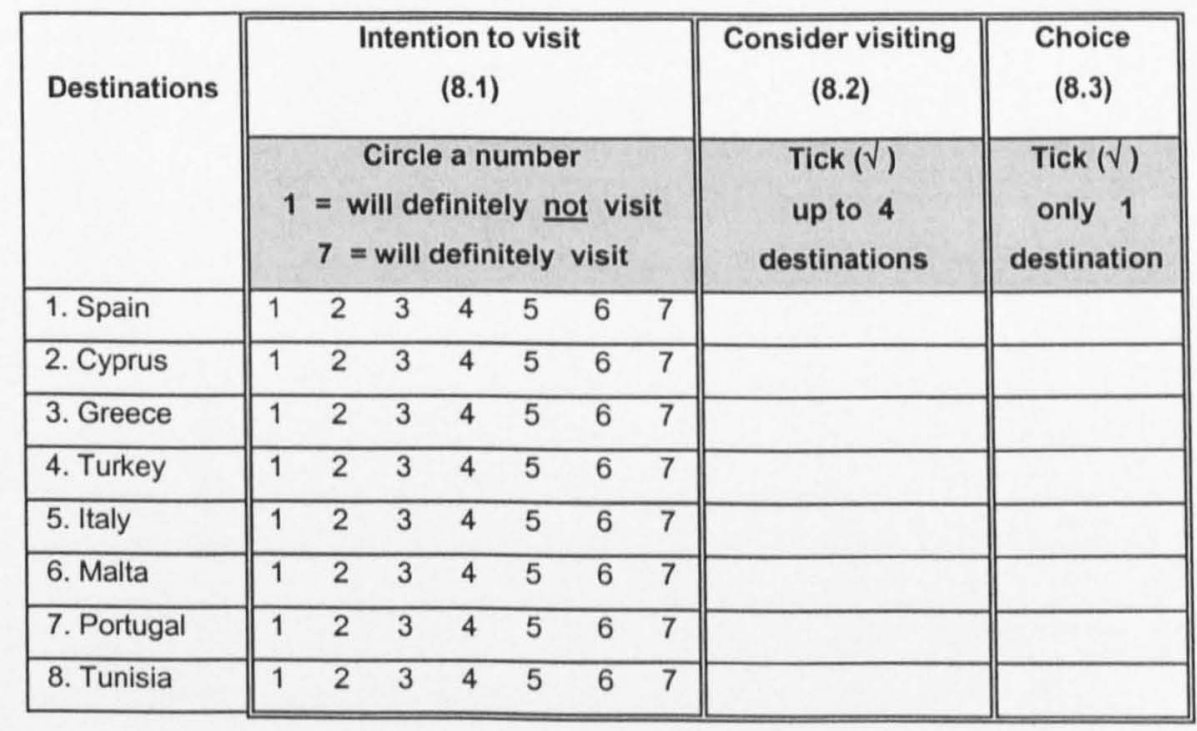

\section{Section 5 (importance of attributes in selecting overseas beach holidays)}

Q.9 Please indicate how you feel towards the following attributes when choosing an overseas beach holiday? Please circle a number in a table below.

\begin{tabular}{|c|c|c|c|c|c|c|c|}
\hline \multirow[t]{2}{*}{ Attributes } & \multicolumn{7}{|c|}{$\begin{array}{c}\text { Circle a number } \\
1=\text { not at all important } \\
7=\text { very important }\end{array}$} \\
\hline & 1 & 2 & 3 & 4 & 5 & 6 & 7 \\
\hline 9.2 Destination & 1 & 2 & 3 & 4 & 5 & 6 & 7 \\
\hline 9.3 Number of nights & 1 & 2 & 3 & 4 & 5 & 6 & 7 \\
\hline 9.4 Price & 1 & 2 & 3 & 4 & 5 & 6 & 7 \\
\hline 9.5 Quality of accommodation & 1 & 2 & 3 & 4 & 5 & 6 & 7 \\
\hline 9.6 Name of travel agent & 1 & 2 & 3 & 4 & 5 & 6 & 7 \\
\hline
\end{tabular}




\section{Section 6 (knowledge and past visits of overseas beach holiday destinations)}

\section{Please answer Q.10 and Q.11 in a table below.}

Q.10 For all of the destinations listed in the table,

10.1 how well are you informed (by friends, television, magazine, etc.) about each as a beach holiday destination?

10.2 how familiar are you with each as a beach holiday destination?

Q.11 Please indicate number of times you have visited each destination in the list for any purposes. If you have never visited a destination before, please write " 0 ".

\begin{tabular}{|c|c|c|c|c|c|c|c|c|c|c|c|c|c|c|c|}
\hline \multirow{3}{*}{ Destinations } & \multicolumn{7}{|c|}{ Indicate all } & \multicolumn{7}{|c|}{ Indicate all } & Indicate all \\
\hline & \multicolumn{7}{|c|}{$\begin{array}{c}\text { Informed about each as a beach } \\
\text { holiday destination (10.1) }\end{array}$} & \multicolumn{7}{|c|}{$\begin{array}{l}\text { Familiar with each as a beach holiday } \\
\text { destination (10.2) }\end{array}$} & $\begin{array}{l}\text { Number of } \\
\text { visits (Q.11) }\end{array}$ \\
\hline & \multicolumn{7}{|c|}{$\begin{array}{c}\text { Circle a number } \\
1=\text { not at all informed } \\
7=\text { very well informed }\end{array}$} & \multicolumn{7}{|c|}{$\begin{array}{c}\text { Circle a number } \\
1=\text { not at all familiar } \\
7=\text { very familiar }\end{array}$} & $\begin{array}{l}\text { Write a } \\
\text { number }\end{array}$ \\
\hline 1. Spain & 1 & 2 & 3 & 4 & 5 & 6 & 7 & 1 & 2 & 3 & 4 & 5 & 6 & 7 & \\
\hline 2. Cyprus & 1 & 2 & 3 & 4 & 5 & 6 & 7 & 1 & 2 & 3 & 4 & 5 & 6 & 7 & \\
\hline 3. Greece & 1 & 2 & 3 & 4 & 5 & 6 & 7 & 1 & 2 & 3 & 4 & 5 & 6 & 7 & \\
\hline 4. Turkey & 1 & 2 & 3 & 4 & 5 & 6 & 7 & 1 & 2 & 3 & 4 & 5 & 6 & 7 & \\
\hline 5. Italy & 1 & 2 & 3 & 4 & 5 & 6 & 7 & 1 & 2 & 3 & 4 & 5 & 6 & 7 & \\
\hline 6. Malta & 1 & 2 & 3 & 4 & 5 & 6 & 7 & 1 & 2 & 3 & 4 & 5 & 6 & 7 & \\
\hline 7. Portugal & 1 & 2 & 3 & 4 & 5 & 6 & 7 & 1 & 2 & 3 & 4 & 5 & 6 & 7 & \\
\hline 8. Tunisia & 1 & 2 & 3 & 4 & 5 & 6 & 7 & 1 & 2 & 3 & 4 & 5 & 6 & & \\
\hline
\end{tabular}




\section{Section 7 (perception of overseas beach holiday destinations)}

Q.12 Please tick $(\sqrt{ })$ the destination that you think it offers the best in each of the following attributes.

\begin{tabular}{|l||l|l|l|l|l|l|l|l||}
\hline \multicolumn{1}{|c|}{} & \multicolumn{7}{c||}{ Tick $(\sqrt{ })$ only one destination for each attribute } \\
\hline \multicolumn{1}{|c|}{ Attributes } & Spain & Cyprus & Greece & Turkey & Italy & Malta & Portugal & Tunisia \\
\hline 12.1 Local food & & & & & & & & \\
\hline 12.2 Beaches & & & & & & & & \\
\hline 12.3 Friendliness of local people & & & & & & & & \\
\hline 12.4 Climate & & & & & & & \\
\hline 12.5 Nightlife and entertainment & & & & & & & & \\
\hline 12.6 Quality of accommodation & & & & & & & & \\
\hline 12.7 Quality of infrastructure & & & & & & & & \\
\hline 12.8 Safety & & & & & & & & \\
\hline 12.9 Hygiene and cleanliness & & & & & & & & \\
\hline 12.10 Value for money & & & & & & & & \\
\hline
\end{tabular}

Q.13 Please indicate how you perceive the overall image of each as an overseas beach holiday destination? Please circle a number in a table below.

\begin{tabular}{|c|c|c|c|c|c|c|c|}
\hline \multirow{2}{*}{$\begin{array}{l}\text { Destinations } \\
\text { 1. Spain }\end{array}$} & \multicolumn{7}{|c|}{$\begin{array}{l}\text { Circle a number } \\
1=\text { very negative } \\
7=\text { very positive }\end{array}$} \\
\hline & 1 & 2 & 3 & 4 & 5 & 6 & 7 \\
\hline 2. Cyprus & 1 & 2 & 3 & 4 & 5 & 6 & 7 \\
\hline 3. Greece & 1 & 2 & 3 & 4 & 5 & 6 & 7 \\
\hline 4. Turkey & 1 & 2 & 3 & 4 & 5 & 6 & 7 \\
\hline 5. Italy & 1 & 2 & 3 & 4 & 5 & 6 & 7 \\
\hline 6. Malta & 1 & 2 & 3 & 4 & 5 & 6 & 7 \\
\hline 7. Portugal & 1 & 2 & 3 & 4 & 5 & 6 & 7 \\
\hline 8. Tunisia & 1 & 2 & 3 & 4 & 5 & 6 & 7 \\
\hline
\end{tabular}

Q.14 If the destinations listed below are offered in package holidays that include return scheduled flights for 7 nights at a three star hotel including breakfast and dinner, departing between June and August 2003, please tick $(\sqrt{ })$ as you think will be the most expensive destination and the cheapest destination.

\begin{tabular}{|c|c|c|c|c|c|c|c|c|}
\hline & \multicolumn{8}{|c|}{ Tick $(\sqrt{ })$ only one destination for each question } \\
\hline & Spain & Cyprus & Greece & Turkey & Italy & Malta & Portugal & Tunisia \\
\hline 14.1 The most expensive destination & & & & & & & & \\
\hline 14.2 The cheapest destination & & & & & & & & \\
\hline
\end{tabular}




\section{Section 8 (your feeling about choosing an overseas beach holiday destination)}

Q.15 Please indicate how much you agree or disagree with the following statements. Please circle a number in a table below.

\begin{tabular}{|c|c|c|c|c|c|c|c|}
\hline Statements & \multicolumn{7}{|c|}{$\begin{array}{c}\text { Circle a number } \\
1=\text { strongly disagree } \\
7=\text { strongly agree }\end{array}$} \\
\hline destination without much effort. & 1 & 2 & 3 & 4 & 5 & 6 & 7 \\
\hline $\begin{array}{l}15.2 \text { I will search for the latest information } \\
\text { before I book my holiday. }\end{array}$ & 1 & 2 & 3 & 4 & 5 & 6 & 7 \\
\hline $\begin{array}{l}15.3 \text { I consider myself knowledgeable about } \\
\text { overseas beach holiday destinations. }\end{array}$ & 1 & 2 & 3 & 4 & 5 & 6 & 7 \\
\hline $\begin{array}{l}15.4 \text { I can recall almost all overseas beach } \\
\text { holiday destinations from memory. }\end{array}$ & 1 & 2 & 3 & 4 & 5 & 6 & 7 \\
\hline
\end{tabular}

\section{Section 9 (about you)}

Q.16 Which gender are you?
$\square$ Male
Female

Q.17 Which of these categories best describes your age?
$\square 15-24$
$\square$ 25-34
35-44
45-54
$55-64$
65 or over

Q.18 Which of these categories best describes you?

$\square$ single

$\square$ Living with a partner / Married

$\square$ Widowed / Divorced / Separated

Q.19 How old is the youngest child in your household? years old

Q.20 Which is the highest qualification you have obtained?

$\square$ GCSEs grade A-C or equivalent

$\square$ GCE A levels or equivalent

$\square$ Vocational qualification

$\square$ First degree (e.g. BA, BSc)

Higher degree (e.g. MA, MSc, PhD, postgraduate certificate diplomas)

Other qualifications (e.g. City and Guilds, RSAJOCR, BTEC/Edexcel) 
Q.21 Which of these categories best describes your annual household income before tax?
$\square$ None
$\square$ Under $£ 10,000$
$\square £ 10,001-£ 20,000$
$\square £ 20,001-£ 30,000$
$\square £ 30,001-£ 40,000$
$\square £ 40,001-£ 50,000$
$\square £ 50,001-£ 60,000$
$\square £ 60,001-£ 70,000$
$\square £ 70,001$ or over
$\square$ would rather not disclose

Q.22 Are you UK resident?
$\square$ Yes
No, specify

If you have any comments or suggestions, please write them below.

\section{TO ENTER THE PRIZE DRAW}

Please provide your name and contact details i.e. email address, telephone number or home address. This information will only be used for the purpose of informing you the results of the prize draw.

Name:

Contact details:

Thank you very much for your time and co-operation. 


\section{Appendix D}

\section{Questionnaire for Experimental Group 2}


November 2002

Dear respondent

Thank you for participating in this survey. My name is Walaiporn. I am a postgraduate research student in the School of Management at the University of Surrey. I am conducting this survey as part of a doctoral degree in tourism. This survey is about overseas holiday destinations and aims to increase our understanding of tourist decision making.

This survey will take approximately 10-15 minutes to complete. There are no right or wrong answers so please give the answers that most reflect your opinion. All your responses will be treated as strictly confidential and will be used for academic purposes only. If you have any questions or concerns, please feel free to email me at msp1wr@surrey.ac.uk or phone me at 01483689664 (Monday to Friday from 9.30 a.m. to 5.00 p.m.).

As an incentive, six prizes will be given to respondents who return their completed questionnaires. You have a chance to win these prizes:

- Two prizes of $£ 40$ cash

- Four cool T-shirts

- Four smart leather folders with A6 notepads

The winners will be chosen at random from the pool of returned questionnaires. The lucky winners will be notifled by their provided contact details.

Thank you for your time and co-operation.

Sincerely yours

Walaiporn Rewtrakunphaiboon

PhD research office

School of Management

University of Surrey

Guildford GU2 7XH 
Please tick $(\sqrt{ })$ only one answer in the appropriate box unless specified otherwise.

\section{Section 1 (vour preference and experience of overseas holidays)}

By "overseas holiday", we mean a visit to any other countries outside the United Kingdom for holiday purposes for a period of less than 12 months.

Q.1 Which type of holiday do you most prefer for your next overseas holiday?

$\square$ Beach $\square$ City $\square$ Cruise $\square$ Ski $\square$ other, specify

Q.2 Which month do you most prefer to take your next overseas holiday?

\begin{tabular}{|c|c|c|c|}
\hline$\square$ January & $\square$ February & $\square$ March & $\square$ April \\
\hline$\square$ May & $\square$ June & $\square$ July & $\square$ August \\
\hline September & $\square$ October & $\square$ November & $\square$ Decembe \\
\hline
\end{tabular}

Q.3 In the past five years, how many times have you been away for any overseas holidays?
$\square$ None
$1-2$
3-4
$5-6$
more than 6

Q.4 In the past five years, how many times have you been away for overseas beach holidays?
None
$1-2$
3-4
5-6
more than 6

\section{Section 2 (vour preference for overseas beach holiday destinations)}

It is important to read the situation below and imagine that you are in this situation throughout this survey.

\section{IMAGINE THIS SITUATION... \\ (IMPORTANT- PLEASE READ)}

Suppose you have won an overseas beach holiday voucher worth $£ 1,000$. This voucher must be spent on flights and accommodation for two persons. It must be used for booking holidays departing between June and August 2003. Assume that you are able to arrange a suitable time for this trip. You are free to take anyone with you. Assume that your travel companion will be happy to go to any destination and will let you decide.

Please note that the voucher cannot be transferred to other persons. If you do not wish to use the $£ 1,000$ voucher at all, you can exchange it for $£ 50$ cash. If you do not spend all of $£ 1,000$ at once, you will be given the remainder as a voucher for an overseas holiday next year. 
Please read the situation on the previous page before answering the questions.

Q.5 Would you use the overseas beach holiday voucher you won?
$\square$ Yes
No, I prefer $£ 50$ cash.

Q.6 With whom would you most likely spend your overseas beach holiday?

$\square$ boyfriend / girlfriend

$\square$ friend

$\square$ partner/spouse

sister/ brother

son / daughter

father / mother

other, specify

\section{Please answer $Q .7$ in a table below.}

Q.7 Assume that the destinations listed in the table below are the only options available for using your overseas beach holiday voucher,

7.1 please rank them according to your preference from 1 (the most preferred destination) and so on to 4 (the least preferred destination).

7.2 how likely are you to visit each destination?

7.3 please tick $(\sqrt{ })$ for destinations that you.......

7.3.3 consider as possible destinations

7.3.4 would consider visiting

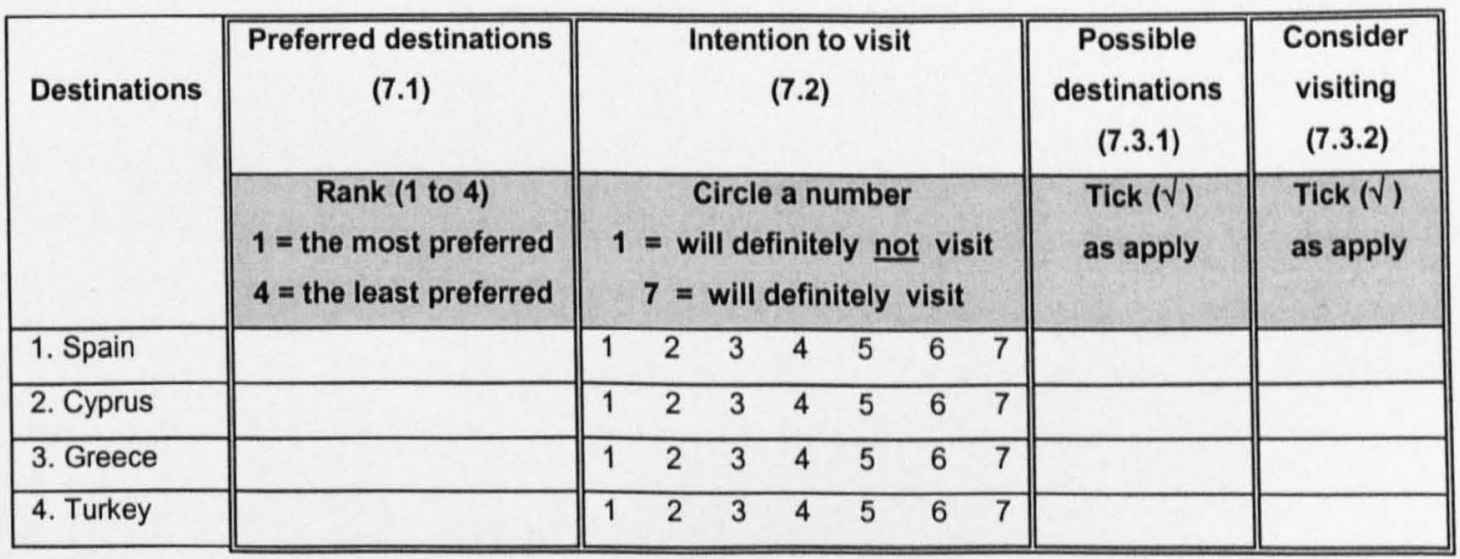




\section{Section 3 (your preference for overseas beach package holidays)}

Package holiday prices shown are per person and include flights, accommodation based on two adults sharing and half board (breakfast and dinner). All prices include pre-paid taxes and are based on London departures.

\section{SCENARIO 1}

Suppose that these four package holidays are the only options available for using your overseas beach holiday voucher. Please indicate how attractive you find each package holiday by circling a number at the bottom of each package holiday ( $1=$ not at all attractive and $7=$ very attractive). Next, please tick $(\sqrt{ })$ your most preferred and your least preferred package holiday.

\begin{tabular}{|c|c|c|c|c|}
\hline & Package No.1 & Package No.2 & Package No.3 & Package No.4 \\
\hline . & $\begin{array}{c}\mathbf{2} 10 \\
3 \text { star hotel } \\
7 \text { nights } \\
\text { Spain } \\
\text { Thomas Cook }\end{array}$ & $\begin{array}{c}2470 \\
3 \text { star hotel } \\
7 \text { nights } \\
\text { Cyprus } \\
\text { Lunn Poly }\end{array}$ & $\begin{array}{l}3 \text { star hotel } \\
9 \text { nights } \\
\text { Italy } \\
\text { Lunn Poly }\end{array}$ & $\begin{array}{l}3 \text { star hotel } \\
9 \text { nights } \\
\text { Malta } \\
\text { Thomas Cook }\end{array}$ \\
\hline Circle a number & $\begin{array}{lllllll}1 & 2 & 3 & 4 & 5 & 6 & 7\end{array}$ & $\begin{array}{lllllll}1 & 2 & 3 & 4 & 5 & 6 & 7\end{array}$ & $\begin{array}{lllllll}1 & 2 & 3 & 4 & 5 & 6 & 7\end{array}$ & $\begin{array}{lllllll}1 & 2 & 3 & 4 & 5 & 6 & 7\end{array}$ \\
\hline Tick $(\sqrt{ })$ only once & \multicolumn{2}{|c|}{ My most preferred package holiday is } & No.1 $\square$ No.2 & No.3 $\square$ No.4 \\
\hline Tick $(\sqrt{ })$ only once & \multicolumn{2}{|c|}{ My least preferred package holiday is } & No.1 $\square$ No.2 & No.3 $\square$ No.4 \\
\hline
\end{tabular}

\section{SCENARIO 2}

Suppose that these four package holidays are the only options available for using your overseas beach holiday voucher. Please indicate how attractive you find each package holiday by circling a number at the bottom of each package holiday ( $1=$ not at all attractive and $7=$ very attractive). Next, please tick $(\sqrt{ })$ your most preferred and your least preferred package holiday.

\begin{tabular}{|c|c|c|c|c|}
\hline & Package No.5 & Package No.6 & Package No.7 & Package No.8 \\
\hline & $\begin{array}{c}2470 \\
4 \text { star hotel } \\
9 \text { nights } \\
\text { Spain } \\
\text { Lunn Poly }\end{array}$ & $\begin{array}{c}2410 \\
4 \text { star hotel } \\
9 \text { nights } \\
\text { Cyprus } \\
\text { Thomas Cook }\end{array}$ & $\begin{array}{c}2470 \\
4 \text { star hotel } \\
7 \text { nights } \\
\text { Italy } \\
\text { Thomas Cook }\end{array}$ & $\begin{array}{c}2410 \\
4 \text { star hotel } \\
7 \text { nights } \\
\text { Malta } \\
\text { Lunn Poly }\end{array}$ \\
\hline Circle a number & $\begin{array}{lllllll}1 & 2 & 3 & 4 & 5 & 6 & 7\end{array}$ & $\begin{array}{lllllll}1 & 2 & 3 & 4 & 5 & 6 & 7\end{array}$ & $\begin{array}{lllllll}1 & 2 & 3 & 4 & 5 & 6 & 7\end{array}$ & $\begin{array}{lllllll}1 & 2 & 3 & 4 & 5 & 6 & 7\end{array}$ \\
\hline Tick $(\sqrt{ })$ only once & \multicolumn{2}{|c|}{ My most preferred package holiday is } & No.5 $\square$ No.6 & No.7 $\square$ No.8 \\
\hline Tick $(\sqrt{ })$ only once & \multicolumn{2}{|c|}{ My least preferred package holiday is } & No.5 $\square$ No.6 & No.7 $\square$ No.8 \\
\hline
\end{tabular}




\section{Section 4 (using your overseas beach holiday voucher today)}

Now, assume that eight destinations listed in a table below are the options available for using your overseas beach holiday voucher. Assume that you can book any overseas beach holidays on offer from any travel agents to one of these eight destinations but you have to use your voucher today to book your holiday, departing between June and August 2003. For this situation, we would like to know your destination preference.

\section{Please answer Q.8 in the table below.}

Q.8 Assume that you have to use your overseas beach holiday voucher today and destinations listed in the table are the only options available,

8.1 how likely are you to visit each destination?

8.2 please tick $(\sqrt{ })$ up to 4 destinations that you would consider visiting

8.3 please tick $(\sqrt{ })$ the destination that you would choose by the end of today

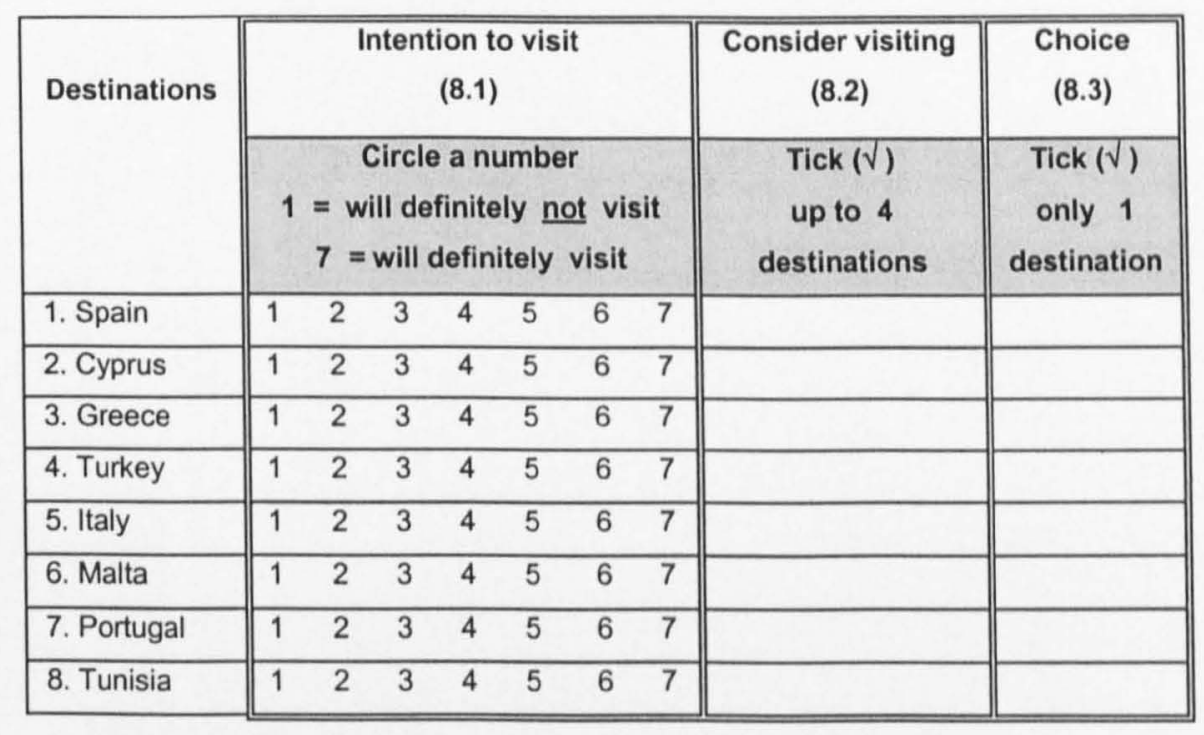

\section{Section 5 (importance of attributes in selecting overseas beach holidays)}

Q.9 Please indicate how you feel towards the following attributes when choosing an overseas beach holiday? Please circle a number in a table below.

\begin{tabular}{|c|c|c|c|c|c|c|c|}
\hline \multirow[t]{2}{*}{ Attributes } & \multicolumn{7}{|c|}{$\begin{array}{c}\text { Circle a number } \\
1=\text { not at all important } \\
7=\text { very important }\end{array}$} \\
\hline & 1 & 2 & 3 & 4 & 5 & 6 & 7 \\
\hline 9.2 Destination & 1 & 2 & 3 & 4 & 5 & 6 & 7 \\
\hline 9.3 Number of nights & 1 & 2 & 3 & 4 & 5 & 6 & 7 \\
\hline 9.4 Price & 1 & 2 & 3 & 4 & 5 & 6 & 7 \\
\hline 9.5 Quality of accommodation & 1 & 2 & 3 & 4 & 5 & 6 & 7 \\
\hline 9.6 Name of travel agent & 1 & 2 & 3 & 4 & 5 & 6 & 7 \\
\hline
\end{tabular}




\section{Section 6 (knowledge and past visits of overseas beach holiday destinations)}

\section{Please answer Q.10 and $\mathbf{Q . 1 1}$ in a table below.}

Q.10 For all of the destinations listed in the table,

10.1 how well are you informed (by friends, television, magazine, etc.) about each as a beach holiday destination?

10.3 how familiar are you with each as a beach holiday destination?

Q.11 Please indicate number of times you have visited each destination in the list for any purposes. If you have never visited a destination before, please write " 0 ".

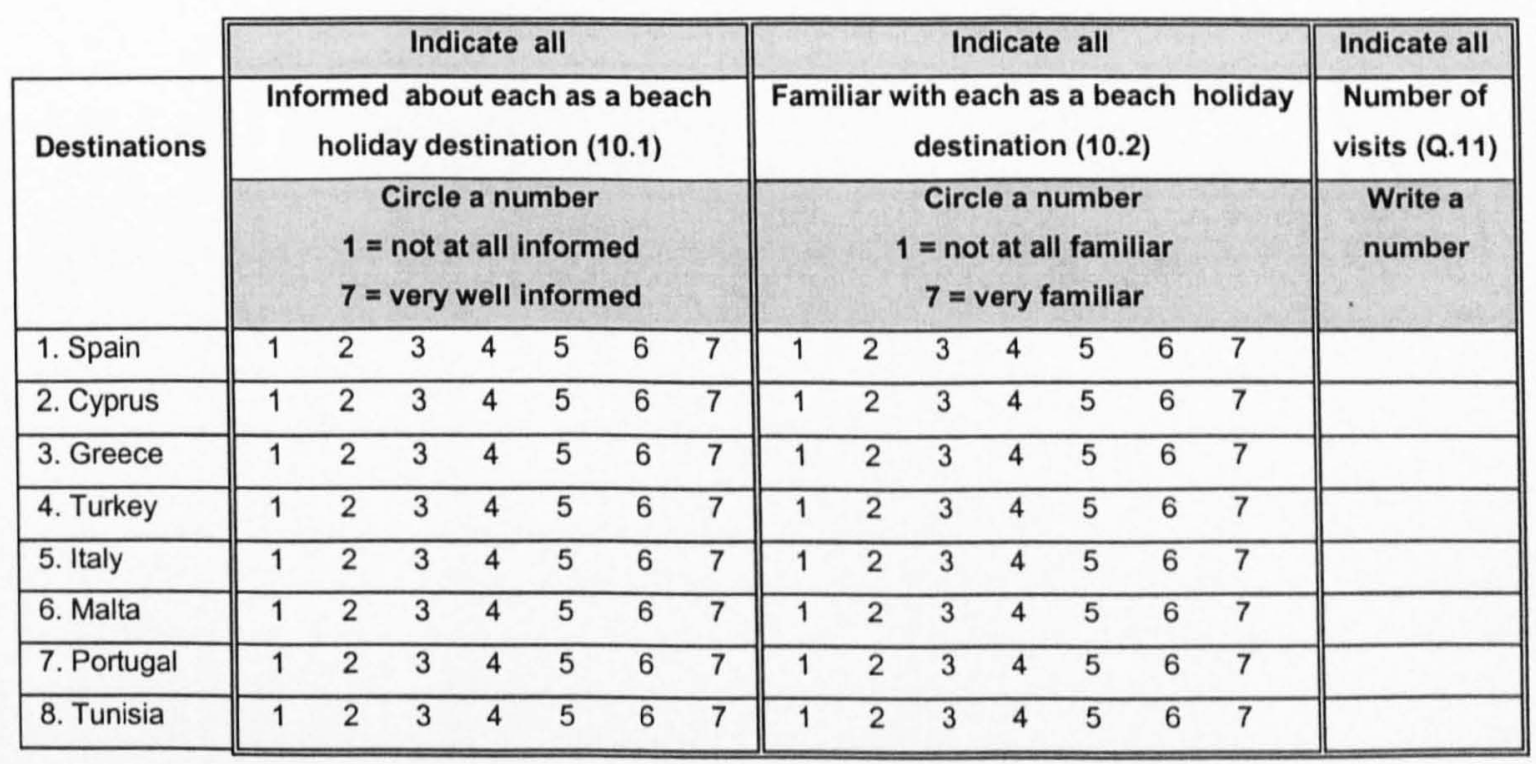




\section{Section 7 (perception of overseas beach holiday destinations)}

Q.12 Please tick $(\checkmark)$ the destination that you think it offers the best in each of the following attributes.

\begin{tabular}{|c|c|c|c|c|c|c|c|c|}
\hline \multirow[b]{2}{*}{ Attributes } & \multicolumn{8}{|c|}{ Tick $(\sqrt{ })$ only one destination for each attribute } \\
\hline & Spain & Cyprus & Greece & Turkey & Italy & Malta & Portugal & Tunisia \\
\hline 12.1 Local food & & & & & & & & \\
\hline 12.2 Beaches & & & & & & & & \\
\hline 12.3 Friendliness of local peop & & & & & & & & \\
\hline 12.4 Climate & & & & & & & & \\
\hline 12.5 Nightlife and entertainmer & & & & & & & & \\
\hline 12.6 Quality of accommodation & & & & & & & & \\
\hline 12.7 Quality of infrastructure & & & & & & & & \\
\hline 12.8 Safety & & & & & & & & \\
\hline 12.9 Hygiene and cleanliness & & & & & & & & \\
\hline 12.10 Value for money & & & & & & & & \\
\hline
\end{tabular}

Q.13 Please indicate how you perceive the overall image of each as an overseas beach holiday destination? Please circle a number in a table below.

\begin{tabular}{|c|c|c|c|c|c|c|c|}
\hline \multirow{2}{*}{$\begin{array}{l}\text { Destinations } \\
\text { 1. Spain }\end{array}$} & \multicolumn{7}{|c|}{$\begin{array}{l}\text { Circle a number } \\
1=\text { very negative } \\
7=\text { very positive }\end{array}$} \\
\hline & 1 & 2 & 3 & 4 & 5 & 6 & 7 \\
\hline 2. Cyprus & 1 & 2 & 3 & 4 & 5 & 6 & 7 \\
\hline 3. Greece & 1 & 2 & 3 & 4 & 5 & 6 & 7 \\
\hline 4. Turkey & 1 & 2 & 3 & 4 & 5 & 6 & 7 \\
\hline 5. Italy & 1 & 2 & 3 & 4 & 5 & 6 & 7 \\
\hline 6. Malta & 1 & 2 & 3 & 4 & 5 & 6 & 7 \\
\hline 7. Portugal & 1 & 2 & 3 & 4 & 5 & 6 & 7 \\
\hline 8. Tunisia & 1 & 2 & 3 & 4 & 5 & 6 & 7 \\
\hline
\end{tabular}

Q.14 If the destinations listed below are offered in package holidays that include return scheduled flights for 7 nights at a three star hotel including breakfast and dinner, departing between June and August 2003, please tick $(\sqrt{ })$ as you think will be the most expensive destination and the cheapest destination.

\begin{tabular}{|l||l|l|l|l|l|l|l|l||}
\hline \multicolumn{1}{|c|}{} & \multicolumn{7}{c|}{ Tick ( $)$ ) only one destination for each question } \\
\cline { 2 - 9 } & Spain & Cyprus & Greece & Turkey & Italy & Malta & Portugal & Tunisia \\
\hline 14.1 The most expensive destination & & & & & & & & \\
\hline
\end{tabular}




\section{Section 8 (your feeling about choosing an overseas beach holiday destination)}

Q.15 Please indicate how much you agree or disagree with the following statements. Please circle a number in a table below.

\begin{tabular}{|c|c|c|c|c|c|c|c|}
\hline Statements & \multicolumn{7}{|c|}{$\begin{array}{c}\text { Circle a number } \\
1=\text { strongly disagree } \\
7=\text { strongly agree }\end{array}$} \\
\hline destination without much effort. & 1 & 2 & 3 & 4 & 5 & 6 & 7 \\
\hline $\begin{array}{l}15.2 \text { I will search for the latest information } \\
\text { before I book my holiday. }\end{array}$ & 1 & 2 & 3 & 4 & 5 & 6 & 7 \\
\hline $\begin{array}{l}15.3 \text { I consider myself knowledgeable about } \\
\text { overseas beach holiday destinations. }\end{array}$ & 1 & 2 & 3 & 4 & 5 & 6 & 7 \\
\hline $\begin{array}{l}15.4 \text { I can recall almost all overseas beach } \\
\text { holiday destinations from memory. }\end{array}$ & 1 & 2 & 3 & 4 & 5 & 6 & 7 \\
\hline
\end{tabular}

\section{Section 9 (about you)}

Q.16 Which gender are you?
Male
Female

Q.17 Which of these categories best describes your age?
15-24
25-34
35-44
$45-54$
$55-64$
65 or over

Q.18 Which of these categories best describes you?

$\square$ single

$\square$ Living with a partner / Married

$\square$ Widowed / Divorced / Separated

Q.19 How old is the youngest child in your household?

years old

Q.20 Which is the highest qualification you have obtained?

$\square$ GCSEs grade $\mathrm{A}-\mathrm{C}$ or equivalent

$\square$ GCE A levels or equivalent

$\square$ Vocational qualification

First degree (e.g. BA, BSc)

Higher degree (e.g. MA, MSc, PhD, postgraduate certificate diplomas)

Other qualifications (e.g. City and Guilds, RSAOOCR, BTEC/Edexcel) 
Q.21 Which of these categories best describes your annual household income before tax?

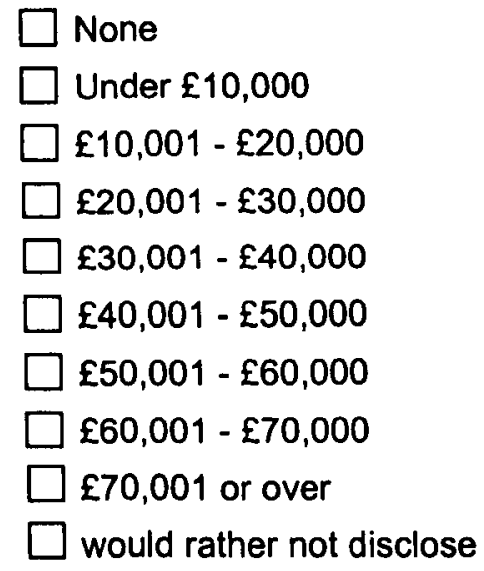

Q.22 Are you UK resident?
$\square$ Yes
$\square$ No, specify

If you have any comments or suggestions, please write them below.

\section{TO ENTER THE PRIZE DRAW}

Please provide your name and contact details i.e. email address, telephone number or home address. This information will only be used for the purpose of informing you the results of the prize draw.

Name:

Contact details:

Thank you very much for your time and co-operation. 


\section{Appendix E}

\section{Analyses for Four Destinations}

\section{(Students)}




\section{Mean Intention to Visit between Group by Preference (Students)}

Dependent Variable: intention to visit-time2

\begin{tabular}{|ll|r|r|r|}
\hline preference & group & Mean & \multicolumn{1}{|c|}{ SD } & N \\
\hline low & exp1(destination heading) & 3.8065 & 1.67912 & 155 \\
& exp2 (price heading) & 4.3687 & 1.64688 & 160 \\
& control (destination only) & 4.1067 & 1.68918 & 75 \\
& Total & 4.0949 & 1.68273 & 390 \\
\hline high & exp1(destination heading) & 5.4615 & 1.47838 & 156 \\
& exp2 (price heading) & 5.7000 & 1.50805 & 160 \\
& control (destination only) & 5.3200 & 1.58677 & 75 \\
& Total & 5.5320 & 1.51518 & 391 \\
\hline Total & exp1(destination heading) & 4.6367 & 1.78338 & 311 \\
& exp2 (price heading) & 5.0344 & 1.71168 & 320 \\
& control (destination only) & 4.7133 & 1.74301 & 150 \\
& Total & 4.8143 & 1.75415 & 781 \\
\hline
\end{tabular}

\section{Two-way ANOVA (Students)}

Dependent Variable: intention to visit-time2

\begin{tabular}{|l|r|r|r|r|r|}
\hline Source & $\begin{array}{r}\text { Type III Sum } \\
\text { of Squares }\end{array}$ & df & Mean Square & \multicolumn{1}{|c|}{ F } & \multicolumn{1}{c|}{ Sig. } \\
\hline Corrected Model & $436.806^{a}$ & 5 & 87.361 & 34.486 & .000 \\
Intercept & 15901.535 & 1 & 15901.535 & 6277.114 & .000 \\
PREF & 338.991 & 1 & 338.991 & 133.847 & .000 \\
GROUP & 27.137 & 2 & 13.569 & 5.356 & .005 \\
PREF * GROUP & 6.468 & 2 & 3.234 & 1.277 & .280 \\
Error & 1963.273 & 775 & 2.533 & & \\
Total & 20502.000 & 781 & & & \\
Corrected Total & 2400.079 & 780 & & & \\
\hline
\end{tabular}

a. R Squared $=.182$ (Adjusted R Squared $=.177$ ) 
Probability of Entering Late Consideration between Group by Preference (Students)

\begin{tabular}{|c|c|c|c|c|c|c|}
\hline \multirow[b]{2}{*}{ group } & & & & \multicolumn{2}{|c|}{ late consideration } & \multirow[b]{2}{*}{ Total } \\
\hline & & & & no & yes & \\
\hline \multirow[t]{6}{*}{ exp 1 (destination heading) } & preference & low & Count & 124 & 36 & 160 \\
\hline & & & $\%$ within preference & $77.5 \%$ & $22.5 \%$ & $100.0 \%$ \\
\hline & & high & Count & 44 & 116 & 160 \\
\hline & & & $\%$ within preference & $27.5 \%$ & $72.5 \%$ & $100.0 \%$ \\
\hline & Total & & Count & 168 & 152 & 320 \\
\hline & & & $\%$ within preference & $52.5 \%$ & $47.5 \%$ & $100.0 \%$ \\
\hline \multirow[t]{6}{*}{ exp2 (price heading) } & preference & low & Count & 109 & 51 & 160 \\
\hline & & & $\%$ within preference & $68.1 \%$ & $31.9 \%$ & $100.0 \%$ \\
\hline & & high & Count & 39 & 121 & 160 \\
\hline & & & $\%$ within preference & $24.4 \%$ & $75.6 \%$ & $100.0 \%$ \\
\hline & Total & & Count & 148 & 172 & 320 \\
\hline & & & $\%$ within preference & $46.3 \%$ & $53.8 \%$ & $100.0 \%$ \\
\hline \multirow[t]{6}{*}{ control (destination only) } & preference & low & Count & 58 & 22 & 80 \\
\hline & & & $\%$ within preference & $72.5 \%$ & $27.5 \%$ & $100.0 \%$ \\
\hline & & high & Count & 23 & 57 & 80 \\
\hline & & & $\%$ within preference & $28.8 \%$ & $71.3 \%$ & $100.0 \%$ \\
\hline & Total & & Count & 81 & 79 & 160 \\
\hline & & & $\%$ within preference & $50.6 \%$ & $49.4 \%$ & $100.0 \%$ \\
\hline
\end{tabular}

Parameter Estimates for Probability of Entering Late Consideration (Students)

\begin{tabular}{|l|r|r|r|r|}
\hline & \multicolumn{1}{|c|}{ B } & \multicolumn{1}{|c|}{ S.E. } & \multicolumn{1}{c|}{ Sig. } & \multicolumn{1}{|c|}{ Exp(B) } \\
\hline PREF & 1.992 & .168 & .000 & 7.327 \\
INFORMATION & -.010 & .094 & .918 & .990 \\
HEADING & .239 & .127 & .060 & 1.269 \\
PREF by INFORMATION & .057 & .132 & .663 & 1.059 \\
PREF by HEADING & -.157 & .180 & .383 & .855 \\
\hline
\end{tabular}


Probability of Becoming a Choice between Group by Preference (Students)

\begin{tabular}{|c|c|c|c|c|c|c|}
\hline \multirow[b]{2}{*}{ group } & & & & \multicolumn{2}{|c|}{ final choice } & \multirow[b]{2}{*}{ Total } \\
\hline & & & & no & yes & \\
\hline \multirow[t]{6}{*}{ exp1(destination heading) } & preference & low & Count & 152 & 8 & 160 \\
\hline & & & $\%$ within preference & $95.0 \%$ & $5.0 \%$ & $100.0 \%$ \\
\hline & & high & Count & 119 & 41 & 160 \\
\hline & & & $\%$ within preference & $74.4 \%$ & $25.6 \%$ & $100.0 \%$ \\
\hline & Total & & Count & 271 & 49 & 320 \\
\hline & & & $\%$ within preference & $84.7 \%$ & $15.3 \%$ & $100.0 \%$ \\
\hline \multirow[t]{6}{*}{ exp2 (price heading) } & preference & low & Count & 144 & 12 & 156 \\
\hline & & & $\%$ within preference & $92.3 \%$ & $7.7 \%$ & $100.0 \%$ \\
\hline & & high & Count & 110 & 46 & 156 \\
\hline & & & $\%$ within preference & $70.5 \%$ & $29.5 \%$ & $100.0 \%$ \\
\hline & Total & & Count & 254 & 58 & 312 \\
\hline & & & $\%$ within preference & $81.4 \%$ & $18.6 \%$ & $100.0 \%$ \\
\hline \multirow[t]{6}{*}{ control (destination only) } & preference & low & Count & 76 & 4 & 80 \\
\hline & & & $\%$ within preference & $95.0 \%$ & $5.0 \%$ & $100.0 \%$ \\
\hline & & high & Count & 64 & 16 & 80 \\
\hline & & & $\%$ within preference & $80.0 \%$ & $20.0 \%$ & $100.0 \%$ \\
\hline & Total & & Count & 140 & 20 & 160 \\
\hline & & & $\%$ within preference & $87.5 \%$ & $12.5 \%$ & $100.0 \%$ \\
\hline
\end{tabular}

Parameter Estimates for Probability of Becoming a Choice (Students)

\begin{tabular}{|l|r|r|r|r|}
\hline & \multicolumn{1}{|c|}{ B } & \multicolumn{1}{|c|}{ S.E. } & \multicolumn{1}{c|}{ Sig. } & \multicolumn{1}{|c|}{ Exp(B) } \\
\hline PREF & 1.683 & .264 & .000 & 5.384 \\
INFORMATION & .077 & .188 & .684 & 1.080 \\
HEADING & .230 & .236 & .329 & 1.258 \\
PREF by INFORMATION & .063 & .214 & .770 & 1.065 \\
PREF by HEADING &. .133 & .267 & .619 & .876 \\
\hline
\end{tabular}


Appendix E: Analyses for Four Destinations (Students)

Mean Intention to Visit between Exposure by Preference (Students)

\begin{tabular}{|c|c|c|c|c|c|}
\hline preference & early exposure & late exposure & Mean & SD & $\mathbf{N}$ \\
\hline \multirow[t]{9}{*}{ low } & no & no & 4.2152 & 1.70723 & 79 \\
\hline & & yes & 3.8462 & 1.69090 & 78 \\
\hline & & Total & 4.0318 & 1.70377 & 157 \\
\hline & yes & no & 4.2911 & 1.72576 & 79 \\
\hline & & yes & 4.0127 & 1.60523 & 79 \\
\hline & & Total & 4.1519 & 1.66713 & 158 \\
\hline & Total & no & 4.2532 & 1.71147 & 158 \\
\hline & & yes & 3.9299 & 1.64517 & 157 \\
\hline & & Total & 4.0921 & 1.68388 & 315 \\
\hline \multirow[t]{9}{*}{ high } & no & no & 5.5316 & 1.42177 & 79 \\
\hline & & yes & 5.8101 & 1.36885 & 79 \\
\hline & & Tolal & 5.6709 & 1.39810 & 158 \\
\hline & yes & no & 5.6203 & 1.47025 & 79 \\
\hline & & yes & 5.3671 & 1.69598 & 79 \\
\hline & & Total & 5.4937 & 1.58716 & 158 \\
\hline & Total & no & 5.5759 & 1.44228 & 158 \\
\hline & & yes & 5.5886 & 1.55219 & 158 \\
\hline & & Total & 5.5823 & 1.49588 & 316 \\
\hline \multirow[t]{9}{*}{ Total } & no & no & 4.8734 & 1.69951 & 158 \\
\hline & & yes & 4.8344 & 1.82169 & 157 \\
\hline & & Total & 4.8540 & 1.75877 & 315 \\
\hline & yes & no & 4.9557 & 1.73148 & 158 \\
\hline & & yes & 4.6899 & 1.78065 & 158 \\
\hline & & Total & 4.8228 & 1.75849 & 316 \\
\hline & Total & no & 4.9146 & 1.71334 & 316 \\
\hline & & yes & 4.7619 & 1.79981 & 315 \\
\hline & & Total & 4.8384 & 1.75730 & 631 \\
\hline
\end{tabular}

\section{Four-way ANOVA (Students)}

Dependent Variable: intention to visit-time2
\begin{tabular}{|l|r|r|r|r|r|}
\hline Source & $\begin{array}{r}\text { Type III Sum } \\
\text { of Squares }\end{array}$ & df & Mean Square & \multicolumn{1}{|c|}{ F } & Sig. \\
\hline Corrected Model & 450.649 & 15 & 30.043 & 12.360 & .000 \\
Intercept & 14745.683 & 1 & 14745.683 & 6066.505 & .000 \\
PREF & 351.136 & 1 & 351.136 & 144.461 & .000 \\
HEADING & 25.150 & 1 & 25.150 & 10.347 & .001 \\
EARLY & .145 & 1 & .145 & .060 & .807 \\
LATE & 3.724 & 1 & 3.724 & 1.532 & .216 \\
PREF * HEADING & 4.082 & 1 & 4.082 & 1.679 & .196 \\
PREF * EARLY & 3.331 & 1 & 3.331 & 1.370 & .242 \\
HEADING * EARLY & 1.963 & 1 & 1.963 & .808 & .369 \\
PREF * HEADING * EARLY & 8.778 & 1 & 8.778 & 3.611 & .058 \\
PREF * LATE & 4.090 & 1 & 4.090 & 1.683 & .195 \\
HEADING * LATE & .949 & 1 & .949 & .391 & .532 \\
PREF * HEADING * LATE & 38.677 & 1 & 38.677 & 15.912 & .000 \\
EARLY* LATE & 1.991 & 1 & 1.991 & .819 & .366 \\
PREF * EARLY * LATE & 3.709 & 1 & 3.709 & 1.526 & .217 \\
HEADING * EARLY LATE & 1.382 & 1 & 1.382 & .569 & .451 \\
PREF * HEADING * EARLY * LATE & 1.670 & 1 & 1.670 & .687 & .407 \\
Error & 1494.863 & 615 & 2.431 & & \\
Total & 16717.000 & 631 & & & \\
Corrected Tolal & 1945.512 & 630 & & & \\
\hline
\end{tabular}

a. $R$ Squared = .232 (Adjusted $R$ Squared a .213) 
Mean Intention to Visit of Late Exposure by Preference (Students)
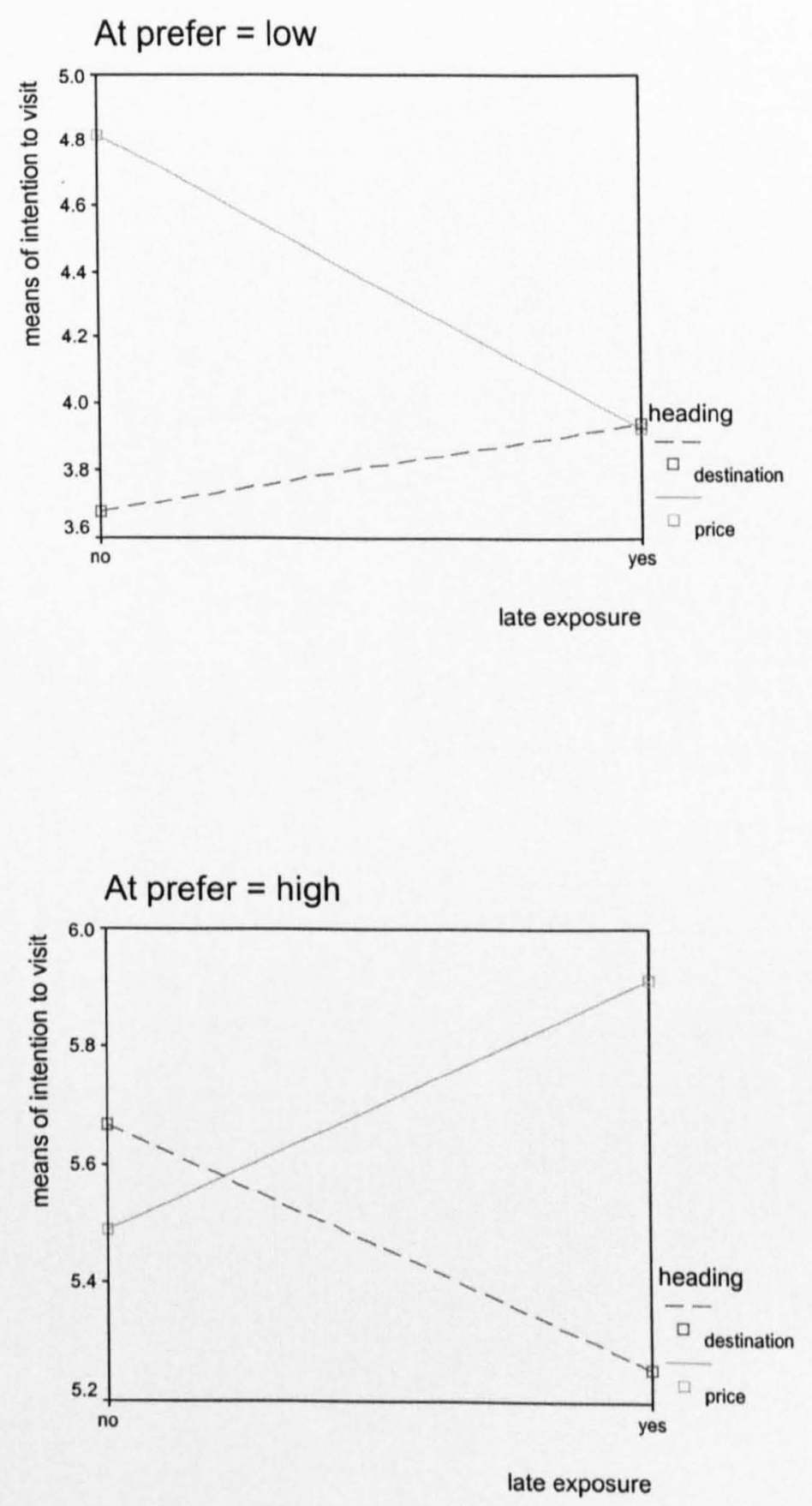
Probability of Entering Late Consideration between Exposure by Preference (Students)

\begin{tabular}{|c|c|c|c|c|c|c|c|}
\hline \multirow[b]{2}{*}{ early exposure } & \multirow[b]{2}{*}{ late exposure } & & & & \multicolumn{2}{|c|}{ late consideration } & \multirow[b]{2}{*}{ Total } \\
\hline & & & & & no & yes & \\
\hline \multirow[t]{12}{*}{ no } & no & preference & low & Count & 56 & 24 & 80 \\
\hline & & & & $\%$ within preference & $70.0 \%$ & $30.0 \%$ & $100.0 \%$ \\
\hline & & & high & Count & 18 & 62 & 80 \\
\hline & & & & $\%$ within preference & $22.5 \%$ & $77.5 \%$ & $100.0 \%$ \\
\hline & & Total & & Count & 74 & 86 & 160 \\
\hline & & & & $\%$ within preference & $46.3 \%$ & $53.8 \%$ & $100.0 \%$ \\
\hline & yes & preference & low & Count & 63 & 17 & 80 \\
\hline & & & & $\%$ within preference & $78.8 \%$ & $21.3 \%$ & $100.0 \%$ \\
\hline & & & high & Count & 18 & 62 & 80 \\
\hline & & & & $\%$ within preference & $22.5 \%$ & $77.5 \%$ & $100.0 \%$ \\
\hline & & Total & & Count & 81 & 79 & 160 \\
\hline & & & & $\%$ within preference & $50.6 \%$ & $49.4 \%$ & $100.0 \%$ \\
\hline \multirow[t]{12}{*}{ yes } & no & preference & low & Count & 55 & 25 & 80 \\
\hline & & & & $\%$ within preference & $68.8 \%$ & $31.3 \%$ & $100.0 \%$ \\
\hline & & & high & Count & 21 & 59 & 80 \\
\hline & & & & $\%$ within preference & $26.3 \%$ & $73.8 \%$ & $100.0 \%$ \\
\hline & & Total & & Count & 76 & 84 & 160 \\
\hline & & & & $\%$ within preference & $47.5 \%$ & $52.5 \%$ & $100.0 \%$ \\
\hline & yes & preference & low & Count & 59 & 21 & 80 \\
\hline & & & & $\%$ within preference & $73.8 \%$ & $26.3 \%$ & $100.0 \%$ \\
\hline & & & high & Count & 26 & 54 & 80 \\
\hline & & & & $\%$ within preference & $32.5 \%$ & $67.5 \%$ & $100.0 \%$ \\
\hline & & Total & & Count & 85 & 75 & 160 \\
\hline & & & & $\%$ within preference & $53.1 \%$ & $46.9 \%$ & $100.0 \%$ \\
\hline
\end{tabular}

Parameter Estimates for Probability of Entering Late Consideration (Students)

\begin{tabular}{|l|r|r|r|r|}
\hline & \multicolumn{1}{|c|}{ B } & \multicolumn{1}{|c|}{ S.E. } & \multicolumn{1}{c|}{ Sig. } & \multicolumn{1}{c|}{ Exp(B) } \\
\hline PREF & 2.084 & .362 & .000 & 8.037 \\
EARLY & .059 & .343 & .864 & 1.061 \\
LATE & -.463 & .366 & .207 & .630 \\
PREF by EARLY & -.263 & .504 & .602 & .769 \\
PREF by LATE & .463 & .527 & .380 & 1.588 \\
EARLY by LATE & .218 & .507 & .667 & 1.244 \\
PREF by EARLY by LATE & -.520 & .722 & .471 & .594 \\
\hline
\end{tabular}


Probability of Becoming a Choice between Exposure by Preference (Students)

\begin{tabular}{|c|c|c|c|c|c|c|c|}
\hline \multirow[b]{2}{*}{ early exposure } & \multirow[b]{2}{*}{ late exposure } & & & & \multicolumn{2}{|c|}{ final choice } & \multirow[b]{2}{*}{ Total } \\
\hline & & & & & no & yes & \\
\hline \multirow[t]{12}{*}{ no } & no & preference & low & Count & 74 & 5 & 79 \\
\hline & & & & $\%$ within preference & $93.7 \%$ & $6.3 \%$ & $100.0 \%$ \\
\hline & & & high & Count & 58 & 21 & 79 \\
\hline & & & & $\%$ within preference & $73.4 \%$ & $26.6 \%$ & $100.0 \%$ \\
\hline & & Total & & Count & 132 & 26 & 158 \\
\hline & & & & $\%$ within preference & $83.5 \%$ & $16.5 \%$ & $100.0 \%$ \\
\hline & yes & preference & low & Count & 76 & 3 & 79 \\
\hline & & & & $\%$ within preference & $96.2 \%$ & $3.8 \%$ & $100.0 \%$ \\
\hline & & & high & Count & 52 & 27 & 79 \\
\hline & & & & $\%$ within preference & $65.8 \%$ & $34.2 \%$ & $100.0 \%$ \\
\hline & & Total & & Count & 128 & 30 & 158 \\
\hline & & & & $\%$ within preference & $81.0 \%$ & $19.0 \%$ & $100.0 \%$ \\
\hline \multirow[t]{12}{*}{ yes } & no & preference & low & Count & 72 & 7 & 79 \\
\hline & & & & $\%$ within preference & $91.1 \%$ & $8.9 \%$ & $100.0 \%$ \\
\hline & & & high & Count & 60 & 19 & 79 \\
\hline & & & & $\%$ within preference & $75.9 \%$ & $24.1 \%$ & $100.0 \%$ \\
\hline & & Total & & Count & 132 & 26 & 158 \\
\hline & & & & $\%$ within preference & $83.5 \%$ & $16.5 \%$ & $100.0 \%$ \\
\hline & yes & preference & low & Count & 74 & 5 & 79 \\
\hline & & & & $\%$ within preference & $93.7 \%$ & $6.3 \%$ & $100.0 \%$ \\
\hline & & & high & Count & 59 & 20 & 79 \\
\hline & & & & $\%$ within preference & $74.7 \%$ & $25.3 \%$ & $100.0 \%$ \\
\hline & & Total & & Count & 133 & 25 & 158 \\
\hline & & & & $\%$ within preference & $84.2 \%$ & $15.8 \%$ & $100.0 \%$ \\
\hline
\end{tabular}

Parameter Estimates for Probability of Becoming a Choice (Students)

\begin{tabular}{|l|r|r|r|r|}
\hline & \multicolumn{1}{|c|}{ B } & \multicolumn{1}{|c|}{ S.E. } & \multicolumn{1}{c|}{ Sig. } & \multicolumn{1}{|c|}{ Exp(B) } \\
\hline PREF & 1.679 & .528 & .001 & 5.359 \\
EARLY & .364 & .608 & .550 & 1.439 \\
LATE & -.537 & .748 & .473 & .584 \\
PREF by EARLY & -.498 & .710 & .483 & .608 \\
PREF by LATE & .898 & .825 & .277 & 2.455 \\
EARLY by LATE & .174 & .965 & .857 & 1.190 \\
PREF by EARLY by LATE & -.466 & 1.090 & .669 & .627 \\
\hline
\end{tabular}




\title{
Appendix F
}

\section{Analyses for Four Destinations}

\author{
(Adults)
}




\section{Mean Intention to Visit between Group by Preference (Adults)}

Dependent Variable: intention to visit-time2

\begin{tabular}{|ll|r|r|r|}
\hline preference & group & Mean & SD & N \\
\hline low & exp1 (destination heading) & 3.5175 & 1.79927 & 143 \\
& exp2 (price heading) & 3.3521 & 1.88761 & 142 \\
& control (destination only) & 3.7297 & 1.80788 & 74 \\
& Tolal & 3.4958 & 1.83673 & 359 \\
\hline high & exp1 (destination heading) & 5.4564 & 1.50442 & 149 \\
& exp2 (price heading) & 5.3882 & 1.74557 & 152 \\
& control (destination only) & 5.4545 & 1.60218 & 77 \\
& Total & 5.4286 & 1.62096 & 378 \\
\hline Total & exp1 (destination heading) & 4.5068 & 1.91664 & 292 \\
& exp2 (price heading) & 4.4048 & 2.07934 & 294 \\
& control (destination only) & 4.6093 & 1.90779 & 151 \\
& Total & 4.4871 & 1.98024 & 737 \\
\hline
\end{tabular}

\section{Two-way ANOVA (Adults)}

Dependent Variable: intention to visit-time2

\begin{tabular}{|l|r|r|r|r|r|}
\hline Source & $\begin{array}{r}\text { Type III Sum } \\
\text { of Squares }\end{array}$ & df & Mean Square & \multicolumn{1}{c|}{ F } & \multicolumn{1}{c|}{ Sig. } \\
\hline Corrected Model & $695.276^{2}$ & 5 & 139.055 & 46.397 & .000 \\
Intercept & 13441.872 & 1 & 13441.872 & 4485.018 & .000 \\
PREF & 603.558 & 1 & 603.558 & 201.383 & .000 \\
GROUP & 5.216 & 2 & 2.608 & .870 & .419 \\
PREF * GROUP & 2.417 & 2 & 1.209 & .403 & .668 \\
Error & 2190.851 & 731 & 2.997 & & \\
Total & 17725.000 & 737 & & & \\
Corrected Total & 2886.128 & 736 & & & \\
\hline
\end{tabular}

a. R Squared $=.241$ (Adjusted R Squared $=.236$ ) 
Probability of Entering Late Consideration between Group by Preference (Adults)

\begin{tabular}{|c|c|c|c|c|c|c|}
\hline \multirow[b]{2}{*}{ group } & & & & \multicolumn{2}{|c|}{ late consideration } & \multirow[b]{2}{*}{ Total } \\
\hline & & & & no & yes & \\
\hline \multirow[t]{6}{*}{ exp1(destination heading) } & preference & low & Count & 129 & 27 & 156 \\
\hline & & & $\%$ within preference & $82.7 \%$ & $17.3 \%$ & $100.0 \%$ \\
\hline & & high & Count & 45 & 111 & 156 \\
\hline & & & $\%$ within preference & $28.8 \%$ & $71.2 \%$ & $100.0 \%$ \\
\hline & Total & & Count & 174 & 138 & 312 \\
\hline & & & $\%$ within preference & $55.8 \%$ & $44.2 \%$ & $100.0 \%$ \\
\hline \multirow[t]{6}{*}{ exp2 (price heading) } & preference & low & Count & 130 & 30 & 160 \\
\hline & & & $\%$ within preference & $81.3 \%$ & $18.8 \%$ & $100.0 \%$ \\
\hline & & high & Count & 52 & 108 & 160 \\
\hline & & & $\%$ within preference & $32.5 \%$ & $67.5 \%$ & $100.0 \%$ \\
\hline & Total & & Count & 182 & 138 & 320 \\
\hline & & & $\%$ within preference & $56.9 \%$ & $43.1 \%$ & $100.0 \%$ \\
\hline \multirow[t]{6}{*}{ control (destination only) } & preference & low & Count & 58 & 22 & 80 \\
\hline & & & $\%$ within preference & $72.5 \%$ & $27.5 \%$ & $100.0 \%$ \\
\hline & & high & Count & 18 & 62 & 80 \\
\hline & & & $\%$ within preference & $22.5 \%$ & $77.5 \%$ & $100.0 \%$ \\
\hline & Total & & Count & 76 & 84 & 160 \\
\hline & & & $\%$ within preference & $47.5 \%$ & $52.5 \%$ & $100.0 \%$ \\
\hline
\end{tabular}

Parameter Estimates for Probability of Entering Late Consideration (Adults)

\begin{tabular}{|l|r|r|r|r|}
\hline & \multicolumn{1}{|c|}{ B } & \multicolumn{1}{|c|}{ S.E. } & \multicolumn{1}{c|}{ Sig. } & \multicolumn{1}{c|}{ Exp(B) } \\
\hline PREF & 2.290 & .176 & .000 & 9.876 \\
INFORMATION & -.182 & .097 & .060 & .834 \\
HEADING & .049 & .146 & .739 & 1.050 \\
PREF by INFORMATION & .042 & .138 & .761 & 1.043 \\
PREF by HEADING & -.135 & .191 & .480 & .874 \\
\hline
\end{tabular}


Probability of Becoming a Choice between Group by Preference (Adults)

\begin{tabular}{|c|c|c|c|c|c|c|}
\hline \multirow[b]{2}{*}{ group } & & & & \multicolumn{2}{|c|}{ final choice } & \multirow[b]{2}{*}{ Total } \\
\hline & & & & no & yes & \\
\hline \multirow[t]{6}{*}{ exp1(destination heading) } & preference & low & Count & 149 & 7 & 156 \\
\hline & & & $\%$ within preference & $95.5 \%$ & $4.5 \%$ & $100.0 \%$ \\
\hline & & high & Count & 112 & 44 & 156 \\
\hline & & & $\%$ within preference & $71.8 \%$ & $28.2 \%$ & $100.0 \%$ \\
\hline & Total & & Count & 261 & 51 & 312 \\
\hline & & & $\%$ within preference & $83.7 \%$ & $16.3 \%$ & $100.0 \%$ \\
\hline \multirow[t]{6}{*}{ exp2 (price heading) } & preference & low & Count & 146 & 12 & 158 \\
\hline & & & $\%$ within preference & $92.4 \%$ & $7.6 \%$ & $100.0 \%$ \\
\hline & & high & Count & 117 & 41 & 158 \\
\hline & & & $\%$ within preference & $74.1 \%$ & $25.9 \%$ & $100.0 \%$ \\
\hline & Total & & Count & 263 & 53 & 316 \\
\hline & & & $\%$ within preference & $83.2 \%$ & $16.8 \%$ & $100.0 \%$ \\
\hline \multirow[t]{6}{*}{ control (destination only) } & preference & low & Count & 75 & 5 & 80 \\
\hline & & & $\%$ within preference & $93.8 \%$ & $6.3 \%$ & $100.0 \%$ \\
\hline & & high & Count & 59 & 21 & 80 \\
\hline & & & $\%$ within preference & $73.8 \%$ & $26.3 \%$ & $100.0 \%$ \\
\hline & Total & & Count & 134 & 26 & 160 \\
\hline & & & $\%$ within preference & $83.8 \%$ & $16.3 \%$ & $100.0 \%$ \\
\hline
\end{tabular}

Parameter Estimates for Probability of Becoming a Choice (Adults)

\begin{tabular}{|l|r|r|r|r|}
\hline & \multicolumn{1}{|c|}{ B } & \multicolumn{1}{|c|}{ S.E. } & \multicolumn{1}{|c|}{ Sig. } & \multicolumn{1}{|c|}{ Exp(B) } \\
\hline PREF & 1.750 & .254 & .000 & 5.752 \\
INFORMATION & -.023 & .174 & .893 & .977 \\
HEADING & .280 & .245 & .253 & 1.323 \\
PREF by INFORMATION & .037 & .198 & .851 & 1.038 \\
PREF by HEADING &. .337 & .276 & .222 & .714 \\
\hline
\end{tabular}


Mean Intention to Visit between Exposure by Preference (Adults)

\begin{tabular}{|c|c|c|c|c|c|}
\hline preference & earty exposure & late exposure & Mean & $\mathrm{SD}$ & $\mathbf{N}$ \\
\hline \multirow[t]{9}{*}{ low } & no & no & 3.5417 & 1.84572 & 72 \\
\hline & & yes & 3.6479 & 1.97194 & 71 \\
\hline & & Total & 3.5944 & 1.90344 & 143 \\
\hline & yes & no & 2.9859 & 1.65178 & 71 \\
\hline & & yes & 3.5634 & 1.84957 & 71 \\
\hline & & Total & 3.2746 & 1.77110 & 142 \\
\hline & Total & no & 3.2657 & 1.76807 & 143 \\
\hline & & yes & 3.6056 & 1.90542 & 142 \\
\hline & & Total & 3.4351 & 1.84243 & 285 \\
\hline \multirow[t]{9}{*}{ high } & no & no & 5.4211 & 1.62697 & 76 \\
\hline & & yes & 5.2933 & 1.67472 & 75 \\
\hline & & Total & 5.3576 & 1.64659 & 151 \\
\hline & yes & no & 5.5600 & 1.57033 & 75 \\
\hline & & yes & 5.4133 & 1.66111 & 75 \\
\hline & & Total & 5.4867 & 1.61260 & 150 \\
\hline & Total & no & 5.4901 & 1.59527 & 151 \\
\hline & & yes & 5.3533 & 1.66341 & 150 \\
\hline & & Total & 5.4219 & 1.62831 & 301 \\
\hline \multirow[t]{9}{*}{ Total } & no & no & 4.5068 & 1.97086 & 148 \\
\hline & & yes & 4.4932 & 1.99740 & 146 \\
\hline & & Total & 4.5000 & 1.98071 & 294 \\
\hline & yes & no & 4.3082 & 2.05968 & 146 \\
\hline & & yes & 4.5137 & 1.98003 & 146 \\
\hline & & Total & 4.4110 & 2.01939 & 292 \\
\hline & Total & no & 4.4082 & 2.01447 & 294 \\
\hline & & yes & 4.5034 & 1.98534 & 292 \\
\hline & & Total & 4.4556 & 1.99887 & 586 \\
\hline
\end{tabular}

Four-way ANOVA (Adults)

Dependent Variable: intention to visit-time2

\begin{tabular}{|c|c|c|c|c|c|}
\hline Source & $\begin{array}{c}\text { Type III Sum } \\
\text { of Squares }\end{array}$ & $d f$ & Mean Square & $\mathbf{F}$ & Sig. \\
\hline Corrected Model & $627.643^{\mathrm{a}}$ & 15 & 41.843 & 13.950 & .000 \\
\hline Intercept & 11473.826 & 1 & 11473.826 & 3825.272 & .000 \\
\hline PREF & 579.667 & 1 & 579.667 & 193.256 & .000 \\
\hline HEADING & 1.845 & 1 & 1.845 & .615 & .433 \\
\hline EARLY & 1.303 & 1 & 1.303 & .434 & .510 \\
\hline LATE & 1.760 & 1 & 1.760 & .587 & .444 \\
\hline PREF * HEADING & .305 & 1 & .305 & .102 & .750 \\
\hline PREF * EARLY & 7.126 & 1 & 7.126 & 2.376 & .124 \\
\hline HEADING * EARLY & .325 & 1 & .325 & .108 & .742 \\
\hline PREF * HEADING * EARLY & .541 & 1 & .541 & .180 & .671 \\
\hline PREF * LATE & 8.230 & 1 & 8.230 & 2.744 & .098 \\
\hline HEADING * LATE & 2.214 & 1 & 2.214 & .738 & .391 \\
\hline PREF * HEADING * LATE & 12.278 & 1 & 12.278 & 4.093 & .044 \\
\hline EARLY * LATE & 1.614 & 1 & 1.614 & .538 & .463 \\
\hline PREF * EARLY * LATE & 2.175 & 1 & 2.175 & .725 & .395 \\
\hline HEADING * EARLY * LATE & 1.251 & 1 & 1.251 & .417 & .519 \\
\hline PREF * HEADING * EARLY * LATE & 8.827 & 1 & 8.827 & 2.943 & .087 \\
\hline Error & 1709.703 & 570 & 2.999 & & \\
\hline Total & 13971.000 & 586 & & & \\
\hline Corrected Total & 2337.346 & 585 & & & \\
\hline
\end{tabular}

a. $R$ Squared $=.269$ (Adjusted $R$ Squared $=.249$ ) 
Probability of Entering Late Consideration between Exposure by Preference (Adults)

\begin{tabular}{|c|c|c|c|c|c|c|c|}
\hline \multirow[b]{2}{*}{ early exposure } & \multirow[b]{2}{*}{ late exposure } & & & & \multicolumn{2}{|c|}{ late consideration } & \multirow[b]{2}{*}{ Total } \\
\hline & & & & & no & yes & \\
\hline \multirow[t]{12}{*}{ no } & no & preference & Tow & Count & 63 & 16 & 79 \\
\hline & & & & $\%$ within preference & $79.7 \%$ & $20.3 \%$ & $100.0 \%$ \\
\hline & & & high & Count & 21 & 58 & 79 \\
\hline & & & & $\%$ within preference & $26.6 \%$ & $73.4 \%$ & $100.0 \%$ \\
\hline & & Total & & Count & 84 & 74 & 158 \\
\hline & & & & $\%$ within preference & $53.2 \%$ & $46.8 \%$ & $100.0 \%$ \\
\hline & yes & preference & low & Count & 61 & 18 & 79 \\
\hline & & & & $\%$ within preference & $77.2 \%$ & $22.8 \%$ & $100.0 \%$ \\
\hline & & & high & Count & 27 & 51 & 78 \\
\hline & & & & $\%$ within preference & $34.6 \%$ & $65.4 \%$ & $100.0 \%$ \\
\hline & & Total & & Count & 88 & 69 & 157 \\
\hline & & & & $\%$ within preference & $56.1 \%$ & $43.9 \%$ & $100.0 \%$ \\
\hline \multirow[t]{12}{*}{ yes } & no & preference & low & Count & 71 & 8 & 79 \\
\hline & & & & $\%$ within preference & $89.9 \%$ & $10.1 \%$ & $100.0 \%$ \\
\hline & & & high & Count & 24 & 55 & 79 \\
\hline & & & & $\%$ within preference & $30.4 \%$ & $69.6 \%$ & $100.0 \%$ \\
\hline & & Total & & Count & 95 & 63 & 158 \\
\hline & & & & $\%$ within preference & $60.1 \%$ & $39.9 \%$ & $100.0 \%$ \\
\hline & yes & preference & low & Count & 64 & 15 & 79 \\
\hline & & & & $\%$ within preference & $81.0 \%$ & $19.0 \%$ & $100.0 \%$ \\
\hline & & & high & Count & 25 & 55 & 80 \\
\hline & & & & $\%$ within preference & $31.3 \%$ & $68.8 \%$ & $100.0 \%$ \\
\hline & & Total & & Count & 89 & 70 & 159 \\
\hline & & & & $\%$ within preference & $56.0 \%$ & $44.0 \%$ & $100.0 \%$ \\
\hline
\end{tabular}

Parameter Estimates for Probability of Entering Late Consideration (Adults)

\begin{tabular}{|l|r|r|r|r|}
\hline & \multicolumn{1}{|c|}{ B } & \multicolumn{1}{|c|}{ S.E. } & \multicolumn{1}{c|}{ Sig. } & \multicolumn{1}{|c|}{ Exp(B) } \\
\hline PREF & 2.386 & .378 & .000 & 10.875 \\
EARLY & -.813 & .466 & .081 & .444 \\
LATE & .150 & .388 & .699 & 1.162 \\
PREF by EARLY & .626 & .585 & .285 & 1.870 \\
PREF by LATE & -.530 & .521 & .309 & .589 \\
EARLY by LATE & .582 & .610 & .339 & 1.790 \\
PREF by EARLY by LATE & -.243 & .782 & .756 & .784 \\
\hline
\end{tabular}


Probability of Becoming a Choice between Exposure by Preference (Adults)

\begin{tabular}{|c|c|c|c|c|c|c|c|}
\hline \multirow[b]{2}{*}{ early exposure } & \multirow[b]{2}{*}{ late exposure } & & & & \multicolumn{2}{|c|}{ final choice } & \multirow[b]{2}{*}{ Total } \\
\hline & & & & & no & yes & \\
\hline \multirow[t]{12}{*}{ no } & no & preference & low & Count & 75 & 4 & 79 \\
\hline & & & & $\%$ within preference & $94.9 \%$ & $5.1 \%$ & $100.0 \%$ \\
\hline & & & high & Count & 60 & 19 & 79 \\
\hline & & & & $\%$ within preference & $75.9 \%$ & $24.1 \%$ & $100.0 \%$ \\
\hline & & Total & & Count & 135 & 23 & 158 \\
\hline & & & & $\%$ within preference & $85.4 \%$ & $14.6 \%$ & $100.0 \%$ \\
\hline & yes & preference & low & Count & 72 & 6 & 78 \\
\hline & & & & $\%$ within preference & $92.3 \%$ & $7.7 \%$ & $100.0 \%$ \\
\hline & & & high & Count & 57 & 21 & 78 \\
\hline & & & & $\%$ within preference & $73.1 \%$ & $26.9 \%$ & $100.0 \%$ \\
\hline & & Total & & Count & 129 & 27 & 156 \\
\hline & & & & $\%$ within preference & $82.7 \%$ & $17.3 \%$ & $100.0 \%$ \\
\hline \multirow[t]{12}{*}{ yes } & no & preference & low & Count & 76 & 3 & 79 \\
\hline & & & & $\%$ within preference & $96.2 \%$ & $3.8 \%$ & $100.0 \%$ \\
\hline & & & high & Count & 56 & 22 & 78 \\
\hline & & & & $\%$ within preference & $71.8 \%$ & $28.2 \%$ & $100.0 \%$ \\
\hline & & Total & & Count & 132 & 25 & 157 \\
\hline & & & & $\%$ within preference & $84.1 \%$ & $15.9 \%$ & $100.0 \%$ \\
\hline & yes & preference & low & Count & 72 & 6 & 78 \\
\hline & & & & $\%$ within preference & $92.3 \%$ & $7.7 \%$ & $100.0 \%$ \\
\hline & & & high & Count & 56 & 23 & 79 \\
\hline & & & & $\%$ within preference & $70.9 \%$ & $29.1 \%$ & $100.0 \%$ \\
\hline & & Total & & Count & 128 & 29 & 157 \\
\hline & & & & $\%$ within preference & $81.5 \%$ & $18.5 \%$ & $100.0 \%$ \\
\hline
\end{tabular}

Parameter Estimates for Probability of Becoming a Choice (Adults)

\begin{tabular}{|l|r|r|r|r|}
\hline & \multicolumn{1}{|c|}{ B } & \multicolumn{1}{|c|}{ S.E. } & \multicolumn{1}{c|}{ Sig. } & \multicolumn{1}{c|}{ Exp(B) } \\
\hline PREF & 1.781 & .577 & .002 & 5.937 \\
EARLY & -.301 & .781 & .700 & .740 \\
LATE & .446 & .666 & .503 & 1.562 \\
PREF by EARLY & .517 & .862 & .549 & 1.676 \\
PREF by LATE & -.295 & .760 & .698 & .745 \\
EARLY by LATE & .301 & .985 & .760 & 1.351 \\
PREF by EARLY by LATE & -.408 & 1.109 & .713 & .665 \\
\hline
\end{tabular}

